Portland State University

PDXScholar

Winter 2-7-2018

\title{
Exploring Technology Forecasting and its Implications for Strategic Technology Planning
}

Yonghee Cho

Portland State University

Follow this and additional works at: https://pdxscholar.library.pdx.edu/open_access_etds

Part of the Engineering Commons, and the Technology and Innovation Commons Let us know how access to this document benefits you.

\section{Recommended Citation}

Cho, Yonghee, "Exploring Technology Forecasting and its Implications for Strategic Technology Planning" (2018). Dissertations and Theses. Paper 4224.

https://doi.org/10.15760/etd.6108

This Dissertation is brought to you for free and open access. It has been accepted for inclusion in Dissertations and Theses by an authorized administrator of PDXScholar. Please contact us if we can make this document more accessible: pdxscholar@pdx.edu. 
Exploring Technology Forecasting and Its Implications for Strategic Technology

\section{Planning}

by

Yonghee Cho

A dissertation submitted in partial fulfillment of the requirements for the degree of

Doctor of Philosophy

in

Technology Management

Dissertation Committee:

Tugrul U. Daim, Chair

Timothy R. Anderson

Robert Fountain

Jisun Kim

Portland State University

2018 
(C) 2017 Yonghee Cho 


\begin{abstract}
As the importance of $R \& D$ has been growing in economic growth, the accountability and effectiveness of R\&D program are highly emphasized. Especially, in times of economic downturn, the evaluation of performance in a firm is needed to justify R\&D investment. In response, various attempts have been made to improve success rates of $R \& D$ projects, gain competitive advantage, and achieve a firm's growth in profitability. In particular, in industries where technological innovation is significant, strategic technology planning and R\&D capabilities may be the lead ones in defining the dynamic capabilities of a firm. In addition, technology forecasting (TF) in technology planning is a crucial step to follow before developing technologies/products/processes in need.

In this regard, researchers have an abiding interest in enhancing methods to forecast emerging technology, while practitioners have a considerable interest in selecting appropriate tools to apply in their field for better forecasting results. Nevertheless, so far it is not well documented how appropriately the current research responds to this need. Thus, a thorough review on TF techniques is conducted to help researchers and practitioners capture methodologies in a tangible way and identify the current trends in the TF arena. Moreover, there is still a lack of clear guidance as to where and how particular TF methods are useful in strategic planning based on technology characteristics as well as the nature of industry. The purpose of this study is to enrich the stream of research on TF activities in a firm for practitioners and
\end{abstract}


researchers, a unique context where TF could lead to technological innovation. This research offers a classification of the approaches, and presents technological, industrial, methodological, and organizational aspects of TF methods that are inherent in TF activities. Furthermore, this study provides empirical evidences to support organizational and managerial implications regarding TF activities associated with technology planning in a firm. Research findings in regimes of technological change suggest insights on technological, organizational, and managerial processes within the firm.

On the other hand, research on the effects on business performance of "best practices" of strategic planning, which enable firms to articulate their plans to develop, acquire, and deploy resources for accomplishing firms' financial growth, has so far ignored the roles of strategic technology planning associated with TF. In this regard, this study explores a set of indicators, discusses, and presents the findings from the literature in such a way that they become useful for researchers or managers who are in charge of measuring the R\&D performance and business performance from innovation activity. Next, this research tested the hypothetical framework proposed not only to provide a current snapshot of how firms across industries implement best practices in strategic technology planning, but also to improve the effectiveness of strategic planning. The results present the positive linkages between TF, technology planning, and superior business performance. The findings in this research help policy makers, universities, research institutes/national labs, and companies to enhance their decision making process on technology development. 
Dedication

To my family (Joy, my wife, Joseph, Grace, and Esther, my children)

$$
\begin{aligned}
& \text { Glory to our God! } \\
& \text { Glory to our King! } \\
& \text { Glory to our Lord! } \\
& \text { Ruler of Everything }
\end{aligned}
$$




\section{Acknowledgments}

This dissertation would not have been done were it not for the guidance and valuable comments from the committee. First, I would like to express my deep gratitude to Dr. Daim who continuously guided me through the completion of this research. His consistent support in many ways helped me go through the long process to finish this dissertation. Dr. Anderson also gave me critical comments on analytical problems in this research and helped me finalize my dissertation in every detail. Dr. Fountain, as a professor of Statistics Department, helped me develop the survey instrument and cover statistical issues through his classes and research guidance during my research for this dissertation. Finally, Dr. Kim also supported and guided me to go through this process and to bear this fruit of research. I benefited greatly from the input and comments by all dissertation committees, for they enriched my views about what I need to look at research problems. Committee whose good advice I did not follow should know that I tried to incorporate their thoughtful feedback, and where the comment was consistent and clear, I did.

I would like to express my special gratitude to all survey respondents who provided their feedbacks and valuable inputs for this research. Without their help and insights, I would not have been done. I owe a special debt of gratitude to them. I want to express my sincere thanks to my colleagues, Chih-Jen Yu, Edwin Garces, João Ricardo Lavoie, and Rafaa Khalifa at ETM department, and expert groups for valuable comments and feedbacks on research contents and constructs, without whose expert advice, reviews of survey design, and other assistance this dissertation would never have been possible. 
Moreover, I would like to express my sincere thanks for the encouragement and prayers of people that I have known in my life, especially Hanna Jung.

Last but not least, this dissertation would not have been done were it not for the encouragement of my family's support. This dissertation is dedicated to my beloved ones in my life: Heejoung Kim, my soulmate and wife, Joseph, Grace, and Esther, my children. They are thanked for their love, unwavering support, understanding, and patience that only family can give.

Any errors are my sole responsibility.

The road less traveled.

Stay hungry, stay foolish in Truth! 


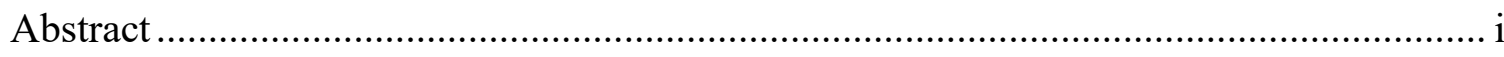

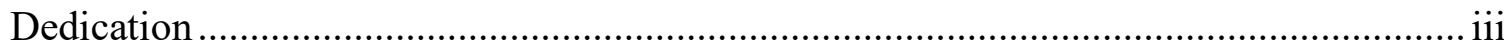

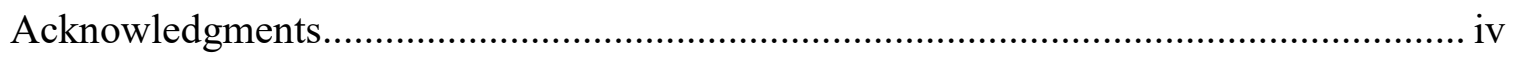

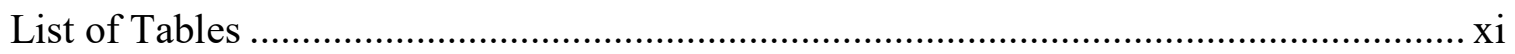

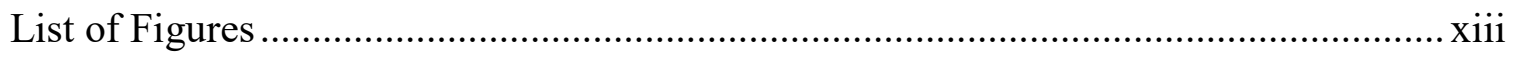

Chapter 1 Introduction............................................................................. 1

Chapter 2 Research Background and Literature Review........................................ 4

2.1. The Concepts of Technology Forecasting and Technology Foresight ............... 7

2.2. The Subsets of Technology Forecasting .......................................................... 11

2.2.1. Characteristics of Technology Forecasting ............................................... 11

2.2.2. Assumptions of Technology Forecasting................................................... 12

2.2.3. Technological Trajectory vs. Discontinuity.............................................. 13

2.3. The Classification of Technology Forecasting Methods …………………...... 15

2.4. Exploratory Forecasting Methods ................................................................. 17

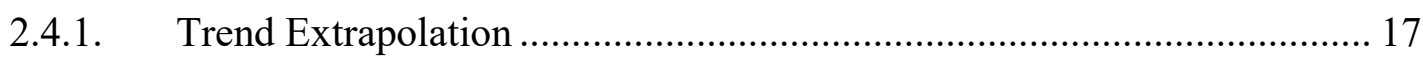

2.4.2. Growth Curves; S-curves ...................................................................... 18

2.4.3. Bibliometrics; Scientometrics ............................................................. 21

2.4.4. Data Mining; Text (Data) Mining ........................................................... 30

2.4.5. Analogies; Comparison-Based Prediction .................................................. 33

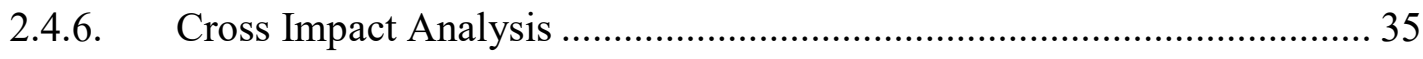

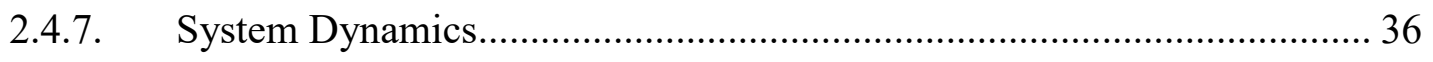

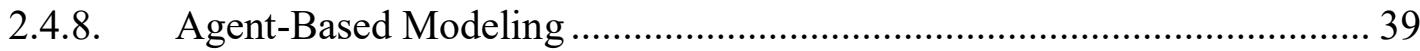

2.4.9. Technology Forecasting using Data Envelopment Analysis (TFDEA).... 40 


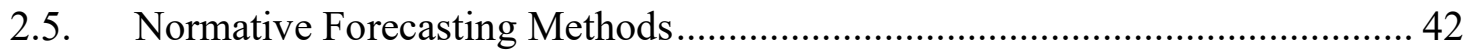

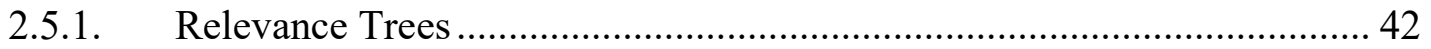

2.5.2. AHP (Analytic Hierarchy Process); Multi-Criteria Decision Model........ 44

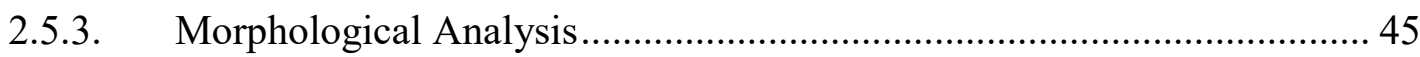

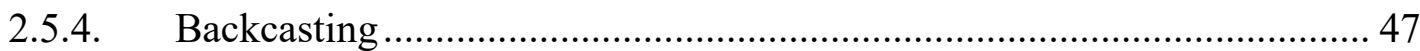

2.6. Normative / Explorative Technology Forecasting .............................................. 48

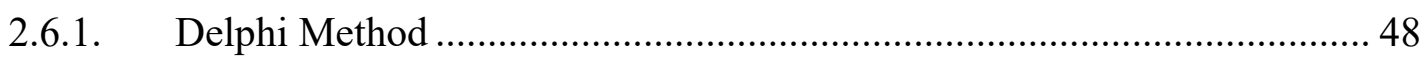

2.6.2. Nominal Group Technique (NGT) ......................................................... 51

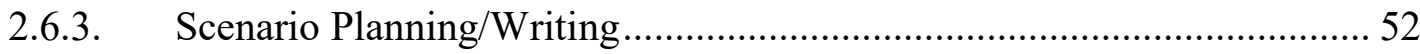

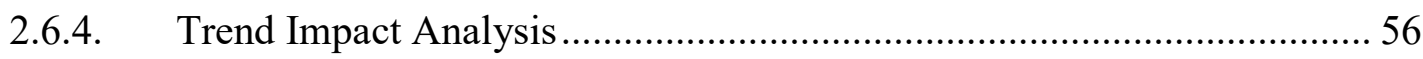

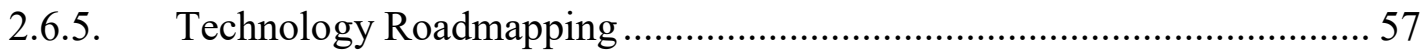

2.7. Analysis of the Relationship among TF Methods............................................ 59

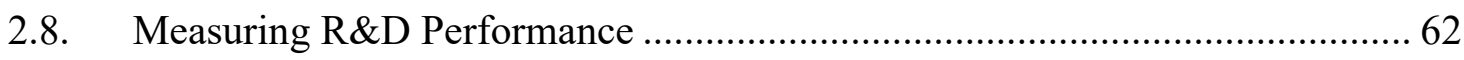

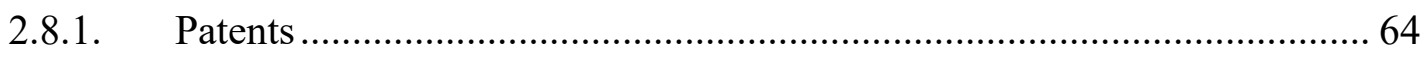

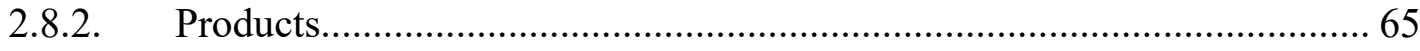

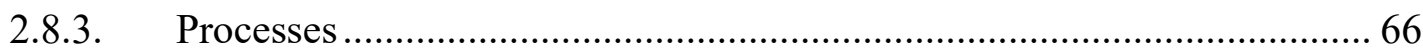

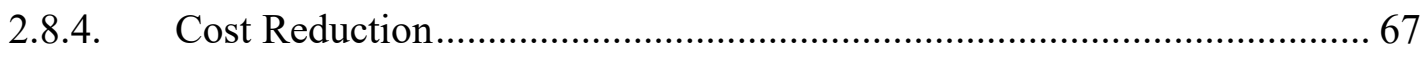

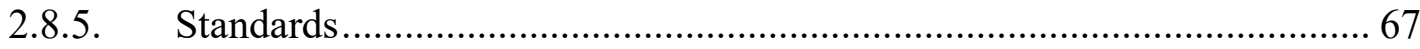

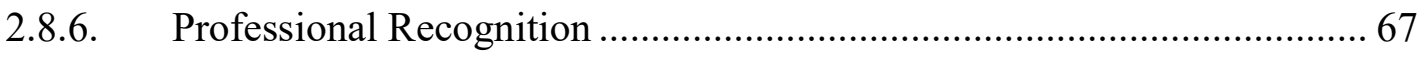

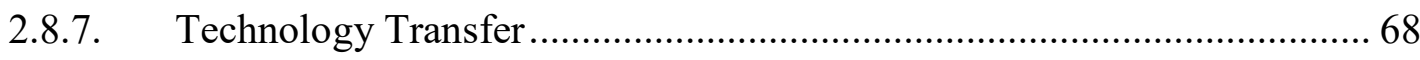

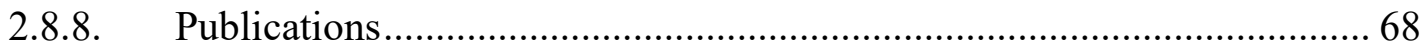

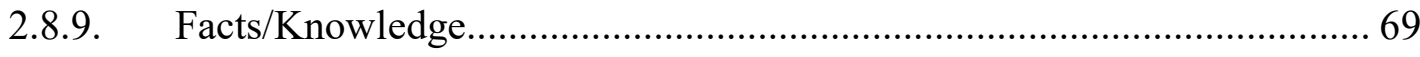

2.9. Measuring Business Performance …………………….................................. 71

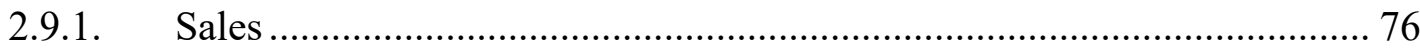

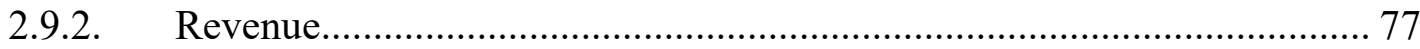

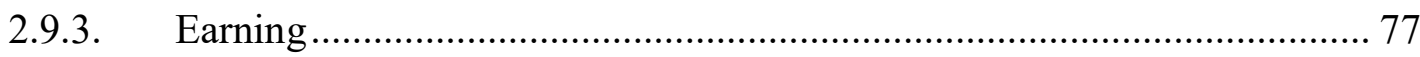

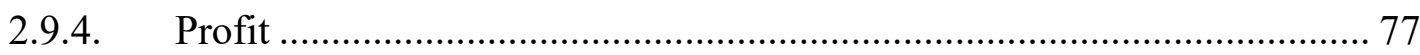

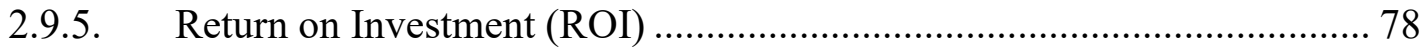

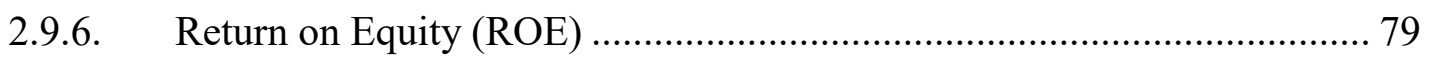




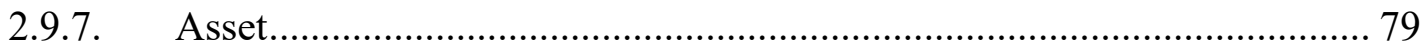

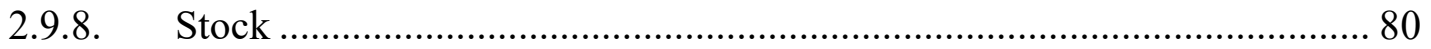

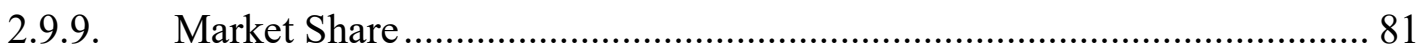

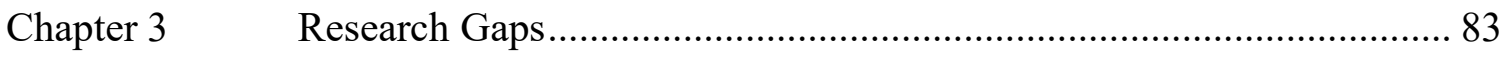

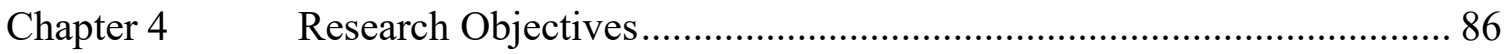

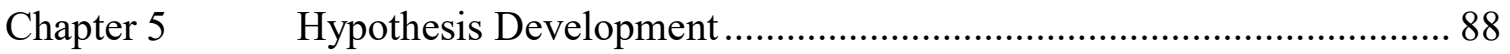

5.1. Technology Characteristics and the Effectiveness of TF ………………….... 88

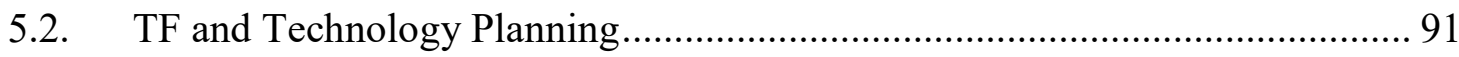

5.3. Firm Size and TF Intensity .......................................................................... 93

5.4. Technology Planning and R\&D Performance …………................................. 95

5.5. Technology Planning and Business Performance ............................................. 96

5.6. R\&D Performance and Business Performance ……………………………...... 97

Chapter $6 \quad$ Research Design................................................................................. 100

Chapter $7 \quad$ Research Methodology ……………............................................... 102

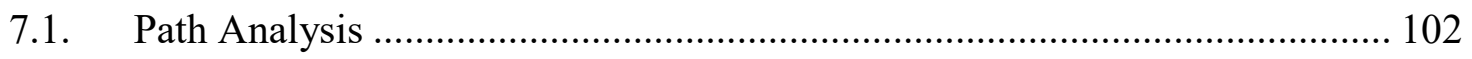

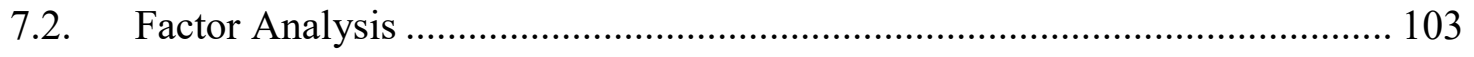

Chapter $8 \quad$ Data Collection ................................................................................. 106

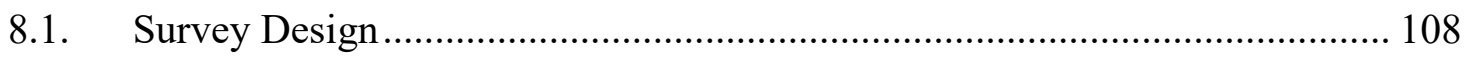

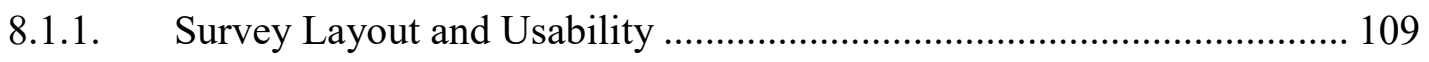

8.1.2. Delivery Method: Email ....................................................................... 112

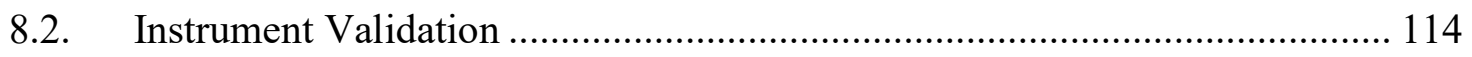

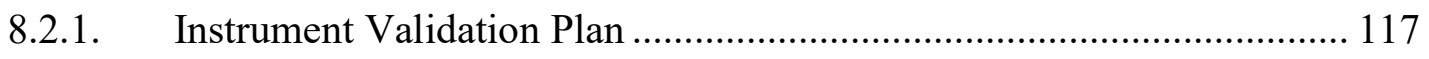

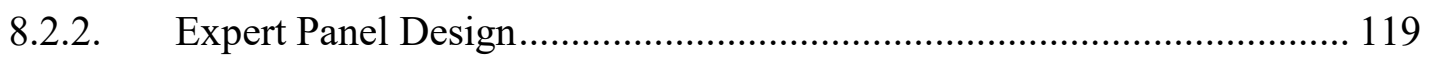

8.2.3. Step 1: Create Initial Draft of the Survey ……………………............... 121 


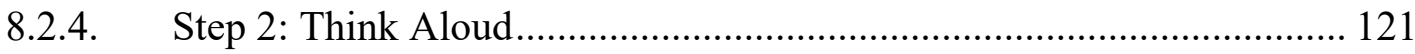

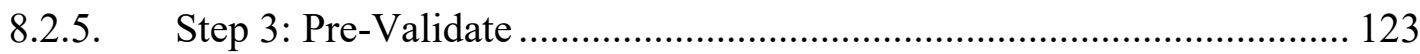

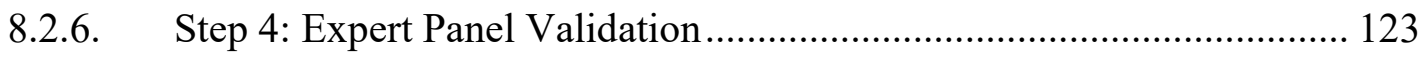

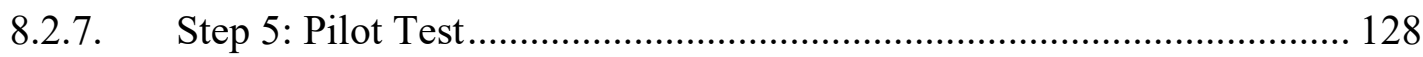

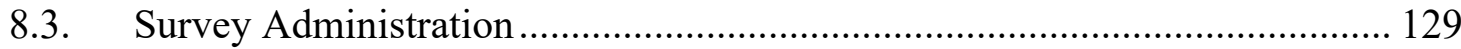

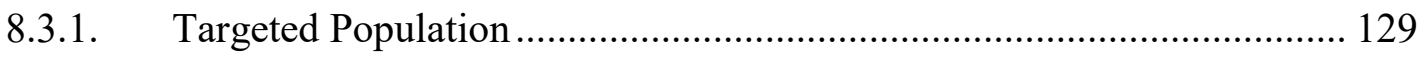

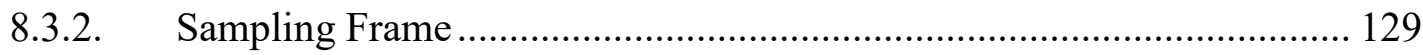

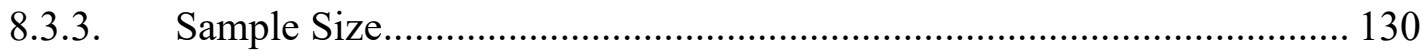

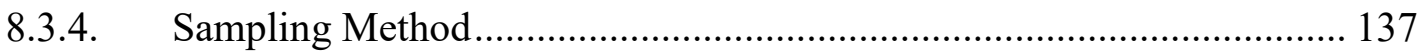

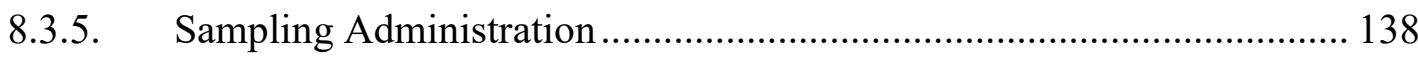

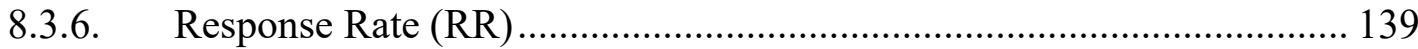

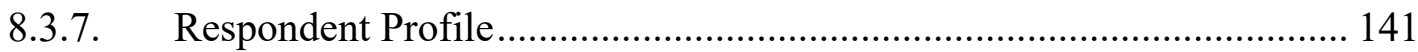

8.3.8. Nonresponse Error; Wave Analysis ......................................................... 142

8.3.9. Nonresponse Error; Item Nonresponse .................................................... 144

8.3.10. Post-survey Adjustments and Missing Data ............................................ 144

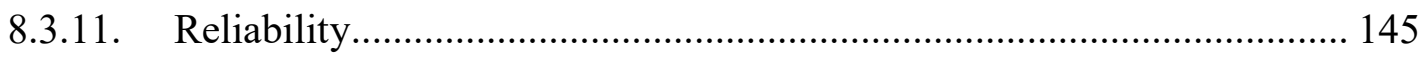

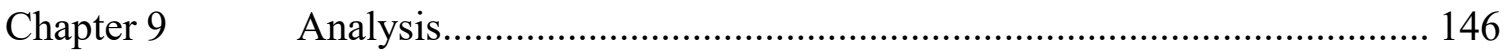

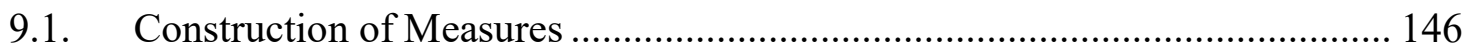

9.2. Confirmatory Factor Analysis (CFA) …………….................................. 149

9.3. Full Structural Equation Model …………………....................................... 152

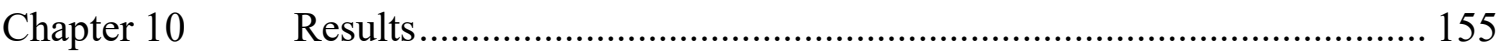

10.1. The Importance of TF ................................................................................ 155

10.2. Planning Activities .................................................................................... 155

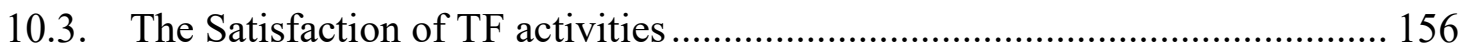

10.4. The Usefulness of TF on Technology Planning ............................................ 157

10.5. The Organizational Structure of Effective TF .............................................. 157

10.6. Technology Forecasting and Technology Characteristics ............................... 158 
10.7. The Use of Hybrid TF Methods and Technology Planning............................ 160

10.8. The Industrial Characteristics of TF ............................................................. 162

10.9. TF Activities based on Technology Characteristics ....................................... 164

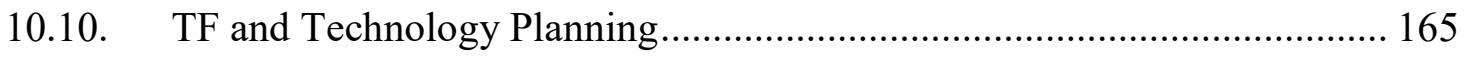

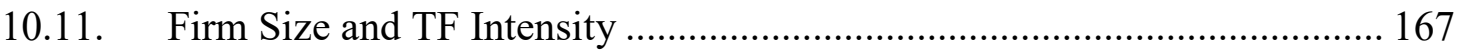

10.12. Firm Size and the Use of TF Resource ……........................................... 168

10.13. Technology Planning and R\&D Performance ........................................... 169

10.14. Technology Planning and Business Performance......................................... 170

10.15. R\&D Performance and Business Performance ........................................... 171

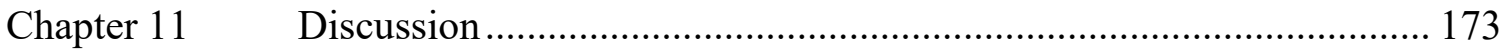

Chapter 12 Conclusions and Contributions....................................................... 179

Chapter 13 Limitations and Future Research ....................................................... 186

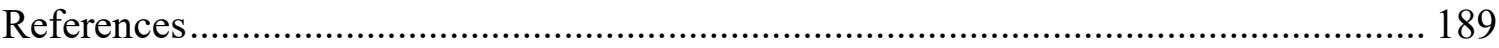

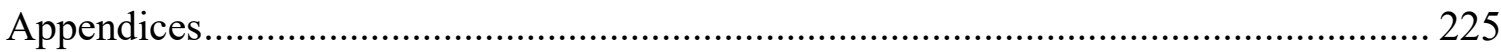

Appendix A. Human Subjects Approval …………………………………….. 225

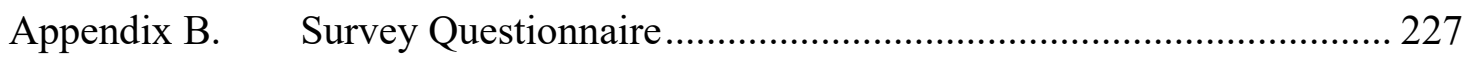

Appendix C. Variables (Descriptive Statistics).................................................... 234

Appendix D. Glossary of Conceptual Terms.................................................... 237 
Table 1 Technology forecasting vs. Technology foresight............................................... 11

Table 2 The classification of TF methods............................................................... 16

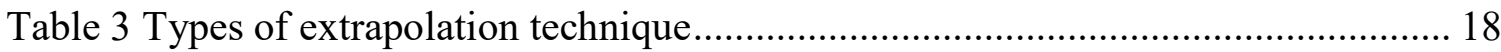

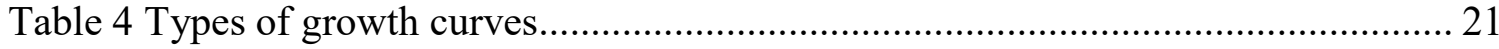

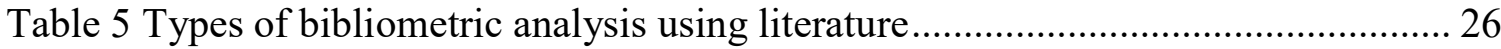

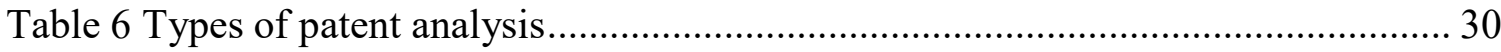

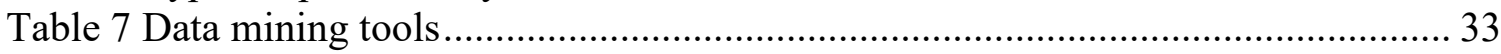

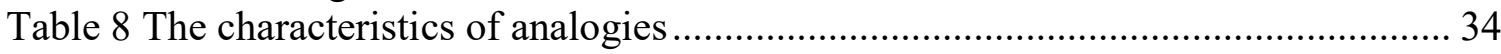

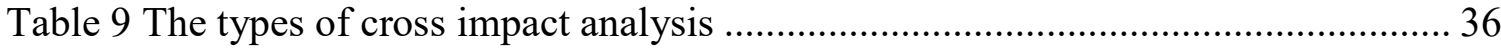

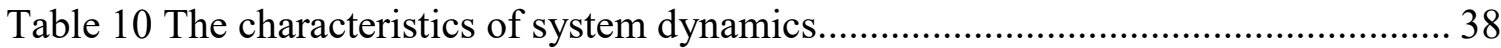

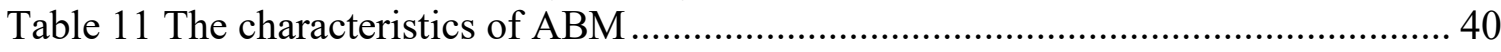

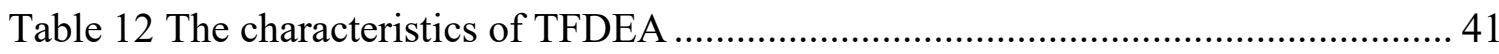

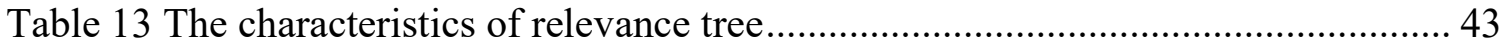

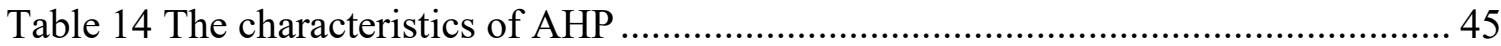

Table 15 The characteristics of morphological analysis .................................................... 46

Table 16 The characteristics of backcasting .................................................................... 48

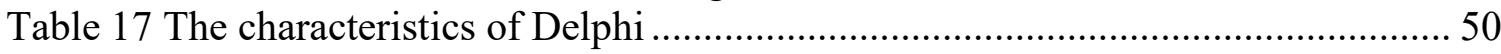

Table 18 The characteristics of Nominal Group Technique ............................................5 52

Table 19 The summary of three approaches of scenario planning ...................................55

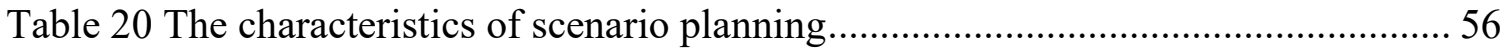

Table 21 The characteristics of trend impact analysis ..................................................5 57

Table 22 The characteristics of technology roadmapping ...............................................59

Table 23 The summary of output indicators from the literature ....................................... 70

Table 24 The summary of outcome indicators from the literature .................................. 82

Table 25 Research questions and hypothesis.................................................................. 99

Table 26 Comparison of mail, fax, and web-based surveys ........................................... 107

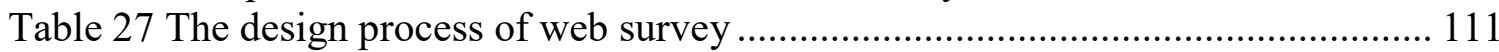

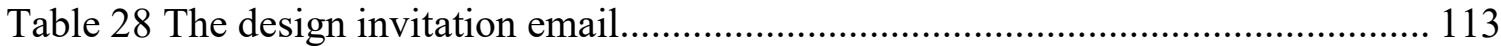

Table 29 Cognitive model of question-response ..................................................... 116

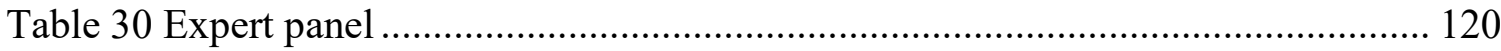

Table 31 Prior research that was used as references in the literature ............................. 121

Table 32 The example of pre-validation result .......................................................... 123

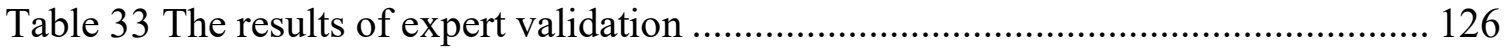

Table 34 Minimum sample size recommendations ................................................... 132

Table 35 Scenarios of properly specified sample sizes .................................................. 133

Table 36 Cutoff criteria for several fit indexes........................................................ 136

Table 37 Prior Ph.D. dissertations and response rate................................................ 141

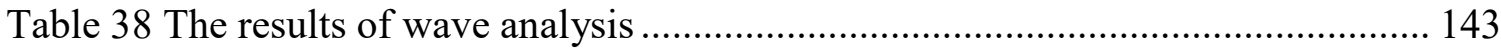

Table 39 Missing measurement items by each survey question ................................... 144

Table 40 Reliability test results............................................................................ 145

Table 41 Technology characteristics ........................................................................ 148

Table 42 The output of three factor loadings.............................................................. 152

Table 43 Goodness of fit indices for full structural equation model .............................. 154 


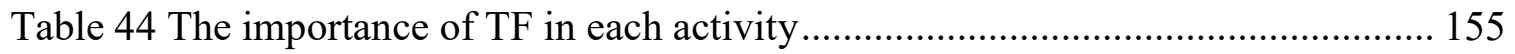

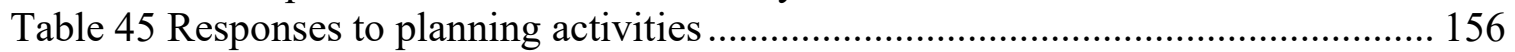

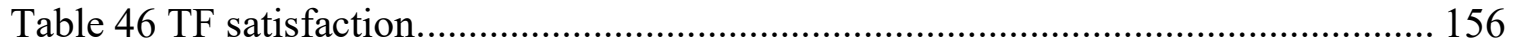

Table 47 The usefulness of TF in technology planning activity................................. 157

Table 48 Each organization's effectiveness for TF ................................................ 158

Table 49 The correlation between TF methods, data type, and tech. characteristics .... 159

Table 50 The correlation between TF methods and technology characteristics ............ 160

Table 51 The correlation between hybrid use of TF methods, TF, and TP .................. 161

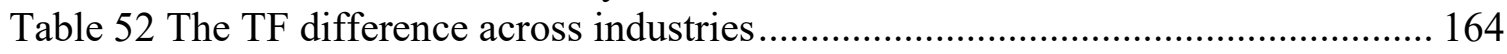

Table 53 The correlation between TF activities and technology characteristics ............ 165

Table 54 The linear relationship between firm size and TF activities ......................... 168

Table 55 The linear relationship between firm size and TF resources ......................... 169

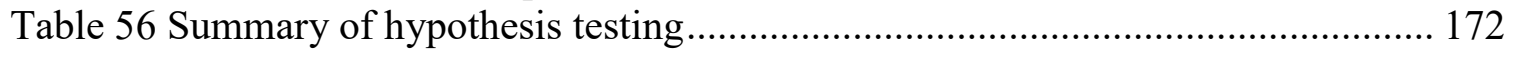




\section{List of Figures}

Figure 1 The chronological tree of technology forecasting techniques ............................... 6

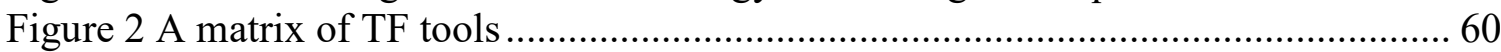

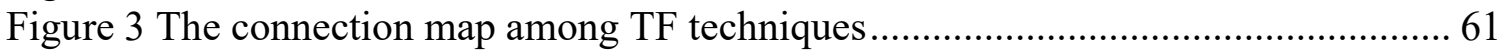

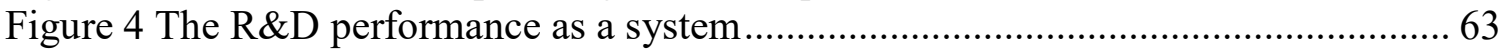

Figure 5 Overview of technology to business management .......................................... 75

Figure 6 Research gaps to research goals and questions ............................................... 87

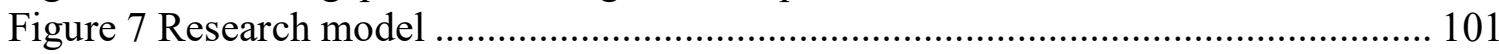

Figure 8 Sources of errors for a survey research design .............................................. 110

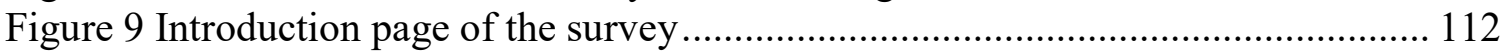

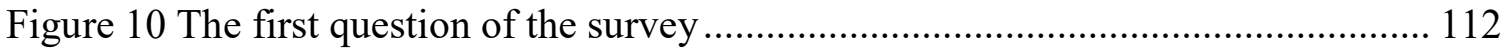

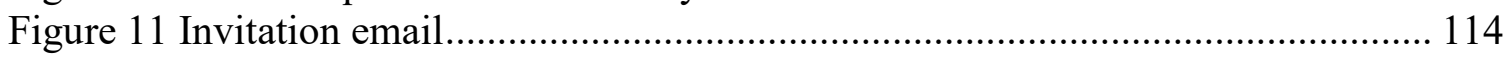

Figure 12 Instrument validation processes .............................................................. 117

Figure 13 Introduction letter of survey validation ..................................................... 124

Figure 14 An example of online survey validation.................................................. 125

Figure 15 Introduction letter of pilot test.................................................................. 129

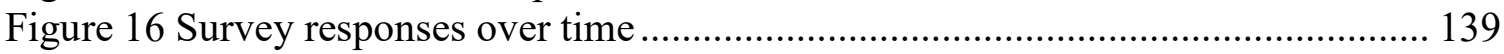

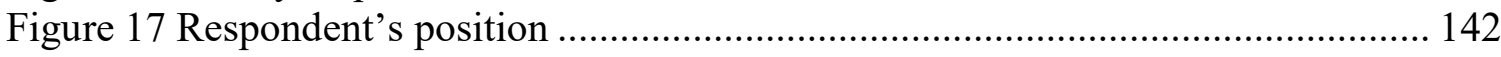

Figure 18 Respondents by industry........................................................................ 142

Figure 19 Full structural equation model with the results ........................................... 153

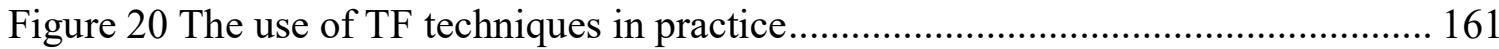

Figure 21 The research share in industry applications in the literature .......................... 163

Figure 22 Systematic decision-making process for strategic technology planning ........ 181

Figure $23 \mathrm{TF}$ data and methods based on technology characteristics and firm size....... 183

Figure 24 Guidance of appropriate selection with respect to TF activities .................... 184 


\section{Chapter 1 Introduction}

With the rapid change of technology platform, the endeavor to grasp the performance potential of current and emerging technologies has brought attention to the significance of technology forecasting $(\mathrm{TF})$ in strategic planning. In practice, $\mathrm{TF}$ is inevitably needed to help firms to identify and assess opportunities and threats in their competitive business environment, allocate resources in R\&D portfolio and new product development, and develop strategies in creating strategic alliances such as licensing in/out and joint ventures. Thus, a thorough review on TF techniques is conducted to help researchers and practitioners capture methodologies in a tangible way and identify the current trends in the TF arena.

On the other hand, little research has been done to identify how a firm's TF activity impacts its performance. Thus, this research provides a current comprehensive snapshot of how firms across industries implement best practices in TF to facilitate organizational functions and strategic technology planning. Moreover, this study offers broader conclusions regarding the relationships between $\mathrm{TF}$, technology planning, research and development (R\&D) performance, and business performance.

Historically, TF has been of much interest to governments and research institutions, and such institutions have employed it to plan technology policy for R\&D programs and to advance their agendas. Public organizations were the early adopters and developers of various TF and foresight methods and practices. However, beginning with the 1960 's, the primary users of TF shifted from government to private companies. As Erich Jantsch and Robert Ayres noted in the late 1960s, companies at the time began to focus on the integration of technological forecasting with long-range planning, and 
the implications for organization structure and operations [1][2]. Thereafter, corporations have increased their use of long-range planning as management began to recognize the importance of a long-term strategy in responding to increased competition among firms [3][4][5], the speed of technological change [6], and particularly the fastpaced advancement in information technology [7].

Long-range planning refers to formalized activities involved in setting long-term goals for business and defining specific plans to achieve these goals [8]. Most firms have some framework of formalized planning, and forecasting is one of the essential inputs to such planning [3]. Several studies underscore the need and the role of TF in strategic planning [9][10][11]. With the rapid change of technology platforms, and the increasing intersection between companies and other functions such as government policymaking, TF activities such as the technology roadmap, business/technology strategy, and information technology (IT) have gained significance.

$\mathrm{TF}$ is necessary to help decision makers identify and assess opportunities and threats in the firm's competitive business environment [9], and to guide planning when creating new venture or strategic alliances such as licensing and joint ventures [12][13]. Moreover, TF is indispensable to corporate planning groups and R\&D laboratories, not only for the purpose of formulating business and technology strategy, but to allocate resources in the $\mathrm{R} \& \mathrm{D}$ portfolio and to shape the direction of new product development [14].

Proactive TF is necessary to transform individual behavior, organization, economy, society, and culture in a turbulent world. Government and companies should strive to anticipate how technology developments will impact future business 
environments and society. Since there is a high degree of uncertainty associated with technological change, it is imperative that organizations periodically reassess the viability of $R \& D$ projects during the planning process at certain milestones.

In order to implement $\mathrm{TF}$ effectively, it is vitally important to understand how technological change occurs. Kuhn suggests that the normal development path of scientific knowledge is heavily selective, often centered on whatever dominant framework to which the leading scientist in the field may adhere [15]. This so called "technology trajectory" often defines the direction of technological evolution [16]. Technological development in this vein is inherently based upon the accumulation of knowledge - a cumulative process. On the other hand, disruptive (discontinuous) technological innovation is different from technological development occurring on a technology trajectory. Discontinuous technological change can be defined as scientific discoveries that breakthrough the usual product/technology capabilities and create an entirely new market through them [17][18][19]. It is very crucial to forecast disruptive technologies for firms to maintain profitable R\&D investments and create feasible business plans for commercialization. 


\section{Chapter 2 Research Background and Literature Review}

A variety of TF methods have been developed and applied to various industries and organizations, suited to different purposes. Few studies, however, have attempted to explore the collective implications of technology forecasting to an organization's business performance. This study sheds a light on the best practices of TF implementation and analyzes how TF functions within organizations. In particular, this study focuses on how systematic forecasting helps businesses make better strategic decision.

Today, organizations are facing an increasingly complex and changeable external environment. In such an environment, being well-informed about technological changes has the potential to dramatically alter the effectiveness of an organization's technology management [20][21][22]. Consequently, establishing systematic technology innovation management, capable of predicting technological change at the pace of innovation, is necessary for business success in a tornado world market. To date, many efforts have been made to determine the governing principles of technology management and to integrate business management with technology management [20]. A number of studies recommend that a company should align $R \& D$ strategy with business strategy in the areas of technology development, manufacturing, sales and marketing, personnel, finance, and accounting. The first step to establishing an appropriate R\&D strategy, however, is to forecast the technological direction of the industry.

In the midst of increasing business uncertainty and complexity, firms have invested in environmental scanning efforts, such as bibliometric/patent trend analysis and market analysis, to identify increasingly diversified needs of customers, establish 
technology initiatives responsive to those needs, and improve their future position. In the last four decades, especially after the widespread availability of information technology (IT), researchers have developed many different approaches to using sources of information and information tools such as patent databases, journals, and research awards, to comb through vast amounts of data and extrapolate trends. Figure 1 presents the chronological tree of TF methods.

Methodologies in technology foresight and technology forecasting are not fixed. Certain TF methods are employed concurrently to predict technological changes or innovations, but others are not. For example, a combination of approaches and methods is required to improve the effectiveness and accuracy of forecasting, since combining multiple techniques enables forecasters to analyze various perspectives (organizational, technological, economic, political, personal, social, and environmental) [23][24]. TF experts maintain that, in order to respond effectively to rapid social change and the increased complexity of state-of-the-art science, one of the next generation of forecasting approaches must combine exploratory and normative forecasting methods [25]. Forecasting done for exploratory or opportunity-oriented purposes may interact with forecasting done for normative or mission-oriented purposes [13]. As a contrasting example, however, it would be theoretically inappropriate to use composite methods to solve forecasting problems that are of a more practical nature. In such instances, the conflicting assumptions inherent in the two or more types of forecasting may lead to an unusable answer. The proper selection of TF methods depends on the nature of the technologies [26]. The first task in forecasting is to choose the forecasting method that is most appropriate to the analysis and the characteristics of the field of technology 
being analyzed—such as whether the technology is disruptive versus incremental.

Selecting a suitable method would depend on several factors, including the level of uncertainty in the technological field, data availability, difficulties inherent in the technology, or the availability of funding for R\&D.

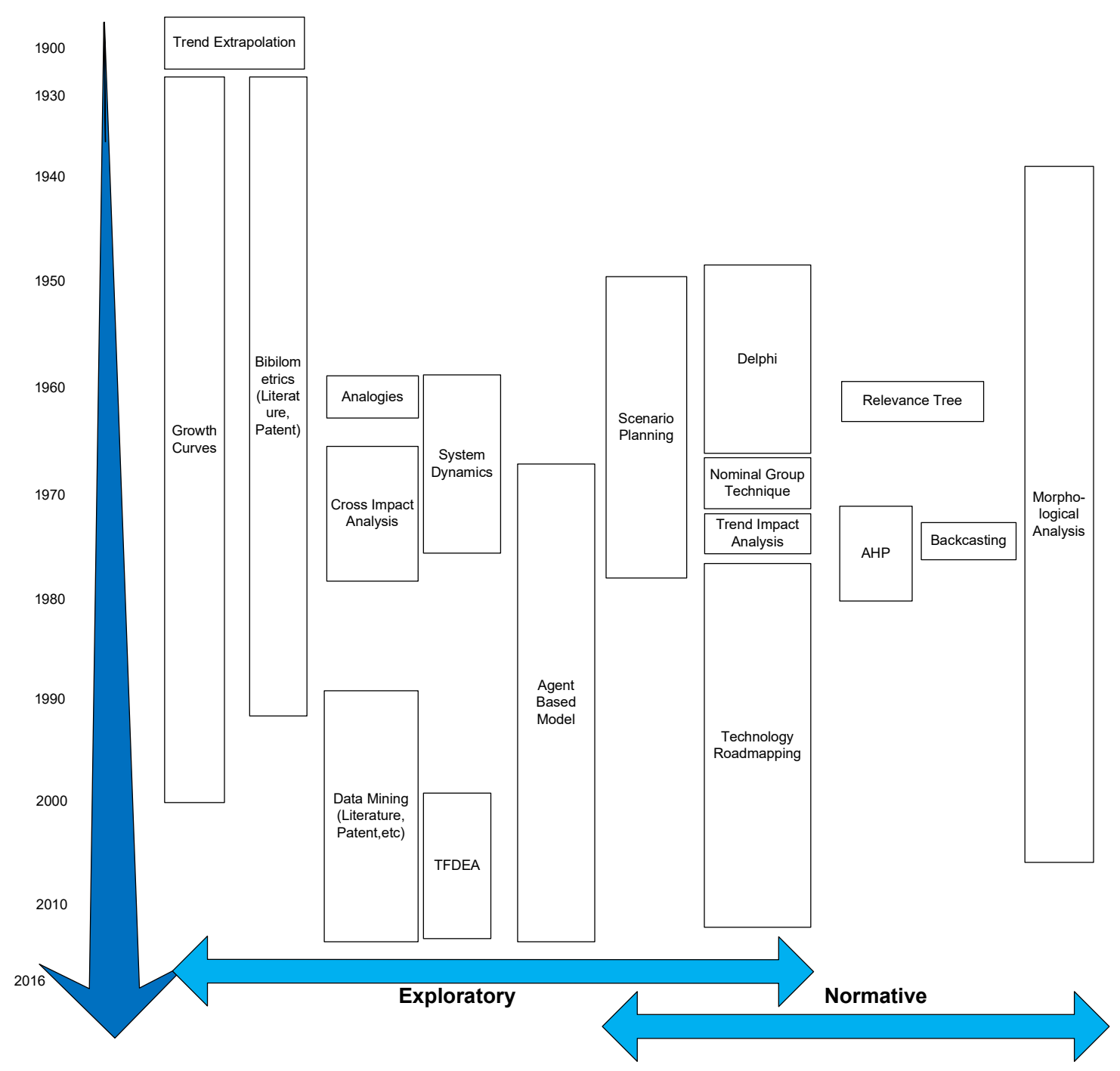

Figure 1 The chronological tree of technology forecasting techniques 


\subsection{The Concepts of Technology Forecasting and Technology Foresight}

There is little agreement over the meaning of the terms, "technology forecasting" and "technology foresight", and there has been relatively little effort to clarify the similarities and differences between the two terms [25]. Historically, the term "technological forecasting", coined around mid 1940s, has been used more often and for longer in literature than the term "technology foresight", coined in the early 1980s [27]. As these two terms have been used interchangeably and inconsistently in the literature of the last decade, it is important to conduct a comprehensive review of the concepts historically associated with these terms and to foreclose potential misinterpretations of these two concepts in future research, by clarifying their meaning.

Technology forecasting is different from social forecasting, economic forecasting, market forecasting, financial forecasting, transportation demand forecasting, and weather forecasting, but in some contexts, these various concepts may intertwine [28][29]. To define TF, we can consider the definition of "technology" and "forecasting", respectively. What is technology? Webster's Dictionary defines it as "[t]he practical application of science to commerce or industry." At times, "technology" can refer to a concrete physical object. One might be accustomed to thinking that the definition of technology does not include a human being's abstract knowledge. However, Quinn defines technology more precisely as "not a single immutable piece of hardware or bit of chemistry, but also knowledge of physical relationshipssystematically applied to the useful arts" [29]. To "forecast" is to predict how something will develop. Forecasting normally ends with the identification of possible futures. 
As more than the sum of its component parts, the definition of "technology forecasting" varies and covers a wide range of activity. In 1962, Lenz, one of the pioneers of technological forecasting, defined technological forecasting as "the prediction of the invention, characteristics, dimensions, or performance of a machine serving some useful purpose. . . The qualities sought for the methods of prediction are explicitness, quantitative expression, reproducibility of results, and derivation on a logical basis" [30]. In 1967, Jantsch, who was a consultant to the OECD, defined technological forecasting as "the probabilistic assessment, on a relatively high confidence level, of future technology transfer" [13]. This definition focused more on the technology transfer perspective. According to Bright, technology forecasting refers to "systems of logical analysis that lead to common quantitative conclusions (or a limited range of possibilities) about technological attributes and parameters, as well as technical-economic attributes" [1]. Cetron describes technological forecasting in more detail as "prediction with a level of confidence of a technical achievement in a given time frame with a specified level of support'[31]. Martino defined technology forecasting as "a prediction of the future characteristics of useful machines, procedures or techniques," explaining that "technology is not restricted to hardware only, but may include 'know-how' and 'software'" [32]. This definition highlights that technology includes practical application and that it is not purely scientific knowledge. Ascher defined technology forecasting as the effort "to project technological capabilities and to predict the invention and spread of technological innovation...." [33]. In addition, Millett and Honton expand the concept of technology forecasting as "the process and result of thinking about the future, whether expressed in numbers or in words, of 
capabilities and applications of machines, physical processes and applied science" [34].

This definition includes business environment and corporate concerns as well as technological performance.

In summary, technology forecasting refers to the analysis and the evaluation of performance parameters, timing of advancements, new concepts, products, processes, market penetration, and sales in a given time frame with probability statements, on a relatively high confidence level, which anticipates opportunities and threats from technological changes in order to provide for more well-informed R\&D decisionmaking.

The main objective of technology forecasting is to support decision making as well as R\&D and business planning. As Swager has identified, technology forecasting play five roles: identifying policy options, aiding strategy formulation, identifying program options, selecting programs for funding, and selecting opportunities for investment [9].

In addition to the term "technology forecasting", the term "technology foresight" has also come into common usage. Initially, foresight and forecasting were used interchangeably [35][27], but, there is now a real difference in the understanding of forecasting as contrasted to foresight [36]. The term "technology foresight" or "national technology foresight" has increasingly been used to signal the role national governments are playing in identifying socially desirable technologies [25]. In 1985, Joseph Coates identified foresight as "the overall process of creating an understanding and appreciation of information of varying degrees of credibility, completeness, and technical and scientific soundness generated by looking ahead" [37]. In 1995, Ben 
Martin defined technology foresight as "the process involved in systematically attempting to look into the longer-term future of science, technology, the economy and society with the aim of identifying the areas of strategic research ${ }^{1}$ and the emerging of generic technologies ${ }^{2}$ likely to yield the greatest economic and social benefits" [38]. Since the 1990s, technology foresight has been actively and broadly implemented in Europe. In some European context, networking and cooperation in identifying future options is as - in some cases even more — significant than the tasks of forecasting [36]. Technology foresight goes further than forecasting, encompassing aspects of networking and the preparation of decisions regarding the future [36]. Foresight broadens the scope of attention to a national scale. Foresight not only looks into the future by using all instruments of futures research, but includes utilizing implementations for the present [36]. The ultimate objective of foresight is to ensure that areas of science and technology that are likely to yield future socio-economic benefits such as health, quality of life, environmental protection and contributions to culture are identified promptly [38]. Table 1 provides a summary of the distinctions between technology forecasting and technology foresight.

\footnotetext{
1 'Strategic research' is defined as "basic research carried out with the expectation that it will produce a broad base of knowledge likely to form the background to the solution of recognized current or future practical problems" [558], p.4.

2 'Generic technology' is defined as "a technology the exploitation of which will yield benefits for a wide range of sectors of the economy and/or society" [559], p.51.
} 
Table 1 Technology forecasting vs. Technology foresight

\begin{tabular}{|c|c|c|c|c|c|c|}
\hline Term & Definition & Characteristics & Elements & $\begin{array}{l}\text { Type of } \\
\text { Affiliation } \\
\text { (Inception) }\end{array}$ & Nation & Citation \\
\hline $\begin{array}{l}\text { Technology } \\
\text { Forecasting }\end{array}$ & $\begin{array}{l}\text { A prediction } \\
\text { of the future } \\
\text { characteristi } \\
\text { cs of useful } \\
\text { machines, } \\
\text { procedures } \\
\text { or } \\
\text { techniques } \\
\text { i.e., } \\
\text { technology } \\
\text { is not } \\
\text { restricted to } \\
\text { hardware } \\
\text { only, but } \\
\text { may include } \\
\text { "know-how" } \\
\text { and } \\
\text { "software }\end{array}$ & $\begin{array}{l}\text { - Prediction, not } \\
\text { necessarily } \\
\text { assessments. } \\
\text { - More } \\
\text { quantitative than } \\
\text { qualitative. } \\
\text { - No information } \\
\text { about consensus } \\
\text { necessary. } \\
\text { - Less dependent } \\
\text { on opinions. } \\
\text { - Identification } \\
\text { of possible } \\
\text { futures. }\end{array}$ & $\begin{array}{l}\text { 1) The time of } \\
\text { the forecast } \\
\text { 2) The } \\
\text { technology } \\
\text { being forecast } \\
\text { 3) A } \\
\text { statement of } \\
\text { the } \\
\text { characteristics } \\
\text { of the } \\
\text { technology } \\
\text { 4) A } \\
\text { statement of } \\
\text { the } \\
\text { probability } \\
\text { associated } \\
\text { with the } \\
\text { forecast }\end{array}$ & $\begin{array}{l}\text { 1. } \\
\text { Government } \\
\text { 2. Academia } \\
\text { 3. Industry }\end{array}$ & $\begin{array}{l}\text { US (1937), } \\
\text { EU[ Netherland } \\
(1949), \text { France } \\
(1961), \\
\text { Germany } \\
(1964), \text { Italy } \\
(1965), \\
\text { Switzerland } \\
\text { (1965), } \\
\text { Austria(1966)], } \\
\text { Israel (1954), } \\
\text { Canada } \\
\text { (1960s), } \\
\text { UK(1963), } \\
\text { Japan (1975), } \\
\text { China (1985), } \\
\text { South Korea } \\
\text { (1990s), } \\
\text { India(1997) }\end{array}$ & $\begin{array}{l}{[1][32]} \\
{[29][13]} \\
{[36][39]} \\
{[40][26]}\end{array}$ \\
\hline $\begin{array}{l}\text { Technology } \\
\text { Foresight }\end{array}$ & $\begin{array}{l}\text { The process } \\
\text { involved in } \\
\text { systematicall } \\
\text { y attempting } \\
\text { to look into } \\
\text { the longer- } \\
\text { term future } \\
\text { of science, } \\
\text { technology, } \\
\text { the economy } \\
\text { and society } \\
\text { with the aim } \\
\text { of } \\
\text { identifying } \\
\text { the areas of } \\
\text { strategic } \\
\text { research and } \\
\text { the } \\
\text { emerging } \\
\text { generic } \\
\text { technologies } \\
\text { likely to } \\
\text { yield the } \\
\text { greatest } \\
\text { economic } \\
\text { and social } \\
\text { benefit }\end{array}$ & $\begin{array}{l}\text { - Outlook, based } \\
\text { on a bundle of } \\
\text { systematic and } \\
\text { comprehensive } \\
\text { processes for } \\
\text { looking ahead, } \\
\text { with criteria for } \\
\text { assessments. } \\
\text { - More } \\
\text { qualitative than } \\
\text { quantitative. } \\
\text { - Finds out if } \\
\text { there is } \\
\text { consensus on } \\
\text { themes. } \\
\text { - Very dependent } \\
\text { on opinions. } \\
\text { - Many possible } \\
\text { futures, neither } \\
\text { too general nor } \\
\text { too detailed. } \\
\text { - Process must } \\
\text { be public. }\end{array}$ & $\begin{array}{l}\text { 1) Direction- } \\
\text { setting } \\
\text { 2) } \\
\text { Determining } \\
\text { priorities } \\
\text { 3) } \\
\text { Anticipatory } \\
\text { intelligence } \\
\text { 4) Consensus } \\
\text { generation } \\
\text { within } \\
\text { research } \\
\text { community or } \\
\text { externally } \\
\text { among } \\
\text { research } \\
\text { funders, } \\
\text { performers } \\
\text { and users } \\
\text { 5) Advocacy } \\
\text { for a new } \\
\text { research } \\
\text { initiative } \\
\text { 6) } \\
\text { Communicati } \\
\text { on and } \\
\text { education } \\
\text { within the } \\
\text { research } \\
\text { community }\end{array}$ & $\begin{array}{l}\text { 1. } \\
\text { Government } \\
\text { 2. Academia } \\
\text { 3. Industry }\end{array}$ & $\begin{array}{l}\text { Japan(1971), } \\
\text { US (1980s), } \\
\text { Canada(1980s), } \\
\text { EU[Netherland } \\
\text { s(1988), } \\
\text { Germany(1991) } \\
\text {, France(1994), } \\
\text { Spain(1995), } \\
\text { Italy(1995), } \\
\text { Hungary(1997), } \\
\text { Austria(1997), } \\
\text { Norway(1998), } \\
\text { Sweden(1998), } \\
\text { Portugal(1999), } \\
\text { Denmark(2000) } \\
\text {,Finland(2001)] } \\
\text {, New Zealand } \\
\text { (1992), UK } \\
\text { (1993), } \\
\text { Australia } \\
\text { (1994), South } \\
\text { Korea (1994), } \\
\text { China (2002) }\end{array}$ & $\begin{array}{l}{[25]} \\
{[36]-[38]} \\
{[41]-[51]}\end{array}$ \\
\hline
\end{tabular}

\subsection{The Subsets of Technology Forecasting}

\subsubsection{Characteristics of Technology Forecasting}

Technology forecasting consists of subset elements such as a certain future time

span, technological change, continuous range of characteristics in applications, and a 
statement of the probability associated with the technology [32]. Technology

forecasting does not necessarily need to predict the exact form of technology

dominating in a given application at some specific future date, since technology

forecasting aims to provide the evaluation of the probability and significance of various possible future developments in order for managers to make better decisions [29]. In most cases, technology forecasting is wrong. Technology forecasting, however, is valuable to give guidance for the direction of promising technology development. The value of technology forecasting lies in its usefulness for making better decisions, not in its coming true [32]. Technology forecasting, in other words, is typically only partially correct and cannot include all exact future forms. Technology forecasting strives not only to identify research and knowledge gaps to find the right path to reach goals, but to search ranges of environment that may be encountered in the future.

\subsubsection{Assumptions of Technology Forecasting}

One of the most significant tasks in technology forecasting is to decide on the right assumptions and appropriate methods for a given situation, so as to predict the right technological change in a certain future, since the methods employed inevitably affect technology forecasting results [26][52]. The selection of methods mainly affects the accuracy and reliability of technology forecasting. If the assumptions are inaccurate, the prediction would go a wrong direction. Many forecasters attempt to resolve the predictive challenges of technology forecasting by increasing the sophistication of their methods and improving the quality of data. When a technological landscape is volatile, however, merely employing increasingly complex methods to capture small analytical gains is likely to be futile. In addition, forecasting requires a technique that is suited to 
the characteristics of a certain technology, but not all problems in technology forecasting are so easily categorized [26]. As a further challenge, only data from the past and present is available. One of the mistakes of technology forecasting is to assume that the future is fixed or pre-determined. Furthermore, mistakes in trend projection most often arise out of the assumption that the future will simply be an addition or subtraction from the present, based upon the assumption that technology will follow past trends. It ignores the effects of unprecedented future events. Therefore, most problems in forecasting are caused not by a lack of sophistication but by drawbacks inherent in the process of technology forecasting [53].

\subsubsection{Technological Trajectory vs. Discontinuity}

For the appropriate use of technology forecasting, it is vitally important to understand how technological change develops and happens. Kuhn describes that the normal development path of scientific knowledge is heavily selective, where the framework adhered to by the leading scientists in the field often limits the direction of development [15]. Technological change thus depends on the evolution of a trajectory [16], the so-called "technology trajectory." The technology trajectory develops as the accumulation of learning processes. Giovanni Dosi defines a technological trajectory as the pattern of actualization of a promise contained in a scientific paradigm solving activity (i.e. of "progress") on the ground of a certain technological progress [54]. In other words, technological trajectory is a cluster of possible technological directions whose outer boundaries are defined by the nature of the paradigm itself [54]. Dosi also describes the "technological frontier" the highest level reached thus far upon a technological path with respect to the relevant technological and economic dimensions 
[54]. Christensen explains the concept of performance trajectories as the rate at which the performance of a product has improved [17]. The technology trajectory reflects the aggregation of technological advances, following on established technological paths.

However, disruptive (discontinuous) technological innovation is different from technological developments following the technology trajectory. Technological discontinuity results from the resolution of technological rivalries among competitive technologies, as one category of technology substitutes another [18]. A technological breakthrough may disrupt the typical life cycle of a technological advance. In this case, the traditional tools of technology forecasting, such as probability statements are not appropriate for the prediction of discontinuous emerging technology. Discontinuous technological change can be defined as scientific discoveries that break through the usual product/technology capabilities and create an entirely new market [17][18][19]. It is very crucial to forecast disruptive technologies in order to aid a firm's decision making regarding R\&D investments and its business plan for commercialization efforts. However, predicting the time at which a disruptive technology will change the existing technology trajectory is difficult. Therefore, given the unique challenges posed by disruptive technology, it is important to distinguish forecasting for "incremental innovation" versus "disruptive innovation", and to distinguish "continuous" technological progress along a trajectory from the "discontinuous" progress associated with the emergence of a new paradigm. 


\subsection{The Classification of Technology Forecasting Methods}

There are multiple ways of classifying technology forecasting methods. Erich Jantsch classified technology forecasting methods in 1967 based on the characteristics of the type of technique used with respect to technology transfer: intuitive, exploratory, normative, and feedback [13]. Stephen Millett and Edward Honton organized TF techniques into three types of analysis: trend analyses, expert judgment, and multioption analyses [34]. John Vanston assorted technology forecasting techniques based on the type of roles involved in forecasting: extrapolators, pattern analysts, goal analysts, counter-punchers, and intuitors [55]. The TF methods are commonly classified under the headings of "exploratory" versus "normative" [56][57]. Following the lead of the Technology Futures Analysis Methods Working Group, this study divides TF techniques into three categories: normative, exploratory, and a combination of the two [58]. (See Table 2). As Jantsch pointed out, technology forecasting always constitutes an iterative process between exploratory and normative technological forecasting [59].

Exploratory technological forecasting is the attempt to predict the technological state-of-art that will or might be in the future [56]. It starts from today's assured knowledge of what has happened to the present day and predicts future events. Exploratory methods extrapolate from the past and extend trends through the present and into the future. This form of forecasting is more focused on predicting how a new technology will evolve on a predetermined curve (an S-shaped growth curve) as opposed to answering questions about whether technology should evolve a certain direction. Exploratory forecasting ascertains what future will inevitably result if trends hold, so that there is little room to affect or alter planning [1]. 
On the other hand, normative technological forecasting starts with the future and plans backwards. It first assesses future goals, needs, desires, and missions - using some desired future state of events as the starting point — and traces backward to determine the steps necessary to reach the end point and to assess the probability of their success [56]. Planners take into account the dynamic progression of events necessary to accomplish a particular mission, the satisfaction of a need, or state of technological development. Such forecasting mainly focuses on what ought to be or needs to be realized at a certain future time. Normative technology forecasting aims to provide the groundwork to allocate technology-generating resources such as investment, human resources and other assets to reach organizational objectives. The table 2 below summarizes the typical characteristics of exploratory and normative forecasting.

Table 2 The classification of TF methods

\begin{tabular}{|c|c|c|c|}
\hline Term & Definition & Characteristics & Citation \\
\hline Exploratory & $\begin{array}{l}\text { The attempt to predict } \\
\text { the technological } \\
\text { state-of-art that will } \\
\text { or might be in the } \\
\text { future. }\end{array}$ & $\begin{array}{l}\text { - evolves on a predetermined curve such as S- } \\
\text { shaped } \\
\text { - too naïve } \\
\text { - projects anticipated consequences } \\
\text { - suggests alternatives to the proposed } \\
\text { allocation }\end{array}$ & {$[56][58]$} \\
\hline Normative & $\begin{array}{l}\text { The statement of what } \\
\text { ought to be or needs } \\
\text { to be possible at some } \\
\text { future time }\end{array}$ & $\begin{array}{l}\text { - more proactive } \\
\text { - too complex and mathematically intricate } \\
\text { - meaningfulness of its treatments of goals is } \\
\text { significant } \\
\text { - recognition of economic potentials } \\
\text { - recognition of responsibility towards society } \\
\text { or nation } \\
\text { - awareness of constraints (natural resources, } \\
\text { company resources, etc.) } \\
\text { - recognition of an ultimate technological } \\
\text { potential } \\
\text { - hedging against threats }\end{array}$ & {$[56][58]$} \\
\hline $\begin{array}{l}\text { Normative/ } \\
\text { Exploratory }\end{array}$ & $\begin{array}{l}\text { Can be used in two } \\
\text { different approaches }\end{array}$ & - & \\
\hline
\end{tabular}




\subsection{Exploratory Forecasting Methods}

In the early ages of TF, attempts to forecast technological change mostly involved exploratory approaches and Delphi technique [30][60]. Exploratory technology forecasting methods simulate movement in the direction of technology transfer [13]. A description of each technology forecasting method and its practical applications is provided below.

\subsubsection{Trend Extrapolation}

Trend extrapolation is a widely used technique in technology forecasting. Extrapolation technique makes predictions based on the premise that the future will be a reasonable projection of some type of time-series data, i.e., the old time-series includes all the information needed to predict the future event, and existing trends will continue in the future rather than producing different pattern [30][32]. A number of economic forecasts are based on this assumption.

To apply this technique, forecasters need to collect appropriate data in terms of an attribute or variable over time. Then they can easily predict the future by identifying previous trends and extrapolating them in an intelligent manner. Since this method relies on finding patterns such as trends or cycles in historical data and fitting a relevant curve to the past data, the selection of the appropriate fitting curve is crucial to successful forecasting by extrapolation [61].

There are three types of curve-fitting equations for trend extrapolation based on the rate of technological progress of historical data—-linear, exponential, and polynomial techniques [2]. Linear extrapolation is used where a linear growth function is predicted. A polynomial trend equation may be applied to identify the trend where the 
trend does not follow either a linear or exponential path. Once forecasters choose the appropriate equation, they can portray the extrapolation mathematically and graphically. Table 3 Types of extrapolation technique

\begin{tabular}{|c|c|c|c|}
\hline Types & Curve-fitting Equation & Characteristics & Reference \\
\hline Linear & $\mathrm{Y}_{\mathrm{t}+1}=\mathrm{y}_{0}+\mathrm{kt}$ & \multirow{3}{*}{$\begin{array}{l}\text { - simple and relatively } \\
\text { inexpensive } \\
\text { - easy to understand } \\
\text { - inaccurate } \\
\text { - appropriate for short-term } \\
\text { forecast } \\
\text { - not applicable for } \\
\text { discontinuous technology } \\
\text { - needs conjunction with } \\
\text { complementary methods }\end{array}$} & \multirow{3}{*}{$\begin{array}{l}{[30][32]} \\
{[34][2]} \\
{[62]}\end{array}$} \\
\hline Polynomial & $\mathrm{Y}_{\mathrm{t}+1}=\mathrm{y}_{0}+\mathrm{k}_{1} \mathrm{t}+\mathrm{k}_{2} \mathrm{t}^{2}$ & & \\
\hline Exponential & $\begin{array}{c}\mathrm{Y}_{\mathrm{t}+1}=\mathrm{y}_{0} \mathrm{e}^{\mathrm{kt}} \text { or } \ln \mathrm{y}_{\mathrm{t}+1}=\ln \\
\mathrm{y}_{0}+\mathrm{kt}\end{array}$ & & \\
\hline
\end{tabular}

Forecasters have used trend extrapolation to predict technological capabilities, the rate of technological change, the level of product sales, and the length of time it will take to develop a new technology, among many other events, on the basis of available variables and data [34]. This method is closely associated with growth curve fitting and projection. In order to improve forecasting accuracy, trend extrapolation should be employed in conjunction with normative forecasting methods such as cross-impact analysis, expert opinion, and monitoring [63].

\subsubsection{Growth Curves; S-curves}

Growth curves are the oldest techniques in TF, and widely used in practical applications. Growth curves typically exhibit an "S-shaped" life cycle over a period of years, since experience has demonstrated that technologies tend to evolve in patterns similar to the growth curves of biological systems [64][32]. Forecasters using growth curves also extrapolate futures, based on current and past trends, in a deterministic way. 
This technique requires fitting a growth curve to a set of data over time to reflect technological characteristics. A number of growth curves have been developed to predict technological advances. Logistic and Gompertz curves among them are most commonly used methods, having a long history since their inception in the field of demography and later applied to technology forecasting. Growth curves have continuously gained popularity due to their relative simplicity, long history of use in various fields, and the assumption that historical data may provide guidance to projecting a technology trajectory [65].

Growth curves are based on three assumptions [32]:

- The upper limit to the growth curve is known; the upper limit of technological change can be set by natural, fundamental, physical and chemical laws that rule the phenomena used in the technical approach.

- The selected growth curve to be fitted to the past data is correct enough to predict technology trajectory.

- The historical data gives correct coefficients of the chosen growth curves equation; much effort is needed to find representative coefficients based on the historical trend [34].

Growth curves presume that a technology will finally reach its upper limit at a certain time; such curves are employed to forecast how and when a technical will reach its upper limit. It reflects that growth is slow initially until difficulties are overcome, then growth is more rapid until the limit is approached, upon which growth slows down again. Therefore, it is critical to estimate the upper limit using historical analogies. At this juncture, previous experience with a similar technology is key to forecasting 
technologies more accurately [34]. Furthermore, growth curves estimate a single variable. If a technology reaches a upper limit, a new technical variable may create a completely new growth curve [32]. These approaches are appropriate for short-term forecasting.

Like life cycle curves, substitution curves are a type of growth curves that project the substitution of one technology for another or the rate of penetration of some technology into a market [66][60]. Since Mansfield, as a pioneer, proposed a technology diffusion model incorporating the rate of imitation and technology adoption, a variety of growth curves such as the Mansfield-Blackman model, the Fisher-Pry model, the Extended Riccati model, the Bass model, etc, have been developed to forecast the S-shaped pattern of technological advance [67]. For the purpose of analysis, the main issue is to determine the curve slope as well as the inflection point using a time series of data. Selecting an appropriate equation of growth curve is somewhat arbitrary. That is why most forecasters experiment with several growth curves to find the best fit to predict the technological change [68]. 
Table 4 Types of growth curves

\begin{tabular}{|l|c|c|l|}
\hline \multicolumn{1}{|c|}{ Types } & Equations & Inception & Reference \\
\hline $\begin{array}{l}\text { Logistic or } \\
\text { Pearl }\end{array}$ & $\mathrm{Y}=\frac{\mathrm{L}}{1+\mathrm{ae}} \mathrm{e}^{-\mathrm{bt}}$ & 1923,1957 & {$[64][69]$} \\
\hline Gompertz & $\mathrm{Y}=\mathrm{Le}^{-\mathrm{b}-\mathrm{kt}}$ & 1932 & {$[70]$} \\
\hline $\begin{array}{l}\text { Mansfield- } \\
\text { Blackman }\end{array}$ & $\ln \left(\frac{\mathrm{Y}_{\mathrm{t}}}{\mathrm{L}-\mathrm{Y}_{\mathrm{t}}}\right)=\beta_{0}+\beta_{0} \mathrm{t}$ & 1961,1972 & {$[67][65]$} \\
\hline BASS & $\mathrm{y}_{\mathrm{t}}=\frac{\left[1-\mathrm{e}^{-(\mathrm{p}+\mathrm{q}) \mathrm{t}}\right]}{\left[1+\left(\frac{\mathrm{q}}{\mathrm{p}}\right) \mathrm{e}^{-(\mathrm{p}+\mathrm{q}) \mathrm{t}}\right]}$ & 1969 & {$[71]$} \\
\hline Fisher-Pry & $\frac{\mathrm{Y}_{\mathrm{t}}}{1-\mathrm{Y}_{\mathrm{t}}}=\mathrm{e}^{2 \mathrm{a}\left(\mathrm{t}-\mathrm{t}_{0}\right)}$ & 1971 & {$[66]$} \\
\hline $\begin{array}{l}\text { Extended } \\
\text { Riccati }\end{array}$ & $\frac{\mathrm{y}_{\mathrm{t}}}{\mathrm{Y}_{\mathrm{t}-1}}=\beta_{0}+\beta_{1} Y_{t-1}+\beta_{2}\left(\frac{1}{\mathrm{Y}_{\mathrm{t}-1}}\right)$ & 1976 & {$[72]$} \\
\hline Weibull & $\ln \left(\ln \left[\frac{L}{\mathrm{~L}-\mathrm{Y}_{\mathrm{t}}}\right]\right)=\beta_{0}+\beta_{1} \ln t$ & 1980 & {$[73]$} \\
\hline NSRL & $\begin{array}{l}\left.\mathrm{Y}_{\mathrm{t}-1}\right) \\
+y_{t}=\beta_{0}+\beta_{1} \ln \left(\mathrm{Y}_{\mathrm{t}-1}\right)\end{array}$ & 1981 & {$[74]$} \\
\hline Harvey & $\ln y_{t}=\beta_{0}+\beta_{1} \mathrm{t}+\beta_{2} \ln \left(\mathrm{Y}_{\mathrm{t}-1}\right)$ & 1984 & {$[75]$} \\
\hline
\end{tabular}

\subsubsection{Bibliometrics; Scientometrics}

\section{Literature analysis}

There are various definitions for "bibliometrics" or "scientometrics" that numerous researchers have conceptualized. One of the general definitions for "bibliometrics" is "the search for systematic patterns in comprehensive bodies of literature" [76]. Bibliometric techniques were initially employed in the field of library and information science. McKeen J. Cattell, a pioneering psychologist, first used literature data to measure the performance and productivity of scientists in 1906 [77]. There were some bibliometric studies around 1920, using statistical techniques,

\footnotetext{
${ }^{3}$ Gompertz named after Benjamin Gompertz, an English demographer, who originally proposed the model as a law governing mortality rates in 1825

${ }^{4}$ NSRL: Non-Symmetric Responding Logistic
} 
although using the older terminology "bibliography" [78]. The term "bibliometrics", however, was coined from Pritchard who introduced it in 1969 to replace the term "statistical bibliography" [79]. In this article, Pritchard defines bibliometrics as "the application of mathematical and statistical methods to books and other media of communication.” That same year, Vassily V. Nalimov and Z. M. Mulchenko started to use the term "scientometrics", a term of Russian origin that is now mainly used to describe research of all aspects of the literature of science and technology [78]. This term has been widely recognized by the journal Scientometrics, established by Tibor Braun in 1978. Scientometrics involves the sociology of science and science policy, and uses qualitative, quantitative, and computational methods [80]. It appears bibliometrics conceptually includes scientometrics, as it quantitatively analyzes scientific and technological literature. These two techniques have many similarities in the way that they employ mathematical models. Scientometrics and scientific literature analysis also analyzes data based on the publications of researchers, not only to measure R\&D activity, impacts, and intellectual linkages as a valid indicator of science and technology [81], but also to identify emerging research fields for forecasting [82][83].

Bibliometrics focuses on statistics with respect to the production, distribution and usage of literatures, rather than the contents of a set of research publications [84]. Bibliometrics aims to analyze the impact of different fields and a set of researchers through exploring historical literature data. In the context of technology forecasting, however, bibliometrics can be defined as the research of statistical analysis to produce and disseminate information concerning the use of recorded literatures for forecasting and decision making. This technique helps to identify the most recent technological 
trends and discover hidden patterns within the trend of authors, affiliations, and recent research in the literature.

Bibliometrics is typically classified as in the same category as descriptive research (regarding the characteristics of a type of literature) and behavioral studies (investigating the relationships involving between elements of a type of literature) [76]. Since the Science Citation Index (SCI) was established in 1961, a systematic analysis has been possible and prevalent thanks to the availability of a wealth of data. In addition, the COMPENDEX, COMPuterized ENgineering inDEX, was established in 1970 as an Engineering Index (EI) which provides a comprehensive engineering bibliographic database. The rapid evolution of information technology enabled researchers to predict technological advances using such comprehensive databases. Bibliometrics has been popularized and has become more significant in technology forecasting over the years with the advancement of DB system [85][86]. For example, Alan Porter presents an illuminating bibliometric analysis of the methodology trends that helps firms capture emerging technologies [87].

The basic process of bibliometrics proceeds as follows [34]:

- Define the technology area

- Establish the problem domain (year, year of publication)

- Search all scientific and technical publications for relevant articles

- Load relevant data (article title, abstract, author names, references given, country, etc.)

- Analyze the database

- Analyze the implications of indicators 
The typical approach of bibliometrics is retrospective, in which one traces the relationship between counts, co-occurrence, and citations among publications to make an evaluation. Since 1927, various types of bibliometric tools have been developed to analyze descriptive statistics, affiliation, authors, countries, and the collaboration of literatures. The major derivatives of bibliometrics are publication counts, citation counts, citation network, co-citation counts, co-word counts, and scientific mapping (cartography). Since D. Price first analyzed literature linkages using citation indices to identify scientific trends, bibliometric citation network analysis has been used to identify research gaps and track emerging research fields in the literature [88][89]. The types of data used in these techniques are as follows:

- Publication count: the counting of scientific publications published by a researcher or a research group

- Bibliographic coupling: one item of reference used by two papers

- Citation analysis: the examination of the frequency, patterns, and graphs of citations in articles and books

- Co-citation analysis: the frequency with which two items of earlier literature are cited together by the later literature

- Co-word analysis: counts and analysis of the co-occurrence of keywords in the publications on a given subject

- Data tomography: an information extraction and analysis system which operates on textual databases, which is keyword-based or index word-based full-text coword analysis 
Bibliometrics can help to measure the impact, productivity, R\&D activity, and scientific and technological advances of specific areas or authors. Technical reports and scientific papers are appropriate literatures to capture the early stage of technology development [90][61]. High citation is broadly used as an indicator of scientific emergence and the significance of prior cited literatures. 
Table 5 Types of bibliometric analysis using literature

\begin{tabular}{|c|c|c|c|}
\hline Types & Characteristics & Inception & Reference \\
\hline Citation & $\begin{array}{l}\text { - impact factors, number of references, number of } \\
\text { citations, }\end{array}$ & $\begin{array}{c}1927 \\
1961(\mathrm{SCI})\end{array}$ & [91] \\
\hline Lotka's law & $\begin{array}{l}\text { - } \mathrm{f}(\mathrm{n})=\mathrm{k} \frac{1}{\mathrm{n}^{2}} ; \text { scientific productivity law (n; number } \\
\text { of papers) } \\
\text { - a number of papers attributed to specific scientists }\end{array}$ & 1926 & {$[92]$} \\
\hline Zipf's law ${ }^{5}$ & $\begin{array}{l}\text { - } \mathrm{f}(\mathrm{n})=\mathrm{k} / \mathrm{n} \text {; word frequency law } \\
\text { - the descriptive evaluation of subject authority files } \\
\text { and related aspects of indexing }\end{array}$ & 1932 & [93] \\
\hline Bradford's law & $\begin{array}{l}\text { - } \mathrm{f}(\mathrm{n})=\mathrm{k} \ln (1+\mathrm{bn}) \text {; bibliographic scattering law } \\
\text { - the cumulated total of papers in the first } \mathrm{n} \text { of the } \\
\text { ranked journals are arranged in descending order of } \\
\text { productivity, }\end{array}$ & 1934 & {$[94]$} \\
\hline $\begin{array}{l}\text { Bibliographic } \\
\text { coupling }\end{array}$ & $\begin{array}{l}\text { - meaningful relation to each other, when they have } \\
\text { one or more reference in common } \\
\text { - based on citation indexing }\end{array}$ & 1962 & {$[95][96]$} \\
\hline $\begin{array}{l}\text { Citation } \\
\text { Network } \\
\text { Analysis }\end{array}$ & $\begin{array}{l}\text { - identify scientific structure } \\
\text { - identify research gaps and track emerging research } \\
\text { fields }\end{array}$ & 1965 & {$[97]$} \\
\hline Co-citation & $\begin{array}{l}\text { - author connections, subject structure, networks, } \\
\text { maps } \\
\text { - cluster co-citation } \\
\text { - time-consuming and expensive } \\
\text { - comparing lists of citing documents in the SCI } \\
\text { - more limited internal description of the state of } \\
\text { each field }\end{array}$ & 1973 & {$[98]-[100]$} \\
\hline Co-word & $\begin{array}{l}\text { - evolution and patterns of interactions of different } \\
\text { subject areas } \\
\text { - description of subject area } \\
\text { - analysis of research trajectory } \\
\text { - time-consuming and expensive } \\
\text { - rather more inclusive, contextual, pictures of } \\
\text { scientific activity } \\
\text { - mapping the structure of scientific research } \\
\text { - interaction dynamics of a research field } \\
\end{array}$ & 1979 & {$[100]-[103]$} \\
\hline $\begin{array}{l}\text { Co- } \\
\text { classification }\end{array}$ & $\begin{array}{l}\text { - the network of interdisciplinary links between } \\
\text { research fields } \\
\text { - the co-occurrence of different subject- } \\
\text { classification } \\
\text { - the strength of interdisciplinary relations } \\
\text { - map of the interdisciplinary structure in a single } \\
\text { field and whole area } \\
\text { - the level of interdisciplinarity in a contributing } \\
\text { research field }\end{array}$ & 1987 & {$[104]-[106]$} \\
\hline
\end{tabular}

5 If words are ranked according to their frequency of occurrence (f), the n-th ranking word will appear approximately $\mathrm{k} / \mathrm{n}$ times where $\mathrm{k}$ is a constant 


\section{Patent analysis}

Patent data has valuable information such as the geographical distribution of particular inventions, citation networks, and patterns in terms of particular technology, providing means by which forecasters may monitor technological trends, innovative activities, and new product development [107][108]. Patent trend analysis provides the growth pattern of a technology and helps forecasters predict its life cycle. In addition, patent data may be used not only to generate a time-series of technology trends, but also detect novel technological developments that could represent opportunities or threats to companies.

Such patent analysis has a long history. Patents are public record, and every patent granted since 1836 has been assigned by the Classification Division to its corresponding class and subclass. Using this widely available store of information, Applebaum made the first attempt to analyze patents statistically in the 1920s [109]. Thereafter, a number of studies have used patents to measure innovativeness and difference, a technological advance, and the rate and direction of technology development since the 1930s [110]-[114]. Gilfillan, for example, tracked the inventive cycle of a patent as a technique for technology forecasting in 1935 [115][116]. A forecaster may also use patent statistics such as the cumulative or actual count of patent applications or grants, a time-series of patent trends, and percentage of patents in total as a measure of innovativeness, the rate of technological change, and research output in a sector [117]-[120]. Currently, the advancement of IT (Information Technology) 
enables researchers to measure the rate of technological change by actual uses of patent data.

While forecasting techniques using patent data have become more sophisticated, the data necessary for such analysis has become more widely available. The U.S. patent system, the largest patent system in the world, has been fully computerized since 1975 [81]. The U.S. Patent Office founded the U.S. Office of Technology Assessment and Forecast (OTAF) in the mid-1970s. It has provided statistical patent information applied for since 1963 [120]. In 1970, United Nations founded the World Intellectual Property Organization (WIPO) as a specialized agency within its administration, having enacted it in Stockholm in 1967. WIPO then established the International Patent Documentation Center (INPADOC) with the agreement of the Austrian government in 1972, which was integrated with the European Patent Office in 1991. The INPADOC database provides information with respect to patent families as well as patent applications in different countries.

There are many more similarities than discrepancies between literature biliometrics and patent bibliometrics [121]. Patents provide complementary information in bibliometrics. Likewise bibliometrics, patent citations have been typically used as indicators of the importance of an innovation, its technological influence and the diffusion of the technology [122][123]. The citation analysis, however, is somewhat different from literature citation analysis, in that it has two different references: both applicant citations and examiner citations are used to determine novelty, similarity and relevance [124]. Patent citation network analysis has also been used to identify the trajectory of a technological subject and to explore the dynamics of technological 
change [125][126]. Patent co-word analysis was first used to improve evaluation of the contents of a large number of patents in biotechnology [127]. Co-word analysis technique provides a research network map which illustrates co-operation, recent technology trends in various sub-fields and promising research directions. In the early 1980s, Battelle devised various patent analysis tools for technology forecasting such as immediacy $^{6}$, patent activity ${ }^{7}$, and patent clustering ${ }^{8}$ [107]. Battelle's process of patent trend analysis involves the following process [34]:

- Define the study objective

- Establish the problem domain (research framework, patent categorization scheme, etc)

- Obtain relevant patents (keyword, patent office classification, citation data, abstract review, full text review)

- Load patent data into software

- Produce computer output

- Interpret analysis results (innovation activity, dominance, company characteristics, portfolio analysis, etc)

\footnotetext{
6 This method measures the age of the closest prior art in technical and scientific papers or in patents.

${ }^{7}$ This method considers the number of patents in a given period to find an increasing or decreasing number of firms and inventors coming into a specific area.

8 This method looks at how the patents in an area are connected together by citations with a network analysis.
} 
Table 6 Types of patent analysis

\begin{tabular}{|c|c|c|c|}
\hline Types & Characteristics & Inception & Reference \\
\hline Citation & $\begin{array}{l}\text { - impact factors, number of citations } \\
\text { - two kinds of reference citations; applicant citations are } \\
\text { occasionally provided by inventor, examiner citations are } \\
\text { made more frequently by the patent examiner to warn the } \\
\text { applicant of related work } \\
\text { - forward/backward citations }\end{array}$ & 1949 & {$[128][124]$} \\
\hline $\begin{array}{l}\text { Patent } \\
\text { citation } \\
\text { network }\end{array}$ & $\begin{array}{l}\text { - represents patents and their respective citations as a } \\
\text { network } \\
\text { - uses critical node, core network, and network topological } \\
\text { analysis }\end{array}$ & 1978 & {$[125]$} \\
\hline Co-citation & $\begin{array}{l}\text { - maps the inter-related development of technical fields } \\
\text { - assesses the similarities in their patents }\end{array}$ & 1988 & [129][130] \\
\hline Co-word & $\begin{array}{l}\text { - interaction between basic and technological research } \\
\text { - analysis of research trajectory } \\
\text { - describes life cycles } \\
\text { - evolution and patterns of interactions of different subject } \\
\text { areas }\end{array}$ & 1986 & {$[127][131]$} \\
\hline $\begin{array}{c}\text { Co- } \\
\text { classificatio } \\
n\end{array}$ & $\begin{array}{l}\text { - co-classification mapping } \\
\text { - belongs to a fixed classification scheme, so might be out } \\
\text { of date } \\
\text { - simplicity } \\
\text { - possible to evaluate the existing classification schemes }\end{array}$ & 1992 & {$[106]$} \\
\hline
\end{tabular}

\subsubsection{Data Mining; Text (Data) Mining}

Through rapid evolution of information technology as well as the flood of available data, Data Mining (DM), Text Mining (TM), Tech Mining, and Database Tomography (DT) have become practical techniques for assisting the forecaster in identifying early signs of technological change [1][84][80]-[82][132][133].

Data mining. In the literature, Michael C. Lovell first used the term "Data Mining" in 1983 to propose econometric data mining in statistical variables' tests [134]. Gregory Piatetsky-Shapiro introduced the concept of Knowledge Discovery and defined it as "the nontrivial extraction of implicit, previously unknown, and potentially useful information from data"[135]. Data mining can be identified as a subset of Knowledge Discovery in Database (KDD), since the KDD process is comprised of data preparation, data selection, data cleaning, data mining, incorporation of appropriate prior knowledge 
and proper interpretation of the results [136]. Data mining is identified as a particular element which extracts patterns or models from massive amounts of data with the application of specific computerized algorithms in the KDD process [84][135]. Data mining is defined as extracting useful information and detecting interesting correlation and patterns from any form of data, especially numeric data. Data mining has been theoretically built on the groundwork in database, machine learning, pattern recognition, statistics, artificial intelligence, information retrieval, reasoning with uncertainty, and knowledge acquisition for expert systems [135][137].

Text mining. Data mining typically makes use of a structured database. Textual data mining, however, is concerned with the process of extracting interesting and nontrivial patterns or knowledge from unstructured text documents [138]. On first glance, text mining may appear to be just another type of data mining, since text is just a different form of data. Textual data mining is often considered a much more difficult activity than numeric data mining, however, since it handles textual databases, which are inherently fuzzy and unsymmetrical. Classification and indexing are never completely accurate. Text mining serves as a powerful technique to explore a textual database, discover useful and understandable patterns within them and automatically extract meaningful information from unstructured textual data. Text mining has been used to discover particular patterns in large-scale databases and analyze technological trends. Analyzing the technology performance in a specific field using keywords or phrases can provide an insight for technology forecasting. In recent years, text mining has gained popularity because of its use in exploring the text-based documents such as literature and patents in bibliometrics [139]. 
Data tomography. Kostoff and his colleagues in the Office of Naval Research developed data tomography, which has a system of algorithms to analyze a large amount of textual data and extract multiword phrase frequency and analyze phrase proximity [85]. Data tomography tool is full-text co-word analysis which can use any key or index word, based upon computational linguistics and lexicography for research evaluation [86]. It assumes the frequencies with which phrases appear in documents are related to the main themes. This method does more than simply retrieve data from any type of large textual databases such as papers, reports, memos, and patents. It also identifies technical thrusts, themes and networks among these areas [140]. This tool has four main processes as follows[139]:

- extract the text to be analyzed from a source of databases

- identify the main themes of the text being analyzed

- determine the quantitative and qualitative relationships among the main themes and sub-themes

- track the evolution of these themes and their relationship over time One of the most unique characteristic of the data tomography technique is that it includes a phase that utilizes an expert panel to identify the appropriate information in disorganized data as well as to interpret the result [141]. Data tomography has been applied many different fields to identify promising research opportunities and emerging technology areas [139].

Tech mining. In 1993, Alan Porter began to develop and commercialize VantagePoint in 2000, a software product built upon "Technology Opportunities Analysis" [87] approach at Georgia Tech. It is a very powerful data mining tool, called 
"tech mining" in his papers, for discovering knowledge in search results from patent and literature databases [142]. Tech mining combines text and numerical data to support technology management decision making and technology forecasting [133]. Tech mining, i.e., text mining of science and technology information resources, aims not only to analyze emerging technologies but to provide technology maturity analysis, identify research trends, and create a research network map [143].

Table 7 Data mining tools

\begin{tabular}{|c|l|l|l|}
\hline Approach & \multicolumn{1}{|c|}{ Characteristics } & Inception & Reference \\
\hline Data Mining & $\begin{array}{l}\text { - time-consuming } \\
\text { - relatively expensive } \\
\text { - appropriate for discontinuous technology } \\
\text { forecasting }\end{array}$ & 1991 & {$[144]$} \\
\hline Data & $\begin{array}{l}\text { - multiword phrase frequency analysis } \\
\text { - phrase proximity analysis } \\
\text { - time-consuming } \\
\text { - identifies promising/emerging } \\
\text { research/technology opportunities } \\
\text { - develop an independent R\&D taxonomy }\end{array}$ & 1991 & {$[85][86]$} \\
\hline Text Mining & $\begin{array}{l}\text { - time-consuming } \\
\text { - relatively expensive } \\
\text { - appropriate for discontinuous technology } \\
\text { forecasting }\end{array}$ & 1995 & {$[145]$} \\
\hline Tech Mining & $\begin{array}{l}\text { - not restricted to mining abstract publication } \\
\text { and patent records. It combines text and } \\
\text { numerical data to best answer the questions }\end{array}$ & 2000 & {$[133]$} \\
\hline
\end{tabular}

\subsubsection{Analogies; Comparison-Based Prediction}

Analogy may be defined as a recognizable similarity or resemblance of form or function, but with no logical connection or equivalence - as distinguished from a model. Forecasting by analogy attempts to predict possible futures by systematic comparison of the technology with a similar one in a certain industry by looking at historical data. Analogizing is a natural process that uses intuition based on similarities and is 
commonly used in inductive inference [146][32]. Analogies are a useful method but must be subservient to general guidelines [24]. Thomas O'Connor provides an insightful overview and various applications of analogical techniques in various fields such as mythology, science, economics, politics, military, philosophy, and religion [146].

A prevalent type of forecasting by analogy is the use of growth curves that follow a S-shape to predict the advance of technology [30][147], since many technologies and products follow a pattern where there is a rapid growth stage that faces constraint as the technology reaches saturation level [18]. Martino identified four major challenges with analogies: lack of inherent necessity, historical uniqueness, historically conditioned awareness, and casual analogy [32]. He asserted these problems can be lessened by a systematic method, where the technological change can be measured with regard to several different dimensions (technological, economic, managerial, political, social, cultural, intellectual, religious-ethical, and ecological) to compare two analogous situations. The key success factor of a forecast by analogy is to choose right technologies that are truly analogous to the one being forecast.

Table 8 The characteristics of analogies

\begin{tabular}{|l|l|l|l|}
\hline Approach & \multicolumn{1}{|c|}{ Characteristics } & Inception & Reference \\
\hline \multirow{5}{*}{ Analogies } & $\begin{array}{l}\text { - easy to use } \\
\text { - the lack of an integrated set of procedures } \\
\text { - deterministic } \\
\text { - intuitive and insightful method } \\
\text { - only works when relevant historical data is } \\
\text { available } \\
\text { - not applicable for discontinuous technology }\end{array}$ & 1962 & {$[30][34]$} \\
\hline
\end{tabular}




\subsubsection{Cross Impact Analysis}

Cross impact analysis was first developed for the Kaiser Aluminum Company by T. J. Gordon and O. Helmer at the Rand Corporation in 1966 [148]. Cross impact analysis was initially designed to eliminate some disadvantages of the Delphi method, a group discussion and consensus-building model that too often ignores potential relationship between future events [149][150]. The development of the cross impact analysis technique was the first attempt by forecasters to assess the interaction of technological and social impacts for the purpose of interrelating intuitive forecasts. It does so by taking into account the average probabilities of occurrence for each event and, considering time sequences, since most events and technology developments have some relation with other events and technology developments. This tool provides a useful means for analyzing the relationship between the factors. "Cross impact," coined by Olaf Helmer at the Rand Corporation, refers to this relationship between events and technology developments [148]. It recognizes mutual effects such as the strength, direction and quality of interrelationship between events and technology developments from expert judgments [151]. This method attempts to gather forecasting information systematically for strategic decision making.

There are two major approaches for cross impact analysis [152]. One is the INTERAX (Interactive Cross Impact Simulation) approach developed by S. Enzer at the Center for Futures Research (CFR) in the University of Southern California. The INTERAX approach combines the advantages of trend impact analysis with the strengths of cross impact analysis [153]. This tool involves an analytic model which analyzes evolutionary conditions and physical changes as well as an expert's analysis to 
describe social change and policy options in an interactive simulation [154]. The second thing is BASICS (Battelle Scenario Inputs to Corporate Strategies) approach mainly used by the Battelle Columbus Division in 1977. The BASICS tool involves heuristic computations with no foundation in probability theory [155]. This approach is different from INTERAX in that it does not use a Monte Carlo simulation, nor does it involve an independent forecast of the major variables [156].

Table 9 The types of cross impact analysis

\begin{tabular}{|l|l|c|c|}
\hline Approach & \multicolumn{1}{|c|}{ Characteristics } & Inception & Reference \\
\hline INTERAX & $\begin{array}{l}\text { - uses Monte Carlo random basis } \\
\text { - produces path scenario } \\
\text { - high start-up cost } \\
\text { - random selection of initial probabilities }\end{array}$ & 1966 & \\
\hline BASICS & $\begin{array}{l}\text { - rapid input and editing of data } \\
\text { - long-range perspective } \\
\text { - numerous on-line sensitivity analyses } \\
\text { - static scenarios }\end{array}$ & 1977 & {$[153][34]$} \\
\end{tabular}

\subsubsection{System Dynamics}

The system dynamics method was first introduced by Jay Forrester at MIT in 1961 [158][159]. System dynamics is an analytical approach that analyzes the dynamic behavior of complex social systems to understand and influence how things change over time, based upon traditional management, cybernetic theories or feedback theory and computer simulation [160][161][34]. In 1968, its application expanded from corporate modeling to broader social systems [162]. Since then, system dynamics has been applied to study social, economic and environmental system behaviors and to analyze policies [163].

As currently practiced, the system dynamics technique employs a quantitative simulation approach illustrating qualitative variables extracted from written databases 
as well as mental databases built up from experience and observation [63][161][164]. It is a very useful technique in dealing with complex and nonlinear problems that may have side-effects, time delays and a series of interlocking feedback loop structures [158]. Several computer modeling tools and software packages exist to assist in such analysis, such as DYSMAP ${ }^{9}$ (Dynamic System Modelling and Analysis Package) [165], STELLA $^{10}$, $^{\text {Think }}{ }^{11}$, Vensim $^{12}$, and Powersim Studio ${ }^{13}$.

System dynamics is used not to predict the emergence of particular technologies, but to forecast future performance and system behavior or a pattern of variation of current system with no modification over a period of time [63]. System dynamics is a completely deterministic modeling that focuses on causal connections, based on the assumption that the system of past development will hold in the future [166]. It requires causal assumptions and the existence of past or analogous data. This method is not quite appropriate as a forecasting tool in that it intends to assume that every event certainly happens, forecasters already know how factors interrelate, and there is only one possible outcome [60][34]. These characteristics do not reflect real-world technological changes. To overcome these disadvantages, system dynamics is often used with other tools to forecast technological change [34]. For example, probabilistic system dynamics integrates system dynamics with stochastic events simulations based on expert decisions $[166][167]$.

\footnotetext{
9 DYSMAP was developed by the System Dynamics Group at Bradford Management Center.

10 STELLA was introduced by isee systems (formerly High Performance Systems) in the late 1980s.

11 isee systems (formerly High Performance Systems Inc.) in USA developed iThink for business simulation in 1990

12 Ventana Systems, Inc. created Vensim language and released Vensim in 1988.

13 Powersim studio was developed Powersim Software AS, based in Bergen Norway
} 
There is no integrated set of procedures in system dynamics modeling. LunaReyes and Andersen described five different system dynamics modeling processes across the classic literature, varying from three to seven different steps [164]. However, the six-step process of system dynamics proposed by Jay Forrester is as follows [168]:

- Describe the system

- Convert description to level and rate equations

- Simulate the model

- Design alternative policies and structures

- Educate and debate

- Implement changes in policies and structure

The system dynamics model is an iterative process that has dynamic cause-andeffect feedback loops and takes a holistic view. Systems are typically described with a diagram that shows the links between stated variables, as indicated by arrows. A diagram can not only illustrate information flow and physical flow but help easily convey the interrelationship between variables. The arrows represent both the direction and plus or minus sign of influence between the different factors (positive or negative effect). The overall sign of the feedback loops is determined by the product of the signs on their constituent links.

Table 10 The characteristics of system dynamics

\begin{tabular}{|c|c|c|c|}
\hline Approach & Characteristics & Inception & Reference \\
\hline $\begin{array}{l}\text { System } \\
\text { dynamics }\end{array}$ & $\begin{array}{l}\text { - useful in complex and systemic thinking } \\
\text { - provides clarity and unity } \\
\text { - the lack of integrated set of procedures } \\
\text { - real world not always cyclical, having } \\
\text { feedback loop } \\
\text { - deterministic } \\
\text { - not applicable for discontinuous technology }\end{array}$ & 1961 & $\begin{array}{l}{[34][164]} \\
{[169][60]}\end{array}$ \\
\hline
\end{tabular}




\subsubsection{Agent-Based Modeling}

Agent-based modeling (ABM) has been widely used to study multi-level interactions between individual behaviors and social environments in various fields such as economic, biological, ecological, behavioral, demographic, anthropological, cultural, political, technological, and so forth [170][171][172]. ABM has been developed based on the groundwork of Ashby's cybernetics [173], von Neumann's work on self-reproducing automata [174], cognitive science [175], and artificial intelligence $[176][177]$.

Various ABMs have been developed to simulate dynamic heterogeneous agent interaction in given complex social systems as a whole. Typically, there are four different types of network model such as random network, two-dimensional lattice (Cellular Automata), small-world network [178], and Baraba'si and Albert's power-law distribution network [179]. Delre et al. proposed a Agent-based simulation (ABS) model incorporating social influences and word-of-mouth processes [180]. They indicated that the speed of the diffusion increased in small-world networks compared to random network.

ABM gives us the benefit of simulation to evaluate this system. In traditional economic theory, basic assumption is that agents interact anonymously with one another via price in the market within a social system. However, in many contexts, agents interact in networks where agents know each other. Bohlmann et al. [179] address heterogeneous network using ABM. It aims to understand how social network affects the innovation diffusion process, focusing on interpersonal and intersegment communications within the market. 
Due to shortened technology life cycle and higher level of uncertainty, technological changes can be characterized by interactive, nonlinear, and chaotic systems [181]. In the regard, ABM provides a benefit to predict interactive and nonlinear outcomes and phenomena [182]. Hicks and Theis predicted energy efficient lighting options incorporating the rebound effect as well as discontinuous evolution of lighting technologies, using ABM [183]. Kolominsky-Rabas et al. also applied ABM to forecast emerging technological innovation of medical devices [184]. On the other hand, Negahban et al. used ABM to predict continuous new product development incorporating the future demand forecasting, production management, and volume flexibility [185].

Table 11 The characteristics of ABM

\begin{tabular}{|c|l|c|c|}
\hline Approach & \multicolumn{1}{|c|}{ Characteristics } & Inception & Reference \\
\hline & $\begin{array}{l}\text { - bottom-up approach } \\
\text { - dynamic and heterogeneous analysis }\end{array}$ & & \\
ABM & $\begin{array}{l}\text { - useful in systemic thinking, complex and } \\
\text { distributed system }\end{array}$ & early & 1970s \\
& - applicable for discontinuous and & & \\
& continuous technology & & \\
\hline
\end{tabular}

\subsubsection{Technology Forecasting using Data Envelopment Analysis}

\section{(TFDEA)}

Companies, governments, and other organizations are currently seeking ways to improve their operations [187]. For such entities, Data Envelopment Analysis (DEA) can provide a systematic process for evaluating alternatives, implementing strategies, and improving performance by benchmarking other decision-making units (DMUs). Based on Debreu [188] and Farrell's [189] early work, DEA was developed by Charnes et al. in 1978 (CCR) [190] and extended by Banker et al. (BCC) in 1984 [191] as a 
linear programming procedure for a frontier analysis of inputs and outputs. There are many theoretical and empirical study extensions that have appeared in the literature concerning this analysis. Benchmarking core technology performance and product trends with DEA offers an effective means of determining technological capability over time as well as component development time without the burden of fixed a priori weighting schemas. It also provides a clear understanding of key characteristics and assists in forecasting technology trends by benchmarking other companies as fastfollowers.

Since its inception in 2001, the technology forecasting using DEA (TFDEA) method can provide an implementable tool to decision makers by bridging the gap between data envelopment analysis (a well-established management science method) and the technology forecasting field. This method measures the technological rate of change in order to forecast future technological advances. There are already some case studies to validate the method applied to a variety of industries including enterprise database systems, microprocessors, hard disk drives, portable flash storage, fighter jets, and turbofan jet engines [192][193][194]. The TFDEA technique provides more accurate results than multiple regression models in cases where both approaches were used.

Table 12 The characteristics of TFDEA

\begin{tabular}{|c|l|c|c|}
\hline Type & \multicolumn{1}{|c|}{ Characteristics } & Inception & References \\
\hline TFDEA & $\begin{array}{l}\text { - retrospective } \\
\text { - quantitative approach } \\
\text { - applicable to continuous and some } \\
\text { discontinuous technologies }\end{array}$ & 2001 & [193]-[195] \\
\hline
\end{tabular}




\subsection{Normative Forecasting Methods}

The normative technology forecasting methods screen technology transfer by running against technology movement [13]. The normative forecasting similarly forces forecasters to consider complex social systems that resisted reductionism with its simplified models based upon system analysis [32][196]. The normative approach considers objectives, needs, and future desires as basic elements for forecasts and identifies constraints. A description of each technology forecasting method and its practical applications is provided below.

\subsubsection{Relevance Trees}

The relevance trees are one of the most traditional normative technology forecasting methods. The concept of relevance trees linked with decision making was first addressed in 1957 by C. W. Churchman et al. in their introductory operation research book [197]. Qualitative relevance trees were first designed to aid decision making process [32][197]. The structure of relevance tree is very similar to that of ordinary decision trees. Thereafter, quantitative relevance tree techniques were pioneered by the PATTERN (Planning Assistance Through Technical Evaluation of Relevance Numbers) scheme that was first applied to military and space activity program in large scale by Honeywell's Military and Space Sciences Department in 1963, then refined and extended to all military and space activities in which Honeywell had interest in 1964 [13][198]. Furthermore, this technique was extensively applied to NASA's Apollo Payload Evaluation, US Air Force, and private advertising companies [13]. 
In essence, the relevance tree technique involves the drawing of hierarchical structure of the technological problems which must be resolved to meet the goals that are at the upper level. The head end of the tree is the final objective of a proposed technology. The hierarchical tree diagrams which have branches and nodes should be deployed by the principle of mutual exclusiveness and collective exhaustiveness [32]. It is prerequisite that forecasters form the hierarchical structure and identify all related factors of technology development. Graphical tree format of relevance trees is very easy to understand various future achievements and relationships among them. Relevance trees can be very useful and powerful tool to identify all problems and solutions and break the performance requirements down for a specific technology in order to achieve some overall objective [32][13]. In addition, the numerical analysis of relevance trees incorporating relevance numbers is a systematic approach to assess probabilities of solutions to meet the objectives of significant social problems [32][52]. The probabilities can be interpreted as the likelihood of achieving the future needs and objectives of individual technology.

Table 13 The characteristics of relevance tree

\begin{tabular}{|c|l|c|c|}
\hline Type & \multicolumn{1}{|c|}{ Characteristics } & Inception & References \\
\hline $\begin{array}{c}\text { Relevance } \\
\text { Tree }\end{array}$ & $\begin{array}{l}\text { - the hierarchical structure of technology } \\
\text { development must be known } \\
\text { - applicable for discontinuous/continuous } \\
\text { technology } \\
\text { - useful for areas of fundamental research } \\
\text { - applicable to the guidance of fundamental } \\
\text { research contributing to social goals }\end{array}$ & 1957 & [32][13] \\
\hline
\end{tabular}




\subsubsection{AHP (Analytic Hierarchy Process); Multi-Criteria Decision Model}

The Analytical Hierarchy Process (AHP) is a method that uses criteria and pairwise comparisons between the criteria to ascertain the relative importance with respect to one another. Since Thomas L. Saaty introduced AHP method in 1980 [199], it has widely been accepted as a technique to prioritize the elemental issues in complex problems in decision making process with the various applications of forecasting, selection, evaluation, Benefit-Cost analysis, allocations, planning and development, priority and ranking [200]. With respect to AHP application within academia, AHP has been utilized in manufacturing, environmental managements and agriculture, transportation, power and energy, healthcare, construction industry, R\&D, education, ebusiness, and various other fields.

Although technology forecasting using AHP provides an opportunity containing both the tangible and non-tangible elements, and the capability to develop environmental factors [201], there are a few application literatures discussing the technology forecasting using AHP method. AHP was employed in forecasting the technological capabilities with growth curves [201]. Recently, this technique was applied to a part of the technology roadmapping framework [202].

AHP method analyzes the hierarchical structure of a future technology and measures the relative importance among the classified element technologies affecting the development process of the technology. Weights and inconsistencies are found based upon algebraic methods and are utilized to apply scores to each decision alternative. Thus, the decision alternative with the highest score should be chosen [203]. By comparing the individual pairs of criteria, these models provide an ability to 
compare an issue with regards to each immediate higher level. This in turn allows a relative importance to be determined by the decision-maker. A pair-wise comparison, comparing each pair at a time in the corresponding level, is employed to estimate major factors on a numerical scale (1-9).

AHP, however, does have some limitations. The "major issue" with AHP is the accuracy of the weightings leading to the paradigm of being "essentially qualitative and not realistically quantitative [204]." On the other hand, it helps to reach a group consensus in a quantitative manner.

Table 14 The characteristics of AHP

\begin{tabular}{|c|c|c|c|c|}
\hline Characteristics & Advantages & Disadvantages & Inception & Reference \\
\hline $\begin{array}{l}\text { - qualitative as well as } \\
\text { quantitative } \\
\text { - subjective judgments } \\
\text { - evaluation of } \\
\text { alternatives } \\
\text { - applicable for } \\
\text { discontinuous/continuo } \\
\text { us technology }\end{array}$ & $\begin{array}{l}\text { - group } \\
\text { consensus } \\
\text { - easy-to- } \\
\text { understand }\end{array}$ & $\begin{array}{l}\text { - accuracy of } \\
\text { the weightings } \\
\text { - rank reversals } \\
\text { are possible } \\
\text { - large number } \\
\text { of pair-wise } \\
\text { comparisons } \\
\text { required }\end{array}$ & $\begin{array}{l}\text { Early } \\
1970 \text { s }\end{array}$ & $\begin{array}{l}{[199][205]} \\
{[204][206]}\end{array}$ \\
\hline
\end{tabular}

\subsubsection{Morphological Analysis}

J.W. von Goethe (1749-1832) introduced the term of "Morphology" to denote the principles of formation and transformation of organic bodies. This early theoretical morphology was eclipsed by Darwinian evolutionary theory in the late $19^{\text {th }}$ century. Goethe initially provided methodological type-concept in his conception of morphotypes [207]. However, Max Weber simplified, generalized, and popularized typology analysis as a simple concept-structuring method applicable to virtually any area of investigation [208]. Morphological analysis (MA) was coined by Fritz Zwicky, a 
Swiss astrophysicist and aerospace scientist, who used the method in 1942, and propagated it via the Society for Morphological Research [209].

The MA analyzes the structure of problems and derive the performance requirements for individual element among the remaining solutions for the normative technology forecasting [32]. MA is concerned with the structure and arrangement of parts of an object, and how these conform to create a whole or a Gestalt [208]. MA is a tool to structure problems rather than solve them [209]. MA can be useful technique to find new relationship or configurations that are not so evident.

The MA has been extended to the areas of policy analysis and future studies. Also, it has been computerized to analyze intricate policy issues, develop future scenarios, and model strategy alternatives [210][211]. In 1995, Tom Ritchey et al., the founder of the Swedish Morphological Society, first developed Casper software, which is advanced computer support for MA at the Institution for Technology Foresight and Assessment under the Swedish Defense Research Agency [210]. Thereafter, they upgraded Casper to a leading proprietary software system, Carma ${ }^{\mathrm{TM}}$ (Computer-Aided Resource for Morphological Analysis), for general morphological analysis in 2005 [211][212].

Table 15 The characteristics of morphological analysis

\begin{tabular}{|c|c|c|c|}
\hline Type & Characteristics & Inception & Reference \\
\hline $\begin{array}{c}\text { Morphological } \\
\text { Analysis }\end{array}$ & $\begin{array}{l}\text { - structures and investigates the total set of } \\
\text { relationships contained in multi-dimensional, } \\
\text { usually non-quantifiable, problem complexes } \\
\text { - qualitative } \\
\text { - complementary method for relevance tree } \\
\text { - combines with scenario method } \\
\text { - applicable for discontinuous/continuous technology } \\
\text { - relatively traceable and even reproducible }\end{array}$ & 1942 & $\begin{array}{l}{[32][209]} \\
{[210][211]}\end{array}$ \\
\hline
\end{tabular}




\subsubsection{Backcasting}

Backcasting is one of the normative technology future analysis techniques which involves setting policy goals at first and then determining how these goals could be reached from desirable future to the present [58]. Backcasting approach can be complementary to technology forecasting tools [213]. Backcasting is not intended to indicate what the future will likely be, based on the probability, but to indicate the relative feasibility and implications of different policy goals and future alternatives on the basis other criteria such as scenario approach [214]. This method, called 'backwardlooking analysis' at that time, was first developed by Amory B. Lovins, in the analysis of Japanese electricity supply and demand futures, employing variants of an alternative method in 1974, and then, Robinson introduced first 'backcasting' terminology in 1982 [214]. Historically, this method has the same origin as the strategic and multiple scenario approaches which was popularized by Shell in the early 1970s during the first oil price crisis [215].

Backcasting has been mainly applied in the energy planning field and extended to transportation, governmental programs for sustainable technology development and technology future analysis in Canada, Sweden, UK, and Netherlands [215]-[218]. Backcasting technique adopts a scenario approach in order to identify possible alternatives and to analyze consequences and conditions for the futures to be achieved [219]. Backcasting studies develop images of the future or scenario that attain the goals addressed in the vision. In essence, the backcasting approach involves three major elements [220]: i) defining long term objectives and goals followed by, ii) developing a 
short term approach resulting into, iii) the implementation requirements of a research and development agenda. Recently, a participatory backcasting approach has gained more popularity in implementation of this technique [221]. It is very vital to understand the culture, interests, and motives of stakeholders when practicing it.

Table 16 The characteristics of backcasting

\begin{tabular}{|c|c|c|c|}
\hline Type & Characteristics & Inception & Reference \\
\hline Backcasting & $\begin{array}{l}\text { - better suited for long-term problems } \\
\text { - interactive and iterative between future visions } \\
\text { and present actions } \\
\text { - participatory approach } \\
\text { - incorporate discontinuous/continuous } \\
\text { technology } \\
\text { - explicitly normative and design-oriented }\end{array}$ & 1974 & $\begin{array}{l}{[214][215]} \\
{[219][221]}\end{array}$ \\
\hline
\end{tabular}

\subsection{Normative / Explorative Technology Forecasting}

\subsubsection{Delphi Method}

The Delphi method is one of the oldest techniques of eliciting responses and refining expert group decisions [222]. Olaf Helmer, Norman Dalkey, Nicholas Rescher, and others at RAND Corporation, established in 1947 by the US Air Force, developed the Delphi method in the early 1950's, which was designed to remove conference room impediments to a more structured expert consensus [223]. The Delphi technique is to integrate subjective expert opinions with respect to the likelihood of realizing uncertain future technology, the probable development date, desirability, etc. Helmer and Rescher set out the philosophical backdrop for Delphi and set limits of expectation about what can and cannot be known when the questions being addressed fall into the category of "inexact science." [224]. Turoff defined Delphi as "a method for the systematic solicitation and collation of informed judgments on a particular topic" [225]. Different types of Delphi such as policy Delphi [225], decision Delphi [226], and goal-Delphi 
[227] have been proposed to meet various purposes. The major series of experiments of Delphi were performed at RAND Corporation to evaluate the procedures [228].

Delphi has gained a large popularity due to its easy implementation and facilitation of group discussions. A variety of technology forecasting and national technology foresight studies mainly use Delphi technique with the participation of hundreds or thousands of experts [27]. It can provide a more feasible forecast in terms of emerging technology and long-range (20-30 years) planning, if trend analysis based on historical quantitative data is not possible. This technique typically is involved when a new technology is emerging, when evaluating ethical or moral considerations, and when expert opinion is the only available source of the prediction of technological change. Moreover, expert opinions are needed when external factors, such as decisions of sponsors and opponents of the technology, and changes in public opinion, are dominant [32].

The Delphi process has two distinct forms: conventional Delphi and Delphi Conference [223]. Delphi process consists of preparation, consecutive survey with 2-6 iterations until a general consensus of the outcome is reached, analysis and implementation. It provides the results of each round so that experts may change their previous assessments to same questions. This method fundamentally relies on the quality of expert panels' knowledge, experience, and judgments. The size of an expert panel in Delphi basically depends on the number of issues. A large number of respondents appear to perform better in order to adequately treat some issues, but the groups with seven or eleven participants are more effective in forecasting than larger groups according to Brockhoff's experiments of Delphi performance [223]. Delphi 
process gives the participants objective feedback from structured group consensus. The basic procedure of Delphi methods proceeds as follows [228][34][32][229]:

- Identify goals of the study and requirements

- Structure the questionnaire with scale or open-ended answer to support study goals

- Identify the experts in each field

- Anonymous response

- Iteration (2-6 times, 3 or 4 as usual)

- Controlled feedback

- Statistical group response $\left(\aleph^{2}\right.$ test, median and upper and lower quartiles for review)

- Present the consensus forecast

It is critical to carefully control a series of intensive questionnaires and feedback between rounds. Panel opinion is accepted as a relevant aggregate of individual estimates on the final round.

Table 17 The characteristics of Delphi

\begin{tabular}{|l|l|l|l|l|}
\hline \multicolumn{1}{|c|}{ Characteristics } & \multicolumn{1}{|c|}{ Advantages } & Disadvantages & Inception & Reference \\
\hline - exhibit bipolar views & - the possible & - time & & \\
not forcing consensus & participation of & consuming & & \\
- foster the better use of & diverse experts & - biases of expert & & \\
group interaction & in disparate & decisions & early & {$[27][32]$} \\
- qualitative approach & geographical & - forced & 1950's & {$[228][230]$} \\
- subjective, intuitive, & areas & consensus & & {$[231]$} \\
anonymous & - structured & - little control & & \\
- indirect interaction & group & over participants & & \\
- iteration and & consensus & & & \\
controlled feedback & & & & \\
\hline
\end{tabular}




\subsubsection{Nominal Group Technique (NGT)}

The nominal group technique (NGT) was introduced in 1968 by Delbecq, Van de Ven, and Gustafson as an organizational planning tool [232]. The nominal group is illustrated as a group in which each panel expert works in the presence of others but does not verbally interact [233]. There is no preliminary discussion in NGT. NGT is designed to remove the problems of group interactions. NGT is similar to Delphi method in that it uses expert panels. In contrast, NGT effectively holds structured meetings facilitated by a third party moderator, and involves efficient discussions among participants concerning each expert's initial opinion [52]. NGT is a very efficiently structured process for idea generation and group consensus in terms of assessing particular issues [234]. NGT prevents a bandwagon effect on the majority such that the group leader or the strong expert may affect the panel consensus by prioritization using secret ballots during the discussion of voting phase. Hence, it is of vital significance to carefully select experts in order to remove this disadvantage in the NGT. There are two types of group idea generation process in NGT: 1) an intraorganizational group decision making, and 2) a solicitation experts' or citizens' views as input for public policy formulation [235].

The NGT has been used for participatory problem solving approach by group analytical decision making in the social science field [233] and extended its application to almost any problem and field, such as health care studies [236][237][238], social services [239], consumer research [235], new product development [240], and information system [241]. The final output in the NGT is a rank-ordered list of new ideas assessed by expert panels with the number of points which account for the level of 
consensus. The 6-step process of group idea generation and prioritization in the NGT are as follows:

- Introduction of the task statement

- Individual, silent generation of ideas

- Round robin listing of ideas

- Clarification of ideas

- Consolidation of ideas

- Voting and ranking of ideas by secret ballot

Table 18 The characteristics of Nominal Group Technique

\begin{tabular}{|c|c|c|c|c|}
\hline Characteristics & Advantages & Disadvantages & Inception & Reference \\
\hline $\begin{array}{l}\text { - qualitative } \\
\text { approach } \\
\text { - alternative to } \\
\text { Delphi method } \\
\text { - information } \\
\text { shared } \\
\text { - involve } \\
\text { intensive } \\
\text { discussion } \\
\text { - aims at panel } \\
\text { consensus } \\
\text { - applicable to } \\
\text { wide variety of } \\
\text { areas }\end{array}$ & $\begin{array}{l}\text { - participation of all } \\
\text { members } \\
\text { - minimizes group } \\
\text { "noise" } \\
\text { - structures and } \\
\text { collects many creative } \\
\text { ideas } \\
\text { - easy to learn } \\
\text { - easy to integrate into } \\
\text { programs and projects } \\
\text { of larger scope } \\
\text { - intra- and intergroup } \\
\text { comparisons are } \\
\text { possible }\end{array}$ & $\begin{array}{l}\text { - mechanical or } \\
\text { overly } \\
\text { simplified } \\
\text { - structure does } \\
\text { not allow for } \\
\text { interaction of } \\
\text { ideas }\end{array}$ & 1968 & $\begin{array}{l}{[232][234]} \\
{[235][52]} \\
{[34]}\end{array}$ \\
\hline
\end{tabular}

\subsubsection{Scenario Planning/Writing}

Scenario planning has gained its popularity in technology forecasting methods and decision making in the face of uncertainty. It formally started from the use of computer simulation to measure the probabilities of the atmosphere and planet catching fire in the Manhattan project in 1942 [242]. RAND Corporation also introduced scenario planning for the US military purpose by Herman Kahn in 1950s, based on the 
previous groundwork of computer simulation, game theory, and war games [243].

Furthermore, private companies such as Royal Dutch/Shell and GE developed scenario planning technique for a corporate strategic planning in the late 1960 and early 1970s [34][244][152]. For instance, Shell's adequate and timely reaction to the oil crisis in 1973, drew attention to the scenario analysis [244][245].

Kahn and Wiener, the pioneers in scenario planning, first defined scenario as "hypothetical sequence of events constructed for the purpose of focusing attention on causal processes and decision-points" [246]. Scenario can be simply considered as a series of events that an expert imagines the plausible future occurrence. Schoemaker illustrated scenario planning as "a disciplined method for imagining possible futures in which organizational decisions may be played out" [247]. Scenario planning is the use of internally consistent narrative descriptions of particular sets of events, diversely possible situations or developments in the future. It explores the future to identify multiple outcomes that can occur. In essence, scenario planning is a systemic approach to create alternative and dynamic stories about many plausible futures in complex and uncertain business environments rather than to focus on a possible single outcome [248]. It explores the joint impact and implications of various different ends. This technique is useful in drastically changing environments including disruptive technologies.

Scenario planning can be variously classified based on the different aspects such as project topic, process design, time, etc [249][250]. There are, however, two forms of distinct scenario approaches with respect to technology forecasting: projective (descriptive) and prospective (normative, prescriptive) [216][249][251]. Projective scenarios explore possible future images projected from current situations to the future 
forward. On the contrary, prospective scenarios describe probable or preferable futures on the basis of different visions of the future. They write scenarios how to reach several significant objectives, which is similar to backcasting tool.

The theoretical foundations of scenario planning are relatively fragile [248][252]. In practice, however, there has been a variety of applications of scenario planning in diverse fields such as energy, electronics, aircraft, telecommunication, healthcare, and environment industry [250][253][254][255]. In the real business world, three distinctive forms of scenario planning have actively been implemented [153]. In this section, the main focus has only been on the "Intuitive Logics" tool typically introduced by Pierre Wack, a planner at Shell Francaise [244][245], because the other two approachestrend impact analysis and cross impact analysis - are described in detail in the other sections. The "Intuitive Logics" was mainly used by SRI International, Global Business Network, and Shell [153]. The Intuitive Logic approach considers a complex set of relationships to make a better decision among STEEP headings (social, technological, economic, environmental, and political) factors that are external environments to organization [153]. This method involves a series of intuitive logics generated by expert communication and analysis without depending on the complex computer simulation model [156]. This approach strongly depends on the participants' intuition and the communication skills of the expert panels [250]. 
Table 19 The summary of three approaches of scenario planning

\begin{tabular}{|l|l|c|c|}
\hline \multicolumn{1}{|c|}{ Types } & \multicolumn{1}{|c|}{ Characteristics } & Inception & Reference \\
\hline $\begin{array}{l}\text { Intuitive } \\
\text { Logics }\end{array}$ & $\begin{array}{l}\text { - developed by Shell } \\
\text { - appropriate for short-term forecast } \\
- \text { restricts the diversity of the constructed } \\
\text { scenarios }\end{array}$ & late 1960s & [245][153] \\
\hline $\begin{array}{l}\text { Trend } \\
\begin{array}{l}\text { Impact } \\
\text { Analysis }\end{array}\end{array}$ & $\begin{array}{l}\text { - employed by the Future Group } \\
\text { - a combination of statistical extrapolations } \\
\text { with probabilities }\end{array}$ & early 1970s & {$[153]$} \\
\hline $\begin{array}{l}\text { Cross- } \\
\text { Impact } \\
\text { Analysis }\end{array}$ & $\begin{array}{l}\text { - practiced by Battelle with BASICS (Batelle } \\
\text { Scenario Inputs to Corporate Strategies) and } \\
\text { the center for Futures Research (INTERAX) } \\
\text { - a highly formalized method }\end{array}$ & 1966 & {$[34][153]$} \\
\hline
\end{tabular}

Scenario developers must be experts in all aspects of the proposed technology to seek out better decisions. They answer two types of questions: 1) 'precisely how might some hypothetical situation come about, step-by-step?' and 2) 'what alternatives exist, for each actor, at each step, for preventing, diverting, or facilitating the process?' [32].

The basic procedures of scenario writing are as follows [256][153]:

- Identifying the decisions and strategic concerns

- Analyzing major appropriate factors (internal and external environmental forces; social, technological, economic, political, and competition)

- Elaborating the assumptions to be implicit in the scenario logics with its scope

- Identifying related sources of information for major factors

- Analyzing the issues/points of divergence resulting from conflicting factors in the current situation

- Consolidating the information and predictions obtained to develop internally coherent pictures or development pathway 
- Analyzing implications for decisions and strategies

Table 20 The characteristics of scenario planning

\begin{tabular}{|c|c|c|c|c|}
\hline Characteristics & Advantages & Disadvantages & Inception & Reference \\
\hline $\begin{array}{l}\text { - manpower intensive } \\
\text { - embraces qualitative } \\
\text { perspectives, } \\
\text { quantitative data, and } \\
\text { macroscopic factors } \\
\text { - tends to be broad and } \\
\text { conceptual rather than } \\
\text { specific }\end{array}$ & $\begin{array}{l}\text { - very flexible } \\
\text { - incorporates } \\
\text { discontinuous } \\
\text { technology or } \\
\text { disruptive } \\
\text { events }\end{array}$ & $\begin{array}{l}\text { - can be too } \\
\text { qualitative } \\
\text { - relatively } \\
\text { expensive } \\
\text { - time- } \\
\text { consuming }\end{array}$ & $1950 \mathrm{~s}$ & $\begin{array}{l}{[243][34]} \\
{[250][257]}\end{array}$ \\
\hline
\end{tabular}

\subsubsection{Trend Impact Analysis}

The trend impact analysis was incepted in the early 1970s, diversified from the scenario planning tool [258]. This method was mainly used to add quantification to a scenario by The Futures Group consulting firm. It is primarily a descriptive approach evolved from the traditional forecasting tools, on the basis of extrapolating historical data with no consideration of unprecedented future situations [152]. This tool aims to enhance the accuracy and usability of approaches to trend extrapolation. The trend impact analysis not only collects past data and projects this to generate 'surprise-free' future trends, but also employs expert judgment tool to seek the possibility of occurrence and its future impact regarding unprecedented events [259]. This technique, in other words, provides a systematic means for combining both statistical extrapolations and expert judgments to identify a set of future situations. The critical part of this tool is to estimate the magnitude of impact at each extraordinary event on the trend from experts' decisions such as the largest impact or the steady-state impact and the beginning time of unusual trend [259]. It captures the product of probabilities 
and impacts in selected significant situations which the forecasters can focus on in an efficient manner.

When compared to the cross-impact analysis, the trend impact analysis merely renders an independent forecast of the key dependent variable, with no consideration of evaluation of possible combination of each event [153]. It also needs to utilize the cross-impact technique to calculate the probability of impacts of coupled events [259]. Furthermore, this technique requires a long past data for extrapolating trends. For these reasons, it is not a popular method among forecasters. The trend impact analysis consists of typical five steps as follows [156]:

- Collecting time-series past data

- Generating a surprise-free extrapolation

- Establishing probabilities of events occurring over time

- Adjusting extrapolation

- Writing scenarios from at least two of the forecasts

Table 21 The characteristics of trend impact analysis

\begin{tabular}{|c|l|c|c|}
\hline Type & \multicolumn{1}{|c|}{ Characteristics } & Inception & Reference \\
\hline & - relatively simple and easy to use & & \\
Trend & - requires long historical data for time-series & & \\
impact & analysis or causal methods & early & {$[258][259]$} \\
analysis & - ensures internal consistency & $1970 \mathrm{~s}$ & {$[152]$} \\
& - provides probable range of possible situations & & \\
& - well suited for policy evaluation & & \\
& - partially applicable to disruptive technology & & \\
\hline
\end{tabular}

\subsubsection{Technology Roadmapping}

Technology roadmapping was first used by Corning and Motorola to develop corporate and business strategy in the late 1970s [260]. In 1984, Motorola first 
introduced its own product technology roadmap as a planning tool to better position themselves and their product in the market. Motorola's product technology roadmap aided the communication between design $\&$ development engineers and the marketing personnel, in order to forecast technologies which would be required in future products [261]. Motorola popularized its own technology roadmap which had a single layer roadmap, focusing on the technological evolution associated with a product and its features as a business planning tool in 1987 [262]. The technology roadmap is a useful tool for managing R\&D planning as well as identifying the future of technological progress. Robert Galvin, former Motorola chairman, defines technology roadmap as "an extended look at the future of a chosen field of inquiry composed from the collective knowledge and imagination of the brightest drivers of change in that field" [263].

Technology roadmap is mainly developed for three purposes: technology forecasting, planning, and communication. Technology roadmapping, in other words, attempts to reveal a specific characteristic or an attribute of technology development over designated future time. It is also an effective tool for technology planning and communication which fits within a broader set of business planning [264][265]. Finally, this method provides a useful means for the communication within cross functional organization. Technology roadmapping technique has gained significant and subsequent acceptance within corporations[266][267][262][268], government agencies [269]-[272], and national foresights [273].

Technology Roadmapping takes a retrospective (top-down) approach which backwardly illustrates how to accomplish a given target from decades past to the present, or a prospective (bottom up) approach which looks forward from the present to 
the future, or a combination of the two [274]. Most technology roadmaps, however, involve a prospective process which has two distinctive types of analysis: market pull and technology push [275][274]. The prospective approach is typically employed in technology forecasting. In addition, there is no standardized roadmapping process to generate roadmaps [276]. It differs based upon the business objectives, product and service types, available resources, and knowledge and information, etc [277].

There are three major questions consider when developing technology roadmap [278]:

- Where does a company want to go?

- Where is a company at now?

- How can a company reach its target?

Table 22 The characteristics of technology roadmapping

\begin{tabular}{|c|l|l|l|}
\hline Type & \multicolumn{1}{|c|}{ Characteristics } & Inception & Reference \\
\hline & - relatively expensive & & \\
- exploratory / normative forecasting tool & & \\
Technology & - subjective exercise & late 1970s & {$[279][260]$} \\
Roadmapping & - not much applicable to disruptive & & \\
& technology but there are some attempts \\
& combining with other techniques & & \\
& & \\
\hline
\end{tabular}

\subsection{Analysis of the Relationship among TF Methods}

This study attempts to analyze the historical relationship between normative and exploratory methods in the literature and identify the methodological linkages among them. Some technology forecasting methods are employed together to predict technological changes or innovations, but others are not. It is, however, theoretically inappropriate to use composite methods among them in order to solve practical 
forecasting problems, owing to conflicts of assumptions. Furthermore, the selection of proper technology forecasting methods depends on the nature of the technologies [26]. Therefore experience and expertise in various $\mathrm{TF}$ techniques is important in selecting the appropriate forecasting models. This study categorizes technology forecasting techniques according to exploratory and normative approaches. This study analyzes the applicability of technology characteristics such as disruptive/discontinuous and continuous technology. Figure 2 presents a matrix of TF methods by type of techniques and technological characteristics. Within each cell, TF methods are listed in descending order of frequent and effective uses.

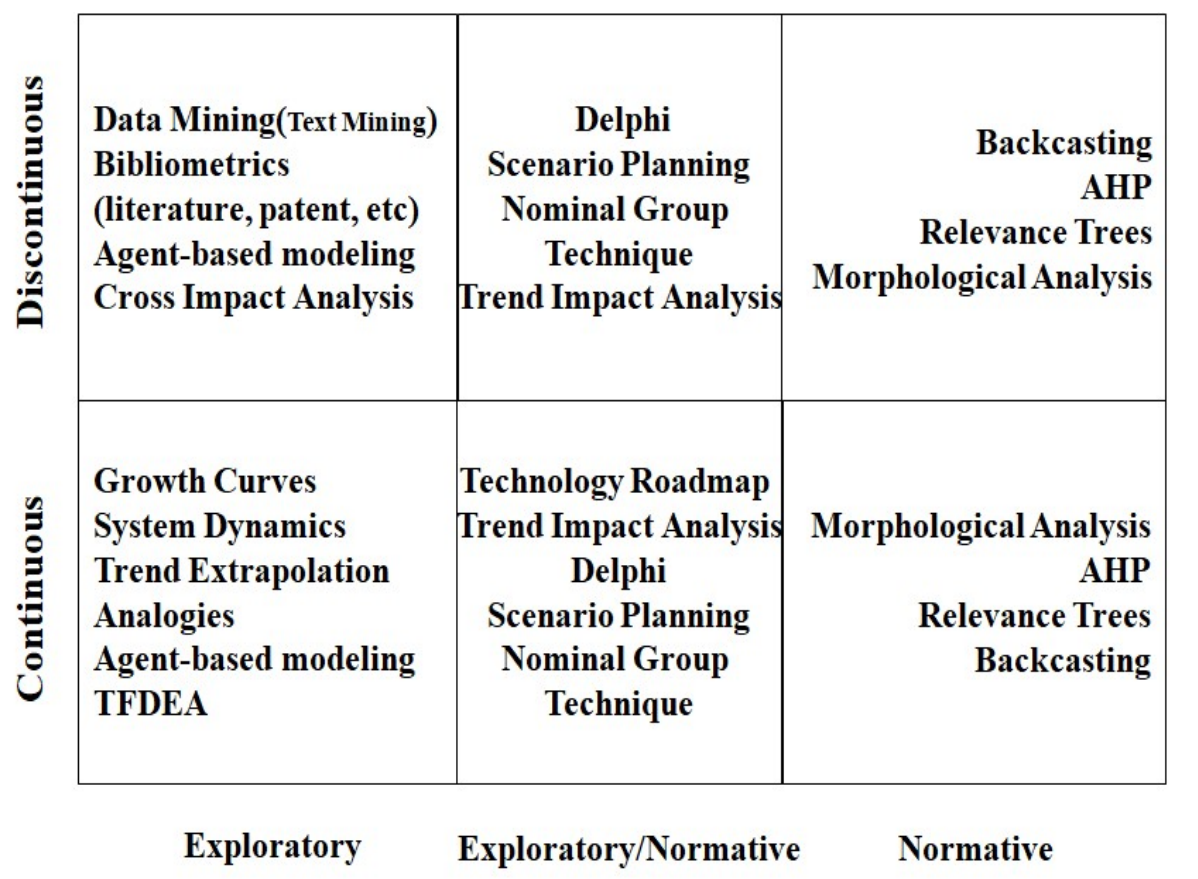

Figure 2 A matrix of TF tools

There are a number of articles that combine multiple TF tools in order to offset the weaknesses of one forecasting technique, such as technology roadmapping with scenario technique [282], Delphi with cross impact analysis [283], bibliometric with 
growth curves and system dynamics [23], and technology roadmapping with morphological analysis and text mining [284], and so forth. This study identifies research method linkages for technology forecasting through a review of the literature. Figure 3 illustrates the correlation among TF methods. Some articles combine the exploratory and the normative approaches to TF. Most of linkages are connected between exploratory and exploratory/normative methods or normative and exploratory/normative techniques. Furthermore, there are a few direct linkages between normative and exploratory methods, excepting the combination of text mining and morphological analysis. These relationships among TF methods reflect similarities in assumptions as well as methodological backgrounds among them. Additionally, a research gap can be found in the correlation map among TF techniques.

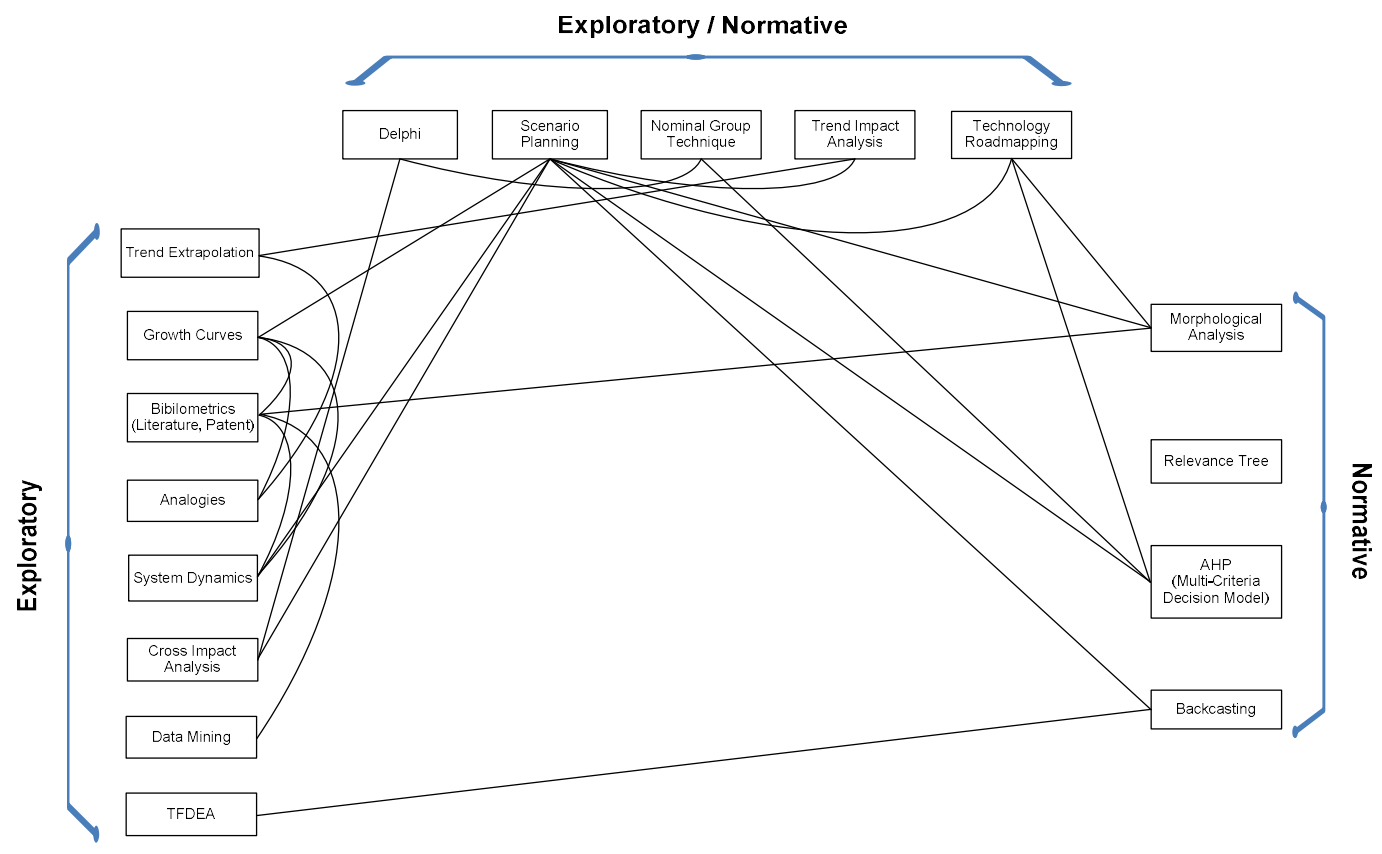

Figure 3 The connection map among TF techniques 


\subsection{Measuring R\&D Performance}

Firms have been focusing on the effectiveness of their R\&D investment as well as uses of R\&D. An effective R\&D operation is considered a primary enabler of competitive advantage in today's drastically changing business environment [10][285]. Since $R \& D$ is a creative, unique, and consists of unstructured process, it is difficult to evaluate its performance. Certain elements inherent in R\&D such as time lag, joint costs and returns, and imputation of a given cost or return item to a given project or program cause trouble in measuring its performance [286][287]. Unfortunately, there are still no methods that are widely accepted for measuring the causes and effects of inventive activity [288][289][290]. In times of economic downturn, the evaluation of performance in a firm is needed to justify R\&D investments. Furthermore, the accountability and effectiveness of R\&D program are highly emphasized. Measuring R\&D performance has been developed in response to the needs of various organizations by employing different methodologies. The literature regarding $R \& D$ performance focuses on three forms of contributions such as improvements in the capabilities and quality of existing products and processes, new product or process developments, and advances in knowledge for future improvements in products or processes [291].

Various forms of R\&D performance present difficulties in determining which elements to measure [292]. A variety of outputs, outcomes, and impacts of R\&D are illustrated in Figure 4. Output is the instant and direct result of the R\&D. Outcome is the expected result that will be realized through receiving system based on the output [293]. Impact is the long-term effect of the R\&D on the society and economy [294][295]. 
There is no single approach or method that provides an entirely satisfactory evaluation. To this, there is no question on that it is difficult to compare such subjective data to quantitative indexes. In this research, therefore, the measurement of R\&D performance focuses on output indicators rather than outcomes or social impact indicators, because the former is not only countable and can be measured at any given time, but also replicable based on verifiable sources.

Rubenstein and Geisler suggested that indexes measuring R\&D performance should be defined on the basis of the information-gathering system. In this regard, typical output indicators are patents, new products, new processes, publications, or simply facts, principles, or knowledge that were unknown before [296]. R\&D performance can, however, be measured by various variables depending on the focus of the analysis. This study focuses on evaluating the technological performance of R\&D efforts of a firm. In addition, the study reviews the literature to seek an objective measurement of R\&D effectiveness.

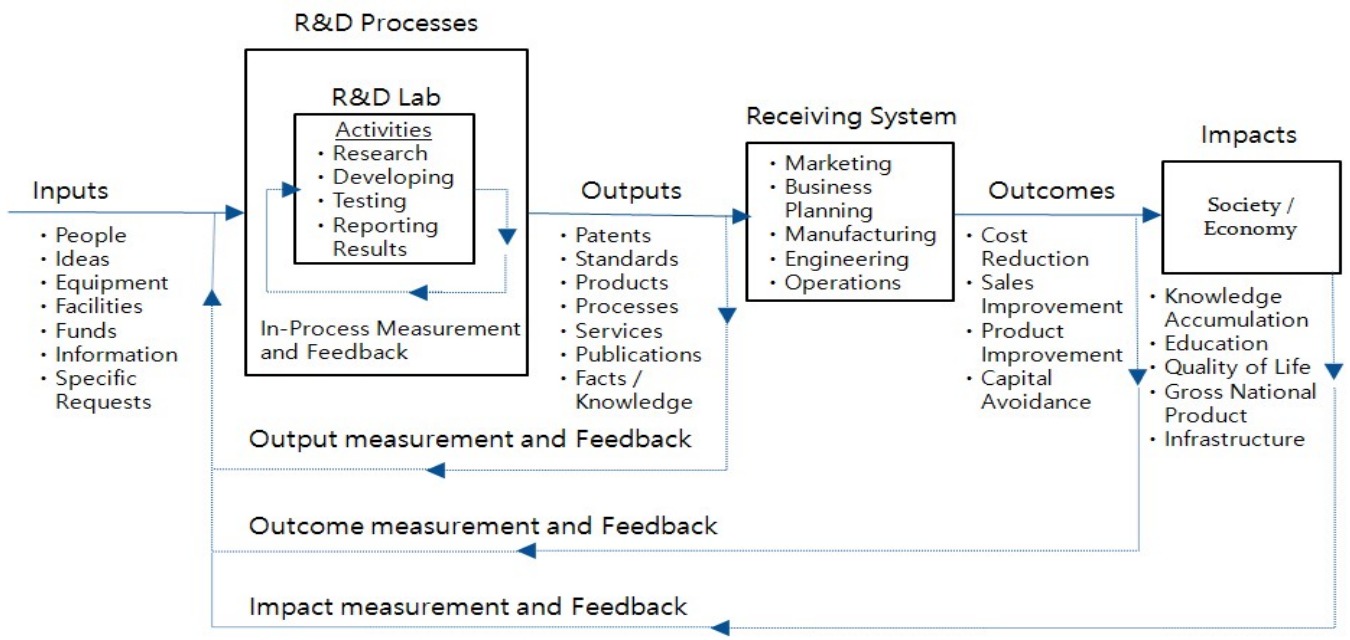

source: modified and adapted from [293][286][297][298]

Figure 4 The R\&D performance as a system 


\subsubsection{Patents}

Technical performance can be used to measure R\&D. Technological inventions and innovations have been playing a crucial role for a firm to compete in the market. Patents can be considered as the output of technically successful R\&D activities. Several studies indicate a positive relationship between patents and R\&D investment in U.S corporations depending on industry sector [299][300][301]. Jaffe indicated that patent counts and R\&D tend to be correlated without a time lag [302]. However, other studies still show little correlation between the level of R\&D spending and financial success [303]. Consequently, it is not enough to suggest that spending more on R\&D is always better [304].

The more R\&D intensive firms have a greater tendency to patent [305]. Comanor and Scherer suggested that the number of patents is highly correlated with the number of research personnel [306]. There have been discussions in the literature as to whether patents are simply an indicator of $R \& D$ expenditure, or whether they measure the output of invention. Several studies indicated that patents have a strong association with ratings of basic research excellence [307][308][309]. On the other hand, there has been mixed support for the association between patents and patent citations [310].

Mansfield indicated that the propensity to patent has inter-industry and inter-firm difference, and difference over time [311][312], and the quality of patents varies enormously. Not all inventions or innovations are patented. The percentage of innovations patented is limited to maintain secrecy among other reasons [313]. Even given all these limitations, patents have a compelling advantage providing a wealth of qualitative and quantitative information on technological change [299]. 
Patents of a proprietary nature have been used for identifying invention, innovations, and innovativeness in a number of studies [312][313][314], despite the fact that they, as intermediate elements, are not a direct measure of their commercialization potential [315]. Patents can be regarded as a medium to reflect the firm's intention to commercialize an innovative idea or invention. There have been a variety of indexes to measure R\&D performance by patents such as total number of patents filed or granted, and total number of patent citations. The most common output indicator is a patent such as number of patents granted or filed. For the virtue of easy accessibility via objective databases, this study selects the total number of patents as an output variable to examine the relationship between technology forecasting, technology planning activity, R\&D performance, and business performance.

\subsubsection{Products}

Product innovations are outputs or services that are introduced for the benefit of customers or clients [316]. Product innovations have a market focus and are primarily customer driven [316]. To gain or maintain competitive advantage, a firm has to innovate in new products or services. The sustainable and profitable growth comes from new or improved products, new services, new or improved processes, or new business model. Francis indicated that corporate R\&D should focus upstream and final product engineering [317]. A firm needs to keep growing its technological capability to protect its position [318]. The concept of new products should be determined to measure R\&D performance since they can be defined in various ways based on a firm's strategy and competitive environment [319]. 
Several studies of successful technological innovations indicate that they are most frequently applied to new products rather than processes [320]. Kleinschmidt and Cooper examined the association product innovativeness and profits at the product level [321]. Many studies use 'the number of new products released to the market' as a common quantitative index to measure R\&D outputs [289][286][297][287][317].

\subsubsection{Processes}

Process innovation can be defined as "new elements introduced into an organization's production or service operations in order to produce a product or provide a service" [322][323][324]. Process innovations have an internal focus and are primarily efficiency driven [316]. R\&D efforts should be directed toward enabling manufacturing processes that use new and different technology [317]. Process innovation is the central type of research in producing rapid effects on corporate profits [325]. Davenport differentiated process innovation from process improvement, which seeks a lower level of change [326]. To measure the entire list of process contributions from R\&D is relatively complex [287].

Geisler suggested improved performance of processes, processes used by others, and number of processes transferred to users or clients as intermediate R\&D outputs [297]. Galloway also indicated the critical contribution of R\&D resources for process improvement or the elaboration of an established product line for evaluating R\&D [287]. Gold pointed out the three types of contributions from R\&D with respect to process: improvements in the capability and quality of existing processes, development of new processes yielding major commercial advantages over competitors, and advances in knowledge likely to generate future improvements in processes [291]. 


\subsubsection{Cost Reduction}

R\&D tends to be applied to existing product extensions and to process refinements as competitors try to reduce their production costs [316]. Cost reduction in existing products contributes to competitive performance. Patterson pointed out that technical innovations may reduce the cost of existing operations [327]. Although cost reduction seems to be the evident benefit for major $R \& D$ accomplishments, short-term cost reduction and short-term sales are often considered to be less significant for overall growth [328].

Geisler proposed new indicators for R\&D performance including changes in the cost of products in manufacturing and actual cost reduction in user's performance/processes by considering the clients and the impactees [297].

\subsubsection{Standards}

For polymer science and standards, Rubenstein and Geisler suggested a number of new or improved standards as an immediate output from federal laboratory science and technology programs [286]. This article emphasized that managers or researchers must develop the R\&D performance index suited for their own organizational settings.

\subsubsection{Professional Recognition}

Professional recognition includes public speeches, prizes, honors, awards, press and media coverage, reviewing and publishing articles and books, and serving on professional society and governmental committees.

When an organization emphasizes basic and applied research over development engineering, Francis suggested professional recognition or technical accomplishments for measuring R\&D effectiveness [317]. 


\subsubsection{Technology Transfer}

Autio and Laamanen defined technology transfer as the "intentional and goaloriented interaction between two or more social entities, during which the pool of technological knowledge remains stable or increases through transfer of one or more components of technology" [329]. Technology transfer is a typical form of research transformation and the result of technology diffusion activities. Technology transfer is distinct and may be readily identified. Azzone and Maccarrone introduced the indices of tacit technology transfer in a informal form [330].

For the output indicator of R\&D effectiveness, Geisler suggested a number of outputs transferred to users or clients (e.g. products, ideas, improvements, etc) [297]. Autio and Laamanen addressed three types of output indicators of technology transfer: research and technology outputs, commercial outputs, and monetary and resource outputs [329]. This output indicator includes economic sense in that the firm's net income can be generated from royalties.

\subsubsection{Publications}

Publications are a common means by which technical knowledge circulates. Scientific publications may lead to technological innovations, which are the catalyst for new product or process development [307]. The number of elite scientists in a firm is more highly correlated with publications rather than patents [331]. Resource intensive industries have more propensity to publish papers rather than patents when compared with capital intensive industries [331].

The number of publications is widely used to assess both a university's performance and an individual scientist's performance, as well as to measure scientific 
and technical outputs [297][332][333]. Narin et al. [307] suggested that papers can be a valuable indicator for the pharmaceutical industry. Gambardella used the number of scientific publications as a proxy for the R\&D capabilities of a firm [334]. To overcome the limitation of the number of publications, Sher and Garfield examined the number and variety of citing publications for evaluating the work of individuals and organizations with a qualitative perspective [335].

\subsubsection{Facts/Knowledge}

Facts and knowledge include the number of technologies and practices formally transferred into operating units, number of requests of consulting on projects, participation in design review, and improved capability of user to absorb/utilize technical knowledge [317][297]. This indicator is also one of the technically driven criteria. There is little research on this index to assess output from R\&D performance. The availability of such information may cause difficulty in adopting this indicator for R\&D measurement. 
Table 23 The summary of output indicators from the literature

\begin{tabular}{|c|c|c|c|}
\hline $\begin{array}{l}\text { Output } \\
\text { Element }\end{array}$ & Index & Description & References \\
\hline \multirow{6}{*}{ Patent } & Patents & $\begin{array}{l}\text { Total number of patents are filed or } \\
\text { granted in a certain period of time }\end{array}$ & $\begin{array}{l}{[286][297][312][336][119]} \\
{[337][317][120][338][306]}\end{array}$ \\
\hline & Patent filed & $\begin{array}{l}\text { Total number of patents filed in a } \\
\text { certain period of time }\end{array}$ & $\begin{array}{l}{[339][340][302][334][288]} \\
{[341][300]}\end{array}$ \\
\hline & Patent granted & $\begin{array}{l}\text { Total number of patents granted in a } \\
\text { certain period of time }\end{array}$ & $\begin{array}{l}{[311][305][331][112][307]} \\
{[342]-[347]}\end{array}$ \\
\hline & $\begin{array}{c}\text { Number of patent } \\
\text { citations }\end{array}$ & Total number of patent being cited & $\begin{array}{l}{[297][336][348][344][346]} \\
{[123][307][333]}\end{array}$ \\
\hline & $\begin{array}{l}\text { Number of patent } \\
\text { ratio }\end{array}$ & $\begin{array}{l}\text { Number of patents per total number } \\
\text { of R\&D employees }\end{array}$ & [349] \\
\hline & $\begin{array}{c}\text { Number of } \\
\text { innovations based on } \\
\text { patents } \\
\end{array}$ & $\begin{array}{l}\text { Total number of innovations based } \\
\text { on patents }\end{array}$ & {$[314][336]$} \\
\hline Products & $\begin{array}{l}\text { Number of new } \\
\text { products }\end{array}$ & $\begin{array}{l}\text { Total number of new products that } \\
\text { are released to the market by a firm }\end{array}$ & {$[286][297][289][287][317]$} \\
\hline Processes & $\begin{array}{c}\text { Number of improved } \\
\text { or new processes }\end{array}$ & $\begin{array}{l}\text { Total number of improved or new } \\
\text { processes }\end{array}$ & {$[297][286][287]$} \\
\hline $\begin{array}{c}\text { Cost } \\
\text { reduction }\end{array}$ & Actual cost reduction & $\begin{array}{l}\text { Actual cost reduction/savings in } \\
\text { client/user's performance }\end{array}$ & {$[297][327][328]$} \\
\hline Standards & $\begin{array}{l}\text { Number of new or } \\
\text { improved standards }\end{array}$ & $\begin{array}{l}\text { Total number of new or improved } \\
\text { standards }\end{array}$ & [286] \\
\hline $\begin{array}{l}\text { Professional } \\
\text { Recognition }\end{array}$ & Awards and Honors & $\begin{array}{l}\text { Total number of awards and honors } \\
\text { by a firm }\end{array}$ & {$[317][297]$} \\
\hline \multirow{4}{*}{$\begin{array}{l}\text { Technology } \\
\text { Transfer }\end{array}$} & $\begin{array}{c}\text { Number of } \\
\text { technology transfer }\end{array}$ & $\begin{array}{l}\text { The overall transfer of outputs to } \\
\text { external organizations }\end{array}$ & {$[297][329]$} \\
\hline & Licensing & Total licensing income & [346][329] \\
\hline & Number of new jobs & $\begin{array}{l}\text { Total number of new jobs created by } \\
\text { the spin-offs }\end{array}$ & [329] \\
\hline & $\begin{array}{l}\text { Amounts of venture } \\
\text { capital investment }\end{array}$ & $\begin{array}{l}\text { Total number and amounts of } \\
\text { venture capital investments in the } \\
\text { spin-offs }\end{array}$ & [329] \\
\hline \multirow{3}{*}{ Publications } & $\begin{array}{l}\text { Number of } \\
\text { publications such as } \\
\text { articles, reports, } \\
\text { books }\end{array}$ & $\begin{array}{l}\text { Total number of publications by a } \\
\text { firm }\end{array}$ & {$[334][317][331][332][307]$} \\
\hline & $\begin{array}{l}\text { Number of requests of } \\
\text { reports }\end{array}$ & $\begin{array}{l}\text { Total number of request of reports } \\
\text { by elsewhere in the company and } \\
\text { from outside }\end{array}$ & {$[317][297]$} \\
\hline & $\begin{array}{c}\text { Number of } \\
\text { publication citations }\end{array}$ & $\begin{array}{l}\text { Total number of publication being } \\
\text { cited }\end{array}$ & {$[335][297][333]$} \\
\hline \multirow{3}{*}{$\begin{array}{c}\text { Facts/ } \\
\text { Knowledge }\end{array}$} & $\begin{array}{c}\text { Number of } \\
\text { technologies and } \\
\text { practices }\end{array}$ & $\begin{array}{l}\text { Total number of technologies and } \\
\text { practices transferred into operating } \\
\text { units }\end{array}$ & [317] \\
\hline & $\begin{array}{l}\text { Number of requests of } \\
\text { consulting }\end{array}$ & $\begin{array}{l}\text { Total number of requests of } \\
\text { consulting on projects, participation } \\
\text { in design review }\end{array}$ & [317] \\
\hline & $\begin{array}{c}\text { Information and its } \\
\text { use by others }\end{array}$ & $\begin{array}{l}\text { Improved capability of user to } \\
\text { absorb/utilize technical knowledge }\end{array}$ & [297] \\
\hline
\end{tabular}




\subsection{Measuring Business Performance}

Economist and strategic management researchers have paid attention to firm performance over a century. In the earlier studies, Joseph Schumpeter created the theoretical concepts and tools in the most famous book titled "The Theory of Economic Development." He explored the evolution of economic development. This Schumpeterian effort formulated a remarkable notion of economic development. The firm equipped with R\&D division became the central innovative actors in Schumpeter's theory [350]. In the history of the neoclassical theory of the firm, neoclassical theorists try to look inside the black box of the firm. Economists treat technology as an exogenous or endogenous variable in the aggregate production function in order to investigate the economic growth [351][352][353]. A great deal of theoretical and empirical research has been made on productivity growth and measured technical change at the levels of single industries and whole economies.

Penrose, meanwhile, pioneered the foundation of resource based theory, and regarded firm growth as a dynamic process of management interacting with resources [354]. She applies this concept to the growth of the firm and its diversification. The resource based theory focuses on the heterogeneity of firm's a set of capabilities and performance. Strategic management, strategy, and firm differences are at the junction of its inquiry. Strategy formulation focuses on organizational resources and competencies aligned with environmental opportunities [355]. Teece explored efficiency rationale of firm diversification by incorporating economies of scope and transaction cost economics [356][357]. Wernerfelt advanced resource-based perspectives on both competitive advantage and firm growth [318]. He proposed a new focus on technology 
in strategy. Barney pointed out that firms can attempt to develop better expectations about the future value of strategic resources by investigating their competitive environments or by analyzing the skills and capabilities they already control [358]. He indicated that strategic choices must come from the analysis of competitive advantages based on strategic resources rather than a competitive environment. Nelson addressed inter-firm differentials with respect to strategy, structure, and core capabilities [350]. $\mathrm{He}$ touched upon the emerging theory of dynamic firm capabilities. However, Teece and Pisano triggered a flood of discussion on the theory of dynamic capabilities in their earlier studies [359][360]. They defined dynamic capabilities as an idiosyncratic set of learned processes and activities that enable a firm to generate a particular outcome.

In the line of this context, Prahalad and Hamel introduced the concept of core competence of a firm, which is difficult for competitors to imitate as embedded skills, the engine for new business development, and the collective learning in the organizations [361]. They defined core competence as a bundle of skills and technologies. A core competence is not only enhanced over time as they are applied, but also provides potential access to a wide variety of markets. They suggested that a firm should develop a corporate-wide strategic architecture for acquiring and deploying core competencies. They also emphasized the needs of 10 to 15 year long-term planning for developing a map of core competencies to bridge the gap between emerging customer needs and changing technologies. These approaches understand the firm performance as a result of the efficient use of unique company capabilities. Furthermore, they emphasize the sensing like technology forecasting and planning setting. 
Mitchell suggested a single system for the strategic management of technology in planning frameworks, which helps firms to deal with the issues of technological change, and their impact on strategy [328]. Cooper indicated that firms' strategies reveal the nature of technology employed [362]. On the flip side, emerging technology may lead to new businesses and even cause a significant change in corporate strategy [363]. For firms in research-intensive industries, technology innovation matters to drive their growth and competitiveness. Strategy is one of the major determinants of business performance. R\&D is a cornerstone of an effective innovation strategy [364]. A firm must deploy R\&D investments more strategically as well as effectively. Technologyfocused firms take into account technology as their primary asset in business strategy. R\&D must be connected with a firm's overall business strategy [285]. The business strategy is coupled with technology strategy. Technology strategy needs to be a subset of the strategic plan [365].

Planning is an integral part of strategy formulation [366]. One of significant contributing factors to corporate success is a formal planning system [366]. Drucker indicated that planning should be an integral part of a well-managed company [367]. Several studies have been conducted to measure the financial impact of strategic planning. Thune and House showed the strong relationship between formal planning and financial performance for firms in six industries [368]. Karger and Malik also found a positive relationship between formal integrated long-range planning and economic performance involving capital spending, stock price, and distribution of earnings for seven industries [369]. Wood and LaForge indicated a strong association between comprehensive long range planning and subsequent financial performance for a bank 
industry [370]. Meanwhile, Kudla indicated no relationship between formal planning and financial performance [371]. Based on the comparative analysis, Armstrong found formal planners were superior in ten cases and concluded planning seemed most useful in situations involving large changes [372]. Although research on the relationship between planning and performance has yielded inconsistent results [373][4], a metaanalysis of 26 studies allows valuable insights by indicating that strategic planning has a positive relationship with firm performance [374]. In recent study, based on metaanalysis of 46 studies, Brinckmann et al. also found a positive association between business planning and performance in small firms [375].

The technology planning and corporate strategic planning processes must complement each other in order to manage R\&D both purposefully and strategically [376]. Fusfeld emphasized that a firm must learn to integrate technology management with strategic planning [376]. In general, firms continuously keep managing and planning their strategies accustomed to drastically changing environment. Zahra and Covin investigated the relationships among business strategy, technology policy, and firm performance [377]. Zahra examined the association between technology strategy and financial performance with considering moderating effect of the environment on them [378].

Franko examined the R\&D factor in world-wide corporate performance and tested the association between corporate R\&D intensity and sales growth and world market share [379]. He stressed the crucial role of technology in the growth of the individual industrial firms. Mendigorri et al. demonstrated that four factors such as firm's R\&D activities, integration of the R\&D activities with business strategy, R\&D planning, 
cross-functional integration influence on the R\&D effectiveness [380]. They also provided the evidence of positive relationship between $R \& D$ effectiveness and the firm's financial performance.

Leonard indicated causal influence of R\&D intensity on the rate of sales growth [381]. Profit and R\&D have a recursive relationship and influence one another [311]. The important question is how to capture expected returns from R\&D. Illustrated in Figure 5 are all these arguments and associations among TF, information system, technology planning, business planning, technology strategy, business strategy, R\&D performance, business performance, and financial system as described above.

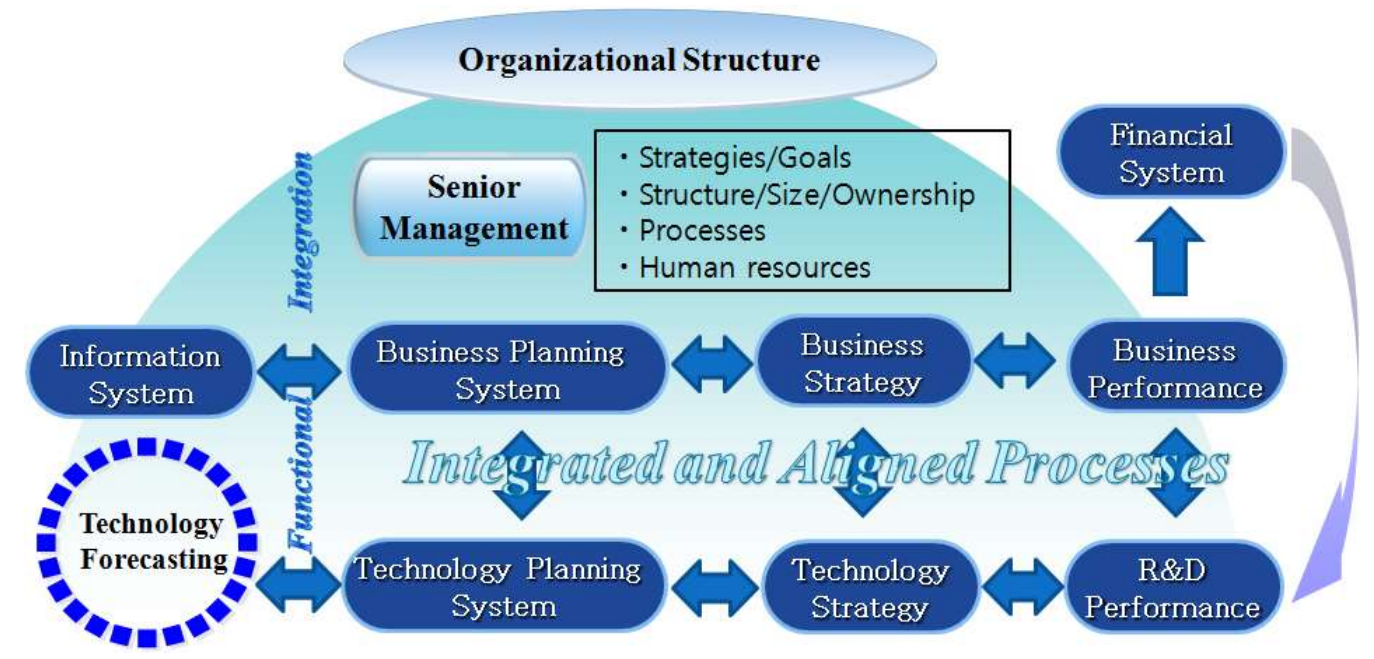

Figure 5 Overview of technology to business management

A number of outcome indicators are identified from the literature. Scholars and practitioners have been using partly different indicators to measure business performance [382]. In this research, the measurement of business performance is based on outcome indicators rather than outputs or impact indicators, because that data convey economic sense. For example, the more patents lead to subsequent change in business 
performance such as sales growth, or profit increases [383][342]. The new invention should lead eventually to the generation of financial profit. There is no significant trend favoring a single measure of firm performance. Due to cost-effectiveness as well as no viable alternative, many studies employ subjective measures of firm's performance [384]. There exists difficulty in obtaining financial data from small firms [385]. In addition, several studies provide the evidence that subjective measures of overall firm performance are closely associated with objective ones [385][386][387].

Miller and Cardinal investigated 35 previous studies and suggested the most popular performance variables: sales growth, earnings growth, deposit growth, return on assets, return on equity, return on sales, and return on total invested capital [374]. Standards for the firm's effectiveness, however, vary widely from industry to industry [388]. Consequently, the selection of a performance index is inevitably arbitrary. This research discusses the economic measures of firm performance.

\subsubsection{Sales}

The rationale for using sales as measures of business performance stems from the fact that despite several limitations, this measure has been extensively used in past research on examining the relationship between TF characteristics and business performance [378][388]. The most common indicator is sales growth. Growth in sales reflects how well an organization relates to their environment [389]. Many studies use sales growth as a measure of the extent to which a firm's innovative activities are stimulating revenue growth [310].

However, like other business performance measures, sales indicators have limitations. Sales indicators include total sales of a firm in certain period of time, sales 
of new products, sales growth, sales per employee, and return on sales. Parasuraman and Zeren suggested that sales may be a more meaningful yardstick rather than profits or earning for evaluating R\&D effectiveness [390]. Fulmer and Rue used the average of annual percentage sales growth experienced over the last three years [4]. The sales growth figures are normally based on nominal sales [303]. Morbey found a strong relationship between R\&D spending and growth in sales [303]. Meanwhile, return on sales (ROS) fails to capture the relative effectiveness of the use of assets by the firm [391].

\subsubsection{Revenue}

Few studies have used revenue to measure a firm's business performance. Bracker and Pearson use revenue growth for financial performance data, which is the absolute annual percentage of growth rates during certain period of time examined [392]. Griffin and Page indicated that revenue can be used to measure customer acceptance in both one-year short and four to five-year long terms [382].

\subsubsection{Earning}

Thune and House measure financial performance with earnings per common share, which is the portion of a firm's profit allocated to each outstanding share of common stock [368]. Narin et al. measured the increase in average annual percent change in earnings per common share (current dollars) by a firm [307]. The earnings per share (EPS) are computed annual rates of change in percentage.

\subsubsection{Profit}

For the R\&D effectiveness index, McGrath and Romeri suggested the new product profit, which can be calculated by multiplying the percentage of revenue from 
products introduced in the last three years by the rate of net profit combined with the percentage of R\&D spending [304]. Grabowski and Mueller use profit rates to determine profitability [393]. They examined the association between profit rates and R\&D intensities. Leonard also focused on the association between the firm's profit and $R \& D$ intensity which is measured by $R \& D$ investment over net sales [381]. For the R\&D effectiveness index from new products, McGrath Romeri suggested representative average profit from a new product rather than actual profit due to limited accuracy [304]. They also indicated difficulty in identifying the actual profit of individual products. Many studies use seven different types of profit for determining financial performance: profit of new products, total profits of a firm in certain period of time, profit margins, net income after tax, net worth, profit rates, and profit growth.

\subsubsection{Return on Investment (ROI)}

The private research sector is notoriously known for closely linking R\&D with Return on Investment (ROI). The ROI approach is based on a comparison of the cost of $R \& D$ over a period of years with the earnings contribution by products from $R \& D$ for the period [287]. Unfortunately, accurate measurement of ROI on R\&D is not a clear cut process. For measuring R\&D effectiveness, ROI can be a misleading indicator which simply depends on a measure of net income or profit at a given time, not over a certain period of time [303]. In other words, ROI accounts for only present activities focusing on short-term profitability. Mechlin and Berg also pointed out that the use of ROI criteria might lead to a decrease in R\&D spending [394]. One reason is that technological innovations usually take several years to produce a commercial success and could have unpredictable success [394]. For example, Westinghouse spent over 30 
years developing a superconducting generator over 30 years [394]. Dupont took about ten years to introduce nylon products to customers [395]. Furthermore, it is significant to note that R\&D spending is embedded in ROI, which may cause artifactual results due to variable construction [396]. Some studies provide the evidence to support positive relationship between market share and ROI [397][398]. Wagner identified nineteen factors, subgroup of three categories such as such as competitive and market factors, sales and expense ratios, and investment and employment ratios, which affect ROI [399].

\subsubsection{Return on Equity (ROE)}

Several studies employ return on equity as a measure for determining firm performance. Rhyne used 1-year return on equity (absolute and relative) to the planning [388]. Thune and House also measured financial performance in terms of return on equity [368]. Leontiades and Tezel used five different measures for investigating economic performance including return on equity (ROE) [366]. Robinson and Pearce employed a percentage change approach based on average performance over time in ROE [400].

\subsubsection{Asset}

After tax return on total assets is commonly regarded as one operational measure of the efficiency of a company regarding the profitable use of its total asset base [401][402]. Return on assets (ROA) is one of the easily obtained and widely circulated of firm financial performance measures [403]. Many innovation studies use ROA as a profitability measure [404][405][310]. Fredrickson and Mitchell used the average after tax return on assets for the most recent five years to assess financial performance [406]. 
Several studies used the average pretax return on assets (ROA) for the previous threeyear period for measuring economic performance [407][408]. Baker suggested ROA measure rather than sales growth or return on equity, due to common usage as well as comprehensive financial measure [407]. He also pointed out that three-year average return on assets is a good compromise measure rather than one-year average return or over four-year average, due to time sensitivity as well as data availability. He also pointed out that three-year average return on assets is a good compromise measure rather than one-year average return or over four-year average, due to time sensitivity as well as data availability. ROA is a useful measure of how well the firm has used its funds [391]. Harling and Funk pointed out that ROA is free from the bias imposed by differences in capital structure caused by financial leverage through high debt/equity ratios [391].

Return on assets (ROA), however, has also limitations, since it is distorted by previous spending decisions [378]. Several previous studies use different types of assets index such as assets growth and net assets per share. Grinyer and Norburn used net assets per share to assess the effectiveness of planning on financial performance [409].

\subsubsection{Stock}

Kudla used stock returns on average as a measure of effects of formal planning on financial performance [371]. He argued that financial performance is measured by common stock returns, since much of business finance focuses on maximizing stockholder wealth. Several studies employ stock market value to determine the effects of planning on economic performance. 


\subsubsection{Market Share}

It has been widely accepted that one of the major measure of business profitability is market share [397]. Market share is positively associated with financial performance [410]. For example, market share and ROI are strongly associated [397]. Gale found the positive relationship between market share and the rate of profitability [401]. Moorman used market share relative to its stated objective for measuring new product performance [411]. Deshpandé et al. also measured financial performance using market share [412]. However, market share, as an indicator, should be used carefully, since low market share is not necessarily indicative of poor performance by R\&D community, as opposed to that high or growing market share almost certainly indicates effective technical efforts [413]. 
Table 24 The summary of outcome indicators from the literature

\begin{tabular}{|c|c|c|c|}
\hline $\begin{array}{l}\text { Outcome } \\
\text { Element }\end{array}$ & Indicators & Description & References \\
\hline \multirow{7}{*}{ Sales } & $\begin{array}{l}\text { Sales of new } \\
\text { products }\end{array}$ & $\begin{array}{l}\text { Percent of sales for new products for a certain } \\
\text { period of time }\end{array}$ & $\begin{array}{l}{[299][345][414][382]} \\
{[306][362][349]}\end{array}$ \\
\hline & Sales growth & $\begin{array}{l}\text { Percent of sales growth of a firm in certain } \\
\text { period of time }\end{array}$ & $\begin{array}{l}{[303][415][381][368]} \\
{[416][366][4][406]}\end{array}$ \\
\hline & Sales volume & Total sales of a firm in certain period of time & {$[390][331][307][369]$} \\
\hline & $\begin{array}{c}\text { Sales per } \\
\text { employee }\end{array}$ & $\begin{array}{l}\text { Percent sales per employee in certain period of } \\
\text { time (e.g. labor productivity) }\end{array}$ & {$[415]$} \\
\hline & Sales per share & Percent sales per share in certain period of time & [369] \\
\hline & Sales per R\&D & Annual sales per R\&D budget & [349] \\
\hline & Return on sales & $\begin{array}{l}\text { Earnings after interest and taxes divided by total } \\
\text { sales }\end{array}$ & [417] \\
\hline Revenue & $\begin{array}{l}\text { Revenue } \\
\text { growth }\end{array}$ & $\begin{array}{l}\text { Percent of revenue growth of a firm in certain } \\
\text { period of time }\end{array}$ & {$[392][382]$} \\
\hline \multirow{4}{*}{ Earning } & $\begin{array}{l}\text { Earnings } \\
\text { growth }\end{array}$ & $\begin{array}{l}\text { Average annual percentage earning growth in } \\
\text { certain period of time }\end{array}$ & {$[4][307]$} \\
\hline & $\begin{array}{c}\text { Earnings/sales } \\
\text { ratio }\end{array}$ & $\begin{array}{l}\text { The average value of the earning/sales ratio over } \\
\text { the last three years }\end{array}$ & {$[4]$} \\
\hline & $\begin{array}{l}\text { Earnings/total } \\
\text { capital }\end{array}$ & $\begin{array}{l}\text { The average earnings/total capital over the last } \\
\text { three years }\end{array}$ & {$[4]$} \\
\hline & $\begin{array}{l}\text { Earnings per } \\
\text { share (EPS) }\end{array}$ & $\begin{array}{l}\text { The portion of a firm's profit allocated to each } \\
\text { outstanding share of common stock }\end{array}$ & {$[368][307][369][409]$} \\
\hline \multirow{7}{*}{ Profit } & $\begin{array}{l}\text { Profit of new } \\
\text { products }\end{array}$ & $\begin{array}{l}\text { Percent profit of new products in a certain } \\
\text { period of time }\end{array}$ & {$[304]$} \\
\hline & Profits & Total profits of a firm in certain period of time & {$[390][287][418]$} \\
\hline & Profit margins & $\begin{array}{l}\text { Percent profits of assets in a certain period of } \\
\text { time }\end{array}$ & {$[415][400]$} \\
\hline & $\begin{array}{c}\text { Net income } \\
\text { after tax }\end{array}$ & $\begin{array}{l}\text { Percent of revenue that reflected in net income } \\
\text { after tax for certain period of time }\end{array}$ & {$[381][370]$} \\
\hline & Net worth & $\begin{array}{l}\text { Percent of revenue that reflected in net worth or } \\
\text { profit for certain period of time }\end{array}$ & {$[381][419]$} \\
\hline & Profit rates & After tax profit rate & [393] \\
\hline & Profit growth & $\begin{array}{l}\text { Percent of profit growth of a corporation in } \\
\text { certain period of time }\end{array}$ & [420] \\
\hline \multirow{2}{*}{$\begin{array}{l}\text { Return on } \\
\text { Investment } \\
\quad(\mathrm{ROI})\end{array}$} & ROI & $\begin{array}{l}\text { Percent change of the ratio of net, pretax } \\
\text { operating income to average investment for } \\
\text { certain period of time }\end{array}$ & {$[399][398][349]$} \\
\hline & $\begin{array}{l}\text { ROI of new } \\
\text { products }\end{array}$ & $\begin{array}{l}\text { Number of year from the beginning of the } \\
\text { investment } \\
\text { until it is paid off }\end{array}$ & [421] \\
\hline $\begin{array}{l}\text { Return on } \\
\text { Equity }\end{array}$ & ROE & Net income divided by shareholder's equity & {$[373][368][366][400]$} \\
\hline \multirow{3}{*}{ Asset } & $\begin{array}{c}\text { Return on } \\
\text { assets (ROA) }\end{array}$ & $\begin{array}{l}\text { Net earnings before interest and taxes divided } \\
\text { by total assets }\end{array}$ & $\begin{array}{l}{[378][422][366][409]} \\
{[400][407][406]}\end{array}$ \\
\hline & Assets growth & $\begin{array}{l}\text { Percent of assets growth of companies in certain } \\
\text { period of time }\end{array}$ & {$[381]$} \\
\hline & $\begin{array}{l}\text { Net assets per } \\
\text { share }\end{array}$ & Net assets per share in certain period of time & [409] \\
\hline \multirow{2}{*}{ Stock } & $\begin{array}{l}\text { Stock market } \\
\text { value }\end{array}$ & $\begin{array}{l}\text { Value of stock market of a company, stock } \\
\text { price, change in the stock market value. }\end{array}$ & {$[368][416][288][369]$} \\
\hline & Stock returns & $\begin{array}{l}\text { Total return includes interest, capital gains, } \\
\text { dividends and distributions }\end{array}$ & {$[371]$} \\
\hline $\begin{array}{l}\text { Market } \\
\text { share }\end{array}$ & - & $\begin{array}{l}\text { Percent of increased market share or the ratio of } \\
\text { dollar sales by a business relative to its targeted } \\
\text { objective in a given time period }\end{array}$ & $\begin{array}{l}{[397][382][411][412]} \\
{[347][349]}\end{array}$ \\
\hline
\end{tabular}




\section{Chapter 3 Research Gaps}

Few studies have attempted to explore the collective implications of technology forecasting within organization for its R\&D performance and, ultimately, business performance. Furthermore, despite substantial interest in forecasting technology, little direct evidence to describe organizational/strategic aspects of a firm's TF activities with technology strategy has appeared in the literature. This study focuses on how systematic forecasting helps businesses make better strategic decision. This study found current research gaps in TF fields with respect to methodological, technological, organizational, financial, and industrial aspects as follows, even the list is not all mutually exclusive and exhaustive.

\section{- Methodological Aspects}

- The relevance and availability of data and the appropriate selection of TF techniques are basic elements to improve the effectiveness of the forecast in strategic technology planning [52][423].

- Some scholars point out that combining different TF methods is significant means to improve the effectiveness of TF [23][24][25], but little statistical evidence to support the proposition exists.

- Technological Aspects

- Little effort has been made to select an appropriate technique with the consideration of technology characteristics such as disruptive vs. incremental technology in technology planning [26][424]. 
-Discrete characteristics of technology require appropriate information pertaining to technology difference as well as TF methods well-suited for their purpose [52].

- The scarcity of empirical studies exists regarding how to select an appropriate technique for a particular technology [26].

- The choice of TF methods might depend on the type of R\&D such as basic research, applied research, and commercialization.

- Organizational/Strategic Aspects

- Little attention has been given to describe organizational/strategic aspects of a company's TF activities integrated with technology strategy for improving organizational performance.

- The study is needed to identify the most efficient organizational structure of TF within a corporate for efficient management of technology.

- The appropriate TF in technology planning could help the firm yield and sustain competitive advantages [52][425].

- Financial/Economic Aspects

- The selection of TF methods also depends on the cost/benefit or the value of the forecast to the firm [423].

- The failure to forecast changing market conditions is a major reason for the failure of some established companies in a variety of industries [426]. 
- Very little empirical research has been conducted to determine the impact of TF on the business performance of the firm in today's competitive environment.

- Application/Industrial Aspects

- Special use and care should be taken to choose the proper TF method for a particular application [423].

- There is a marked shortage of clear guideline as to where and how particular TF methods are useful in strategic planning based upon product and service characteristics or the nature of industry [26].

In consequence, this research identified that very little attention has been paid to the suitability and the effectiveness of TF methods in the literature. 


\section{Chapter 4 Research Objectives}

The primary objective of this study is to investigate the effectiveness of technology forecasting in strategic decision making process for developing products and services based on exploratory approach. The strategic planning for technology development and a systematic integration process has become a significant issue. This study contributes to the identification of the degree of usability and usefulness of TF techniques for the development of products and services in practice. In order to do that, this research set questionnaires to the companies listed in manufacturing and engineering service industries.

The goals of the proposed research are:

- To identify technology forecasting tools in a strategic decision making process to develop technology, product and service.

- To provide a current snapshot of how firms across industries implement best practices in technology forecasting to facilitate organizational functions and strategic technology planning in the U.S. industrial firms.

- To help decision makers or forecasters select appropriate techniques in their business domains.

- To investigate if firms utilizing more sophisticated technology forecasting methods exhibit better R\&D performance as well as business performance than firms utilizing less ones.

- To improve the effectiveness of technology forecasting in strategic planning by capturing technology characteristics in various industries. 
- To provide an appropriate organizational decision making guideline to effectively implement in technology forecasting activities for supporting

\section{R\&D planning}

- To give recommendations to policymakers, researchers and other stakeholders to better develop and implement R\&D projects in their country.

Each research goal has generated research questions pertaining to it. These research questions are in need of much more study.

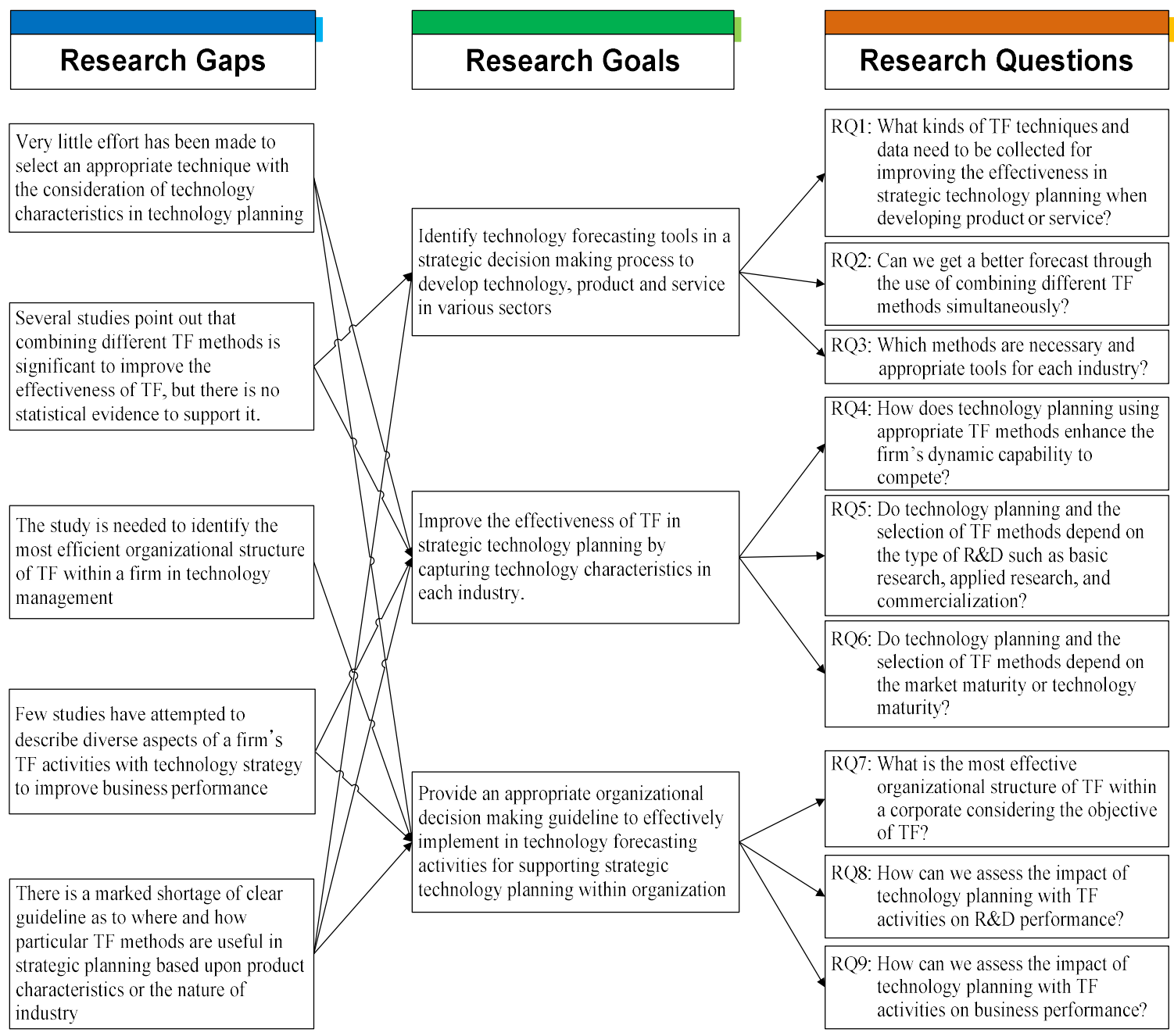

Figure 6 Research gaps to research goals and questions 


\section{Chapter 5 Hypothesis Development}

This section of the study addresses the theoretical support for the development of the research hypotheses. Based on the prior studies and strategic management theory, eleven statistical hypotheses are formulated.

\subsection{Technology Characteristics and the Effectiveness of TF}

One of the most significant tasks is to select appropriate methods for a given situation, so as to predict the right technological change in a certain future, since the methods employed inevitably affect technology forecasting results [26][52]. It is theoretically inappropriate to use composite methods among them in order to solve practical forecasting problems, in case of that it has the conflict of assumptions based on them. If TF methods and data are matched and utilized appropriately to the nature of technology in a firm, the effectiveness of technology planning may become distinctive relative to those that are not. Cho and Daim [427], and Mishra et al. [26] indicated that a company should select proper technology forecasting methods based on the nature of the technology. Walsh concluded that the qualitative knowledge of technology is required to detect the emergence of major or radical innovations which may lead to rapid growth, due to the limitation of quantitative patent statistics [428]. Furthermore, several studies indicated that the type of R\&D such as basic research, exploratory research, applied research, development, and product improvement influences measurement techniques and the metrics [296][349][429]. Likewise, a firm in slowly growing industries is likely to use methods applied to incremental and continuous technology, while as the firm in emerging industries or drastically changing business environments has a tendency to use tools applied to discontinuous (disruptive) 
technology. For example, when historical quantitative data is not available, in most cases, qualitative data and tools are used to forecast emerging technologies.

Cho and Daim [427] identified TF methods according to exploratory and normative approaches, and analyzed application tools associated with the nature of technology such as disruptive/discontinuous and continuous technology. Their previous research helps to identify whether a firm use proper TF tools to predict technological changes for its strategic management of technology planning or not. Therefore, it is significant to note that it requires experience and expertise in various TF techniques to select appropriate forecasting methods. The majority of the previous studies applied qualitative approaches when considering radical or disruptive technology innovations, supporting this claim. In addition, qualitative approach has been used in many previous studies to forecast long-term technological changes. Based on these arguments, the following hypotheses are proposed for this research.

H1a: Qualitative data and technique would be preferable in radical technology innovation.

H1b: Quantitative data and technique would be preferable in continuous technology innovation.

Certain technology forecasting methods are employed concurrently to predict technological changes or innovation, but others are not. Many studies point out that a combination of different approaches and methods are required to improve the effectiveness of forecasting, since a combination of multiple techniques enables forecasters to analyze various perspectives (organizational, technological, economic, 
political, personal, social, and environmental) [23]. There are a number of papers to use hybrid TF tools in order to offset weaknesses of one forecasting technique such as technology roadmapping with scenario technique [282], Delphi with cross impact analysis [283], bibliometric with growth curves and system dynamics [23], and technology roadmapping with morphological analysis and text mining [284], etc.

\section{H2: Combining multiple methods simultaneously has a positive relationship} with the effectiveness of $T F$.

TF is critical to all firms. However, in mature industries, research and technology development tends to be applied to existing product extensions and to process refinements as competitors try to reduce their production costs [316]. Life cycle of a product depends on the industry. High-tech industries like electronics have a short life cycle compared to low-tech industries like cement [430]. Abernathy and Townsend indicated that technological inputs have the least impact where they are needed most, in mature or stagnant industries [431]. In industries where technological innovation is significant, R\&D capabilities may be the lead ones in defining the dynamic capabilities of a firm [350]. Technology forecasting in technology planning is a critical step to follow before developing the technology. Therefore, this research claims that the use of $\mathrm{TF}$ techniques will be different across industry sectors.

\section{H3: The use of TF techniques differs across sectors.}

Tushman, Abernathy and Utterback made arguments that it is significant to understand life cycle of innovation or technology, which helps a firm predict the timing 
of radical change [430][432][426]. Several studies describe innovation streams in both incremental and discontinuous innovations, which illustrate the evolutionary cycle of innovations with technological discontinuity phase, dominant design phase, and retention phase [426][430]. If a firm manages innovation and change, it must acknowledge about these streams of innovations. During the dominant design stage, R\&D efforts shift from major product innovation to process innovation and incremental innovation [433]. In this phase, technology monitoring and TF activities in technology or strategic planning would be reduced compared to technological variation phase. These hypotheses are based on the belief that TF activities within a firm are more inclined to focus on radical innovations rather than incremental innovations from R\&D efforts due to increase of uncertainty and risk on business environment.

\section{H4: TF activities differ across the type of innovation the firm creates.}

\subsection{TF and Technology Planning}

Technology forecasting has evolved as a means for strategic planning in a firm [434]. Erich Jantsch categorized the scope of technological forecasting into three planning levels: policy planning, strategic planning, and tactical planning [59]. At the strategic planning level, TF is used to enrich this basis for strategic selection [59]. For tactical planning, TF involves in the probabilistic assessment of future technology transfer [59]. At policy planning level, TF more focuses on basic scientifictechnological potentialities and limitations as well as ultimate outcomes in a large systems context [59]. Firms must be able to integrate technology planning with strategic planning so that they may deal with technological evolution [376]. R\&D managers and 
other senior management group work together to formulate and execute complementary technology and strategic plans [376]. TF plays a crucial role in developing a technology plan [376]. A variety of use of TF makes it difficult to measure its contribution as a source of R\&D performance and business performance. $R \& D$ funding is allocated through technology forecasting, technology evaluation for project selection, technology strategy, to strategic planning.

Technology planning is critical both for cost-competitiveness and differentiation in business strategies [435]. TF plays a significant role to identify areas for research in many firms during planning process [436]. Frederick Betz also described TF as a critical step in technology and business planning to predict and implement technological changes in a firm with the consideration of new product development, production, and marketing [437]. It is significant to note that a structured process for technology planning should be established in a firm [438]. This process helps a firm to identify its competitive advantage by providing a picture of R\&D's role in business success. Technology forecasting is needed to predict promising alternatives as well as to assess alternatives in planning process [439]. Technology forecasting, technology planning, technology strategy, business strategy, product lines, and R\&D funding are tied together.

\section{H5: The use of TF has a positive relationship with technology planning}

\section{activities in a firm.}

Meanwhile, it is theoretically inappropriate to use composite methods among them in order to solve practical forecasting issues, owing to conflicts of assumptions. 
Firms in slowly growing industries are likely to use methods applied to incremental and continuous technology, whereas firms in emerging industries or drastically changing business environments have a tendency to use tools applied to discontinuous technology. For example, when historical quantitative data is not available, in most cases, qualitative data and tools are used to forecast emerging technologies. Accordingly, experience and expertise in various TF techniques is important in selecting the appropriate forecasting models. The firm's competitiveness would be perceived to be associated with the contribution of strategic technology planning efforts with the appropriate use of TF.

\section{H6: The appropriate use of data and TF methods improves the firm's}

\section{capability for technology planning activities.}

\subsection{Firm Size and TF Intensity}

Due to fixed costs of $R \& D$, some minimum size is required before a firm can maintain effective R\&D program [440]. If larger firms possess relatively more resources and assets such as financial capabilities, commercialization assets, and strong marketing assets to exploit technological opportunities, they should benefit more from TF activities. When examining manufacturing firms, economies of scale and experience should be considered, which leads for larger firms to greater efficiency in production process [441]. Furthermore, large firms may be better able to retain qualified staff who might be tempted to forecast emerging technologies.

There are still controversial debates on whether propensity rate to patent increases with firm size in the literature. Some studies report that small firms have more 
propensities to file a patent than larger ones [442]. Halperin and Chakrabarti found that R\&D productivity has a negative association with firm size [331]. Although this proposition sounds reasonable, there has been weak evidence to support this proposition, however [443][338]. Other studies found the evidence that firm size affects the probability of conducting R\&D [444]. Scherer proposed that patents have slightly positive association with larger companies [299]. Arundel and Kabla also found the evidence in favor of positive relationship between patent productivity and firm size [313]. Consequently, this study makes a proposition that there is a positive association between firm size and TF activities in planning processes.

\section{H7: The size of a firm has a positive relationship with TF activities in} planning processes within organization.

Small- and medium-sized enterprises (SMEs) are important sources of innovation. A small firm, however, may be technically and managerially quite competent yet unable to absorb new technology easily because of the extra demands placed on its scarce managerial and technical manpower [445]. Small firms are vulnerable to technological changes in their competitive environment. Due to lack of resources, SMEs will experience more intense competition on their market. Finally, large firms will have a propensity to be more R\&D intensive than small companies. In sum, this study suggests that small and large firms can benefit from technology forecasting activities in the United States. Large firms, however, seem to derive considerable benefits from not only internal TF activities, but also external TF sources. 
Because of lack of internal resource, small firms can have a propensity to gain benefits from mainly external TF resources.

\section{H8: The use of internal/external TF sources differs across the firm size.}

\subsection{Technology Planning and R\&D Performance}

High internal planning capability enables a firm to more effectively select R\&D projects that present themselves fulfilling technological changes. Careful forecasting clearly identifies customer's technological needs, and the technological threats and opportunities relevant to the firm's strategic goals [436]. Baker et al. suggested that the success of R\&D projects highly depends on how to resolve the initial uncertainty associated with their technical and commercial goals and objectives [446]. Although R\&D progress depends on non-technical factors such as investment, staff size, facilities, morale, and top management support [447], it appears reasonable to expect that systematic forecasting exhibits differing degrees of effectiveness on R\&D.

On the other hand, technical performance can be used as a measure of R\&D. Technological inventions and innovations have been playing a significant role for a firm to compete in the targeted market. Patents would be regarded as the output of technically successful R\&D activities. Scherer suggested a positive relationship between patents and R\&D investment in the U.S corporations depending on industry sectors [299]. The more R\&D intensive firms have a greater tendency to patent [305].

There have been discussions in the literature as to whether patents are simply an indicator of R\&D expenditure, or whether they measure the output of invention, however. 
Objective probability of success ratings from technology forecasting on selected R\&D projects in technology planning process is correlated with the eventual success and failure of these projects. Consequently, this research aims to investigate the effect of technology planning with TF on the R\&D performance based on the proposition that technology planning activities will be positively related to R\&D performance.

H9: R\&D performance has a positive relationship with technology planning activities in a firm.

\subsection{Technology Planning and Business Performance}

The participation of TF in long-range company goals setting is a good indicator of the degree to which $R \& D$ is integrated into the company as a whole [448]. With deliberate attention to this, technology should be managed strategically. Quinn and Mueller emphasized that a systematic planning process and management skills are required not only to align R\&D efforts with the company's business goals, but also to effectively transfer research results to commercial success [449]. Roy Rothwell pointed out that good technology planning and management techniques are one of the success factors for innovation [450]. However, the empirical evidence for such a claim is thin.

TF plays various roles in formulating business strategy [9] as well as setting long-term goals. Technological opportunity captured by technology forecasting must have market reference. Cooper indicated that top performing firms possess the most active idea search efforts of all firms to identify market needs, while poor performing firms have the most passive of all idea search efforts with the weakest R\&D orientation 
of all firms [362]. A firm with poor planning has a tendency to look for derivatives of existing products, or reacting to a competitors' moves [451]. It has little idea about what its business will be like in five years. A series of empirical studies have provided mixed support for the association between corporate planning and business performance [373][4][371]. Despite the wide recognition of the importance of technology planning, the association between technology planning and business performance has not, in general, been well documented empirically in the literature. A great majority of technology planning literature deals with how to plan and not the effects of R\&D planning. Very little practical guideline for technology planning has been introduced to determine the effectiveness of technology planning on the business performance of the firm. This hypothesis is based on the belief that firms which have systematic technology planning activities are more likely to identify opportunities and threats that could significantly result in commercial success from $R \& D$ efforts in the operation.

H10: Business performance has a positive relationship with technology planning activities in a firm.

\subsection{R\&D Performance and Business Performance}

$R \& D$ investment is one of diverse factors which can affect the sales growth and profitability in a firm. The firm should make R\&D a strategic force in its growth and competitiveness [285][376]. There is no question about that low profit would be likely to lead to low $R \& D$ expenditure. Profit and $R \& D$ have a recursive association one another [311]. Some scholars suggested the tenuous association between $R \& D$ expenditure and growth in profitability [303][399], although R\&D should be designed 
to result in market payoffs. There might be developing technology simply for R\&D. Also, despite the success of technological development, there might be failure from lack of management skills or market knowledge to make a profit out of it [425]. However, investing in future technologies can prove to have ROI with the prospect of licensing loyalties. The important thing is how to capture expected returns from R\&D. The question on the association between patents and financial performance remains unresolved depending on the research scope and design, specifically at the firm level [452]. The more patents, however, lead to subsequent change in business performance such as sales growth, or profit increases [383][342]. The new invention should lead eventually to the generation of financial profit. In sum, financial performance relative to a firm's industry will be positively related to $R \& D$ performance.

\section{H11: R\&D performance has a positive relationship with business}

performance of a firm.

These research hypotheses derived from the literature review are summarized in Table 25 as follows. 
Table 25 Research questions and hypothesis

\begin{tabular}{|c|c|}
\hline Research questions & Hypothesis \\
\hline $\begin{array}{l}\text { RQ1: What kinds of technology forecasting data } \\
\text { and techniques need to be collected for } \\
\text { improving the effectiveness in strategic } \\
\text { technology planning in order to develop } \\
\text { product and service? }\end{array}$ & $\begin{array}{l}\text { H1a: Qualitative data and technique would be } \\
\text { preferable in radical technology innovation } \\
\text { H1b: Quantitative data and technique would be } \\
\text { preferable in continuous technology } \\
\text { innovation }\end{array}$ \\
\hline $\begin{array}{l}\text { RQ2: Can we get a better forecast through the use } \\
\text { of combining different TF methods } \\
\text { simultaneously? }\end{array}$ & $\begin{array}{l}\text { H2: Combining multiple methods simultaneously } \\
\text { has a positive relationship with the } \\
\text { effectiveness of } \mathrm{TF}\end{array}$ \\
\hline $\begin{array}{l}\text { RQ3: Which methods are necessary and } \\
\text { appropriate tools for each industry? }\end{array}$ & $\begin{array}{l}\text { H3: The use of TF techniques differs across } \\
\text { sectors }\end{array}$ \\
\hline $\begin{array}{l}\text { RQ4: How does technology planning using } \\
\text { appropriate TF methods enhance the firm's } \\
\text { capability to compete? } \\
\text { RQ5: Does technology planning and the selection } \\
\text { of TF methods depend on the type of R\&D } \\
\text { such as basic research, applied research, and } \\
\text { commercialization? } \\
\text { RQ6: Does technology planning and the selection } \\
\text { of TF methods depend on the market } \\
\text { maturity or technology maturity? }\end{array}$ & $\begin{array}{l}\text { H4: TF activities differ across the type of } \\
\text { innovation the firm creates } \\
\text { H5: The use of TF has a positive relationship with } \\
\text { technology planning activities in a firm } \\
\text { H6: The appropriate use of data and TF methods } \\
\text { improves the firm's capability for technology } \\
\text { planning activities }\end{array}$ \\
\hline $\begin{array}{l}\text { RQ7: What is the most effective organizational } \\
\text { structure of TF within a corporate } \\
\text { considering the objective of TF? } \\
\text { RQ8: How can we assess the impact of technology } \\
\text { planning with TF activities on R\&D } \\
\text { performance? } \\
\text { RQ9: How can we assess the impact of technology } \\
\text { planning with TF activities on business } \\
\text { performance? }\end{array}$ & $\begin{array}{l}\text { H7: The size of a firm has a positive relationship } \\
\text { with TF activities in planning processes } \\
\text { within organization } \\
\text { H8: The use of internal/external TF sources } \\
\text { differs across the firm size } \\
\text { H9: R\&D performance has a positive relationship } \\
\text { with technology planning activities in a firm } \\
\text { H10: Business performance has a positive } \\
\text { relationship with technology planning } \\
\text { activities in a firm } \\
\text { H11: R\&D performance has a positive } \\
\text { relationship with business performance of a } \\
\text { firm }\end{array}$ \\
\hline
\end{tabular}




\section{Chapter 6 Research Design}

Technology forecasting activities and TF techniques can be considered differently based on managerial levels within a corporation, organizational structures, firm size, and industry sectors. This study attempts to examine the association between several dimension of the technology forecasting such as methodological, organizational, technological, industrial, organizational, and economic aspects.

To perform this study, it is necessary to identify the firms that are engaged in technology forecasting activities. The only feasible technique for collecting this information is survey. Using survey instrument, the purpose of the study is to analyze the effects of technology forecasting activities on R\&D performance in manufacturing sectors, with a special emphasis on technology planning, and to assess technology forecasting on business performance through R\&D performance. For the comparison among industries, therefore, the study will explore major industries dealing with technology forecasting such as manufacturing, communication, and professional, scientific and technical services with respect to TF activities, since the lifecycle of technologies in these industries are transparently different. Along with that, technologies can be intertwined to meet the market requirements in some fields. This research aims to reveal the extent of use of TF methods in the U.S. industry.

The interest of this study is in causal structure. This study proposes that R\&D performance serves as a moderator of the association between technology forecasting and business performance in a firm. Base on the literature, the structural equation model is developed concerning both the impact of $\mathrm{R} \& \mathrm{D}$ performance on business performance and implications about technology forecasting returns to internal planning in a firm. 


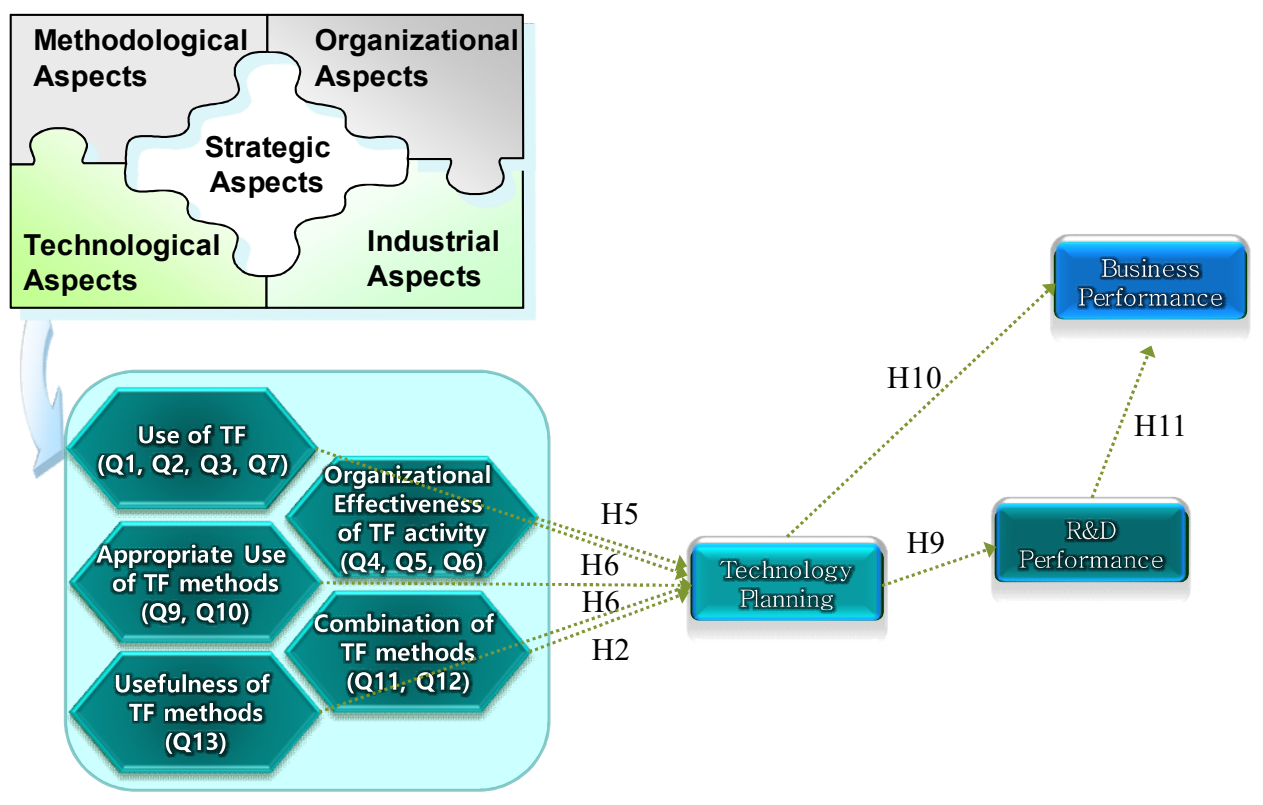

Figure 7 Research model 


\section{Chapter 7 Research Methodology}

In this study, structural equation model (SEM) is used to test hypotheses proposed in Figure 7 in previous section because SEM is appropriate to analyze path model with latent variables in order to uncover causal structures. The hypothesized relationships in this model have multiple intercorrelations between a set of variables, which are developed based on literature review and hypothetical assumptions. A straight, one-headed arrow represents a causal association between two variables. This model cannot be solved by ordinary least squares regression techniques. Multiple regression can be regarded a special case of SEM [453]. By contrast, SEM approach is a multivariate tool that takes into account complete and simultaneous equation of all relationship in a given model. SEM approach allows us to easily articulate relationships of all variables with one another [454].

\subsection{Path Analysis}

This research focuses on the causal inference in latent variable models. Causal relationship is the focal point of SEM analysis [453]. Path model incepted in population genetics to model inheritance by Sewall Wright in 1918 [455] and later widely applied to various situations in psychology and sociology [456]. Path models and multiple regression provide the core information needed to understand the broad class of SEM [454]. Path analysis gauges the strength of causal relations among variables in a multiple systems of equations based on the correlation matrix of observed variables [457]. In the 1970s cross-disciplinary integration ended up with structural equation modeling. SEM mainly deals with the specification of causal relations among variables. Path analysis in SEM has become one of the most widely used techniques to investigate 
the direct and indirect effect of causal variables on dependent variable [458]. In causal relations, mediation is a hypothesized causal chain in which one variable affects a second variable that, in turn, affects a third variable [459]. The indirect effect represents the portion of the relationship between $\mathrm{X}$ and $\mathrm{Y}$ that is mediated by $\mathrm{M}$ (mediator or mediating variable or intervening variable) [460]. By contrast, moderation is a hypothesized causal chain in which one variable affects the direction and/or strength of the relation between an independent variable and a dependent variable [461]. In recent years, SEM has been advanced by incorporating additional statistical models such as growth models, generalized linear models, and multi-level models [462]. In conclusion, SEM allows researchers to examine theoretical propositions with respect to how factors are theoretically interrelated and directionality of associations among variables.

\subsection{Factor Analysis}

Path modeling is integrated with logic of factor analysis [454]. Based on the groundwork Karl Pearson and Charles Spearman made in 1900s, factor analysis was developed to explore the structure of intelligence in multivariate data [462]. Factor analysis has been widely used for the analysis of correlated data [463]. Factor analysis is designed to link factors to measures that are defined in terms of weights [454]. The construct of achievement in a factor is defined by what those measures have in common [454]. The applications of factor analysis can be categorized into two different approaches such as common factor analysis and principal components analysis, which help to examine the variance for a given variable relative to other variables in the data set [463]. There are exploratory factor analysis (EFA) and confirmatory factor analysis 
(CFA) to examine the internal reliability of a measure. These techniques are used to investigate the theoretical constructs, or factors, that might be represented by a set of items. Both are used to assess the quality of individual items.

EFA has been a widely used method to determine the number of factors to retain, which explain the variation and covariation in a set of measured variables [464]. EFA can be used to evaluate construct validity [465]. EFA play a role in not only evaluating variables preliminarily, but also developing and refining the instrument's scales [465]. EFA is often employed when researchers have no hypotheses about the nature of the underlying factor structure of their measure [466]. EFA is pragmatic rather than theoretical in use. EFA has basically three steps: deciding the number of factor, choosing an extraction method, and choosing rotation method. At first step, the most common technique to decide the number of factors is generate a scree plot [467]. Once the number of factors is determined, the researcher runs factor analysis to identify the loadings for each of the factors. For factor extraction, principal components analysis (PCA) is widely used, which assumes there is no measurement error. However, Snook and Gorsuch suggested that PCA generate better estimates of population loadings with larger samples, and poor estimates in small samples [468]. Finally, after an initial solution is obtained, the loadings are rotated. Rotation is a way of maximizing high loadings and minimizing low loadings in an attempt to attain the simplest possible structure [466]. The researchers must decide what type of rotation to use. Newsom recommends promax rotation since it is known to be relatively efficient at achieving simple oblique structure. 
On the other hand, CFA is differentiated from EFA. CFA requires the specification of particular factor structure, whereas EFA allows all items to load on all factors [466]. In other words, with CFA, the research should specify which items load on which factor a priori. CFA examines a fit of the hypothesized factor structure to the observed data [454]. CFA approach attempts to examine whether or not observed data are consistent with the posited theoretical model. CFA provides a chi-square test and goodness-of-fit indicators. CFA is more theoretical than pragmatic. CFA is a specific instance of the general structural equation model [469]. The difference between CFA and SEM is that unmeasured constructs are hypothesized to be causally interrelated, whereas they are intercorrelated in CFA models [454]. CFA has become popular with the aid of statistical software package since late 1970s [454].

When researchers implement the model which departs from the posited theoretical model, it is recommended to use both CFA and EFA along the continuum in some circumstances [469]. Each method has some advantages and drawbacks. Therefore, researchers can use each method for a complementary purpose. 


\section{Chapter 8 Data Collection}

This chapter describes the data collection process, which covers survey design, instrument validation, instrument administration, targeted population, sampling strategy, and response rate.

Surveys can be administered by online, mail, phone, fax, or in-person, and there are different questionnaire considerations for each mode. Electronic using internet is the easiest to administer and tabulate, but most susceptible to "survey fatigue." Paper or mail adds additional layer of confidentiality, but less efficient medium for tabulating results. Telephone is easier to tabulate than paper, but increasingly difficult to administer due to cell phones because cell phone numbers are much less tied to where people geographically live [470]. Cobanoglu, Warde, and Moreo compared mail, fax, and web-based surveys with respect to response rate, response speed, and costs [471].

Internet web-based survey has become popularized in form of surveying in the world because it allows researcher to conduct the survey with speed, low cost, flexibility, easy execution, convenience, and economies of scale, when compared to traditional telephone or mail methods [472]-[475]. On the other hand, a mixed-mode strategy has been suggested as a means to improve response rates [476]. The comparison of each survey mode is summarized in detail in Table 26. 
Table 26 Comparison of mail, fax, and web-based surveys

\begin{tabular}{|c|c|c|c|}
\hline Factor & Mail & Fax & Web-based \\
\hline Coverage & High & Low & Low \\
\hline Speed & Low & High & High \\
\hline Return cost & Preaddressed/Pre-stamped & 800 return fax number & No cost \\
\hline Incentives & $\begin{array}{c}\text { Cash/Non-cash incentives } \\
\text { can be included }\end{array}$ & $\begin{array}{l}\text { Coupons may be } \\
\text { included }\end{array}$ & $\begin{array}{c}\text { Coupons may } \\
\text { be included }\end{array}$ \\
\hline Wrong addresses & Low & Low & High \\
\hline $\begin{array}{l}\text { Risk of delivery } \\
\text { failure }\end{array}$ & Medium & Medium & Low \\
\hline Labor needed & High & Medium & Low \\
\hline Expertise to construct & Low & Medium & High \\
\hline Perceived urgency & Low & Medium & High \\
\hline Level of detail & Low & Low & High \\
\hline Cost effectiveness & Low & Low & High \\
\hline $\begin{array}{l}\text { Variable cost/ } \\
\text { each survey }\end{array}$ & About $\$ 1.00$ & About $\$ 0.50$ & No cost \\
\hline Cost/response & $\$ 4.78$ & - & $\$ 0.64$ \\
\hline
\end{tabular}

Source: adapted and modified from [471][477][478][479]

Internet surveys are suitable for tremendous survey efforts and for the larger targeted populations that are difficult to reach with traditional survey methods [474][473]. Survey would be difficult to reach out to corporate executives in any method other than internet survey [480]. People with high level of computer abilitycorporate executives and policy experts - are more likely to respond by online survey [472]. On the other hand, Kaplowitz, Hadlock and Levine found the largest response rate difference between the mail and the email only distribution mode [481]. Dillman et $a l$. suggested that switching to a second mode is an effective means of improving response [482]. In this research, however, due to enough responses from email invitations and time constraints, follow-up fax invitations to participate in a web-based survey were not sent out to remaining respondents. In this study, a web-based survey 
questionnaire was developed and was conducted to uncover the relationships between TF activities, organizational effectiveness, R\&D performance, and business performance.

\subsection{Survey Design}

For self-administered survey, the design of the instrument is significant to obtain unbiased answers from respondents [483][484]. Form and graphic layout of the questionnaire are particularly important. A web survey should be designed with the survey population in mind [472]. In this study, firms that have invested R\&D for the new product or service development are included in the survey. The web-based survey questionnaire was designed and sent to a person who has a high probability of being acquainted with technology forecasting within organization such as CEO, Vice President of Engineering, CTO or R\&D Manager. These survey respondents would be expected to have a high level of technical proficiency with both the internet and mobile device [472].

i. For the construct validation, prior to administration, a web-based survey was administered to the expert panel to evaluate the survey using focus group interviews and cognitive interviews. Pre-test has been informed by theoretical work in the area of cognitive psychology [485][486] and social psychology [487][488]. The cognitive processes is to probe the subjects' internal states by verbalizing thoughts and feelings as they examine information in order to reduce measurement error by evaluating and improving survey questions. 
ii. To validate the content, a web-based survey was administered to the expert panel to validate the instrument that will be emailed to targeted respondents.

\subsubsection{Survey Layout and Usability}

The web-based survey instrument is comprised of three elements:

i) Introduction page: This page describes the objective of this study, and includes the consent form along with instructions for taking the survey. It also incorporates asking the intention to receive the summary results of this study to appeal interest in this research and optional contact information section for further question about this survey.

ii) The survey question: This page includes 14 survey questions and an optional section about a reward. The final survey questionnaire is presented in Appendix B.

iii) Termination page: This page gives a short message notifying the respondent that the survey is successfully submitted, giving gratitude to them for this survey.

A variety of errors involved in survey method is illustrated in Figure 8. Therefore, it is critical to reduce or remove the error that might occur at each stage. 


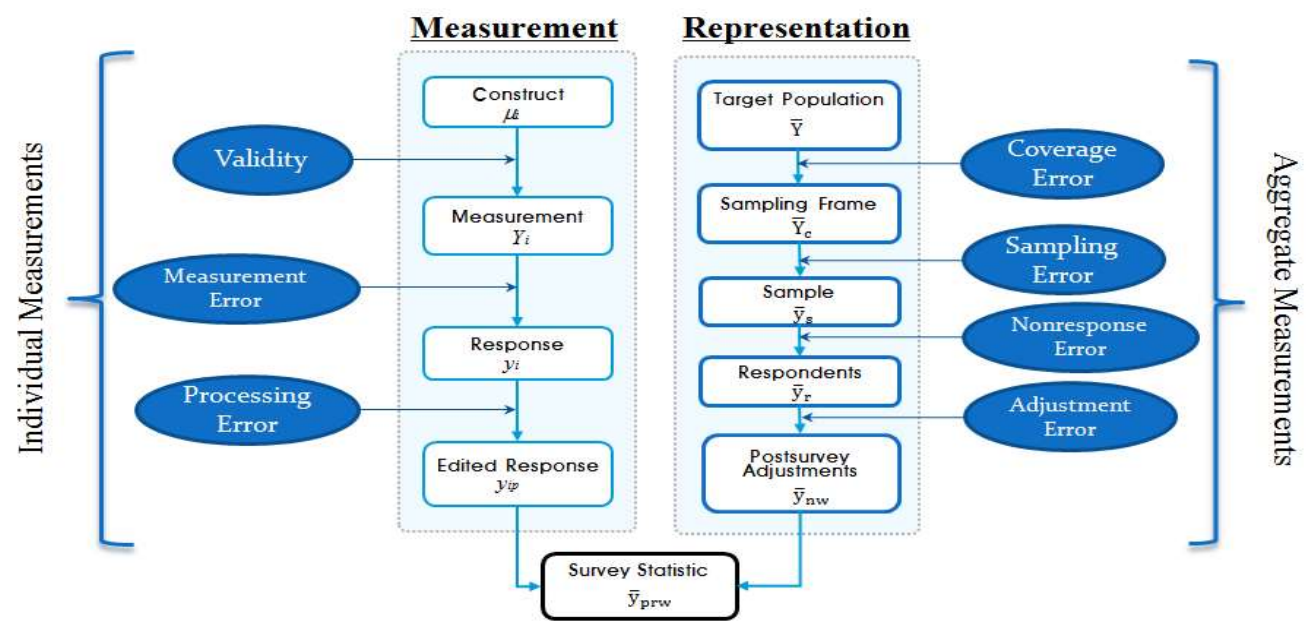

Source: [489]

Figure 8 Sources of errors for a survey research design

Dillman proposes 32 principles to help reduce sampling error, coverage, measurement, and non-response in the survey with respect to web-based survey and mail [472][490]. These principles are helpful to enhance the usability of a survey. As presented in Table 27, the layout of web survey is designed, following some part of Dillman's guidelines [472]. The designed web survey is graphically illustrated in Figure 9 and 10. 
Table 27 The design process of web survey

\begin{tabular}{|c|l|}
\hline Guidelines & \multicolumn{1}{c|}{ Description } \\
\hline G1 & $\begin{array}{l}\text { Create interesting and informative welcome and closing screens that will } \\
\text { have wide appeal to respondents }\end{array}$ \\
\hline G2 & $\begin{array}{l}\text { Use a consistent page layout across screens and visually emphasize } \\
\text { information that is essential to completing the survey while deemphasizing } \\
\text { inessential information }\end{array}$ \\
\hline G3 & Allow respondents to back up in the survey \\
\hline G4 & $\begin{array}{l}\text { Do not require responses to questions unless absolutely necessary for the } \\
\text { survey }\end{array}$ \\
\hline G5 & Do not include a graphical progress indicator \\
\hline G6 & Allow respondents to stop the survey and finish completing it at a later time \\
\hline G8 & Ask one question at a time \\
\hline G9 & $\begin{array}{l}\text { Use specific and concrete words to specify the concepts clearly } \\
\text { structures }\end{array}$ \\
\hline G10 & $\begin{array}{l}\text { Organize questions in a way to make it easier for respondents to comprehend } \\
\text { the response task }\end{array}$ \\
\hline G11 & $\begin{array}{l}\text { Separate optional or occasionally needed instructions from the question stem } \\
\text { by font or symbol variation }\end{array}$ \\
\hline G12 & Provide a single answer box if only one answer is needed \\
\hline G13 & Provide answer spaces that are sized appropriately for the response task \\
\hline G14 & $\begin{array}{l}\text { Align response options vertically in one column or horizontally in one row, } \\
\text { and provide equal distance between categories }\end{array}$ \\
\hline G15 & Group related questions that cover similar topics together \\
\hline G16 & $\begin{array}{l}\text { Begin with questions likely to be salient and interesting to nearly all } \\
\text { respondents }\end{array}$ \\
\hline G17 & $\begin{array}{l}\text { Place sensitive or potentially objectionable questions near the end of the } \\
\text { questionnaire }\end{array}$ \\
\hline G19 & Restrain use of color to improve readability \\
\hline Provide specific instructions and clarifications as needed for each question \\
\hline
\end{tabular}

Source: adapted from Dillman [472] 


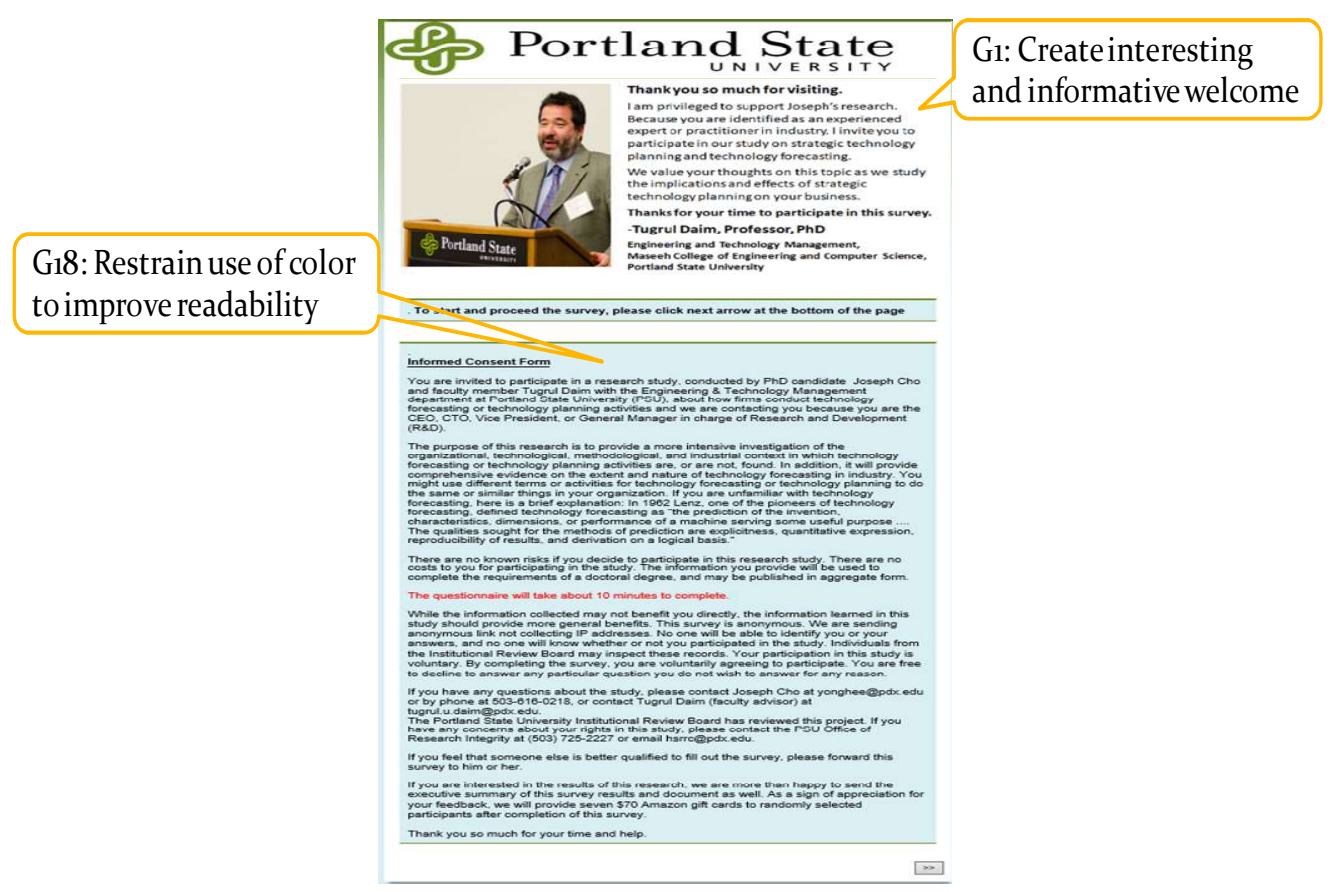

Figure 9 Introduction page of the survey

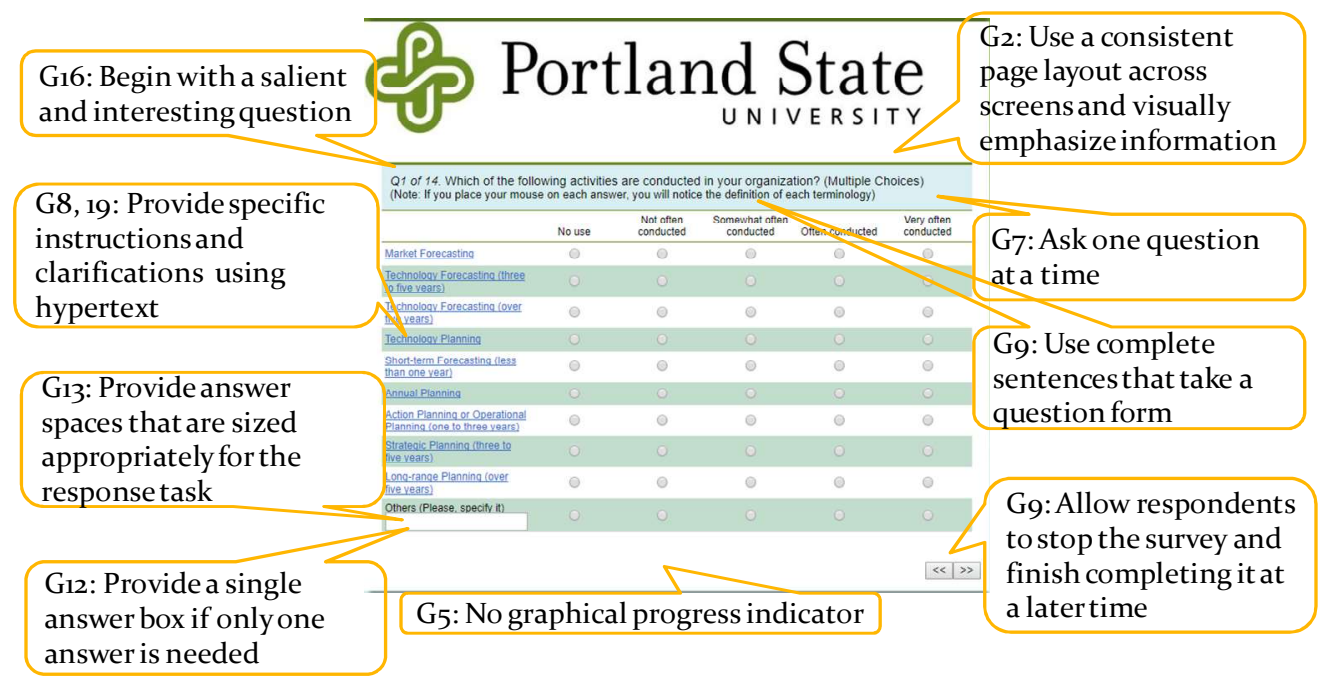

Figure 10 The first question of the survey

\subsubsection{Delivery Method: Email}

The web-based survey questionnaire was emailed to targeted samples with the invitation to take this online survey by clicking on a proper Uniform Resource Locator (URL) link. Respondents can access to web survey through their computers or mobile 
devices with an internet connection. As described in Table 28, the layout of invitation email was designed, following parts of Dillman's guidelines [472]. The designed invitation email is graphically illustrated in Figure 11.

Table 28 The design invitation email

\begin{tabular}{|c|c|}
\hline Guidelines & Description \\
\hline G1 & $\begin{array}{l}\text { Create an integrated look and feel between the email invitation letter and the } \\
\text { web survey }\end{array}$ \\
\hline G2 & $\begin{array}{l}\text { Appeal to respondents, whereby responding they would be helping complete } \\
\text { important research }\end{array}$ \\
\hline G3 & Emphasize the survey is anonymous \\
\hline G4 & Highlight the prize drawing to entice respondents \\
\hline G5 & Provide clear instructions for how to access the survey \\
\hline G6 & Have the survey web address jump out when viewing the email \\
\hline G7 & Emphasize that the survey is short and will not be time consuming \\
\hline G8 & $\begin{array}{l}\text { Highlight that the request is from an academic institution, rather than, from a } \\
\text { marketing business firm. }\end{array}$ \\
\hline G9 & To the extent possible, personalize all contacts to respondents \\
\hline G10 & Keep e-mail contacts short and to the point \\
\hline G11 & $\begin{array}{l}\text { Carefully select the sender name and address and the subject line text for } \\
\text { email communications. }\end{array}$ \\
\hline G12 & Take steps to ensure that emails are not flagged as spam \\
\hline G13 & Work within the capabilities and limits of the web server(s) \\
\hline G14 & $\begin{array}{l}\text { Provide contact information in case there is a need for recipients to contact } \\
\text { researcher }\end{array}$ \\
\hline
\end{tabular}

Source: adapted from Dillman [472] 


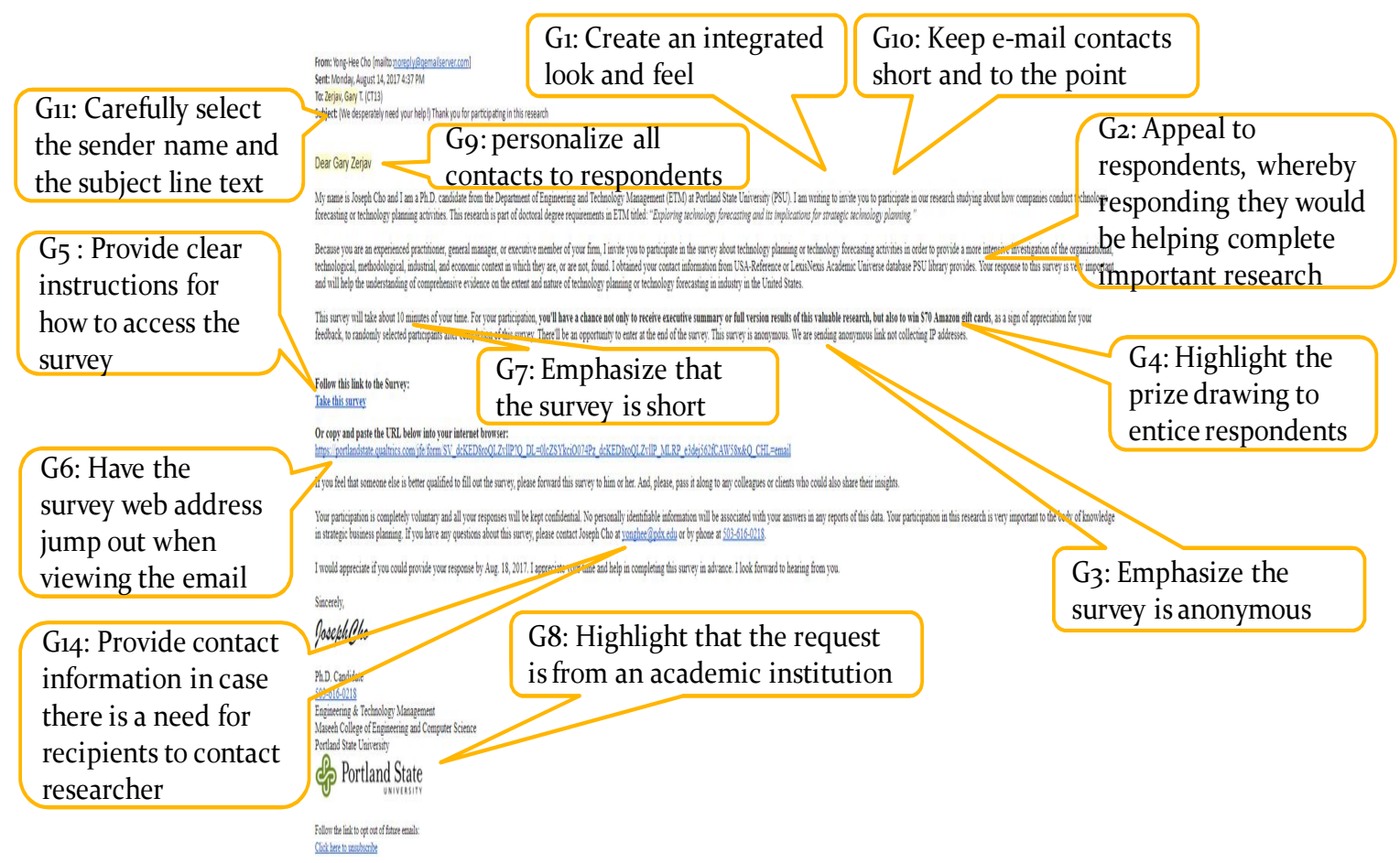

Figure 11 Invitation email

\subsection{Instrument Validation}

Prior to survey administration, survey contents and constructs should be validated by experts who make a judgment about survey items. To begin with, the Question Understanding Aid (QUAID) ${ }^{14}$ was used to evaluate syntax and test to flag some common problems with survey questions. Thereafter, to investigate the degree to which a measure appropriately represents what it is intended to, this research uses two approaches: content validity and construct validity [480].

Content validity. This measures the extent to which the content of each survey item accurately and comprehensively represents the content to be evaluated. For content validity, this study uses several tools such as literature review, cognitive interview, and

14 An interactive version of the software is available at: http://mnemosyne.csl.psyc.memphis.edu/QUAID/quaidindex.html 
expert panel. The typical way to measure content validity is to utilize experts' judgments. To assess the measurement of content validity for this survey, the expert panel was formed and their judgments and opinions were collected. More details are discussed later in this chapter.

Construct validity. This is related to the question what construct, trait, or concept underlies a respondent's score on a measure [491]. Construct validity is established by assessing convergent and discriminant validity [492]. This specifies the domain of the construct, and generates specific items represent the domain. It requires internally consistent or internally homogeneous set of items. In this regard, researchers should determine the degree to which the measure correlates with other measures designed to assess the same construct, which is convergent validity. Discriminant validity is the degree to which the measure is not correlated with other measures designed to assess different constructs. For construct validity, this research uses several techniques: literature review and expert panel. To evaluate the measurement of construct validity for this instrument, the expert panel was formed and their judgments and opinions were incorporated. More details are discussed later in this chapter.

Pre-test has been informed by theoretical work in the area of cognitive psychology [485][486] and social psychology [487][488]. The cognitive processes is to probe the subjects" internal states by verbalizing thoughts and feelings as they examine information in order to reduce measurement error by evaluating and improving survey questions. Questions that are misunderstood by respondents or that are difficult to answer can be improved prior to fielding the survey. Pre-testing is the opportunity to see what questions work well, what questions sound strange, what questions can be 
eliminated and what needs to be added. Thereafter, the expert panel is supposed to review model development and content validation. Expert panel is consisted of potential survey respondents to evaluate the survey. Cognitive interview was conducted to reduce response error such as interpretive errors and recall accuracy covered in this way.

It can be achieved by administering the survey to a few potential respondents (or your friends) to get feedback, and ask people to think out loud as they are answering the survey questions and probe them by questioning "What does that mean to you?", "How well each survey question presents the intention of the measurement", and "How well constructed is it for targeted population to answer each question". In evaluating a question's performance, cognitive testing examines the question-response process that is consisted of four basic stages: comprehension, retrieval, judgment and response, which is mainly credited to Tourangeau [485]. Some errors are also involved in this process as described in Table 29. In 1991, Edwards and Cantor suggested a modified five-step process adding encoding [493], while Willimack and Nicholes proposed three step modifications to the basic four step cognitive model inductively based on results of exploratory research [494].

Table 29 Cognitive model of question-response

\begin{tabular}{|l|l|l|}
\hline Cognitive Stage & \multicolumn{1}{|c|}{ Definition } & \multicolumn{1}{c|}{ Errors involved } \\
\hline Comprehension & $\begin{array}{l}\text { Respondent interprets the } \\
\text { question }\end{array}$ & $\begin{array}{l}\text { Attending to and interpreting survey } \\
\text { questions (careless responding) }\end{array}$ \\
\hline Retrieval & $\begin{array}{l}\text { Respondent searches memory } \\
\text { for relevant information }\end{array}$ & $\begin{array}{l}\text { Generating a retrieval strategy and } \\
\text { retrieving relevant beliefs from memory } \\
\text { (confirmation bias) }\end{array}$ \\
\hline Response & $\begin{array}{l}\text { Respondent evaluates and/or } \\
\text { estimates response }\end{array}$ & $\begin{array}{l}\text { Integrating the information (Biased or } \\
\text { sensitive, Estimation Difficulty) into a } \\
\text { judgment }\end{array}$ \\
\hline
\end{tabular}

Source: [485] 


\subsubsection{Instrument Validation Plan}

The survey instrument was validated in five steps, resulting in five survey questionnaire revisions over a 10 month period. The survey instrument was modified as necessary in accordance with expert panel's feedbacks and judgments. The instrument validation procedure is presented in Figure 12. The detail description of each step is as follows.

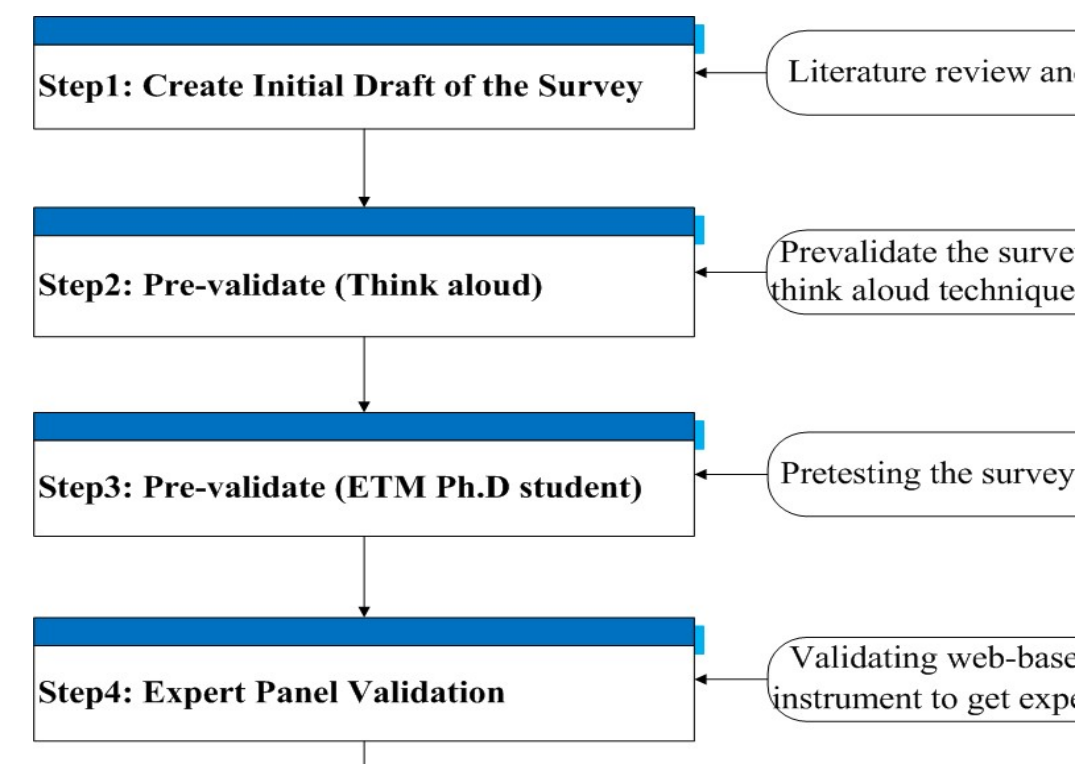

Figure 12 Instrument validation processes

i) Step 1: Create initial draft of the survey

Initial version of web-based survey was created based on literature review and brainstorming with both Ph.D. students and the dissertation committee.

ii) Step 2: Pre-validate (Think aloud)

The initial draft of survey was administrated to a group of Ph.D. students at the Department of the Engineering and Technology Management at PSU by employing the think aloud technique in order to obtain their feedback and comments. While they were going through all questions, they were asked to think aloud; to tell the interviewer all 
they read and what they are thinking about at every time [472]. Based on their feedback, the second version of the survey was made.

iii) Step 3: Pre-validate (ETM Ph.D. students)

At this stage, the second version of the survey was administered to a group of Ph.D. students at the Department of Engineering and Technology Management to prevalidate for completeness and quality of the second version of the survey. Based on their feedback, the third version of the survey was developed.

iv) Step 4: Expert panel validation

A validation tool was developed, based on the third version of survey questionnaires, to obtain experts judgment on the relevance of each question to its intention and the ease of answering each question. At this step, instrument validation was conducted by asking expert panel to evaluate each survey items. The first question is that "how well each survey question presents the intention of the measurement". The second question is that "how well constructed is it for targeted population to answer each question". The validation tool was administered to an expert panel of 79 members who agreed to participate in this survey validation process. Finally, 37 experts responded and gave their feedbacks on survey items. Based on their feedback, the fourth version of the survey was created.

v) Step 5: Pilot test the survey to the subset of potential respondents

Prior to survey administration, the fourth version of the survey was incorporated into a web-based survey and a link was emailed to a subset of expert panel by asking them to complete the survey and provide overall feedback on the content. At this step, the survey instrument was verified with a subset of potential respondents. The 
pilot survey instrument was administered to an expert group of 79 members. Finally, 32 experts responded to this pilot test and gave their feedbacks on survey items. For further investigation, cognitive walkthrough method such as one-on-one interview or email discussion was used to obtain their feedback and comments on the survey.

\subsubsection{Expert Panel Design}

It is important to select appropriate experts who have a sufficient level of knowledge and experience on the subject matter for incorporating valuable and various perspectives. Prior research provides several criteria that can be used in forming the expert panel [495][496]. In this research, expert panel that composed of CEO, CTO, Vice President of Engineering or General Manager in a firm was formed to validate the survey instrument and clarify survey questionnaires. Experts were selected based on following criteria:

- Expertise in strategic decision making process for technology forecasting, R\&D planning, strategic planning, and long-term planning from various sectors of U.S.-based manufacturing industries.

- Ensure the reduction of measurement errors by selecting the experts from different sizes such as small, medium, and large-sized companies.

- Easy to contact and get the feedback on the survey instrument

- Represent objective viewpoint in a firm to safeguard for individual biases on the results.

Initially, 6,563 expert panel candidates were contacted with an invitation email for the selection of expert panel. 79 experts agreed to be panel members. Finally, 37 experts participated in validation process of the survey instrument as listed in Table 30. 
Table 30 Expert panel

\begin{tabular}{|c|c|c|c|}
\hline No. & Title & Company & Location \\
\hline 1 & $\mathrm{CTO}$ & Metacog & Worcester, MA \\
\hline 2 & Sr. Vice President & Rockford Ball Screw & Rockford, IL \\
\hline 3 & $\mathrm{CEO}$ & Jamison Door Company & Hagerstown, MD \\
\hline 4 & $\begin{array}{l}\text { CTO, Worldwide IBM IT Economics } \\
\text { Practice }\end{array}$ & IBM & $\begin{array}{c}\text { Farmington Hills, } \\
\text { MI }\end{array}$ \\
\hline 5 & $\begin{array}{c}\text { Director, Business Development \& } \\
\text { Licensing }\end{array}$ & Medtronic & Mansfield, MA \\
\hline 6 & CTO \& VP Engineering & Socket Mobile, Inc. & Newark, CA \\
\hline 7 & Director of Systems and Strategies & $\begin{array}{l}\text { Quantum Technology } \\
\text { Sciences, Inc. }\end{array}$ & Indialantic, FL \\
\hline 8 & Chief Technical Officer & K2 Energy Solutions & Henderson, NV \\
\hline 9 & VP & SUMCO & Phoenix, AZ \\
\hline 10 & VP - R\&D & IEM Power Systems & Jacksonville, FL \\
\hline 11 & Director of Technology & VersaLogic Corp. & Tualatin, OR \\
\hline 12 & VP Engineering & $\begin{array}{c}\text { Microbest Precision Turned } \\
\text { Components }\end{array}$ & Waterbury, CT \\
\hline 13 & Executive Director & $\begin{array}{c}\text { Micro Systems } \\
\text { Engineering, Inc. }\end{array}$ & Lake Oswego, OR \\
\hline 14 & Engineering & Sargento Foods Inc. & Elkhart Lake, WI \\
\hline 15 & VP Engineering & Watchfire Signs & Danville, IL \\
\hline 16 & CTO & Exterro & Portland, OR \\
\hline 17 & VP Engineering/CTO & Univision & New York, NY \\
\hline 18 & R\&D Director & The Procter \& Gamble Co. & Cincinnati, $\mathrm{OH}$ \\
\hline 19 & Chief Digital Officer & $\begin{array}{l}\text { Hart Energy Publishing } \\
\text { Lllp } \\
\end{array}$ & Houston, TX \\
\hline 20 & $\begin{array}{c}\text { Director of Business Solutions \& } \\
\text { Pathfinding } \\
\end{array}$ & Intel & Hillsboro, OR \\
\hline 21 & $\begin{array}{l}\text { Director Engineering \& Asset } \\
\text { Reliability }\end{array}$ & $\begin{array}{c}\text { Sapa Extrusions North } \\
\text { America }\end{array}$ & Monument, $\mathrm{CO}$ \\
\hline 22 & Director & Matheson & Humble, TX \\
\hline 23 & Director of Advanced Technology & Thermo Fisher Scientific & Hillsboro, OR \\
\hline 24 & Senior Analog Design Manager & Microchip & San Jose, CA \\
\hline 25 & Manager Project Management & $\begin{array}{l}\text { Leviton Manufacturing } \\
\text { Company, Inc. }\end{array}$ & Tualatin, OR \\
\hline 26 & Director of Business Development & DeltaTrak Inc. & Pleasanton, CA \\
\hline 27 & Director of Strategic Accounts & SP Controls & $\begin{array}{l}\text { S San Francisco, } \\
\text { CA }\end{array}$ \\
\hline 28 & $\mathrm{CTO}$ & Source Photonics & West Hills, CA \\
\hline 29 & Director, Product and Market Dev. & ZOLL & San Jose, CA \\
\hline 30 & Manager Engineering Design & AT\&T Inc. & Dallas, TX \\
\hline 31 & Manager of Software Development & Vital Images, Inc. & Minnetonka, MN \\
\hline 32 & R\&D Manager & Voith Fabrics Inc & Appleton, WI \\
\hline 33 & CEO & $\begin{array}{l}\text { Global Packaging } \\
\text { Machinery Co., Inc }\end{array}$ & Paterson, NJ \\
\hline 34 & Director R\&D & Serim Research Corp & Elkhart, IN \\
\hline 35 & $\mathrm{CEO}$ & Arrington Performance & Martinsville, VA \\
\hline 36 & $\mathrm{CTO}$ & Cengage & Boston, MA \\
\hline 37 & VP Engineering/ CTO & Millar Inc. & Houston, TX \\
\hline
\end{tabular}




\subsubsection{Step 1: Create Initial Draft of the Survey}

As a first step, this study reviews the literature to develop initial draft of the survey instrument with respect to technology forecasting and technology planning as summarized in Table 31 . This study attempted to identify various aspects of TF related to technology planning and firm performance from prior research employing similar types of methods.

Table 31 Prior research that was used as references in the literature

\begin{tabular}{|l|l|l|c|}
\hline \multicolumn{1}{|c|}{ Topic } & \multicolumn{1}{c|}{ Methodology } & \multicolumn{1}{c|}{ Implications } & Date \\
\hline $\begin{array}{l}\text { Matching of TF } \\
\text { technique to a technology } \\
\text { [26] }\end{array}$ & $\begin{array}{l}\text { Survey, scoring } \\
\text { model, and } \\
\text { expert-based } \\
\text { decision }\end{array}$ & $\begin{array}{l}\text { - Identify TF methods for IT, } \\
\text { MBT technologies } \\
\text { - Identify variables and } \\
\text { characteristics affecting tech. }\end{array}$ & 2002 \\
\hline $\begin{array}{l}\text { Identifying TF methods } \\
\text { for predicting the new } \\
\text { materials development } \\
\text { [424] }\end{array}$ & $\begin{array}{l}\text { Fuzzy AHP, } \\
\text { survey }\end{array}$ & $\begin{array}{l}\text { Identify TF methods for the } \\
\text { new materials development }\end{array}$ & 2008 \\
\hline $\begin{array}{l}\text { Choosing a TF method } \\
\text { [52] }\end{array}$ & $\begin{array}{l}\text { Situations } \\
\text { analysis, case } \\
\text { study }\end{array}$ & $\begin{array}{l}\text { Identify various combinations } \\
\text { of degree of individual factors } \\
\text { affecting TF }\end{array}$ & 1995 \\
\hline $\begin{array}{l}\text { Industrial applications of } \\
\text { technological forecasting } \\
\text { [497] }\end{array}$ & $\begin{array}{l}\text { Survey, case } \\
\text { study }\end{array}$ & $\begin{array}{l}\text { Provide an intensive } \\
\text { examination of the } \\
\text { organizational aspect in TF }\end{array}$ & 1971 \\
\hline
\end{tabular}

This research created online survey instrument using Qualtrics, as an online survey vendor, provided by Portland State University. The survey consisted of 16 questions about technology planning or technology forecasting activities in order to provide a more intensive investigation of the technological, methodological, organizational, and industrial aspects in which they are, or are not, found.

\subsubsection{Step 2: Think Aloud}

As a next step, this research conducted a "Think Aloud" session as a part of developing the survey questionnaire. The think aloud technique is typically used for usability test. The objective of the think aloud session is to read the survey 
questionnaires aloud and improve, correct or modify the questionnaire as needed. A group of Ph.D. students from the department of Engineering and Technology Management at PSU were recruited to take part in this process. Four Ph.D. students participated in this session, which took about 1.5 hours to complete. While they were going through the questionnaire, they were instructed to speak aloud and make a note of their thoughts and feelings with great attention to the wording and visual layout. They were also asked to fill out feedback form about their impressions with respect to each survey question. The valuable feedback from each participant was applied into the survey questionnaire, resulting in removing redundancy and filtering the survey element for improving response rate from companies. Total questions are reduced from 16Qs of initial survey to 14Qs of post survey of cognitive interview. Through this process, second version of the survey questionnaire was created by matching question wording to the concepts being measured and the population studied. The examples of feedback and modification are presented as follows:

Participant: "What is the meaning of each forecasting activity?"

Modification: Added definition of each forecasting activity to clarify survey items using hypertext function at Qualtrics.

Participant: "The question asks about what and when. The answer lists only about what is the purpose."

Modification: Modified the question to clarify intention of survey item. Participant: "A little confused with the alternatives, i.e. Tech. Roadmapping is part of Tech. Planning and you also ask it in methodology questions."

Modification: Removed Tech. Roadmapping from answering lists. 


\subsubsection{Step 3: Pre-Validate}

The second version of the survey questionnaire was tested in this process. The intention of this step was to develop and validate the preliminary web-based survey instrument. A group of Ph.D. students and colleagues who have experience in R\&D, TF, or technology planning activities were invited to participate in this process. 26 colleagues and Ph.D. students participated in this step. They were asked to go through each survey question and give any feedback, comments, and suggestions that they might have in this survey questionnaire. The feesdback from each participant was reviewed and incorporated into the web-based survey questionnaire accordingly. The third version of the survey questionnaire was created. The example of feedback and modification is presented as follows:

Table 32 The example of pre-validation result

\begin{tabular}{|c|c|c|c|c|c|c|c|}
\hline Second version & \multicolumn{6}{|c|}{ Modification for third version } & Note \\
\hline \multirow{2}{*}{ 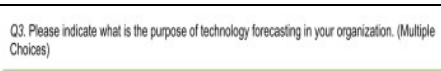 } & \multicolumn{6}{|c|}{ 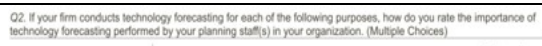 } & \multirow{13}{*}{$\begin{array}{l}\text { Question number was } \\
\text { corrected (from Q3 to } \\
\text { Q2). They asked me to } \\
\text { clarify the meaning of } \\
\text { 'redesign process.' They } \\
\text { recommended me to use } \\
\text { Likert Scale to get more } \\
\text { specific informative data }\end{array}$} \\
\hline & & aroum & neximoterst & Mosoment & mosenest & 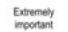 & \\
\hline 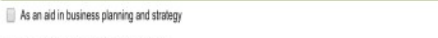 & 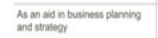 & 0 & 0 & 0 & 0 & 0 & \\
\hline 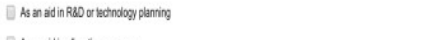 & 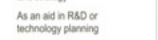 & - & - & 。 & 。 & 。 & \\
\hline 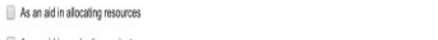 & 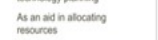 & 0 & 。 & 。 & - & 。 & \\
\hline 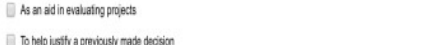 & 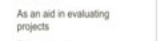 & 0 & 0 & - & - & 0 & \\
\hline 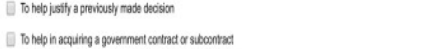 & 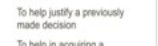 & 0 & 0 & 0 & 0 & 0 & \\
\hline 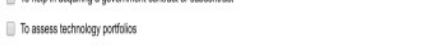 & 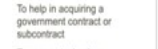 & ० & 0 & 0 & ○ & o & \\
\hline 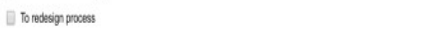 & 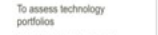 & 0 & 0 & 0 & 0 & 0 & \\
\hline 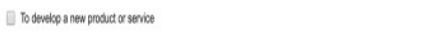 & 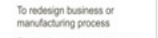 & 0 & 0 & 0 & 0 & 0 & \\
\hline 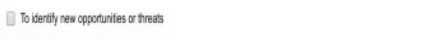 & & 0 & - & ○ & • & 0 & \\
\hline \multirow[t]{2}{*}{ Dathes (peass searin) } & 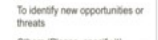 & 0 & - & • & 0 & 0 & \\
\hline & 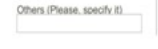 & 0 & • & $\circ$ & • & - & \\
\hline
\end{tabular}

\subsubsection{Step 4: Expert Panel Validation}

Expert panel was formed to assess and validate the third version of the survey questionnaire. They were asked to provide their feedback about this research on technology planning or technology forecasting within their firm. They were asked to evaluate each question with respect to intention of survey question, easiness of 
answering a question, and other additional comments on each question. Invitation emails were sent to 6,563 experts and 79 experts agreed to participate as an expert panel. Finally, 37 experts involved in this step. This step took four weeks to complete. They were provided a link to web-based survey. Figure 13 presents the introduction page with instructions to the nature of this survey validation and what was expected.

\section{f Portland $\underset{\text { SNIVERITY }}{\text { State }}$}

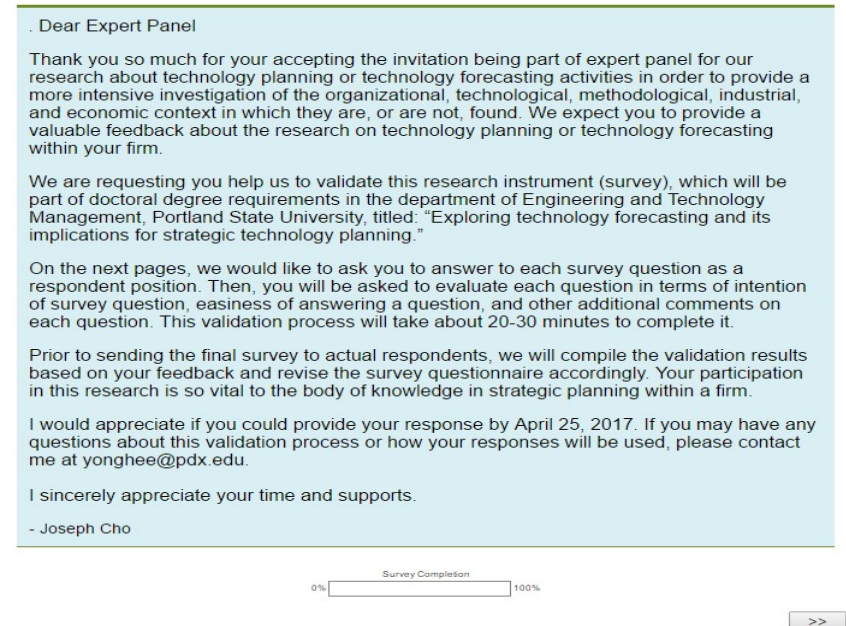

Figure 13 Introduction letter of survey validation

The questions were presented to the expert panel one per page. For each question, this study provided expert panel with a textual definition of intention, along with background information. Expert panel were asked to answer three questions. First, they were asked to evaluate how the text of the question represents the intention of it on a scale of one to five. Second, evaluate how easy CEO, CTO, Vice President of Engineering, or General Manager answers to this question on a scale of one to five. Finally, they were asked to provide their feedback about anything missing from the text 
or any additional opinion for each question. Figure 14 presents a screen shot of an example question and how these steps were implemented.

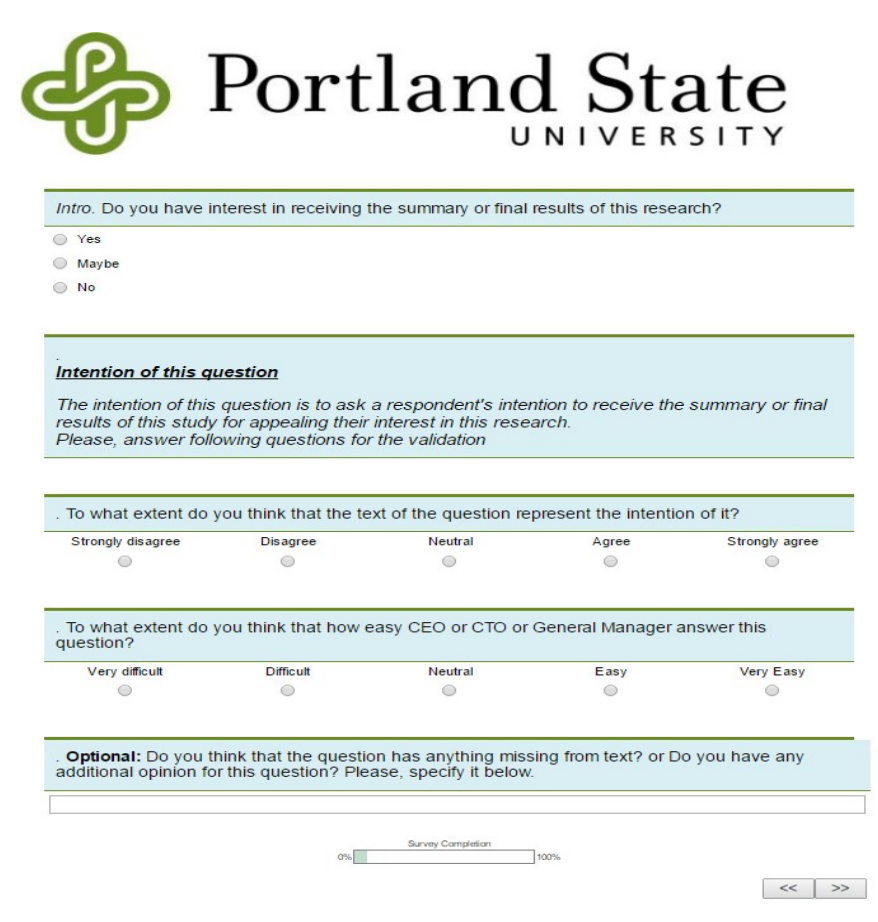

Figure 14 An example of online survey validation

- Intention; how well the question represents the intention of it, using a 5-point Likert scale:

1-Strongly Disagree ....2-Disagree .....3-Neutral....4-Agree.....5-Strongly Agree

- Ease of answering; how easy respondents answer to this question, using a 5point Likert scale:

1-Very Difficult......2-Difficult......3-Neutral.........4-Easy.......5-Very Easy

The goal of this validation is to estimate the level of relevance and ease of answering in terms of each question. Achieving over four point scales for each evaluation would help demonstrate that each survey item is appropriately designed, well suited for the research question and objective, and easy to take this survey. 
As presented in Table 33, the validation results safeguarded the rule of thumb, which is over four point scales. The mean of intention score was 4.27 , and the mean of ease of answering was 4.17. To improve survey response, special care needs to be taken in ease of answering for Q4 (3.92), Q6 (3.9), Q7 (3.66), and Q8 (3.82).

Table 33 The results of expert validation

\begin{tabular}{|c|c|c|c|c|}
\hline Question & $\begin{array}{c}\text { Intention } \\
(\text { Mean })\end{array}$ & $\begin{array}{c}\text { Standard } \\
\text { Dev. }\end{array}$ & $\begin{array}{c}\text { Ease of Answering } \\
(\text { Mean })\end{array}$ & $\begin{array}{c}\text { Standard } \\
\text { Dev. }\end{array}$ \\
\hline Introduction & 4.50 & 0.69 & 4.55 & 0.69 \\
\hline Basic info. & 4.31 & 0.73 & 4.34 & 0.75 \\
\hline Q1 & 4.41 & 0.60 & 4.33 & 0.66 \\
\hline Q2 & 4.44 & 0.55 & 4.36 & 0.67 \\
\hline Q3 & 4.34 & 0.63 & 4.37 & 0.59 \\
\hline Q4 & 4.18 & 0.64 & 3.92 & 1.06 \\
\hline Q5 & 4.29 & 0.65 & 4.27 & 0.84 \\
\hline Q6 & 4.05 & 0.92 & 3.9 & 1.05 \\
\hline Q7 & 4.08 & 0.81 & 3.66 & 1.24 \\
\hline Q8 & 4.11 & 0.84 & 3.82 & 1.14 \\
\hline Q9 & 4.24 & 0.68 & 4.23 & 0.78 \\
\hline Q10 & 4.35 & 0.54 & 4.32 & 0.70 \\
\hline Q11 & 4.22 & 0.59 & 4.35 & 0.63 \\
\hline Q12 & 4.35 & 0.68 & 4.32 & 0.88 \\
\hline Q13 & 4.24 & 0.76 & 4.03 & 1.08 \\
\hline Q14 & 4.21 & 0.70 & 4.0 & 1.04 \\
\hline Average & 4.27 & & 4.17 & \\
\hline
\end{tabular}

Note: Intention Scoring Guidelines (1-Strongly disagree, 2-Disagree, 3-Neutral, 4Agree, 5-Strongly agree), Easiness Scoring Guidelines (1-Very difficult, 2- Difficult, 3-Neutral, 4-Easy, 5-Very easy)

The expert panel responded additional comments on each question. Three to six experts proactively involved in questions and provided valuable feedbacks for each optional comment. A sample of notes from expert panel is as follows:

- Introduction:

- Three letter acronyms should always be defined, no matter how simple they are. 
- Engineering and Technology is a very broad term. If the target of this survey is for industrial operations, I would tend to go to the VP or Director of Engineering and/or R\&D. I don't know that the gift cards are of any particular value or need.

- Basic information:

- The number of employees is often not public information and cannot be disclosed by employees.

- Do you really need all this from all respondents? Respondents sometimes wish to remain anonymous and are wary of providing email addresses.

- Question 2:

- One thing - I don't know what "To redesign process" means. Does it mean to change the fabrication process by which a product is built or a service is supported? Does it mean to change processes by which products are designed? Does it mean to change business processes within the company? Does it mean to change how technologies are forecast? All of the above? This entry needs to be more specific.

- Fairly difficult question as many answers may apply. But a good question.

- Question 5:

- Missing are technology journals, magazines, newsletters.

- Most organizations use a complex mix of sources; I'm not sure if this is useful.

- Question 8: 
- Many techniques have multiple names. A glossary is needed. Methods have

different purposes in technology forecasting-again I think you need to focus on a narrower purpose for this survey to be useful.

- Maybe a hyperlink to a definition for each term?

\subsubsection{Step 5: Pilot Test}

After consolidating expert panel's feedback with respect to relevance and ease of answering and additional clarifications, fourth version of the survey questionnaire was incorporated into a web-based survey instrument. The invitation emails were sent to a total 79 expert panel members who are the subset of potential respondents such as CEO, CTO, Vice President of Engineering, and Senior Managers of firms in manufacturing sectors, which range from 20 to 39 based on the two digit code of standard industrial classification (SIC) and 8711 code. They were asked to answer each question in the actual respondent position. A pilot test with 79 experts was performed before the final survey was sent out to actual respondents in order to ensure that the measurement errors were removed. Finally, this study collected 32 valid responses and the final version of the survey instrument was established. Specifically, the survey data includes such variables as the total number of employees, the ratio of R\&D investment, sales revenues, etc. This research also gathered the total number of patents granted of each firm from second-hand objective data sourced from USPTO and WIPO. The patents examined in this research include utility and invention patents since design patents generally have no association with technological changes. I measured R\&D performance by employing the number of all patents granted in a particular year on the basis of recent five-year window. 


\section{Portland State \\ U N I V E S I T Y}

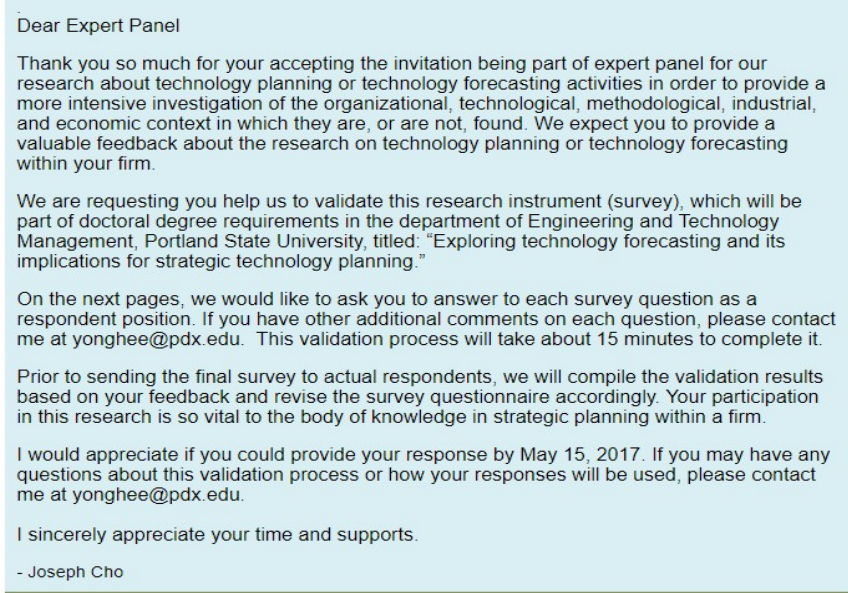

Figure 15 Introduction letter of pilot test

\subsection{Survey Administration}

\subsubsection{Targeted Population}

The unit of analysis in this study is "a firm" and the key informant is a CEO, CTO, Vice President of Engineering, or General Manager who is involved in strategic planning, technology planning, or technology forecasting of R\&D projects from each company. The rational scope described in the next section presents U.S.-based manufacturing and engineering service companies that involves in R\&D activity as the population of interest.

\subsubsection{Sampling Frame}

This study attempts to select a sample that is representative of the relevant population. This research utilizes ReferenceUSA and LexisNexis database as a university accessible database to obtain the list of manufacturing and engineering 
service firms in the U.S. One can search a firm with a wealth of individual criteria such as company name, SIC or NAICS description, geography, category, size, revenue, annual sales volume, total assets, gross profit, earnings per share (EPS), job titles, name, gender, website, email, phone number, fax number, and etc.

The focus of this research is on SIC codes from 20 to 39, and 8711, which mainly describe manufacturing and engineering service industries. Based on this database, industry code, job titles, and geography are the criteria to select companies. If a firm has multiple people to be targeted, a single contact is retained. Finally, single contact information per a firm was used for this survey. The List in manufacturing directory has email contact information of 6,563 companies. At the validation stage, 437 emails were identified as no longer active, available or invalid emails.

Consequently, 6,000 out of 6,126 firms were randomly selected to be reached from this database for the survey.

\subsubsection{Sample Size}

A number of simulation studies have been conducted to investigate the effects on SEM fit indexes of sample size. In addition, there are many issues to take into account with respect to minimum sample sizes. Minimum sample size is recommended based on having sufficient sample size to reduce the likelihood of convergence issues and to obtain unbiased estimates or standard errors. Based on simulation studies, which indicate an unacceptable number of models failed to converge when the sample size was 50, Anderson and Gerbing suggested 100 minimum sample sizes [498]. For analyses with fewer than 100 or so cases, some researchers would suggest using $t$ critical values instead of $\mathrm{z}$ critical values for parameter significance tests. After 
reviewing previous studies regarding sample size and goodness-of-fit issue in SEM, Tanaka proposed a maximum entropy measurement error (ME2) estimation as an alternative solution to the small sample size [499]. Ad hoc rules of thumb given for statistical models would be 10:1 subjects-to-parameters ratio for arbitrary distribution [500]. The optimal ratio of subject to free parameters is unclear, however. Although the 10:1 ratio is often considered safe, simulation work by Nevitt and Hancock propose that there are some conditions when this is not sufficient [501]. Jackson identified the improvement of GFI, $\chi 2$ goodness-of-fit index bias, and the RMSEA, when sample size reaches 200 to 400 [502]. Yu pointed out that overcorrection of standard errors can occur if sample sizes are smaller than 250 under moderate non-normality [503] . Another approach to dealing with nonnormality in SEM is bootstrap resampling, which requires over 200 bootstrap samples in the simulation [504]. However, performance may depend on the complexity of the model. Savalei and Bentler recommend the direct maximum likelihood (ML) method with appropriate corrections as a reliable approach to handling incomplete nonnormal data [504].

In summary, presented in table 34 are recommendations commonly noted in the literature with respect to the minimum sample size. These recommendations, however, should not be taken as definitive, infallible, or exact, because simulation studies can only examine a few conditions at a time and often involve simplified conditions compared with actual practice. Therefore, there has been increased demand for methods that perform optimally at smaller sample sizes and under varied distributional conditions [501]. 
Table 34 Minimum sample size recommendations

\begin{tabular}{|c|c|c|c|}
\hline Estimator & $\begin{array}{l}\text { Recommended } \\
\text { Minimum N }\end{array}$ & References & Notes \\
\hline \multirow{4}{*}{$\begin{array}{l}\text { Maximum Likelihood } \\
\text { (ML) with multivariate } \\
\text { normal data }\end{array}$} & $>100$ & [498] & \multirow{4}{*}{$\begin{array}{l}\text { These recommended } \\
\text { sample sizes are based } \\
\text { on ML estimation with } \\
\text { multivariate normal } \\
\text { data, which may be } \\
\text { somewhat rare in } \\
\text { practice, and correctly } \\
\text { specified models }\end{array}$} \\
\hline & $200-400$ & {$[502]$} & \\
\hline & $\begin{array}{l}5: 1 \text { ratio of cases } \\
\text { to free parameters }\end{array}$ & [499][500] & \\
\hline & $\begin{array}{l}10: 1 \text { ratio of cases } \\
\text { to free parameters }\end{array}$ & [500] & \\
\hline $\begin{array}{l}\text { MLM (ML with robust } \\
\text { standard errors and } \\
\text { scaled chi-square), for } \\
\text { nonnormal continuous } \\
\text { variables }\end{array}$ & $>250$ & {$[505][503]$} & $\begin{array}{l}\text { When data are } \\
\text { multivariate normal, } \\
\text { standard ML and } \\
\text { MLM will have the } \\
\text { same estimates }\end{array}$ \\
\hline $\begin{array}{l}\text { Bootstrap, for } \\
\text { nonnormal continuous } \\
\text { variables }\end{array}$ & $200-1000$ & [504] & $\begin{array}{l}\text { They note that a sample } \\
\text { size of } 100 \text { could be } \\
\text { sufficient for simple } \\
\text { models }\end{array}$ \\
\hline $\begin{array}{l}\text { MLR (robust ML), for } \\
\text { continuous nonnormal } \\
\text { missing data }\end{array}$ & $>400$ & [506] & $\begin{array}{l}\text { This recommended } \\
\text { sample sizes is based } \\
\text { on percentage of } \\
\text { missing data. (e.g. } 30 \% \\
\text { missing) }\end{array}$ \\
\hline $\begin{array}{l}\text { Robust DWLS with } \\
\text { polychoric correlations, } \\
\text { with binary ordinal } \\
\text { variables (WLSMV in } \\
\text { Mplus and lavaan) }\end{array}$ & $200-500$ & {$[507]$} & $\begin{array}{l}500 \text { or more samples } \\
\text { may be need for } \\
\text { sufficient power to } \\
\text { reject models. Less } \\
\text { than } 200 \text { seem to be }\end{array}$ \\
\hline
\end{tabular}




\begin{tabular}{|l|l|l|}
\hline & & $\begin{array}{l}\text { associated with serious } \\
\text { standard error bias }\end{array}$ \\
\hline
\end{tabular}

Source: adapted and modified from [466]

Based on various scenarios of response rate as well as recommendations in the literature, the minimum effective sample sizes for this research are simulated as follows. The initial model of this research consists of eight factors and 12 indicators. Sample size conditions reflect subject-to-estimated parameter ratios and recommended minimum sample size. (See table 35)

Table 35 Scenarios of properly specified sample sizes

\begin{tabular}{|c|c|c|c|c|c|c|c|}
\hline \multirow{2}{*}{$\begin{array}{c}\text { Scenarios of } \\
\text { expected } \\
\text { response rate }(\%)\end{array}$} & \multirow{2}{*}{$\begin{array}{l}\text { Model } \\
\text { estimator }\end{array}$} & \multirow{2}{*}{$\begin{array}{l}\text { Number } \\
\text { of factors }\end{array}$} & \multirow{2}{*}{$\begin{array}{l}\text { Number } \\
\text { of } \\
\text { indicators }\end{array}$} & \multicolumn{3}{|c|}{$\begin{array}{l}\text { Minimum sample size } \\
\text { conditions }\end{array}$} & \multirow{2}{*}{$\begin{array}{l}\text { Targeted } \\
\text { sampling } \\
\text { space }(\mathrm{N})\end{array}$} \\
\hline & & & & $5: 1$ & $10: 1$ & $>200$ & \\
\hline $5 \%$ & \multirow{6}{*}{$\begin{array}{l}\text { ML with } \\
\text { multivariate } \\
\text { normal data }\end{array}$} & 8 & 11 & 130 & 260 & 200 & 4,000 \\
\hline $6 \%$ & & 8 & 11 & 130 & 260 & 200 & 3,333 \\
\hline $7 \%$ & & 8 & 11 & 130 & 260 & 200 & 2,857 \\
\hline $8 \%$ & & 8 & 11 & 130 & 260 & 200 & 2,500 \\
\hline $9 \%$ & & 8 & 11 & 130 & 260 & 200 & 2,222 \\
\hline $10 \%$ & & 8 & 11 & 130 & 260 & 200 & 2,000 \\
\hline
\end{tabular}

Sufficient power to reject a model based on the chi-square test of the model is another significant subject. Hu and Bentler examined how alternative fit indices perform with different sample sizes [505]. The assessment of model fit in SEM depends on the probability level of the chi-square value, which examine the discrepancy between the original sample covariance matrix and the reproduced covariance matrix based on the model specifications [508]. When sample size is large, the assessment of model fit would be stringent. The statistical test, however, is lenient, when sample size is small. 
Normally, sample size has an increasing effect on chi-square values. Models with more variables tend to have larger chi-squares. Absolute fit indices (e.g., chi-square, RMSEA) appear to be more sensitive to misspecification than relative fit indices (e.g., CFI).

To supplement the chi-square estimate, a variety of fit indexes have been developed to assess different criteria under different theoretical rationales. (See Table 36) Tanaka divided fit index into six dimensions to justify the use of fix indices [509]. Although there are many contradictory claims over the ideal use of diverse fit indexes, the following fit indices are normally considered: Comparative Fit Index (CFI), Bollen's Incremental Fit Index (IFI), Tucker-Lewis Index (TLI) and the Root Mean Square Error of Approximation (RMSEA). Bentler introduced the comparative fit index (CFI) based on the noncentrality parameters [510]. Bollen developed new incremental fit index (IFI), which adjusts the normed fit index for sample size and for the degrees of freedom of the maintained model [511]. Both IFI and TLI fall into relative fit indices, which compare a chi-square for the model tested to one from a so-called null model. TLI and IFI are relatively unaffected by sample size [512][513].

$$
T L I=\frac{\left(d_{0} / d f_{0}\right)-\left(d_{\text {model }} / d f_{\text {model }}\right)}{d_{0} / d f_{0}}
$$

Where $d_{\text {model }}$ and $d f_{\text {model }}$ are the noncentrality parameter and the degrees of freedom for the model tested and $d_{0}$ and $d f_{0}$ are the noncentrality parameter for the null model. In addition, RMSEA proposed by Steiger and Lind[514], a noncentrality-based index, is based on a test that the null hypothesis is true $\left(\chi^{2}=0\right)$. RMSEA represents that how well the model, with unknown but optimally chosen parameter estimates, would fit the population covariance matrix [515]. RMSEA is less preferable when sample size is 
small, because it has a tendency to overreject true-population models at small sample size [505]. Most of these fit indices are computed by using ratios of the model chisquare and the null model chi-square taking into account their degrees of freedom. An earlier convention used above .90 as a cutoff for good fitting models. Hu and Bentler, however, suggest that there seems to be some consensus now that this value should be increased to approximately .95 [505]. Hu and Bentler in their study empirically examine various cutoffs for many of these measures, and their data suggest that researchers should use a combination of one of the relative fit indexes and the SRMR, in order to minimize Type I and Type II errors under various conditions [505].

Missing data as same as given dataset is a pervasive problem in the social sciences. Unfortunately, dropping incomplete cases results in sacrificing information from the sample and can lead to biased estimates when the data is not missing completely at random. In recent years, probably the most pragmatic missing data estimation approach for structural equation modeling is full information maximum likelihood (FIML), which has been shown to produce unbiased parameter estimates and standard errors under MAR and MCAR. Just "ML," is currently available in all major SEM packages. In this analysis, this study also used FIML to deal with missing value as well. 
Table 36 Cutoff criteria for several fit indexes

\begin{tabular}{|c|c|c|c|}
\hline Index & Shorthand & General rule for fit (continuous data) & $\begin{array}{c}\text { Categorical } \\
\text { data }\end{array}$ \\
\hline \multicolumn{4}{|l|}{ Absolute/predictive fit } \\
\hline Chi-square & $\chi^{2}$ & $\begin{array}{l}\text { Ratio of } \chi^{2} \text { to } \mathrm{df} \leq 2 \text { or } 3, \text { useful for nested } \\
\text { models } / \text { model trimming }\end{array}$ & \\
\hline $\begin{array}{l}\text { Akaike information } \\
\text { criterion }\end{array}$ & AIC & $\begin{array}{l}\text { Smaller the better; good for model } \\
\text { comparison (nonnested), not a single model }\end{array}$ & \\
\hline $\begin{array}{l}\text { Browne-Cudeck } \\
\text { criterion }\end{array}$ & $\mathrm{BCC}$ & $\begin{array}{l}\text { Smaller the better; good for model } \\
\text { comparison, not a single model }\end{array}$ & \\
\hline $\begin{array}{l}\text { Bayes information } \\
\text { criterion }\end{array}$ & $\mathrm{BIC}$ & $\begin{array}{l}\text { Smaller the better; good for model } \\
\text { comparison (nonnested), not a single model }\end{array}$ & \\
\hline Consistent AIC & CAIC & $\begin{array}{l}\text { Smaller the better; good for model } \\
\text { comparison (nonnested), not a single model }\end{array}$ & \\
\hline $\begin{array}{l}\text { Expected cross- } \\
\text { validation index }\end{array}$ & ECVI & $\begin{array}{l}\text { Smaller the better; good for model } \\
\text { comparison (nonnested), not a single model }\end{array}$ & \\
\hline \multicolumn{4}{|l|}{ Comparative fit } \\
\hline Normed fit index & NFI & $\geq .95$ for acceptance & \\
\hline Incremental fit index & IFI & $\geq .95$ for acceptance & \\
\hline Tucker-Lewis index & TLI & $\geq .95$ can be $0>$ TLI $>1$ for acceptance & 0.96 \\
\hline Comparative fit index & CFI & $\geq .95$ for acceptance & 0.95 \\
\hline $\begin{array}{l}\text { Relative noncentrality } \\
\text { fit index }\end{array}$ & RNI & $\begin{array}{l}\geq .95 \text {, similar to CFI but can be negative, } \\
\text { therefore CFI better choice }\end{array}$ & \\
\hline \multicolumn{4}{|l|}{ Parsimonious fit } \\
\hline $\begin{array}{l}\text { Parsimony-adjusted } \\
\text { NFI }\end{array}$ & PNFI & Very sensitive to model size & \\
\hline $\begin{array}{l}\text { Parsimony-adjusted } \\
\text { CFI }\end{array}$ & PCFI & Sensitive to model size & \\
\hline $\begin{array}{l}\text { Parsimony-adjusted } \\
\text { GFI }\end{array}$ & PGFI & $\begin{array}{l}\text { Closer to } 1 \text { the better, though typically } \\
\text { lower than other indexes and } \\
\text { sensitive to model size }\end{array}$ & \\
\hline \multicolumn{4}{|l|}{ Other } \\
\hline Goodness-of-fit index & GFI & $\geq .95$ Not generally recommended & \\
\hline Adjusted GFI & AGFI & $\begin{array}{l}\geq .95 \text { Performance poor in simulation } \\
\text { studies }\end{array}$ & \\
\hline Hoelter .05 index & & $\begin{array}{l}\text { Critical } \mathrm{N} \text { largest sample size for accepting } \\
\text { that model is correct }\end{array}$ & \\
\hline Hoelter .01 index & & $\begin{array}{l}\text { Hoelter suggestion, } \mathrm{N}=200 \text {, better for } \\
\text { satisfactory fit }\end{array}$ & \\
\hline $\begin{array}{l}\text { Root mean square } \\
\text { residual }\end{array}$ & RMR & Smaller, the better; 0 indicates perfect fit & \\
\hline Standardized RMR & SRMR & $\leq .08$ & \\
\hline $\begin{array}{l}\text { Weighted root mean } \\
\text { residual }\end{array}$ & WRMR & $<.90$ & $<.90$ \\
\hline $\begin{array}{l}\text { Root mean square } \\
\text { error of } \\
\text { approximation }\end{array}$ & RMSEA & $<.06$ to .08 with confidence interval & $<.06$ \\
\hline
\end{tabular}

Source: [516] 


\subsubsection{Sampling Method}

Sampling methods can be divided as either probability or nonprobability [517]. In probability samples, each population element has a known non-zero chance of being selected for the sample. Probability methods include random sampling, systematic sampling, stratified sampling and cluster sampling [480]. The advantage of probability sampling is that sampling error can be identified. Sampling error is the extent to which a sample might differ from the population [472]. Sampling error depends on sample size. In nonprobability sampling, the extent to which the sample differs from the population remains unknown.

For this research, simple random sampling tool is used to determine the targeted samples. Simple random sampling is that members of the subset are chosen completely at random so that every member of the population has an equal probability of being selected. Systematic sampling is a versatile form of random sampling [480]. After the required sample size has been computed, every Nth element is chosen from the population. If the list does not include any hidden order, this sampling method is as good as the random sampling. The advantage of systematic sampling over the random sampling is flexibility and simplicity [480]. Stratified Sample is that the population is divided up into relatively homogeneous groups [518]. A stratum is a subset of the population that shares at least one common characteristic. A proportionate sample is drawn from the groups. Cluster sampling is employed when natural but homogeneous groupings are evident in a population. So, the total population is divided into clusters and random sample is drawn from each natural grouping. 


\subsubsection{Sampling Administration}

After the survey design had been finalized, the survey invitation emails were sent out to randomly chosen 6,000 firms with four follow-ups, following 14 parts of Dillman's guidelines as presented in Figure 11. The initial round of survey invitations were sent during the first week of June 2017. Typically, follow-ups after sending a selfadministered questionnaire increase response rates [480]. In this research, four followups were conducted to improve response rates. All subsequent follow-up emails were sent out to only non-respondents, so that respondents do not receive additional requests to take the survey, emphasizing the significance of their response as well as highlighting some incentives to improve response rate [519][480]. All follow-up emails also stressed that the survey would take a short amount of time (10-min) to complete.

Contact timing is important. However, the optimal timing sequence for webbased surveys varies based on the objectives and targeted population [472]. In this research, follow-up contacts were sent in about two weeks' interval for giving adequate time to respond since most management group tends to be out of office for business trips. In this study, the initial survey invitations and four follow-ups were sent out to respondents. Consistent with prior research [472], second follow-up yielded significant gains in this study. Figure 16 illustrates survey responses over time, which takes three months to collect enough responses for the SEM analysis in this research. At the conclusion of data collection, 87 non-engaged responses had been identified and removed, finally 253 responses were usable. 


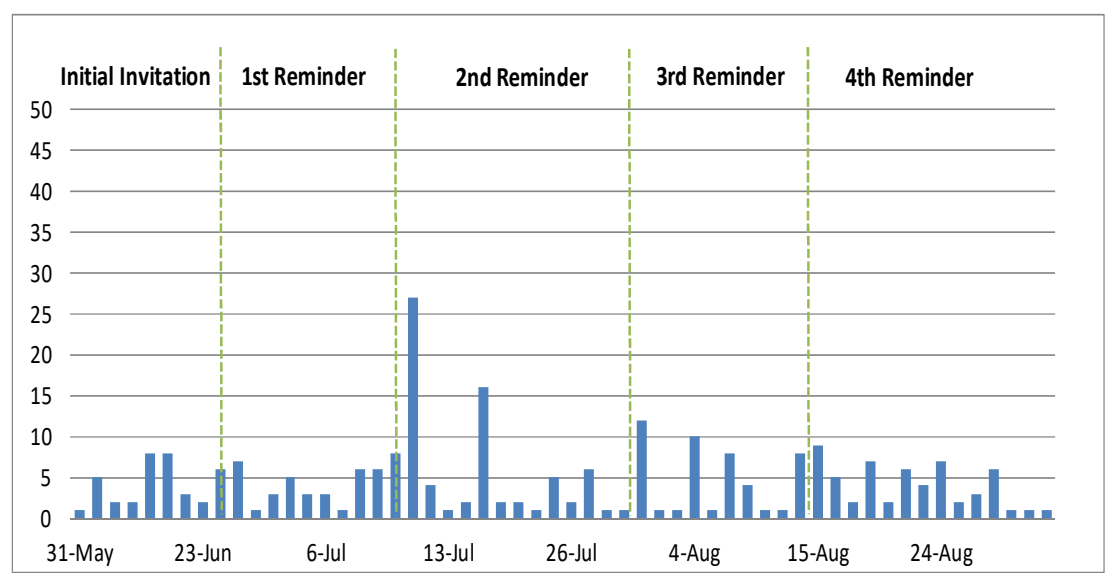

Figure 16 Survey responses over time

\subsubsection{Response Rate (RR)}

Due to increase of mistrust, a sense of being "over-surveyed," and the proliferation of "sugging," the response rate of the survey has been declined [520][480]. The response rate varies widely depending on the goals and needs of the study, survey mode, targeted population, and sampling frame. Reported response rates to mail surveys differ considerably ranging from $2.5 \%$ to $97.7 \%$ [521]. Kaplowitz et al. indicated that the response rate to the mail is typically larger than the web-only [481].

As illustrated in Figure 11 in this chapter, following Dillman's design technique, some measures were taken to increase response rate as follows:

- Trust: Portland State sponsorship in the email headline and survey instrument design, emphasizing their significant contribution to the body of literature, personalizing the emails with first and last name, and responding quickly to all participants' inquiries.

- Rewards: offering the summary of the results at the introduction page, and monetary incentives.

- Ensure anonymity and confidentiality. 
- Four follow-ups to increase response rate.

The response rate for this survey is as follows:

Initial invitation: $\quad \mathrm{RR}=\frac{37}{6,000}=0.62 \%$

First reminder: $\quad \mathrm{RR}=\frac{35}{5,963}=0.59 \%$

Second reminder: $\quad R R=\frac{77}{5,928}=1.3 \%$

Third reminder: $\quad \mathrm{RR}=\frac{40}{5,851}=0.68 \%$

Fourth reminder: $\quad \mathrm{RR}=\frac{64}{5,451}=1.17 \%$

Total: $\quad$ RR $=\frac{253}{6000}=4.22 \%$

In this research, consistent with the expectation of prior research [472], the response rate $(4.22 \%)$ of web-only survey seemed to be low. As presented in Table 37, a typical response rate of Ph.D. dissertations ranges about $2 \sim 13 \%$. However, low response rate simply do not necessarily indicate bias or problem [522][472]. On the other hand, higher response rates do not necessarily mean that nonresponse error is reduced [523]. Respondent characteristics are representative of non-respondents. In SEM research, several studies have suggested various minimum sample sizes, ranging from roughly 50 [524] to 250 [505][503] based on estimators as described in Table 34. Prior research indicated that 200 or more responses would be satisfactory for complex models [525]. Consequently, the sample size in this research is within the expected and acceptable range. 
Table 37 Prior Ph.D. dissertations and response rate

\begin{tabular}{|l|l|c|c|}
\hline \multicolumn{1}{|c|}{ Title } & \multicolumn{1}{|c|}{ Sample size } & Responses & RR (\%) \\
\hline $\begin{array}{l}\text { Technology evaluation and acquisition } \\
\text { strategies and their implications } \\
\text { in the U.S. electronics manufacturing } \\
\text { industry [526] }\end{array}$ & $\begin{array}{l}\text { 1,987 U.S.-based } \\
\text { electronics } \\
\text { manufacturing } \\
\text { firms }\end{array}$ & 226 & 11.4 \\
\hline $\begin{array}{l}\text { Supply chain integration practices in the } \\
\text { U.S. electronics industry [527] }\end{array}$ & $\begin{array}{l}1,917 \text { US Electronics } \\
\text { firms in the U.S. }\end{array}$ & 227 & 1.65 \\
\hline $\begin{array}{l}\text { Supply chain orientation: Refining a } \\
\text { nascent construct [528] }\end{array}$ & $\begin{array}{l}13,705 \text { Manufacturing } \\
\text { firms in Canada }\end{array}$ & 59.16 \\
\hline $\begin{array}{l}\text { Examining health information technology } \\
\text { implementations: Case of the patient- } \\
\text { centered medical home [529] }\end{array}$ & 1,820 clinics in the U.S. \\
\hline $\begin{array}{l}\text { Exploring capability maturity models and } \\
\text { relevant practices as solutions addressing } \\
\text { IT service offshoring project issues [530] }\end{array}$ & $\begin{array}{l}\text { 9,030 IT and Software } \\
\text { developing firms in the } \\
\text { U.S. }\end{array}$ & 551 & 6.1 \\
\hline $\begin{array}{l}\text { Exploratory study of the adoption and use } \\
\text { of the Smartphone technology in } \\
\text { emerging regions: Case of Saudi Arabia } \\
\text { [531] }\end{array}$ & $\begin{array}{l}5,000 \text { Smartphone users } \\
\text { in Saudi Arabia }\end{array}$ & 657 & 13.14 \\
\hline
\end{tabular}

\subsubsection{Respondent Profile}

The completed surveys demonstrated that typical respondents could be described as senior managers of engineering who had experienced in new product development, strategic planning, technology planning, and forecasting activities before. As presented in Figure 17, a total of $121(47.8 \%)$ respondents identified themselves as a director in their firms. The respondents' average of experience in industry was 27 years (S.D. $=8.7 \mathrm{yrs})$.

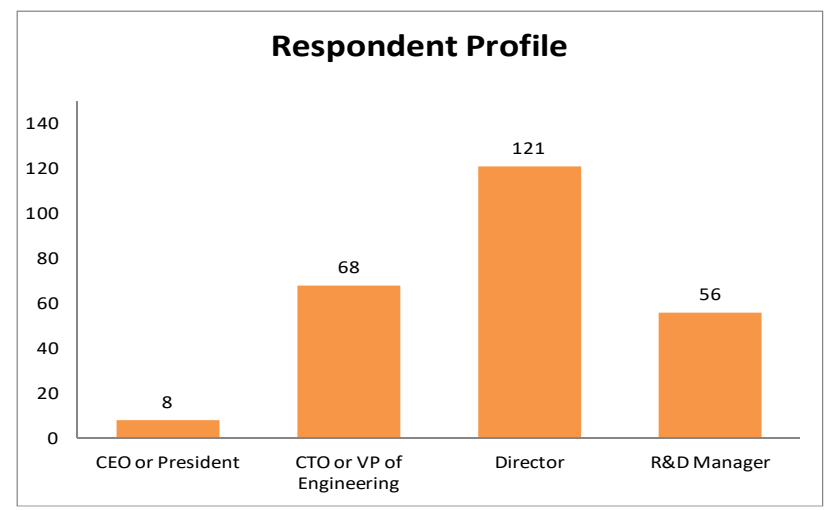


Figure 17 Respondent's position

They could have applied one or more TF techniques when involving in their R\&D projects. The firms they represent could be described as all sizes of U.S.-based manufacturing companies that engage in R\&D. A total of $128(50.6 \%)$ were identified as large firms based on small business size standards matched to North American Industry Classification System (NAICS) codes by U. S. Small Business Administration (SBA) [532]. As shown in Figure 18, SIC 36 electronics (52, 20.6\%), SIC 35 computer equipment $(50,19.8 \%)$, and SIC 38 analyzing instruments $(38,15 \%)$ are the top three most frequent responses by sector in this survey.

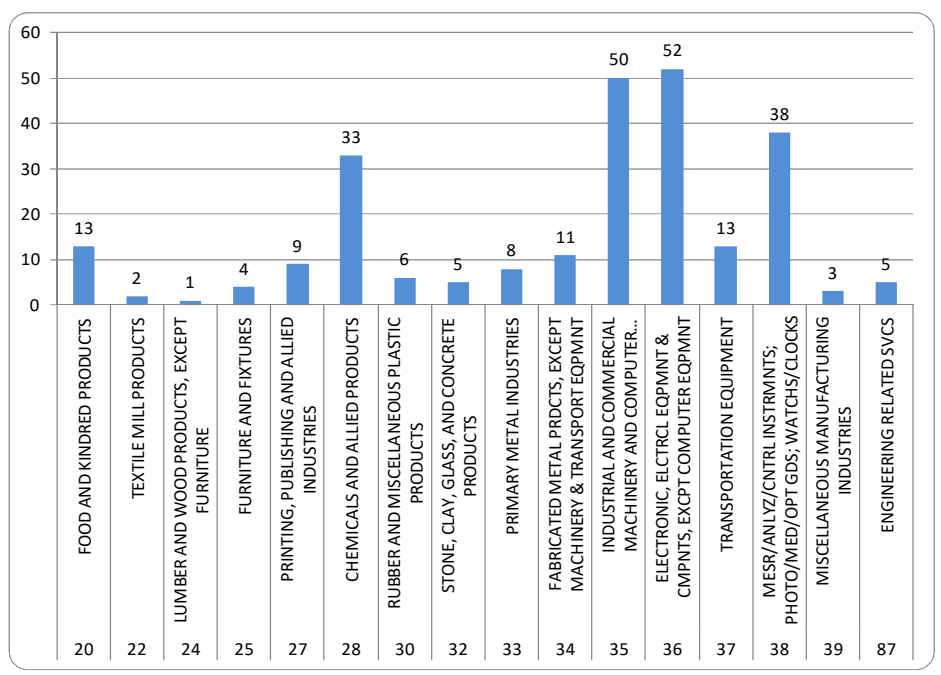

Figure 18 Respondents by industry

\subsubsection{Nonresponse Error; Wave Analysis}

Extrapolation approach of time trends was used to test non-response error $[533][523][522]$. It assumes that non-respondents would be similar to the individuals who responded later in the administration period. Analysis of variance (ANOVA) was performed to examine the possibility of absence of response bias. The results revealed 
that there were no significant differences between respondents among the four followups, compared based on variables - firm size, TF activities, technology planning, return on assets (ROA), earnings growth, sales growth, and other variables measured in this survey. Thus, the results indicated that there was no evidence of non-response bias.

Table 38 The results of wave analysis

\begin{tabular}{|c|c|c|c|c|c|c|}
\hline \multicolumn{2}{|c|}{ Variables } & Sum of Squares & $\mathrm{df}$ & Mean Square & $F$ & $p$ \\
\hline \multirow{3}{*}{$\begin{array}{l}\text { Technology forecasting } \\
\text { (three to five years) }\end{array}$} & Between Groups & 1.349 & 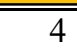 & 0.337 & \multirow[t]{3}{*}{0.282} & \multirow[t]{3}{*}{0.890} \\
\hline & Within Groups & 272.900 & 228 & 1.197 & & \\
\hline & Total & 274.249 & 232 & & & \\
\hline \multirow{3}{*}{$\begin{array}{l}\text { Technology forecasting } \\
\text { (over five years) }\end{array}$} & Between Groups & 5.390 & 4 & 1.348 & \multirow[t]{3}{*}{0.991} & \multirow[t]{3}{*}{0.413} \\
\hline & Within Groups & 310.001 & 228 & 1.360 & & \\
\hline & Total & 315.391 & 232 & & & \\
\hline \multirow{3}{*}{ Technology planning } & Between Groups & 1.697 & 4 & 0.424 & \multirow[t]{3}{*}{0.426} & \multirow[t]{3}{*}{0.790} \\
\hline & Within Groups & 229.324 & 230 & 0.997 & & \\
\hline & Total & 231.021 & 234 & & & \\
\hline \multirow{3}{*}{$\begin{array}{l}\text { Multiple use of TF } \\
\text { methods }\end{array}$} & Between Groups & .361 & 4 & 0.090 & \multirow[t]{3}{*}{0.156} & \multirow[t]{3}{*}{0.960} \\
\hline & Within Groups & 108.975 & 188 & .580 & & \\
\hline & Total & 109.337 & 192 & & & \\
\hline \multirow{3}{*}{$\begin{array}{l}\text { Satisfaction with the } \\
\text { results of TF }\end{array}$} & Between Groups & 12.300 & 4 & 3.075 & \multirow[t]{3}{*}{1.343} & \multirow[t]{3}{*}{0.256} \\
\hline & Within Groups & 435.187 & 190 & 2.290 & & \\
\hline & Total & 447.487 & 194 & & & \\
\hline \multirow{3}{*}{$\begin{array}{l}\text { The usefulness of TF on } \\
\text { technology planning }\end{array}$} & Between Groups & 3.643 & 4 & 0.911 & \multirow[t]{3}{*}{0.439} & \multirow[t]{3}{*}{0.780} \\
\hline & Within Groups & 390.109 & 188 & 2.075 & & \\
\hline & Total & 393.751 & 192 & & & \\
\hline \multirow{3}{*}{$\begin{array}{l}\text { R\&D Fundamental or } \\
\text { basic research }\end{array}$} & Between Groups & 26.843 & 4 & 6.711 & \multirow[t]{3}{*}{1.875} & \multirow[t]{3}{*}{0.117} \\
\hline & Within Groups & 654.875 & 183 & 3.579 & & \\
\hline & Total & 681.718 & 187 & & & \\
\hline \multirow{3}{*}{ R\&D Applied research } & Between Groups & 38.080 & 4 & 9.520 & \multirow[t]{3}{*}{1.859} & \multirow[t]{3}{*}{0.120} \\
\hline & Within Groups & 932.016 & 182 & 5.121 & & \\
\hline & Total & 970.096 & 186 & & & \\
\hline \multirow{3}{*}{ R\&D Development } & Between Groups & 35.931 & 4 & 8.983 & \multirow[t]{3}{*}{1.248} & 0.292 \\
\hline & Within Groups & 1324.735 & 184 & 7.200 & & \\
\hline & Total & 1360.667 & 188 & & & \\
\hline & Between Groups & 14.017 & 4 & 3.504 & 1.990 & 0.098 \\
\hline Sales growth & Within Groups & 318.720 & 181 & 1.761 & & \\
\hline & Total & 332.737 & 185 & & & \\
\hline & Between Groups & 12.104 & 4 & 3.026 & 2.072 & 0.087 \\
\hline Return on assets (ROA) & Within Groups & 249.691 & 171 & 1.460 & & \\
\hline & Total & 261.795 & 175 & & & \\
\hline & Between Groups & 6.844 & 4 & 1.711 & 1.074 & 0.371 \\
\hline Earnings growth & Within Groups & 283.462 & 178 & 1.592 & & \\
\hline & Total & 290.306 & 182 & & & \\
\hline
\end{tabular}




\subsubsection{Nonresponse Error; Item Nonresponse}

In Qualtrics system, 87 non-engaged respondents who did not answer any questions were identified and removed. The survey questions were designed for participants to skip or move to the next question before they select an answer to each question. Thus, there were some of incomplete or missing data in the surveys that were employed in the analysis for this study. Missing measurement items were presented in Table 39.

Table 39 Missing measurement items by each survey question

\begin{tabular}{|c|c|c|c|c|}
\hline Question & Validation Type & \# of Records & Missing & \% of Total \\
\hline Basic info. & Validated optional & 253 & 0 & 0 \\
\hline Q1 & optional & 235 & 18 & 7.1 \\
\hline Q2 & optional & 219 & 34 & 13.4 \\
\hline Q3 & optional & 211 & 42 & 16.6 \\
\hline Q4 & optional & 200 & 53 & 20.9 \\
\hline Q5 & optional & 197 & 56 & 22.1 \\
\hline Q6 & optional & 188 & 65 & 25.7 \\
\hline Q7 & optional & 201 & 52 & 20.6 \\
\hline Q8 & optional & 184 & 69 & 27.3 \\
\hline Q9 & optional & 193 & 60 & 23.7 \\
\hline Q10 & optional & 195 & 58 & 22.9 \\
\hline Q11 & optional & 193 & 60 & 23.7 \\
\hline Q12 & optional & 194 & 59 & 23.3 \\
\hline Q13 & optional & 189 & 64 & 25.3 \\
\hline Q14 & optional & 186 & 67 & 26.5 \\
\hline
\end{tabular}

\subsubsection{Post-survey Adjustments and Missing Data}

After data have been collected, post-survey adjustments can be conducted to address survey nonresponse. However, the extensive efforts such as additional call or interview attempts and refusal conversion protocols have been realistically ineffective and costly [534]. In this regard, several weighting techniques [535][536] can be one of the post-survey adjustment methods. However, unfortunately, it is difficult to identify available variables that are highly correlated with both participation propensity and with 
the survey outcome variable of interest for nonresponse adjustment [537]. Typically, geographic and demographic variables can be used in post-survey adjustments, but those variables cannot be applied to this research.

On the other hand, nonresponse items are typically regarded as either missing at random (MAR) or being systematic. According to prior research [538], the missing data mechanism in this sample can be considered as MAR, so other adjustment methods are not needed to reduce nonresponse bias. Thus, there are several techniques to deal with missing data relevant to the hypotheses. Listwise deletion has been the most common way of dealing with missing data in structural equation model. In recent years, however, researchers have begun to employ data estimation tools - maximum likelihood (ML)/full information maximum likelihood (FIML), expectation maximization algorithm (EM), and Bayesian multiple imputation (MI) — for dealing with missing data in SEM [539]. Consequently, this research used FIML to deal with missing data issue.

\subsubsection{Reliability}

This study employs Chronbach's alpha to examine for internal consistency and reliability of the scale items in the hypothesized model. Cronbach alpha coefficient was computed for each variable as presented in Table 40. A Chronbach's alpha coefficient of greater than 0.7 indicated that the factors have an acceptable level of internal consistency and reliability of the survey-based constructs.

Table 40 Reliability test results

\begin{tabular}{|c|c|c|c|}
\hline Factor & Number of items & Chronbach's Alpha & Specifications \\
\hline Appropriate use of TF & 2 & .982 & Reflective \\
\hline The use of TF & 2 & .826 & Reflective \\
\hline Business performance & 3 & .807 & Reflective \\
\hline
\end{tabular}




\section{Chapter 9 Analysis}

\subsection{Construction of Measures}

Measures of the use of TF techniques, the effectiveness of TF activities, TF activities, technology planning, R\&D performance, and business performance were used in this research. Multi-item indicators used in the survey were developed and adopted through a review of prior research. Existing measurement scales were identified from the literature. This study adjusted these measurement scales to fit the variables.

\section{Technology forecasting}

TF consists of subset elements such as a certain future time span, technological change, continuous range of characteristics in applications, and a statement of the probability associated with the technology [32]. It is important to note that determining appropriate TF methods is critical for a given situation in order to forecast proper technological changes, since the methods employed inevitably affect TF results [23][49]. Furthermore, several studies indicated that the type of R\&D such as basic research, exploratory research, applied research, development, and product improvement influences measurement techniques and the metrics [288][341][421]. The choice of TF methods might depend on the type of R\&D such as basic research, applied research, and commercialization [26]. Furthermore, the selection of proper TF tools depends on the nature of the technologies [26]. The relevance and availability of data and the appropriate selection of TF techniques are basic elements to improve the effectiveness of the forecast in strategic technology planning [49][415]. 
To measure the use of TF, two items were developed. For the appropriate use of sophisticated TF practices, 28 items were measured and standardized before conducting the analysis.

Variable 1: the use of TF. This variable represents the firm's commitment to TF. It also showed a firm's aggressive use of TF in developing new products/processes/technologies. Two items were created to measure short-term and long-term TF activities in a firm. This variable captures the breadth of the firm's use of $\mathrm{TF}$ associated with technology characteristics. The respondents were asked to indicate on five-point Likert-type scales the extent to which each measure characterizes a firm's TF activities. A high score on this variable indicates a strong commitment to TF. This scale has a mean of 3.19 and a standard deviation of $0.19(\alpha=0.82)$.

Variable 2: the appropriate use of TF. This variable captured the breadth of the firm's use of TF associated with technology characteristics - continuous and discontinuous technology. It also indicated its strong commitment to TF. A high score on this indicated that the firm properly uses TF methods based on technology characteristics and showed intensive commitment to TF.

\section{Technology characteristics}

Several studies indicated that the type of R\&D—basic research, exploratory research, applied research, development, and product improvement—influences measurement techniques and the metrics [296][349][429]. Hauser [540] divided innovation activity into three stages — basic research, development, and applied engineering, while Leifer and Triscari [541] into research and development. Werner and Souder [542] classified R\&D into four types: basic research, applied research, product 
development, and manufacturing process R\&D. Organization for Economic Cooperation and Development (OECD) organized R\&D into three types of activity—basic research, applied research, and experimental development [543]. Although there seems lack of clear-cut classification, they all characterize the focal points of unstructured R\&D activities. Following the lead of OECD, this research divides technology into three categories: basic research, applied research, and development. Table 41 presents the characteristics of each R\&D.

Table 41 Technology characteristics

\begin{tabular}{|l|l|}
\hline Technology characteristics & \multicolumn{1}{c|}{ Description } \\
\hline - Basic research & $\begin{array}{l}\text { Experimental or theoretical work undertaken primarily to acquire } \\
\text { knowledge related to disruptive product/process or service }\end{array}$ \\
\hline - Applied research & $\begin{array}{l}\text { Original investigation undertaken to acquire knowledge directly related } \\
\text { to next generation product/process or service }\end{array}$ \\
\hline - Development & $\begin{array}{l}\text { Systematic work or practical research for new applications/discoveries } \\
\text { related to the current product/process or service }\end{array}$ \\
\hline
\end{tabular}

\section{TF resources}

To measure internal/external TF resources, two items were developed respectively. 13 indicators of each item were measured before conducting the analysis. The respondents were asked to indicate on five-point Likert-type scales the extent to which each measure characterizes the use of internal/external resources. A high score on this variable shows the extent to which the firm devotes internal/external resources to TF activities. This scale has a mean of 2.54 , and a standard deviation of $0.16(\alpha=$ $0.91)$

\section{$R \& D$ performance}

As summarized in Table 22, there have been a variety of indexes to measure R\&D performance by patents - total number of patents filed or granted, and the total 
number of patent citations. The most common output indicator is a patent such as the number of patents granted that is used in this research.

\section{Business Performance}

In this study, the measurement of business performance is based on outcome indicators rather than outputs or impact indicators, because the data should convey the economic sense. This study found that there is no significant trend favoring a single measure of a firm's business performance. In this regard, this study identifies that sales growth, ROA, earnings, and market share are the most extensively used to measure business performance in the literature as described in Table 23. This study initially considers sales growth, ROA, earnings growth, and market share changes for the previous five-year period as indicators of a firm's business performance in order to examine the association between technology planning, R\&D and business performance. Consequently, based on the results of confirmatory factor analysis, this research used a firm's five-year average changes in sales growth, earnings growth, and ROA to measure its business performance.

\subsection{Confirmatory Factor Analysis (CFA)}

To assess the unidimensionality of the survey-based constructs, this research used confirmatory factor analysis. Moreover, to answer to the hypothesis, Pearson's correlation, CFA, and structural equation modeling (SEM) are employed to investigate not only relationship between TF activities and technology characteristics but also causal relationship among variables, and finally statistically test hypotheses proposed in Figure 3, based on the literature review. SEM is an appropriate tool to analyze path 
model with latent variables in order to uncover causal structures. The hypothesized relationships in this model have multiple intercorrelations between a set of variables, which are developed based on literature review and hypothetical assumptions. A straight, one-headed arrow represents a causal association between two variables. This model cannot be solved by ordinary least squares (OLS) regression techniques. Multiple regression can be regarded a special case of SEM [453]. By contrast, SEM approach is a multivariate tool that takes into account complete and simultaneous equation of all relationship in a given model. SEM approach allows us to easily articulate relationships of all variables with one another [454]. This research focuses on the causal inference in latent variable models. The causal relationship is the focal point of SEM analysis [453]. Path model incepted in population genetics to model inheritance by Sewall Wright in 1918 [455] and later widely applied to various situations in psychology and sociology [456]. Path models and multiple regression provide the core information needed to understand the broad class of SEM [454]. Path analysis gauges the strength of causal relations among variables in multiple systems of equations based on the correlation matrix of observed variables [457]. In the 1970s cross-disciplinary integration ended up with structural equation modeling. SEM mainly deals with the specification of causal relations among variables. Path modeling is integrated with the logic of factor analysis [454]. Based on the groundwork Karl Pearson and Charles Spearman made in the 1900s, factor analysis was developed to explore the structure of intelligence in multivariate data [462]. Factor analysis has been widely used for the analysis of correlated data [463]. Factor analysis is designed to link factors to measures that are defined in terms of weights [454]. CFA requires the specification of particular factor 
structure, whereas exploratory factor analysis (EFA) allows all items to load on all factors [466]. CFA approach attempts to examine whether or not observed data are consistent with the posited theoretical model. CFA provides a chi-square test and goodness-of-fit indicators.

CFA with full information maximum likelihood using SPSS Amos 22 was performed to establish the measurement of the constructs in the model. A major component of a CFA is to test the reliability of the observed variables [516]. Initial measure items were constructed based on the knowledge and empirical research through the literature review. In terms of business performance measure, market share was ruled out, since it resulted in an unsatisfactory model fit. Consequently, three accountingbased indicators such as ROA, earnings growth, and sales growth are loaded for measuring business performance. The chi-square value was insignificant, $\chi^{2}(11)=$ $12.167, \mathrm{p}=0.35$, indicating good fit to the data [544]. Alternative fit indices were also examined to decide whether the model fit was adequate. Alternative fit indices indicated acceptable fit, Comparative Fit Index $(\mathrm{CFI})=.998$, Bollen's Incremental Fit Index (IFI) $=.998$, Tucker-Lewis Index $(\mathrm{TLI})=.995$, Root Mean Square Error of Approximation $($ RMSEA $)=0.028$. All measure items loaded significantly on their intended constructs, demonstrating convergent validity. All results of CFA are presented in Table 42. In addition, the Cronbach's alpha coefficient over 0.70 is considered an adequate level of internal consistency estimate [545]. Cronbach's alpha of all three latent variables (The use of TF (0.83), Business performance (0.81), and Appropriate use of TF (0.98)) was the acceptable level of reliability. 
Table 42 The output of three factor loadings

\begin{tabular}{|lccc|}
\hline \multicolumn{1}{|c}{ Observed variables } & $\begin{array}{c}\text { Latent } \\
\text { construct }\end{array}$ & $\begin{array}{c}\text { Standardized } \\
\text { Loading }\end{array}$ & S.E. \\
\hline \hline & $\begin{array}{c}\text { The use of TF } \\
\text { (UTF) }\end{array}$ & & \\
- TF activity (three to five years) & & 0.74 & 0.093 \\
- TF activity (over five years) & & 0.93 & 0.098 \\
\hline \multicolumn{4}{l}{ Business } \\
& Performance & & \\
- Changes - Return on Assets (ROA) & (BP) & 0.82 & 0.108 \\
- Changes - Earnings growth & & 0.93 & 0.112 \\
- Changes - Sales growth & & 0.78 & 0.115 \\
& Appropriate & & \\
& use of TF & & \\
- Appropriate TF use for discontinuous tech & (AUTF) & 0.89 & 2.370 \\
- Appropriate TF use for continuous tech & & 0.91 & 2.298 \\
\hline
\end{tabular}

\subsection{Full Structural Equation Model}

The graphic representation illustrated in Figure 19 is the hypothesized model that was tested to see how TF activities affect technology planning, R\&D performance, and the business performance. SEM analysis was conducted to measure hypothesized associations among model constructs with full information maximum likelihood (FIML). The structural equation model (SEM) in Figure 19 presents the relationships among latent constructs and observable variables as a succession of seven structural equations. SEM technique, as implemented by SPSS AMOS 22, was used for data analyses. 


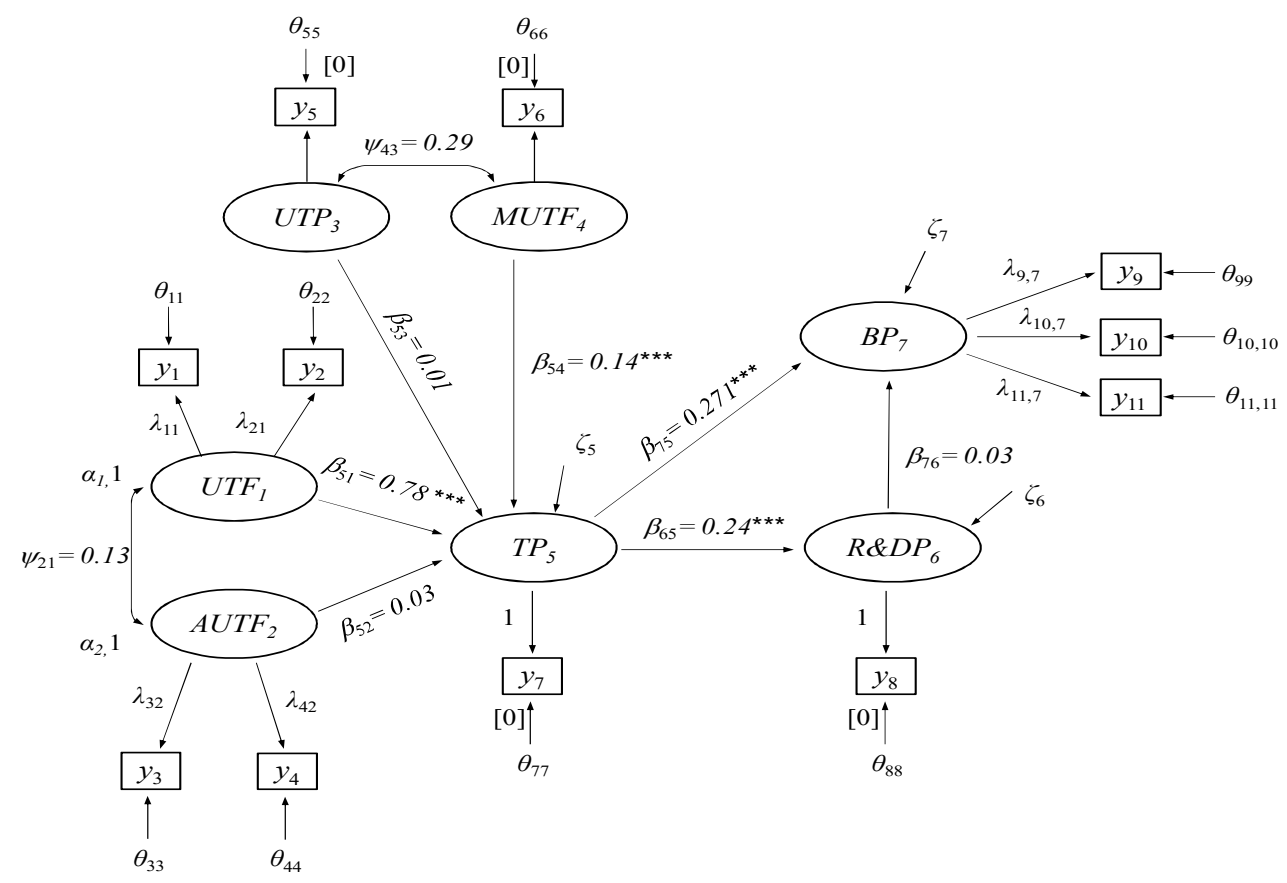

Note: The Use of TF (UTF), The Appropriate Use of TF (AUTF), The Usefulness of TF in TP (UTP), The Multiple Use of TF (MUTF), Technology Planning Activity (TP), R\&D Performance (R\&DP), Business Performance (BP)

Figure 19 Full structural equation model with the results

The following fit indices were considered: CFI, IFI, TLI and RMSEA. Most of these fit indices are computed by using ratios of the model chi-square and the null model chi-square considering their degrees of freedom. As described in detail in Table 43, this research used above .95 as a cutoff for good fitting models, as Hu \& Bentler suggest that there seems to be some consensus now that this value should be increased to approximately .95 [544]. As shown in Table 43, alternative fit indices suggested highly acceptable fit of full structural equation model. The model presented variance and covariance between factors with good fit indicators. 
Table 43 Goodness of fit indices for full structural equation model

\begin{tabular}{|l|l|l|}
\hline \multicolumn{1}{|c|}{ Index } & \multicolumn{1}{c|}{ Threshold } & Value \\
\hline CFI & $\geq .95$ for acceptance & 0.989 \\
\hline IFI & $\geq .95$ for acceptance & 0.989 \\
\hline TLI & $\geq .95$ for acceptance & 0.978 \\
\hline RMSEA & $<.06$ to .08 with confidence interval & 0.052 \\
\hline
\end{tabular}

Description

The Use of TF (UTF)

The Usefulness of TF in TP (UTP)

The Multiple Use of TF (MUTF)

R\&D Performance (R\&DP)

Business Performance (BP)
Measurement scale

1-No use

2-Not often conducted

3-Somewhat often conducted

4-Often conducted

5 -Very often conducted

1 -Very negative

2-Negative

3-Somewhat negative

4-Neutral

5-Somewhat positive

6-Positive

7-Very positive

$1-\mathrm{No}$

2-Do not know

3-Yes

Technology Planning Activity (TP) 1-No use

2-Not often conducted

3-Somewhat often conducted

4-Often conducted

5 -Very often conducted

The number of patent granted ('12-'16)

1-Less than $-30 \%$

2- -10 to $-20 \%$

3 - Larger than equal to $-10 \%$

4- 0

5 -Less than equal to $10 \%$

$6-10$ to $20 \%$

7-Over $30 \%$ 


\section{Chapter 10 Results}

\subsection{The Importance of $\mathbf{T F}$}

TF methods have been used for various purposes as discussed in chapter 1 . Thus, the respondents were asked to rate how they have used TF techniques for following objectives. As presented Table 44, the results confirm that TF plays a crucial role to identify potential areas for research or new business in many firms in strategic planning and assessing processes. Developing a new product or service, aiding in R\&D planning and identifying new opportunities and threats are the top three most frequent responses in this survey.

Table 44 The importance of TF in each activity

\begin{tabular}{|l|l|l|c|}
\hline \multicolumn{1}{|c|}{ The purpose of TF } & N & Mean & Std. Deviation \\
\hline To develop a new product or service & 219 & 4.087 & 0.8866 \\
\hline As an aid in R\&D or technology planning & 216 & 4.060 & 0.9406 \\
\hline To identify new opportunities or threats & 219 & 4.037 & 0.9426 \\
\hline As an aid in business planning and strategy & 218 & 3.890 & 0.9391 \\
\hline As an aid in evaluating projects & 217 & 3.664 & 0.8290 \\
\hline As an aid in allocating resources & 219 & 3.648 & 0.8724 \\
\hline To redesign business or manufacturing process & 219 & 3.306 & 1.0148 \\
\hline To assess technology portfolios & 217 & 3.143 & 1.1558 \\
\hline To help justify a previously made decision & 219 & 2.868 & 0.9935 \\
\hline To help in acquiring a government (sub)contract & 215 & 2.284 & 1.1635 \\
\hline
\end{tabular}

Note: the mean is the average on a scale of 1 (of no use) to 5 (extremely important)

\subsection{Planning Activities}

There are various planning activities conducted not only to establish a various type of strategic plans in companies but also to identify opportunities or risks that they face. Thus, to capture the intensity of planning activities in firms, participants were asked to answer how often they have used each planning activity in their organization. As 
shown in Table 45, most companies involve in short-term planning activities such as annual planning, short-term forecasting, and action planning.

Table 45 Responses to planning activities

\begin{tabular}{|l|c|c|c|c|c|c|c|}
\hline \multicolumn{1}{|c|}{ Planning activity } & $\begin{array}{c}\text { No } \\
\text { use }\end{array}$ & $\begin{array}{c}\text { Not } \\
\text { often }\end{array}$ & $\begin{array}{c}\text { Somewhat } \\
\text { often }\end{array}$ & Often & $\begin{array}{c}\text { Very } \\
\text { often }\end{array}$ & Mean & $\begin{array}{c}\text { Std. } \\
\text { Deviation }\end{array}$ \\
\hline Annual Planning & 4 & 9 & 17 & 62 & 139 & 4.398 & 0.9121 \\
\hline $\begin{array}{l}\text { Short-term } \\
\text { Forecasting (less } \\
\text { than one year) }\end{array}$ & 6 & 16 & 30 & 56 & 122 & 4.183 & 1.0703 \\
\hline $\begin{array}{l}\text { Action Planning or } \\
\text { Operational Planning } \\
\text { (one to three years) }\end{array}$ & 4 & 13 & 36 & 85 & 93 & 4.082 & 0.9678 \\
\hline $\begin{array}{l}\text { Strategic Planning } \\
\text { (3 to 5 years) }\end{array}$ & 4 & 25 & 47 & 74 & 78 & 3.864 & 1.0636 \\
\hline Market Forecasting & 10 & 25 & 43 & 85 & 70 & 3.773 & 1.1199 \\
\hline Technology Planning & 3 & 22 & 73 & 76 & 61 & 3.723 & 0.9936 \\
\hline $\begin{array}{l}\text { Technology } \\
\text { Forecasting } \\
\text { (3 to 5years) }\end{array}$ & 6 & 41 & 66 & 71 & 49 & 3.498 & 1.0872 \\
\hline $\begin{array}{l}\text { Technology } \\
\text { Forecasting } \\
\text { (over 5 years) }\end{array}$ & 20 & 85 & 61 & 38 & 29 & 2.876 & 1.1660 \\
\hline $\begin{array}{l}\text { Long-range Planning } \\
\text { (over 5 years) }\end{array}$ & 19 & 56 & 65 & 42 & 47 & 3.183 & 1.2466 \\
\hline
\end{tabular}

\subsection{The Satisfaction of TF activities}

Table 46 shows the results for the satisfaction of TF activities. Participants were asked to evaluate the degree to which they are satisfied with the results of TF at their practices. The 7-point Likert scaled ranged from 'very unsatisfied' to 'very satisfied'. The result indicated that the respondents somewhat satisfied with the results of TF in their organizations.

Table 46 TF satisfaction

\begin{tabular}{|c|c|c|l|c|}
\hline Question & $\begin{array}{c}\text { Very } \\
\text { unsatisfied }\end{array}$ & $\begin{array}{c}\text { Very } \\
\text { satisfied }\end{array}$ & Mean & $\begin{array}{c}\text { Std. } \\
\text { Deviation }\end{array}$ \\
\hline Satisfaction with the results of TF & 1 & 7 & 4.051 & 1.519 \\
\hline
\end{tabular}




\subsection{The Usefulness of TF on Technology Planning}

Table 47 list the results of how TF activities affect the effectiveness of technology planning and strategy in their practices. Based on their previous experience and knowledge, participants were asked to quantify the extent to how they evaluate the usefulness of TF on technology planning activity. The 7-point Likert scaled ranged from 'very negative' to 'very positive'. The result indicated that the respondents think TF activities are useful in establishing technology planning in an effective way.

Table 47 The usefulness of TF in technology planning activity

\begin{tabular}{|l|c|c|c|c|}
\hline \multicolumn{1}{|c|}{ Question } & $\begin{array}{c}\text { Very } \\
\text { negative }\end{array}$ & $\begin{array}{c}\text { Very } \\
\text { positive }\end{array}$ & Mean & $\begin{array}{c}\text { Std. } \\
\text { Deviation }\end{array}$ \\
\hline $\begin{array}{l}\text { How TF is useful in } \\
\text { technology planning activity }\end{array}$ & 1 & 7 & 4.71 & 1.432 \\
\hline
\end{tabular}

\subsection{The Organizational Structure of Effective TF}

To identify the organizational structure of effective and efficient TF activity in firms, respondents were asked to rate each organization's effectiveness for efficient TF activity in their firms. As presented in Table 48,66\% of the participants suggested that TF activity within R\&D division was the most effective organizational structure of TF. $58 \%$ of the participants indicated that TF activity within engineering was the second effective organizational structure of efficient TF. $44 \%$ of the participants responded that TF activity comprised of cross functional team were the third effective organizational structure of efficient TF. As a result, this study suggests that TF organization would be better to be placed within $\mathrm{R} \& \mathrm{D}$ division, engineering or cross functional team. 
Table 48 Each organization's effectiveness for TF

\begin{tabular}{|l|c|c|c|c|c|c|}
\hline Organization & $\begin{array}{l}\text { Strongly } \\
\text { ineffective }\end{array}$ & Ineffective & $\begin{array}{l}\text { Somewhat } \\
\text { effective }\end{array}$ & Effective & $\begin{array}{l}\text { Strongly } \\
\text { effective }\end{array}$ & Mean \\
\hline $\begin{array}{l}\text { Within R\&D } \\
\text { division }\end{array}$ & 5 & 11 & 52 & 85 & 44 & 3.772 \\
\hline $\begin{array}{l}\text { Within } \\
\text { engineering }\end{array}$ & 0 & 17 & 65 & 85 & 27 & 3.629 \\
\hline $\begin{array}{l}\text { Cross } \\
\text { functional } \\
\text { team }\end{array}$ & 6 & 26 & 76 & 65 & 18 & 3.330 \\
\hline $\begin{array}{l}\text { Within } \\
\text { business } \\
\text { management }\end{array}$ & 3 & 28 & 92 & 65 & 12 & 3.275 \\
\hline $\begin{array}{l}\text { Within } \\
\text { marketing }\end{array}$ & 7 & 38 & 88 & 53 & 13 & 3.136 \\
\hline $\begin{array}{l}\text { Within } \\
\text { operation } \\
\text { management }\end{array}$ & 10 & 55 & 74 & 51 & 7 & 2.949 \\
\hline $\begin{array}{l}\text { Separate TF } \\
\text { unit }\end{array}$ & 33 & 41 & 42 & 35 & 7 & 2.633 \\
\hline $\begin{array}{l}\text { Outsourcing } \\
\text { to a } \\
\text { consulting } \\
\text { firm }\end{array}$ & 34 & 53 & 60 & 34 & 2 & 2.546 \\
\hline $\begin{array}{l}\text { Outsourcing } \\
\text { to academia }\end{array}$ & 39 & 56 & 56 & 24 & 0 & 2.371 \\
\hline $\begin{array}{l}\text { Outsourcing } \\
\text { to national } \\
\text { labs }\end{array}$ & 38 & 60 & 54 & 17 & 0 & 2.296 \\
\hline
\end{tabular}

\subsection{Technology Forecasting and Technology Characteristics}

This research examined the relationship between technology forecasting methods and technology characteristics such as basic research, applied research, and development. Q5, 6, 7, 8, and 13 were used in this analysis. The association between seven variables was developed for statistical analysis.

\section{H1a: Qualitative data and technique would be preferable in radical}

technology innovation.

H1b: Quantitative data and technique would be preferable in continuous technology innovation. 
This research investigated the interplay between TF methods, data usage for TF and technology characteristics such as disruptive/discontinuous and continuous technology in TF activities. H1 predicts that the relationship between TF and technology characteristics would be unique. It is based on the assumption that the use of TF methods and data would differ to the nature of technology in a firm as previous studies [26][52][427] pointed out that a firm should pay attention to choose appropriate TF methods and data for forecasting technological changes for a given situation. This study measured TF usages with three different R\&D phases.

Pearson correlation test was conducted to examine the association between TF methods, data usage, and R\&D stages concerning H1. As shown in Table 49, this research could not find sufficient evidence to reject that the choice of TF tools do not depends on technology characteristics. There was only weak support, indicating the weak relationship between the use of quantitative data and development focus. This is contrary to the proposition this research made in $\mathrm{H} 1$ based on previous research [427][428] in the literature. In consequence, these results reveal that many firms in the sample hardly employ appropriate TF methods and data, although they are actively involved in TF activities predicting three to five years forward.

Table 49 The correlation between TF methods, data type, and tech. characteristics

\begin{tabular}{|l|c|c|c|c|}
\hline $\begin{array}{l}\text { Technology } \\
\text { characteristics }\end{array}$ & $\begin{array}{l}\text { The use of } \\
\text { qualitative } \\
\text { data }\end{array}$ & $\begin{array}{l}\text { The use of } \\
\text { quantitative } \\
\text { data }\end{array}$ & $\begin{array}{l}\text { TF methods for } \\
\text { discontinuous } \\
\text { tech }\end{array}$ & $\begin{array}{l}\text { TF methods } \\
\text { for continuous } \\
\text { tech }\end{array}$ \\
\hline \hline Basic research & 0.115 & -0.023 & -0.027 & -0.075 \\
\hline Applied research & 0.041 & -0.083 & -0.103 & -0.092 \\
\hline Development & 0.079 & $0.141^{*}$ & 0.041 & 0.061 \\
\hline
\end{tabular}

Note: ${ }^{*} \mathrm{p}<0.10,{ }^{* *} \mathrm{p}<0.05,{ }^{* * *} \mathrm{p}<0.01 . \mathrm{n}=187$ 
Furthermore, this research investigated the use of TF methods based on three different $R \& D$ phases. Pearson correlation test was performed to examine the relationship between them. As shown in Table 50, only four TF tools among 20 methods were statistically significant, indicating the association between the use of each technique and technology characteristics. The results indicated that several methodstechnology roadmapping and trend extrapolation — have been widely used by firms that involved in the development stage related to continuous/incremental technology, while multi-criteria method has a negative association with the applied research phase. The negative relationship between both data mining and multi-criteria techniques and early phase of R\&D reveals that many firms have little knowledge in properly applying these techniques to their applications.

Table 50 The correlation between TF methods and technology characteristics

\begin{tabular}{|l|c|c|c|c|}
\hline $\begin{array}{l}\text { Technology } \\
\text { characteristics }\end{array}$ & $\begin{array}{l}\text { Multi-Criteria } \\
\text { Methods }\end{array}$ & $\begin{array}{l}\text { Technology } \\
\text { Roadmapping }\end{array}$ & $\begin{array}{l}\text { Data Mining; Text } \\
\text { (Data) Mining }\end{array}$ & $\begin{array}{l}\text { Trend } \\
\text { Extrapolation }\end{array}$ \\
\hline \hline Basic research & -0.155 & $-0.215^{* * *}$ & $0.138^{*}$ & -0.040 \\
\hline Applied research & $-0.160^{* *}$ & 0.041 & -0.056 & -0.058 \\
\hline Development & 0.078 & $0.268^{* * *}$ & 0.064 & $0.141^{* *}$ \\
\hline N & 172 & 177 & 186 & 184 \\
\hline
\end{tabular}

Note: ${ }^{*} \mathrm{p}<0.10,{ }^{* *} \mathrm{p}<0.05,{ }^{* * *} \mathrm{p}<0.01$.

\subsection{The Use of Hybrid TF Methods and Technology Planning}

As prior research suggested that hybrid methods may improve the effectiveness of forecasting by offsetting weaknesses of single forecasting technique, resulting in effective technology planning activity, this study investigated the association between the use of hybrid TF techniques and technology planning activity. Q1, 9, 10, and 11 were used in this analysis. The relationship between four variables was developed for statistical test and SEM. 


\section{H2: Combining multiple methods simultaneously has a positive relationship}

with the effectiveness of TF.

To investigate empirical evidence of whether the use of multiple techniques is associated with the effectiveness of TF in a firm, this study examined the relationship between the use of hybrid methods and the effectiveness of TF. As presented in Table 51 , it provides general support for Hypothesis 2 (standardized $\beta=.322, \mathrm{p}<.01$ ).

Consistent with arguments of prior research [546][24][25], empirical results indicated that the simultaneous use of multiple methods has a positive impact on the effectiveness of TF associated with technology planning. In consequence, this study confirms that combining different TF methods is significant means to enhance the effectiveness of TF associated with technology planning.

Table 51 The correlation between hybrid use of TF methods, TF, and TP

\begin{tabular}{|l|c|c|c|}
\hline \multicolumn{1}{|c|}{ TF characteristics } & 1 & 2 & 3 \\
\hline \hline 1. Mutiple use of TF methods & - & & \\
\hline 2. Satisfaction with the results of TF & $0.322^{* * *}$ & - & \\
\hline 3. The usefulness of TF on technology planning & $0.269^{* * *}$ & $0.746^{* * *}$ & - \\
\hline
\end{tabular}

Note: ${ }^{*} \mathrm{p}<0.10,{ }^{*} \mathrm{p}<0.05,{ }^{* * *} \mathrm{p}<0.01 . \mathrm{n}=192$

\begin{tabular}{|c|c|c|c|c|c|c|c|c|c|}
\hline & TF methods & Never heard of it & Heard of it & Read about it & Considered it & Plan to use it & Used it & \begin{tabular}{|l|} 
Currently in use \\
\end{tabular} & $\mathrm{N}$ \\
\hline \multirow{9}{*}{ Explorative TF } & Trend Extrapolation & $16 \%$ & $21 \%$ & $10 \%$ & $10 \%$ & $3 \%$ & $23 \%$ & $17 \%$ & 174 \\
\hline & Growth Curves; S-Curves & $25 \%$ & $21 \%$ & $14 \%$ & $11 \%$ & $2 \%$ & $17 \%$ & $10 \%$ & 167 \\
\hline & Bibliometrics; Scientometrics & $62 \%$ & $18 \%$ & $5 \%$ & $5 \%$ & $5 \%$ & $4 \%$ & $2 \%$ & 170 \\
\hline & Data Mining; Text (Data) Mining; Tech Mining & $3 \%$ & $16 \%$ & $17 \%$ & $14 \%$ & $6 \%$ & $22 \%$ & $22 \%$ & 175 \\
\hline & System Dynamics & $44 \%$ & $20 \%$ & $8 \%$ & $9 \%$ & $4 \%$ & $8 \%$ & $7 \%$ & 130 \\
\hline & Agent-based modeling & $54 \%$ & $18 \%$ & $9 \%$ & $7 \%$ & $3 \%$ & $6 \%$ & $2 \%$ & 164 \\
\hline & Cross impact analysis & $43 \%$ & $18 \%$ & $12 \%$ & $7 \%$ & $4 \%$ & $11 \%$ & $6 \%$ & 166 \\
\hline & Analogies & $28 \%$ & $21 \%$ & $15 \%$ & $10 \%$ & $2 \%$ & $15 \%$ & $8 \%$ & 168 \\
\hline & TFDEA & $65 \%$ & $11 \%$ & $10 \%$ & $4 \%$ & $3 \%$ & $4 \%$ & $2 \%$ & 167 \\
\hline \multirow{5}{*}{ Normative / Explorative TF } & Delphi & $50 \%$ & $18 \%$ & $11 \%$ & $4 \%$ & $3 \%$ & $9 \%$ & $5 \%$ & 160 \\
\hline & Nominal Group Technique & $31 \%$ & $10 \%$ & $6 \%$ & $8 \%$ & $4 \%$ & $22 \%$ & $19 \%$ & 159 \\
\hline & Scenario Planning & $20 \%$ & $11 \%$ & $6 \%$ & $8 \%$ & $9 \%$ & $22 \%$ & $24 \%$ & 162 \\
\hline & Trend impact analysis & $21 \%$ & $15 \%$ & $6 \%$ & $12 \%$ & $5 \%$ & $23 \%$ & $19 \%$ & 160 \\
\hline & Technology roadmapping & $10 \%$ & $7 \%$ & $4 \%$ & $8 \%$ & $4 \%$ & $20 \%$ & $47 \%$ & 162 \\
\hline \multirow{4}{*}{ Normative } & Relevance Trees; Decision Trees & $46 \%$ & $20 \%$ & $8 \%$ & $9 \%$ & $3 \%$ & $9 \%$ & $6 \%$ & 158 \\
\hline & AHP/ANP & $60 \%$ & $17 \%$ & $8 \%$ & $4 \%$ & $3 \%$ & $5 \%$ & $4 \%$ & 156 \\
\hline & Morphological Analysis & $61 \%$ & $18 \%$ & $6 \%$ & $4 \%$ & $1 \%$ & $6 \%$ & $4 \%$ & 154 \\
\hline & Backcasting & $50 \%$ & $20 \%$ & $11 \%$ & $7 \%$ & $2 \%$ & $5 \%$ & $5 \%$ & 159 \\
\hline
\end{tabular}

Figure 20 The use of TF techniques in practice 
Moreover, as illustrated in Figure 20, this study provides a current snapshot of how companies across sectors use TF methods to facilitate strategic technology planning in the U.S-based manufacturing firms. Most companies are familiar with both exploratory/normative and exploratory techniques rather than normative methods. For exploratory/normative tools, many firms employ technology roadmapping (67\%), scenario planning (46\%), trend impact analysis (42\%), and nominal group technique (41\%) for predicting technological change. For exploratory methods, most firms among respondents have used data mining (44\%), trend extrapolation (40\%), and growth curves $(27 \%)$ in practices. For normative methods, decision trees $(15 \%)$ are highly used for TF.

\subsection{The Industrial Characteristics of TF}

This research analyzed research trends of TF tools in the literature and identifies the industry applications among them. The results reveal the industrial aspects of TF tools. TF is critical to every industry. However, in mature industries, technology development tends to be applied to existing product extensions and to process refinements as competitors try to reduce their production costs [316]. Thus, TF activities in emerging or high-tech industry would be higher than in mature industry. 


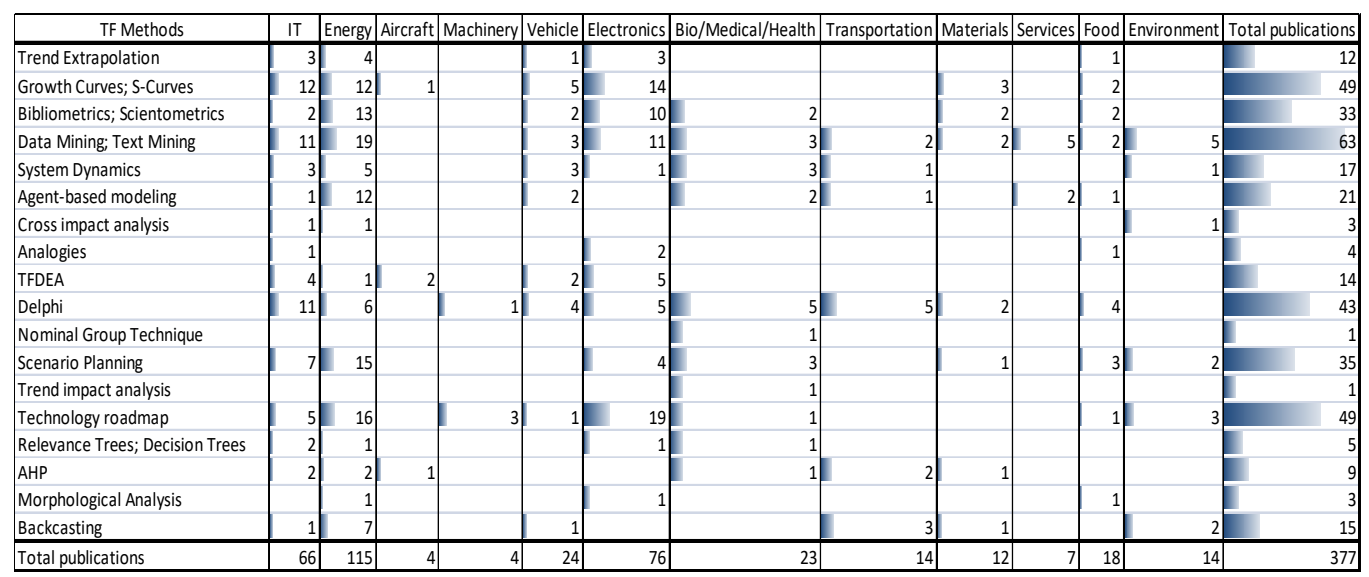

Figure 21 The research share in industry applications in the literature

As presented in Figure 21, among 377 publications, high-tech industries have published a wealth of TF research such as IT, Bio, energy, and electronics, when compared to mature industries such as machinery, aircraft, and food. In light of industry perspective, growth curves, data mining, Delphi, and scenario planning have been widely used in IT industry. Data mining, technology roadmapping, and scenario planning have been mostly employed in the energy sector. Technology roadmapping, growth curves, and data mining have been widely used in electronics sector in the literature. Pavitt and Rothwell pointed out that the nature of the firm's industry may be a more important factor of the character of its innovation [547]. The results might reflect the characteristics or the nature of the industry across sectors. Therefore, this research claims that:

\section{H3: The use of TF techniques differs across sectors.}

To investigate the industrial aspects of TF tools with respect to $\mathrm{H} 3$, ANOVA was conducted to examine whether there is a significant difference in using TF tools 
across industries. As presented in Table 52, the results indicated that there was a weak support for H3. In particular, the use of TF tools hardly differs across sectors. However, the TF activities predicting three to five years or over five years in companies show a statistically significant difference between sectors. The results reveal that electronics, transportation equipment, and chemicals are more likely to actively engage in $\mathrm{TF}$ activities within their firms. This outcome has a similarity with the results from bibliometrics.

Table 52 The TF difference across industries

\begin{tabular}{|c|c|c|c|c|c|}
\hline \multicolumn{2}{|c|}{ The Use of TF } & $\mathrm{df}$ & Mean Square & $F$ & $p$ \\
\hline \multirow{3}{*}{$\begin{array}{l}\text { The Use of Exploratory } \\
\text { TF Methods }\end{array}$} & Between Groups & 15 & 1.72 & \multirow{3}{*}{0.722} & \multirow{3}{*}{0.761} \\
\hline & Within Groups & 235 & 2.38 & & \\
\hline & Total & 250 & & & \\
\hline \multirow{3}{*}{$\begin{array}{l}\text { The Use of Normative } \\
\text { TF Methods }\end{array}$} & Between Groups & 15 & 1.26 & \multirow{3}{*}{0.463} & \multirow{3}{*}{0.948} \\
\hline & Within Groups & 235 & 2.73 & & \\
\hline & Total & 250 & & & \\
\hline \multirow{3}{*}{$\begin{array}{l}\text { The Use of Exploratory } \\
\text { /Normative TF Methods }\end{array}$} & Between Groups & 15 & 2.33 & \multirow{3}{*}{0.482} & \multirow{3}{*}{0.934} \\
\hline & Within Groups & 235 & 4.85 & & \\
\hline & Total & 250 & & & \\
\hline \multirow{3}{*}{$\begin{array}{l}\text { TF Activities } \\
\text { ( } 3 \text { to } 5 \text { years) }\end{array}$} & Between Groups & 15 & 2.27 & \multirow{3}{*}{2.052} & \multirow{3}{*}{$0.013^{* *}$} \\
\hline & Within Groups & 235 & 1.11 & & \\
\hline & Total & 250 & & & \\
\hline \multirow{3}{*}{$\begin{array}{l}\text { TF Activities } \\
\text { (over } 5 \text { years) }\end{array}$} & Between Groups & 15 & 2.42 & \multirow{3}{*}{1.866} & \multirow{3}{*}{$0.028 * *$} \\
\hline & Within Groups & 235 & 1.29 & & \\
\hline & Total & 250 & & & \\
\hline
\end{tabular}

Note: ${ }^{*} \mathrm{p}<0.10,{ }^{* *} \mathrm{p}<0.05,{ }^{* * *} \mathrm{p}<0.01$.

\subsection{TF Activities based on Technology Characteristics}

This research explores the interplay between technology characteristics such as disruptive/discontinuous and continuous technology, TF, and technology planning activities in the design of a performance measurement for R\&D activities. Hypothesis 4 predicts that the association between TF activities and technology characteristics would be unique. Q1, 7, 8, and 13 were used in this analysis. 


\section{H4: TF activities differ across the type of innovation the firm creates.}

It is based on the insight that TF activities in a firm would differ according to the type of innovations a company focuses. This study measures TF and technology planning activities with different stages of R\&D process. Pearson correlation test was conducted to identify the relationship between TF activities, action planning (AP), and technology planning (TP) with respect to Hypothesis 4. As presented in Table 53, the results indicated the positive relationship between development stage, AP for one to three years, and TF activity predicting three to five years ahead. However, other stages of R\&D have no effect on TF and TP activities within a firm. The results uncover that many firms in the sample are involved in incremental/continuous technology development for commercialization with short-term sights and goals rather than focusing on long-term disruptive/discontinuous product or service development.

Table 53 The correlation between TF activities and technology characteristics

\begin{tabular}{|l|c|c|c|c|c|}
\hline R\&D characteristics & Total use of TF & $\mathrm{AP}(1-3 \mathrm{yrs})$ & $\mathrm{TF}(3-5 \mathrm{yrs})$ & $\mathrm{TF}($ over 5yrs) & $\mathrm{TP}$ \\
\hline \hline - Basic research & -0.08 & -0.12 & 0.03 & -0.03 & 0.001 \\
\hline - Applied research & -0.14 & 0.03 & -0.04 & 0.04 & 0.12 \\
\hline - Development & 0.12 & $0.25 * * *$ & $0.21 * *$ & 0.07 & 0.09 \\
\hline
\end{tabular}

\subsection{TF and Technology Planning}

A variety of use of TF makes it difficult to measure its contribution as a source of $\mathrm{R} \& \mathrm{D}$ and business performance. $\mathrm{R} \& \mathrm{D}$ funding is allocated through $\mathrm{TF}$, technology evaluation for project selection, technology strategy, to strategic planning. TF is needed not only to predict promising alternatives but also to assess alternatives in planning process [439]. Therefore, this research claims that: 


\section{H5: The use of TF has a positive relationship with technology planning}

activities in a firm.

Hypothesis 5 theorized that TF activities would have positive relationship with technology planning within a firm. This study found a significant evidence supporting H5 (standardized $\beta=0.781, \mathrm{p}<.01$ ). Hence, the firms that involve in TF activities are more likely to have active technology planning activities. This is consistent with the results that TF activity plays a critical role in strategic planning and new product development.

\section{Appropriate Use of TF and Technology Planning}

The selection of methods mainly affects the accuracy and reliability of TF. If the assumptions are inaccurate, the prediction would go a wrong direction. If TF methods and data are matched and utilized appropriately to the nature of technology in a firm, the effectiveness of technology planning may become distinctive relative to those that are not. For example, one of the mistakes in trend projection most often arise out of the assumption that the future will simply be an addition or subtraction from the present, based on the assumption that technology will follow past trends. It ignores the effects of unprecedented future events. Therefore, most problems in forecasting are caused not by a lack of sophistication but by drawbacks inherent in the process of TF [53]. Therefore, this research claims that:

\section{H6: The appropriate use of data and TF methods improves the firm's} capability for technology planning activities. 
However, the results did not support Hypothesis 6 that the appropriate use of data and TF methods would have a positive association with the efficacy of technology planning activity for enhancing a firm's competitiveness (standardized $\beta=0.029, \mathrm{p}>$ $.05)$. The result reflected that the firms do not use appropriate methods and data based on its characteristics of $R \& D$ activities since $T F$ activities has a positive relationship with the appropriate use of TF variable (standardized $\beta=0.23, \mathrm{p}<.01$ ).

\subsection{Firm Size and TF Intensity}

This study examined differences in size-related innovative activities by suggesting that the size of a firm would have a positive relationship with TF activities in planning processes within an organization. Large firms are inclined to have more technology planning activities for identifying emerging technologies and market opportunities. Large firms by virtue of their size may have advanced complementary assets. SMEs are more likely to compete for acceptance of their technology rather than capturing new opportunities in their market [548]. Therefore, this research claims that:

H7: The size of a firm has a positive relationship with $T F$ activities in planning processes within organization

Linear regression was performed to identify the relationship between TF activities and firm size after controlling for R\&D output with respect to H7. As presented in Table 54, there was strong support, indicating the positive relationship between long-term TF activities and firm size. However, other TF activities including 
the use of TF tools have excluded due to multicollinearity issue. Consequently, larger firms have a propensity to involve in long-term TF activities.

Table 54 The linear relationship between firm size and TF activities

\begin{tabular}{c|cc}
\hline Independent variables & Firm size (Total number of employees) \\
\hline Main effects & standardized $\beta$ & $p$ \\
TF activities (over 5 years) & 0.145 & $0.014^{* *}$ \\
Controls & & $0.000^{* * *}$ \\
Number of patents & 0.452 & \\
Adjusted $R^{2}$ & 0.249 & \\
\hline
\end{tabular}
Note: $* \mathrm{p}<0.10, * * \mathrm{p}<0.05, * * * \mathrm{p}<0.01$.

\subsection{Firm Size and the Use of TF Resource}

Strategy formulation focuses on organizational resources. In the era of open innovation, many innovative large firms tend to use a wide range of external sources and actors to maintain sustainable capabilities [549]. Thus, the use of external resources plays a vital role to help firms exploit innovative opportunities and gain more knowledge for the sake of their needs. To investigates the organizational functions in TF activities, ANOVA was performed to determine if the use of external or internal TF resources differs based on firm size with F-test regarding $\mathrm{H} 8$.

H8: The use of internal/external TF sources differs across the firm size.

As presented in Table 55, this study only found sufficient evidence to reject the null hypothesis for the use of external resources in TF activities. Moreover, supporting $\mathrm{H} 8$, comparing the resource-related characteristics of large firms and SMEs reveals that there is a statistically significant relationship between firm size and the use of external resources in $\mathrm{TF}$ activities, whereas there is no difference between SMEs and large firms in using internal TF resources and data for predicting technological changes. Due to 
lack of internal resource, small firms might be more likely to gain benefits from mainly external TF resources. As a result, however, large firms have a tendency to utilize external resources in TF activities, while small firms are likely to employ internal resources.

Table 55 The linear relationship between firm size and TF resources

\begin{tabular}{|c|c|c|c|c|c|c|c|}
\hline $\begin{array}{l}\text { Independent } \\
\text { Variables }\end{array}$ & $\begin{array}{c}\text { Firm Size (Total \# } \\
\text { of employees) }\end{array}$ & \multicolumn{3}{|c|}{ External TF resources } & \multicolumn{3}{|c|}{ Internal TF resources } \\
\hline $\begin{array}{l}\text { External TF } \\
\text { resources }\end{array}$ & $0.164 * * *$ & & & & & & \\
\hline $\begin{array}{l}\text { Internal TF } \\
\text { resources }\end{array}$ & 0.041 & & & & & & \\
\hline External data & -0.085 & & & & & & \\
\hline Internal data & -0.004 & & & & & & \\
\hline Controls & & & & & & & \\
\hline Total patents & $0.744 * * *$ & & & & & & \\
\hline Adjusted $R^{2}$ & 0.547 & Mean & S.D. & $F$ & Mean & S.D. & $F$ \\
\hline Firm size & & & & $5.65 * *$ & & & 0.066 \\
\hline 1. SMEs & & 2.02 & 1.11 & & 3.23 & 0.96 & \\
\hline 2. Large firms & & 2.41 & 1.17 & & 3.19 & 1.01 & \\
\hline
\end{tabular}

\subsection{Technology Planning and R\&D Performance}

High internal planning capability enables a firm to select effectively R\&D projects that present themselves fulfilling technological changes. Objective probability of success ratings from $\mathrm{TF}$ on selected $\mathrm{R} \& \mathrm{D}$ projects in technology planning process is correlated with the eventual success and failure of these projects. Therefore, this research claims that:

H9: R\&D performance has a positive relationship with technology planning activities in a firm. 
With regard to $\mathrm{H} 9$, this research examined the relationship between technology planning and R\&D performance using SEM. As a result, the technology planning would have a positive relationship with $R \& D$ performance based on patent activity. The results support H9 (standardized $\beta=0.241, \mathrm{p}<.01$ ). Technology planning capability has a positive relationship with the level of R\&D outputs. Thus, firms with richer TF and TP activities tend to produce better R\&D performance.

\subsection{Technology Planning and Business Performance}

With deliberate attention to strategic technology planning, technology must be managed strategically. TF plays various roles in formulating a business strategy [9] and setting long-term goals. Technological opportunity captured by TF must have a market reference. The question on the relationship between corporate planning and business performance remains unresolved. This study investigated the direct association between technology planning and firm performance.

H10: Business performance has a positive relationship with technology planning activities in a firm.

In terms of H10, this research examined the relationship between technology planning and business performance using SEM. As a result, this research found significant evidence supporting H10 (standardized $\beta=0.271$ and $\mathrm{p}<.01$ ) and indicating that technology planning has a positive association with the business performance of a firm. Hence, technology planning capability has a positive relationship with the level of profitability. 


\subsection{R\&D Performance and Business Performance}

The association between $R \& D$ and business performance has been extensively discussed in various aspects so far in the innovation literature. $R \& D$ investment is one of diverse factors that can affect the sales growth and profitability in a firm. A series of empirical studies in the literature have provided mixed support for the relationship between innovation activity and financial performance. Thus, this study revisited this association and SEM is designed to test indirect effect of R\&D performance on firm performance.

\section{H11: R\&D performance has a positive relationship with business} performance of a firm.

To investigate whether R\&D performance mediates the relation between technology planning and business performance, a path model was tested using AMOS 22. With respect to H11, this research examined the relationship between R\&D performance and business performance. Results indicated that, although technology planning significantly predicted positive effect (standardized $\beta=0.271$ and $\mathrm{p}<.01$ ), R\&D performance was not significantly related to business performance (standardized $\beta$ $=0.031, \mathrm{p}>.05)$. As a result, these findings do not support the hypothesized mediation model. This result is consistent with arguments that patents, as intermediate outputs, are not a direct measure of their commercialization potential [315], that the percentage of innovations patented is limited to maintain secrecy among other reasons [313]. 
The analyses showed that there was enough evidence to support Hypothesis 2, 4, 5, 7, 9, and 10; weak evidence to support Hypothesis 1 and 8 and no evidence to support Hypothesis 3, 6, and 11. Table 56 presents a summary of the hypothesis testing results.

Table 56 Summary of hypothesis testing

\begin{tabular}{|c|c|c|}
\hline Hypothesis & Hypothesis & Result \\
\hline $\mathrm{H} 1$ & $\begin{array}{l}\text { The choice of TF methods might depend on } \\
\text { technology characteristics }\end{array}$ & Weak Support \\
\hline $\mathrm{H} 2$ & $\begin{array}{l}\text { The use of combining multiple methods } \\
\text { simultaneously will improve the effectiveness of TF }\end{array}$ & Supported \\
\hline $\mathrm{H} 3$ & The use of TF techniques will differ across sectors & Not Supported \\
\hline H4 & $\begin{array}{l}\text { TF activities will be different in accordance with the } \\
\text { types of innovation the firm offers }\end{array}$ & Supported \\
\hline H5 & $\begin{array}{l}\text { The use of TF will have a positive relationship with } \\
\text { firm's technology planning }\end{array}$ & Supported \\
\hline H6 & $\begin{array}{l}\text { The appropriate use of data and TF methods will } \\
\text { enhance the firm's capability for technology } \\
\text { planning }\end{array}$ & Not Supported \\
\hline $\mathrm{H} 7$ & $\begin{array}{l}\text { The firm size will be positively related with TF } \\
\text { activities in planning processes within organization }\end{array}$ & Supported \\
\hline H8 & $\begin{array}{l}\text { The use of internal/external TF sources will depends } \\
\text { on the firm size }\end{array}$ & Weak Support \\
\hline H9 & $\begin{array}{l}\text { R\&D performance will be a positive function of } \\
\text { technology planning activities }\end{array}$ & Supported \\
\hline $\mathrm{H} 10$ & $\begin{array}{l}\text { Business performance will be a positive function of } \\
\text { technology planning activities }\end{array}$ & Supported \\
\hline H11 & $\begin{array}{l}\text { R\&D performance is a positive function of business } \\
\text { performance of a firm }\end{array}$ & Not Supported \\
\hline
\end{tabular}




\section{Chapter 11 Discussion}

Currently, there is a lack of discussion regarding the impact of a firm's TF activities and technology planning on its performance. This research contributes to the body of knowledge in strategic management and technology management in a couple of ways. First, this study tackles the issue of how the outputs and outcomes of R\&D activities can be measured. The main issue with measuring R\&D outputs and outcomes stems from the fact that they are a multi-dimensional phenomenon. This research explores the metrics of R\&D and business performance and proposes linkages between $\mathrm{TF}$, technology planning, R\&D performance, and business performance based on the literature review. Furthermore, this study verifies the hypotheses using the structural equation model. The results showed that there was enough evidence to indicate the positive associations between TF, technology planning, R\&D performance, and business performance, supporting Hypotheses 5, 9 and 10. However, this study found weak evidence to support Hypothesis 6 and no evidence to support the positive association between R\&D performance and business performance (H11), which is still controversial in the literature. Taken together, the results reveal the interactive effect of TF and technology planning activities on a firm's business performance.

The results extend previous research on firm performance by elaborating on the association between technology characteristics, various technology management activities, R\&D outputs, and firm performance. Consistent with expectations, empirical results indicate that planning capability has a positive relationship with the level of profitability. As measured by sales growth, ROA, and earnings growth, firms with higher TF and R\&D planning activities are more likely to have better financial 
performance. Moreover, as measured with patents granted, firms with richer TF and TP activities have a tendency to produce better R\&D performance. Consistent with a resource-based view, the results indicate that companies are able to acquire and sustain a competitive advantage through effective TF and technology planning activities. Patents as an innovation output showed an insignificant relationship with firm performance. This result is consistent with arguments that patents, as intermediate outputs, are not a direct measure of their commercialization potential [315], that the percentage of innovations patented is limited to maintain secrecy among other reasons [313]. Thus, patents would be regarded as a measure of inventive output rather than innovative success. In other words, it would be possible that overinvested R\&D activities may erode a firm's profitability.

In addition, there is currently a lack of discussion in understanding firms' TF activities and technology planning in technology and innovation management literature. This study analyzed trends in TF research both in methods and applications. This research presents how TF research has evolved in the literature on technology and innovation management with the overview of chronological evolution, identifies the current trends, and discusses various characteristics in a variety of TF methods. Based on the literature review, this study explores the use of TF in various ways-TIMO aspects - for providing managerial implications of TF to an organization's application. The results are based on an examination of multiple dimensions of TF, and provide empirical findings not only to identify research trends but to select applicable and practical TF methods for future study in different fields. This research provides basic guidance and evidence with respect to TF activities in practice by statistically 
examining five propositions. This study contributes to the body of knowledge in strategic technology management in various ways.

First, technological implications of this study reveal that many firms hardly use appropriate TF methods and data, although they have conducted three to five years of TF activities. Consistent with prior research [26][52], the results confirm that determining appropriate TF methods is critical for a given situation in order to predict technological changes in accordance with the technology characteristics. R\&D managers should hone their technology planning skills associated with TF even more than they already have. The results suggest that management group should deepen their knowledge of TF techniques and data usage based on their R\&D focus for taking benefits out of it. Moreover, firms should identify and develop their own distinct and effective approaches for capturing emerging opportunities/threats. For example, if firms focus on applied or basic research, they should adopt normative approaches and qualitative data. In this regard, this study helps to identify whether a firm uses appropriate TF tools to predict technological changes for its strategic management of technology planning or not. In consequence, experience and expertise in various TF techniques and data usage is an important element in expanding a firm's innovative capability.

Second, this research provides statistical evidence to support that the use of composite TF techniques is a significant means to enhance the effectiveness of TF. The methodological implications: firms should have more knowledge in combing TF techniques to identify opportunities/threats effectively. Thus, preferred approaches would incorporate hybrid TF tools, not simply relying on any single TF method. This 
study provides several conclusions as to how to integrate two or more approaches into the decision-making process. Moreover, this study identifies research trends and the practices of TF methods in industry. Both researchers and practitioners have mainly used data mining, growth curves, scenario planning, and technology roadmapping for predicting technological changes. While bibliometric, Delphi, and AHP/ANP are typically used for TF in the literature; trend impact analysis, nominal group technique, and decision trees are widely utilized in practice. The discrepancy between research and practice might partially stem from the fact that the expert-based tools are not easily implementable for TF analysis in practice; many techniques applied by corporations are introduced by consulting firms that help companies adopt them and increase their use of TF methods in responding to drastic competition among them. As a result, researchers should put more effort into introducing novel methods or enhanced applications for providing the better implementable measures based on various types of data in practice.

Third, the TF activities in corporations show dissimilarity between industries. However, the results of the industrial aspects of TF suggested weak support of that the use of TF tools differs across sectors, similar to the results from bibliometrics. There might be no support of the myth that there are "high technology industries" and "low technology industries." The results reflect that many firms in each sector seldom use appropriate TF methods in accordance with industry characteristics. This study also identifies that researchers focus on TF studies related to IT, electronics, and energy in the literature. Moreover, the use of TF tools in practice reinforces this finding of bibliometrics. Firms in electronics and chemicals tend to utilize a variety of TF methods. 
Fourth, systematic TF in strategic planning processes can reduce firms' vulnerability to changes of industry structure and industry evolution. Technology management groups should focus their attention on which stages of evolution in which they engage, and intensify their expertise in technological and structural characteristics in which they are involved. For instance, firms that engage in the late mature stage should become skilled at predicting whether such markets can be substituted by other technologies/products, and deciding the types of technological capabilities that will be needed to sustain the substitution effort. However, firms that are in development or in the growth stages of evolution would be good at predicting technology using exploratory TF methods and data. Thus, they need to become strategic technology planning experts in the industries in which they invest. In addition, they should continue to seek opportunities/threats that enable them to develop a unique product or service features in order to achieve sustainable competitiveness.

Finally, if an SME lacks resources, it should use the informal network to get informed of technological changes [550]. Although many studies pointed out that SMEs are required to take advantage of external resources, firms in the sample of this study represented that they depend on internal resources led by entrepreneurs who have technical skills for predicting technological changes in strategic technology planning. The results indicated that the role of the entrepreneur is crucial in developing technology, which is consistent with the previous studies [551]. Consequently, the key determinant of R\&D success in SMEs would be the capability of a technical entrepreneur to develop strategic technology planning. Technical entrepreneurs would be a critical source of their competitive advantage. Regardless of firm size, this research 
suggests that a firm should proactively seek out internal or external persons who have detailed knowledge of strategic technology planning and TF principles. 


\section{Chapter 12 Conclusions and Contributions}

Although strategic management research has expanded and increased since the 1960s, the technology planning-performance relationship has been poorly understood. The assumption that technology planning provides economic value was adopted since it was consistent with findings in prior planning-performance research. This research provides arguments based on both RBV and dynamic capability and describes an empirical trial. This study concludes that TF and firm performance are more highly associated with planning disequilibrium industries. The greater degree of technology planning linked with TF reflects a firm's dynamic capability rather than planning disequilibrium. An attempt was made to identify sectors with different levels of TF dissemination. The results weakly supported the difference in TF across industries. The important contribution of this study is, however, its linkage of technology planning with TF and firm performance, as a potential source of competitive advantage. The TF process is a strategic asset with competitive advantage, in the long run, as a fundamental organizing category for the strategic planning field.

This research contributes to the current literature by proposing an appropriate organizational decision making process to implement effectively in TF activities and to aid in strategic planning and technology development. One of the contributions of this study is to elaborate on the perceived usefulness of TF methods for new product and service development and its connection to the organizational or industry characteristics of the firm. This study provides a comprehensive illustration of TF tools in order to assist policy makers, universities, research institutes/national labs and companies to enhance the decision making process on technology development and new research 
fields. The strategic decision support process identified in this study fills a gap that a company is facing in a turbulent environment with a view toward emerging technology fields. This model provides various types of values as follows:

i. A decision maker can effectively identify emerging technologies with the aid of $\mathrm{TF}$ activities in a firm.

ii. Universities, research institutes, and national labs can capture areas of research focus with the use of the effective TF techniques identified in this study.

iii. Companies can identify the direction of customer needs and areas of commercialization endeavors.

This research not simply identifies research gaps but also selects applicable and practical TF methods for future study. This study identified whether the use of multiple perspectives merging the normative and the exploratory approach could improve the effectiveness of forecasting technological change. In summary, this study provides a comprehensive TF activity for the researchers and practitioners.

\section{Contributions to strategic management}

This study attempts to present findings useful for consideration in an integrated innovation framework. Major findings in this research provide important implications for work on TF, strategic technology planning, technology assessment, and firm operation. As presented in Figure 22, this research provides a systematic process as to when, where, and how to implement TF activities in strategic planning in accordance with several critical factors - industry structure, the stage of industry life cycle, the stage of innovation, technology characteristics, available data, and techniques. 


\begin{tabular}{|c|c|}
\hline \multirow{3}{*}{$\begin{array}{l}\text { Form effective TF Staffs within R\&D } \\
\text { Division } \\
\text { - R\&D staff, CTO/VP, Cross-functional } \\
\text { team, Heads of departments, and Project } \\
\text { manager }\end{array}$} & $\begin{array}{l}\text { Identify Technology Characteristics } \\
\text { - Basic research } \\
\text { - Applied research } \\
\text { - Development }\end{array}$ \\
\hline & \multirow{6}{*}{$\begin{array}{l}\text { Identify Available Data and Determine it } \\
\text { - Internal data } \\
\text { (Preference: Expert's opinion, Technical data, } \\
\text { Market data, Top manager's intuitive decision) } \\
\text { - External data } \\
\text { (Preference: Customer's input, Technical } \\
\text { reports, Market data, Expert's opinion, Research } \\
\text { journal, Conference proceeding, Patents, } \\
\text { Vendor's input, Magazine, and Newsletter) }\end{array}$} \\
\hline & \\
\hline$\downarrow$ & \\
\hline $\begin{array}{l}\text { Analyze Industry Structure } \\
\text { - Supply chain structure } \\
\text { - Market structure and positioning }\end{array}$ & \\
\hline$\downarrow$ & \\
\hline $\begin{array}{l}\text { Identify Industry Life Cycle } \\
\text { - What is the maximum level of saturation? } \\
\text { - What is the inflection point or half life }\end{array}$ & \\
\hline cycle of the product? & \multirow{4}{*}{\begin{tabular}{l}
\multicolumn{1}{c}{$\downarrow$} \\
\multicolumn{1}{c}{ Select TF Techniques } \\
- Exploratory \\
- Normative / Exploratory \\
- Normative
\end{tabular}} \\
\hline $\begin{array}{l}\text { - Where are you positioned in your } \\
\text { industry life cycle? }\end{array}$ & \\
\hline$\downarrow$ & \\
\hline \multirow{3}{*}{$\begin{array}{l}\text { Identify Stage of Innovation } \\
\text { - Product innovation } \\
\text { - Process innovation } \\
\text { - Standardization } \\
\end{array}$} & \\
\hline & $\downarrow$ \\
\hline & $\begin{array}{l}\text { Propose action items required to take to } \\
\text { capture technological opportunities and } \\
\text { overcome threats }\end{array}$ \\
\hline
\end{tabular}

Figure 22 Systematic decision-making process for strategic technology planning

First, the advantage of the proposed research is to provide appropriate organizational decision-making metrics to effectively aid in strategic technology planning and technology assessment. This research attempts to present findings useful for considering an integrated innovation management framework. Major findings in this study provide important implications for work on TF, strategic technology planning, and firm operation. The hypothetical framework presented in this research not only provides a current snapshot of how firms across industries implement best practices in TF to facilitate organizational functions and strategic technology planning in the U.S. manufacturing firms but also improves the effectiveness of TF in strategic planning by capturing technology characteristics in various industries. This study provides a comprehensive illustration of some of the most common metrics used for evaluating R\&D performance and business performance in order to assist policy makers, 
universities, research institutes/national labs, and companies to enhance the decision making process on technology development and new research fields.

The empirical results reveal that most of the firms put an effort to predict shortterm technological changes, focusing on short-term profitability regardless of firm size. However, not all R\&D efforts may result in quick financial returns. Short-term sights and goals for product or service development are likely to produce a negative association between $R \& D$ activities and firm performance. $R \& D$ is not a clear-cut process. Technological innovations typically take a long time to make a predictable or unpredictable commercial success [394]. For example, Dupont took about ten years to introduce nylon products to customers [395]. In this regard, the recommendation out of the results is that a firm should support short-term and long-term TF activities when it focuses on the applied research and basic research as well, enhancing its focal products to flourish.

\section{Contributions to managerial aspects}

For managerial implications, TF activities were found in firms to yield more efficacy of technology planning activities which overall results in improved business performance. This has managerial implications: there is strong evidence that a firm should emphasize the importance of TF activities in technology planning to sustain competitiveness in the market. Recently companies have realized how important these efforts are and have attempted to improve current practices. The results were consistent with the findings in prior TF-performance research [378][552]. The results in this study extend the literature by showing that with strategic technology planning, TF activities have a positive association with ROA, earnings growth, and sales growth. Moreover, 
this research identified the difference in data usage based on the firm size. This study also found the difference in TF methods based on the type of innovation stage. Therefore, decision makers need to determine TF methods/data and TP strategies in accordance with technology characteristics, firm size, and their goals (R\&D and business performance), as presented in Figure 23.

\begin{tabular}{|c|c|c|c|c|}
\hline Goals & Size & $\begin{array}{c}\text { Type of } \\
\text { innovation }\end{array}$ & Data & Methods \\
\hline \multirow{6}{*}{$\begin{array}{l}\text { R\&D } \\
\text { performance }\end{array}$} & \multirow[t]{3}{*}{ Large } & Basic & $\begin{array}{l}\text { Customers input, Technical reports, Research journals, } \\
\text { Patents, External experts opinions, External market data }\end{array}$ & $\begin{array}{l}\text { Data Mining, Analogies, Cross Impact } \\
\text { Analysis }\end{array}$ \\
\hline & & Applied & $\begin{array}{l}\text { Customers input, Technical reports, Research journals, } \\
\text { Patents, External experts opinions, External market data }\end{array}$ & $\begin{array}{l}\text { Scenario Planning, Cross Impact } \\
\text { Analysis, Analogies }\end{array}$ \\
\hline & & Dev. & $\begin{array}{l}\text { Customers input, Technical reports, Research journals, } \\
\text { Patents, External experts opinions, External market data }\end{array}$ & $\begin{array}{l}\text { Technology Roadmapping, Scenario } \\
\text { Planning, Trend Extrapolation, Trend } \\
\text { Impact Analysis, Growth Curves }\end{array}$ \\
\hline & \multirow[t]{3}{*}{ SMEs } & Basic & $\begin{array}{l}\text { Internal Expert's opinion, Internal Technical data, } \\
\text { Internal Market data, Top manager's intuitive decision }\end{array}$ & $\begin{array}{l}\text { Data Mining, Analogies, Cross Impact } \\
\text { Analysis }\end{array}$ \\
\hline & & Applied & $\begin{array}{l}\text { Internal Expert's opinion, Internal Technical data, } \\
\text { Internal Market data, Top manager's intuitive decision }\end{array}$ & $\begin{array}{l}\text { Scenario Planning, Cross Impact } \\
\text { Analysis, Analogies }\end{array}$ \\
\hline & & Dev. & $\begin{array}{l}\text { Internal Expert's opinion, Internal Technical data, } \\
\text { Internal Market data, Top manager's intuitive decision }\end{array}$ & $\begin{array}{l}\text { Technology Roadmapping, Scenario } \\
\text { Planning, Trend Extrapolation, Trend } \\
\text { Impact Analysis, Growth Curves }\end{array}$ \\
\hline \multirow{6}{*}{$\begin{array}{l}\text { Business } \\
\text { performance }\end{array}$} & \multirow[t]{3}{*}{ Large } & Basic & $\begin{array}{l}\text { Customers input, Technical reports, Research journals, } \\
\text { Patents, External experts opinions, External market data }\end{array}$ & $\begin{array}{l}\text { Data Mining, Analogies, Cross Impact } \\
\text { Analysis }\end{array}$ \\
\hline & & Applied & $\begin{array}{l}\text { Customers input, Technical reports, Research journals, } \\
\text { Patents, External experts opinions, External market data }\end{array}$ & $\begin{array}{l}\text { Scenario Planning, Cross Impact } \\
\text { Analysis, Analogies }\end{array}$ \\
\hline & & Dev. & $\begin{array}{l}\text { Customers input, Technical reports, Research journals, } \\
\text { Patents, External experts opinions, External market data }\end{array}$ & $\begin{array}{l}\text { Technology Roadmapping, Scenario } \\
\text { Planning, Trend Extrapolation, Trend } \\
\text { Impact Analysis, Growth Curves }\end{array}$ \\
\hline & \multirow[t]{3}{*}{ SMEs } & Basic & $\begin{array}{l}\text { Internal Expert's opinion, Internal Technical data, } \\
\text { Internal Market data, Top manager's intuitive decision }\end{array}$ & $\begin{array}{l}\text { Data Mining, Analogies, Cross Impact } \\
\text { Analysis }\end{array}$ \\
\hline & & Applied & $\begin{array}{l}\text { Internal Expert's opinion, Internal Technical data, } \\
\text { Internal Market data, Top manager's intuitive decision }\end{array}$ & $\begin{array}{l}\text { Scenario Planning, Cross Impact } \\
\text { Analysis, Analogies }\end{array}$ \\
\hline & & Dev. & $\begin{array}{l}\text { Internal Expert's opinion, Internal Technical data, } \\
\text { Internal Market data, Top manager's intuitive decision }\end{array}$ & $\begin{array}{l}\text { Technology Roadmapping, Scenario } \\
\text { Planning, Trend Extrapolation, Trend } \\
\text { Impact Analysis, Growth Curves }\end{array}$ \\
\hline
\end{tabular}

Figure 23 TF data and methods based on technology characteristics and firm size Clearly, firms can benefit from predicting technological changes that not only affect the market and industry structural changes but also create new supply chains and market segments. The identification of the distinct characteristics of effective technology planning is proven to be a fruitful focus for firms' performance. $R \& D$ managers should hone their technology planning skills linked with TF even more than they already have. Integration of equivalent TF and planning capabilities and R\&D 
efforts enables a firm not only to increase R\&D productivity but also to achieve financial success. Hence, the results suggest that an executive management group should enhance their core competence by improving sensing and planning activities.

Second, the results suggest that a management group also should deepen their knowledge of TF techniques and data usage based on their R\&D focus. Moreover, firms should identify and focus on their own distinct and effective approaches to generate expected R\&D outputs and financial outcomes by capturing emerging trends. For example, while firms are involved in applied or basic research, they should adopt normative approaches and qualitative data. Besides, facing the drastic technological change on its turf, a firm's planning activities should pay attention to appropriate TF tools and data. The previous research [427] helps to identify whether a firm uses appropriate TF tools for predicting technological changes in its strategic management of technology planning. Figure 23 illustrates the systematic process as to how to select appropriate TF tools for specific cases.

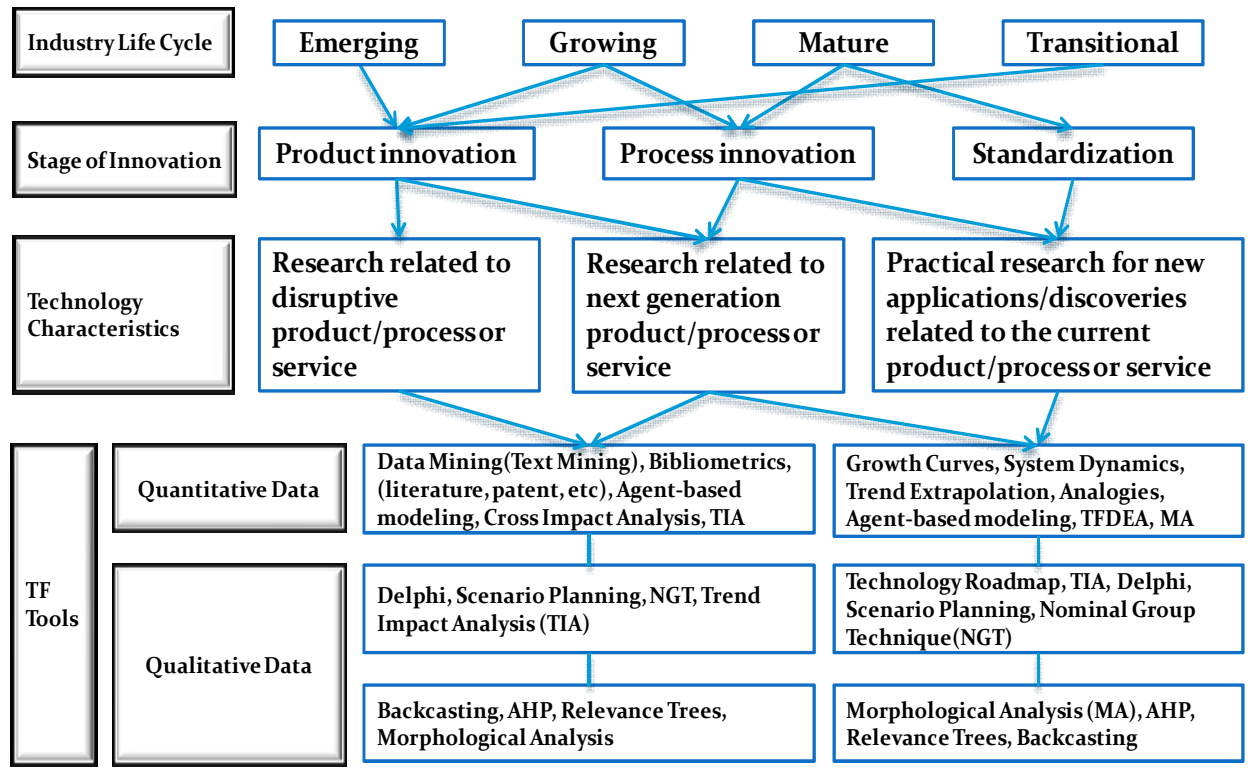

Figure 24 Guidance of appropriate selection with respect to TF activities 
If firms understate TF activities based on technology characteristics, ineffective planning might deteriorate the subsequent $\mathrm{R} \& \mathrm{D}$ outputs and thus result in poor business performance. Consequently, experience and expertise in various TF techniques and data usage is an important complementary asset in expanding a firm's innovative capability. Firms should screen their ideas along with TF to help ensure that they can make an effective strategic decision in the fuzzy front end of new product development.

Finally, in accordance with best practices in TF, firms can gain insight into industry dynamics as well as how to deal with the changing environments that they face. Strategic technology planning associated with TF seems to have value for companies that focus on R\&D activities. The results advance the role of TF in strategic planning as a capability. As a firm has a deeper understanding of TF in strategic technology planning, there is the potential for turning the systematic process toward dynamic capability. As Teece [553] describes this process—sensing and capturing opportunities - this research characterizes systematic strategic technology planning processes as a resource and potential source of competitive advantage. According to a dynamic perspective, the proposed systematic technology planning process should be adapted and evolved for specific conditions and integrated into other organizational processes. 


\section{Chapter 13 Limitations and Future Research}

Survival in every sector now depends on technological innovations leading to innovative products and services and their successful commercialization. Meanwhile, the literature concerning TF activity for particular situations - technology characteristics, market structure, and industry evolution —is still scarce. This study provides basic decision-making guidelines for firms, government agencies, and researchers to effectively implement in TF activities for supporting strategic technology planning as well as implementing R\&D projects in their field. The results of this research help decision makers or forecasters select appropriate techniques in their business domains. Thus, it is significant to note that it requires experience and expertise in various $\mathrm{TF}$ techniques to select appropriate TF methods.

One of the limitations is that this study did not measure objective financial performance - sales growth, ROA, and earnings growth, respectively, but instead inferred them from survey respondents' subjective measures. Further research is required to illuminate the association between $R \& D$ capabilities and actual firm performance. Future research should further investigate the strategic decision making process of technology planning to identify additional criteria to measure $R \& D$ performance related to financial performance. Special care should be taken to identify any other contingent parameters employed in strategic decision-making in the manufacturing sector. Efforts to identify such key factors of R\&D outputs and capabilities might substantially strengthen both firms' practices and academic research.

The other limitation is related to the notion of causality. This research considered the use of TF and technology planning activities as it relates to enhancing 
both R\&D performance and business performance. The results only guarantee the high probability of predicting events rather than the ability to control events. Thus, it allows a limited degree of control. The SEM method cannot prove causation. The relationship between planning and performance still lacks theoretical grounding. A further study may help uncover causation or demonstrate associations between those variables. Despite these limitations, future research should pay more attention to utilize appropriate TF methods and data in strategic technology planning.

Numerous factors may influence a firm's decision to invest in innovation activities. Hence, future research should examine more carefully the impacts of R\&D outputs on financial performance. Several studies indicated that R\&D investments are highly associated with a firm's level of innovation performance [554]-[556]. Prior research indicated that $R \& D$ expenditure has a positive relationship with firm size [556][557]. Moreover, it would be important to analyze multiple perspectives on complex system issues such as societal and institutional environment aspects in this model. Thus, other issues associated with R\&D investment and firm performance should be discussed by further empirical research design. Therefore, it would seem reasonable that future research should focus on comprehensive linkages as illustrated in Figure 5.

Further research is needed to verify the efficiency and effectiveness of combining methods for comparing outcomes in this research. This research was mainly conducted in the U.S. and it could be extended to other regions for comparison of the results. To apply this framework further in a different setting, the survey could be distributed to a more geographically dispersed sample set in the world for comparison. 
For example, interesting follow-up studies might investigate other countries in order to examine cultural or environmental differences. Abstract-based or keyword-based coword analysis in the literature with respect to composite TF techniques may be ripe for a quantitative analysis of the relationship among TF methods. It might be useful to identify TF tools based on the product and service category. Further improvements including managerial implications based on firm size are recommended. Lastly, more comprehensive reviews including econometrics, correlation method, and a causal model would benefit the analysis.

In spite of several limitations, it is meaningful that this research provides a current snapshot of how firms across industries implement best practices in TF to facilitate organizational functions and strategic technology planning in the United States. The study also presents an informative research focus as well as potential research gaps in TF fields to the researchers and practitioners. New approaches with the different combination of TF tools would be open to all researchers and practitioners. 


\section{References}

[1] J. R. Bright, Technological Forecasting For Industry and Government: Methods and Applications. Englewood Cliffs, N.J.: Prentice-Hall Inc., 1968.

[2] R. U. Ayres, Technological Forecasting and Long-Range Planning. New York: McGraw-Hill, Inc., 1969.

[3] B. Payne, "Long-range and strategic planning-its history and its future," J. Eng. Ind., vol. 93, no. 2, p. 415, 1971.

[4] R. M. Fulmer and L. W. Rue, "The practice and profitability of long-range planning," Manag. Plan., vol. 22, no. 6, pp. 1-7, 1974.

[5] G. M. Scott, "Strategic planning for technology products," R\&D Manag., vol. 31, no. 1, pp. 15-26, 2001.

[6] N. O'Regan and A. Ghobadian, "Strategic planning - a comparison of high and low technology manufacturing small firms," Technovation, vol. 25, no. 10, pp. 1107-1117, 2005.

[7] R. J. Arend, Y. L. Zhao, M. Song, and S. Im, "Strategic planning as a complex and enabling managerial tool," Strateg. Manag. J., vol. 38, no. 1, pp. 1741-1752, 2015.

[8] H. E. Wrapp, “Organization for long-range planning," Harv. Bus. Rev., vol. 35, no. 1, pp. 37-47, 1957.

[9] W. L. Swager, "Strategic planning I: the roles of technological forecasting," Technol. Forecast. Soc. Chang., vol. 4, pp. 85-99, 1972.

[10] R. N. Foster, "Boosting the payoff From R\&D," Res. Manage., vol. 25, no. 1, pp. 22-27, 1982.

[11] W. L. Swager, "Strategic planning III: objectives and program options," Technol. Forecast. Soc. Change, vol. 4, no. 3, pp. 283-300, 1973.

[12] A. W. Blackman, "New venture planning: the role of technological forecasting," Technol. Forecast. Soc. Change, vol. 5, pp. 25-49, 1973.

[13] E. Jantsch, Technological Forecasting In Perspective: A Framework for Technological Forecasting, its Techniques and Organization. Organisation for Economic Co-operation and Development, 1967.

[14] R. L. Schmidt and J. R. Freeland, "Recent progress in modeling R\&D projectselection processes," IEEE Trans. Eng. Manag., vol. 39, no. 2, pp. 189-201, 1992.

[15] T. S. Kuhn, The Structure of Scientific Revolutions, 2nd ed., vol. II, no. 2. USA: The University of Chicago, 1970.

[16] D. Foray, "The dynamic implications of increasing returns: technological change and path dependent inefficiency," Int. J. Ind. Organ., vol. 15, no. 6, pp. 733-752, 
Oct. 1997.

[17] J. L. Bower and C. M. Christensen, "Disruptive technologies: catching the wave," Harv. Bus. Rev., vol. 73, no. 1, pp. 43-53, 1995.

[18] P. Anderson and M. L. Tushman, "Technological discontinuities and dominant designs: a cyclical model of technological change," Adm. Sci. $Q$., vol. 35, no. 4, pp. 604-633, 1990.

[19] C. M. Christensen and M. Overdorf, "Meeting the challenge of disruptive change," Harv. Bus. Rev., vol. 78, no. 2, pp. 1-10, 2000.

[20] H. P. Tschirky, "The role of technology forecasting and assessment in technology management," $R \& D$ Manag., vol. 24, no. 2, pp. 121-129, 1994.

[21] M. Iansiti, "How the incumbent can win: managing technological transitions in the semiconductor industry," Manage. Sci., vol. 46, no. 2, pp. 169-185, 2000.

[22] R. L. Daft and K. E. Weick, "Toward a model of organizations as interpretation systems," Acad. Manag. Rev., vol. 9, no. 2, pp. 284-295, 1984.

[23] T. Daim, G. Rueda, H. Martin, and P. Gerdsri, "Forecasting emerging technologies: use of bibliometrics and patent analysis," Technol. Forecast. Soc. Change, vol. 73, no. 8, pp. 981-1012, Oct. 2006.

[24] S. P. Schnaars, Megamistakes: Forecasting and The Myth of Rapid Technological Change. New York and London: Free Press, 1989.

[25] V. Coates et al., "On the future of technological forecasting," Technol. Forecast. Soc. Change, vol. 67, no. 1, pp. 1-17, May 2001.

[26] S. Mishra, S. G. Deshmukh, and P. Vrat, "Matching of technological forecasting technique to a technology," Technol. Forecast. Soc. Change, vol. 69, no. 1, pp. $1-27,2002$.

[27] H. Grupp and H. A. Linstone, "National technology foresight activities around the globe: resurrection and new paradigms," Technol. Forecast. Soc. Change, vol. 60 , no. 1, pp. 85-94, 1999.

[28] Donald A. Schon, "Forecasting and technological forecasting," Daedalus, vol. 96, no. 3, pp. 759-770, 1967.

[29] J. B. Quinn, “Technological forecasting," Harv. Bus. Rev., vol. 45, no. 2, pp. 89106, 1967.

[30] R. C. J. Lenz, “Technological Forecasting," US Air Force, Cameron station, Alexandria, Virginia, 1962.

[31] Marvin J. Cetron, Technological Forecasting: A Practical Approach. New York London Paris: Gordon and Breach, Science, 1969.

[32] J. P. Martino, Technological Forecasting for Decision Making, Third. New York, NY: McGraw-Hill, Inc., 1993. 
[33] William Ascher, Forecasting: An Appraisal for Policy-Makers and Planners. The Johns Hopkins University Press, 1979.

[34] S. M. Millett and E. J. Honton, A Manager's Guide to Technology Forecasting and Strategy Analysis Methods. Columbus, Ohio: Battelle Press, 1991.

[35] National Resources Committee, "Technological Trends and National Policy, Including the Social Implications of New Inventions," Washington, DC, 1937.

[36] K. Cuhls, "From forecasting to foresight processes - new participative foresight activities in Germany," J. Forecast., vol. 22, no. 2-3, pp. 93-111, Mar. 2003.

[37] F. J. Coates, "Foresight in federal government policy making," Futur. Res. Q., vol. 1, no. 2, pp. 29-53, 1985.

[38] Ben R. Martin, "Foresight in science and technology," Technol. Anal. Strateg. Manag., vol. 7, no. 2, pp. 139-168, 1995.

[39] F. J. Coates, J. B. Mahaffie, and A. Hines, "Technological forecasting: 19701993," Technol. Forecast. Soc. Change, vol. 47, no. 1, pp. 23-33, 1994.

[40] T. Shin, S. Hong, and H. Grupp, "Technology foresight activities in Korea and in countries closing the technology gap," Technol. Forecast. Soc. Change, vol. 60, no. 1, pp. 71-84, 1999.

[41] K. Blind, K. Cuhls, and H. Grupp, "Current foresight activities in central Europe,” Technol. Forecast. Soc. Change, vol. 60, no. 1, pp. 15-35, Jan. 1999.

[42] I. Miles, "The development of technology foresight: a review," Technol. Forecast. Soc. Change, vol. 77, no. 9, pp. 1448-1456, Nov. 2010.

[43] T. Könnölä, V. Brummer, and A. Salo, "Diversity in foresight: insights from the fostering of innovation ideas," Technol. Forecast. Soc. Change, vol. 74, no. 5, pp. 608-626, Jun. 2007.

[44] B. R. Martin and R. Johnston, "Technology foresight for wiring up the national innovation system: experiences in Britain, Australia, and New Zealand," Technol. Forecast. Soc. Change, vol. 60, no. 1, pp. 37-54, 1999.

[45] B. van der Meulen, "The impact of foresight on environmental science and technology policy in the Netherlands," Futures, vol. 31, no. 1, pp. 7-23, 1999.

[46] B. R. Martin, "The origins of the concept of 'foresight' in science and technology: an insider's perspective," Technol. Forecast. Soc. Change, vol. 77, no. 9, pp. 1438-1447, Nov. 2010.

[47] B. R. Martin, “Technology Foresight in a Rapidly Globalizing Economy,” no. April. UNIDO, Vienna, Austria, 2001.

[48] J. Heraud and K. Cuhls, "Current foresight activities in France, Spain, and Italy," Technol. Forecast. Soc. Change, vol. 60, no. 1, pp. 55-70, Jan. 1999.

[49] J. Molas-Gallart, R. Barre, M. Zappacosta, and J. Gavigan, A Trans-National 
Analysis of Results and Implications of Industrially-oriented Technology Foresight Studies, no. February. European Commission, 2002.

[50] A. Eerola and B. H. Jørgensen, "Technology Foresight in the Nordic Countries," 2002 .

[51] T. Kuwahara, "Technology forecasting activities in Japan," Technol. Forecast. Soc. Change, vol. 60, no. 1, pp. 5-14, Jan. 1999.

[52] R. R. Levary and D. Han, "Choosing a technological forecasting method," Ind. Manag., vol. 1, no. 37, 1995.

[53] J. B. Robinson, "Backing into the future: on the methodological and institutional biases embedded in energy supply and demand forecasting," Technol. Forecast. Soc. Change, vol. 21, no. 3, pp. 229-240, 1982.

[54] G. Dosi, "Technological paradigms and technological trajectories," Res. Policy, vol. 11, no. 3, pp. 147-162, Jun. 1982.

[55] J. H. Vanston, "Technology forecasting: a practical tool for rationalizing the R\&D process," New Telecom Q., vol. 4, no. 1, pp. 57-62, 1996.

[56] E. B. Roberts, "Exploratory and normative technological forecasting: a critical appraisal," Technol. Forecast., vol. 1(2), p. 113, 1969.

[57] B. C. Twiss, Managing Technological Innovation, 4th ed. London and New York: Longman, 1992.

[58] Technology Futures Analysis Methods Working Group, "Technology futures analysis: toward integration of the field and new methods," Technol. Forecast. Soc. Change, vol. 71, no. 3, pp. 287-303, Mar. 2004.

[59] E. Jantsch, "Technological Forecasting in Corporate Planning," in Technological Forecasting and Corporate Strategy, and B. T. Gordon Wills, David Ashton, Ed. New York: American Elsevier Publishing Company Inc., 1969, pp. 17-38.

[60] J. P. Martino, "Technological forecasting-an overview," Manage. Sci., vol. 26, no. 1, pp. 28-33, 1980.

[61] J. P. Martino, "A review of selected recent advances in technological forecasting," Technol. Forecast. Soc. Change, vol. 70, no. 8, pp. 719-733, Oct. 2003.

[62] S. P. Schnaars, "Situational factors affecting forecast accuracy," J. Mark. Res., vol. 21, no. 3, pp. 290-297, 1984.

[63] A. L. Porter, A. T. Roper, T. W. Mason, F. A. Rossini, J. Banks, and B. J. Wiederholt, Forecasting and Management of Technology. New York, Chichester, Brisbane, Toronto, Singapore: John Wiley \& Sons, Inc., 1991.

[64] T. B. Robertson, The Chemical Basis of Growth and Senescenc. Philadelphia and London: J. B. Lippincott Company, 1923. 
[65] A. W. Blackman, "A mathematical model for trend forecasts," Technol. Forecast. Soc. Change, vol. 3, pp. 441-452, 1972.

[66] J. C. Fisher and R. H. Pry, "A simple substitution model of technological change,” Technol. Forecast. Soc. Change, vol. 88, no. 3, pp. 75-88, 1971.

[67] E. Mansfield, "Technical change and the rate of imitation," Econometrica, vol. 29, no. 4, pp. 741-766, 1961.

[68] N. Meade and T. Islam, "Technological forecasting-model selection, model stability, and combining models," Manage. Sci., vol. 44, no. 8, pp. 1115-1130, 1998.

[69] Z. Griliches, "Hybrid corn: an exploration in the economics of technological change," Econometrica, vol. 25, no. 4, pp. 501-522, 1957.

[70] C. P. Winsor, "The Gompertz curve as a growth curve," in National Academy of Sciences, 1932, vol. 18, no. 1, pp. 1-8.

[71] F. M. Bass, “A new product growth for model consumer durables," Manage. Sci., vol. 15 , no. 5, pp. 215-227, 1969.

[72] H. Levenbach and B. E. Reuter, "Forecasting trending time series with relative growth rate models," Technometrics, vol. 18, no. 3, pp. 261-272, 1976.

[73] M. N. Sharif and M. N. Islam, "The Weibull distribution as a general model for forecasting technological change," Technol. Forecast. Soc. Change, vol. 18, no. 3, pp. 247-256, 1980.

[74] C. Easingwood, V. Mahajan, and E. Muller, "A nonsymmetric responding logistic model for forecasting technological substitution," Technol. Forecast. Soc. Change, vol. 20, no. 3, pp. 199-213, Nov. 1981.

[75] A. C. Harvey, "Time series forecasting based on the logistic curve," J. Oper. Res. Soc., vol. 35, no. 7, pp. 641-646, 1984.

[76] F. De Glas, "Fiction and bibliometrics: analyzing a publishing house's stocklist," Libri, vol. 36, no. 1, pp. 40-64, 1986.

[77] J. M. Cattell, "Statistics of American psychologists," Am. J. Psychol., vol. 14, no. 3, pp. 310-328, 1903.

[78] W. W. Hood and C. S. Wilson, "The literature of bibliometrics, scientometrics, and informetrics," Scientometrics, vol. 52, no. 2, pp. 291-314, 2001.

[79] A. Pritchard, "Statistical bibliography or bibliometrics?," J. Doc., vol. 25, pp. 348-349, 1969.

[80] J. Tague-sutcliffe, "An introduction to informetrics," Inf. Process. Manag., vol. 28, no. I, pp. 1-3, 1992.

[81] F. Narin, D. Olivastro, and K. A. Stevens, "Bibliometrics/theory, practice and problems," Eval. Rev., vol. 18, no. 1, pp. 65-76, Feb. 1994. 
[82] S. Morris, C. DeYong, Z. Wu, S. Salman, and D. Yemenu, "DIVA: a visualization system for exploring document databases for technology forecasting," Comput. Ind. Eng., vol. 43, no. 4, pp. 841-862, Sep. 2002.

[83] M. Bengisu and R. Nekhili, "Forecasting emerging technologies with the aid of science and technology databases," Technol. Forecast. Soc. Change, vol. 73, no. 7, pp. 835-844, Sep. 2006.

[84] P. Losiewicz, D. W. Oard, and R. Kostoff, "Textual data mining to support science and technology management," J. Intell. Inf. Syst., vol. 15, no. 2, pp. 99 $119,2000$.

[85] R. Kostoff, "Database tomography: multidisciplinary research thrusts from coword analysis," in Portland International Conference on Management of Engineering and Technology, 1991, pp. 27-31.

[86] R. Kostoff, "Database tomography: origins and duplications," Compet. Intell. Rev., vol. 5, 1994.

[87] A. L. Porter and M. J. Detampel, “Technology opportunities analysis," Technol. Forecast. Soc. Change, vol. 49, no. 3, pp. 237-255, 1995.

[88] Y. Kajikawa, K. Abe, and S. Noda, "Filling the gap between researchers studying different materials and different methods: a proposal for structured keywords," $J$. Inf. Sci., vol. 32, no. 6, pp. 511-524, Dec. 2006.

[89] Y. Kajikawa, J. Yoshikawa, Y. Takeda, and K. Matsushima, "Tracking emerging technologies in energy research: toward a roadmap for sustainable energy," Technol. Forecast. Soc. Change, vol. 75, no. 6, pp. 771-782, Jul. 2008.

[90] M. S. Brenner, "Technology intelligence and technology scouting," Compet. Intell. Rev., vol. 7, no. 3, pp. 20-27, 1996.

[91] P. L. K. Gross and E. M. Gross, "College libraries and chemical education," Science, vol. 66, no. 1713, pp. 385-389, 1927.

[92] A. J. Lotka, "The frequency distribution of scientific productivity," J. Washingt. Acad. Sci., vol. 16, pp. 317-323, 1926.

[93] G. Zipf, Selective Studies and the Principle of Relative Frequency in Language. Cambridge: Mass, 1932.

[94] S. C. Bradford, "Sources of information on specific subjects," J. Inf. Sci., vol. 10, no. 4, pp. 173-180, 1985.

[95] M. M. Kessler, "Bibliographic coupling extended in time: ten case histories," Inf. Storage Retr., vol. 1, no. 4, pp. 169-187, 1963.

[96] M. M. Kessler, "An experimental study of bibliographic coupling between technical papers," IEEE Trans. Inf. Theory, vol. 9, no. 1, p. 49, 1963.

[97] D. J. D. S. Price, "Networks of scientific papers," Science, vol. 149, no. 3683, pp. 510-515, 1965. 
[98] H. Small, "Co-citation in the scientific literature: a new measure of the relationship between two document," J. Am. Soc. Inf. Sci., vol. 24, no. 4, pp. 265-269, 1973.

[99] H. Small and B. C. Griffith, "The structure of scientific literatures I: identifying and graphing specialties," Sci. Stud. (St. Bonaventure)., vol. 4, no. 1, pp. 17-40, 1974.

[100] P. Healey, H. Rothman, and P. K. Hoch, “An experiment in science mapping for research planning," Res. Policy, vol. 15, no. 5, pp. 233-251, Oct. 1986.

[101] M. Callon, J.-P. Courtial, and W. A. Turner, "PROXAN: a visual display technique for scientific and technical problem networks." Second Workshop on the Measurement of R\&D Output, Paris, France, pp. 5-6, 1979.

[102] M. Callon, J.-P. Courtial, W. A. Turner, and S. Bauin, "From translations to problematic networks: an introduction to co-word analysis," Soc. Sci. Inf., vol. 22, no. 2, pp. 191-235, Mar. 1983.

[103] A. Rip and J.-P. Courtial, "Co-word maps of biotechnology: an example of cognitive scientometrics," Scientometrics, vol. 6, no. 6, pp. 381-400, 1984.

[104] H. P. F. Peters, D. Hartmann, and A. F. J. Van Raan, "Monitoring Advances in Chemical Engineering: A Multi-Database Approach," Research Report to the Netherlands Technological Research Council, Report SSU-87-01, Leiden, 1987.

[105] A. F. J. Van Raan and H. P. F. Peters, "Dynamics of a scientific field analysed by co-subfield structures," Scientometrics, vol. 15, no. 5-6, pp. 607-620, May 1989.

[106] J. W. R. Tijssen, "A quantitative assessment of interdisciplinary structures in science and technology: co-classification analysis of energy research," Res. Policy, vol. 21, no. 1, pp. 27-44, 1992.

[107] R. S. Campbell, "Patent trends as a technological forecasting tool," World Pat. Inf., vol. 5, no. 3, pp. 137-143, 1983.

[108] H. Ernst, "Patent information for strategic technology management," World Pat. Inf., vol. 25, no. 3, pp. 233-242, Sep. 2003.

[109] A. L. Applebaum, “A monthly application curve,” J. Pat. Off. Soc., vol. 2, p. 433, 1919.

[110] M. Jefferson, "The geographic distribution of inventiveness," Geogr. Rev., vol. 19, no. 4, pp. 649-661, 1929.

[111] L. J. Carr, "The patenting performance of 1,000 inventors during ten years," Am. J. Sociol., vol. 37, no. 4, pp. 569-580, 1932.

[112] F. M. Scherer, "Firm size, market structure, opportunity, and the output of patented inventions," Am. Econ. Rev., vol. 55, no. 5, pp. 1097-1125, 1965.

[113] A. B. Stafford, "Is the rate of invention declining?," Chicago Journals, vol. 57, no. 6 , pp. 539-545, 1952. 
[114] J. Schmookler, "The level of inventive activity," Rev. Econ. Stat., vol. 36, no. 2, pp. 183-190, 1954.

[115] S. C. Gilfillan, Sociology of Invention. Chicago: Follett Publishing Co, 1935.

[116] S. C. Gilfillan, "The prediction of technical change," Rev. Econ. Stat., vol. 34, no. 4, pp. $368-385,1952$.

[117] W. D. Reekie, "Patent data as a guide to industrial activity," Res. Policy, vol. 2, no. 3, pp. 246-264, Oct. 1973.

[118] D. Schiffel and C. Kitti, "Rates of invention: international patent comparisons," Res. Policy, vol. 7, pp. 324-340, 1978.

[119] Z. Griliches, "Patent statistics as economic indicators: a survey," J. Econ. Lit., vol. 28, no. 4, pp. 1661-1707, 1990.

[120] K. Pavitt, "Patent statistics as indicators of innovative activities: possibilities and problems," Scientometrics, vol. 7, no. 1-2, pp. 77-99, 1985.

[121] F. Narin, "Patent bibliometrics," Scientometrics, vol. 30, no. 1, pp. 147-155, 1994.

[122] M. M. S. Karki and K. S. Krishnan, "Patent citation analysis: a policy analysis tool," World Pat. Inf., vol. 19, no. 4, pp. 269-272, 1997.

[123] M. Trajtenberg, "A penny for your quotes: patent citations and the value of innovations," RAND J. Econ., vol. 21, no. 1, pp. 172-187, 1990.

[124] E. Garfield, "Patent citation indexing and the notions of novelty, similarity, and relevance," J. Chem. Doc., vol. 6, no. 2, pp. 63-65, 1966.

[125] P. Ellis, G. Hepburn, and C. Oppenheim, "Studies on patent citation networks," J. Doc., vol. 34, no. 1, pp. 12-20, 1978.

[126] R. Fontana, A. Nuvolari, and B. Verspagen, "Mapping technological trajectories as patent citation networks: an application to data communication standards," Econ. Innov. New Technol., vol. 18, no. 4, pp. 311-336, 2009.

[127] M. Callon, "Pinpointing Industrial Invention: An Exploration of Quantitative Methods for The Analysis of Patents," in Mapping the dynamics of science and technology, M. Callon, J. Law, and A. Rip, Eds. UK: Palgrave Macmillan, 1986, pp. 163-188.

[128] Arthur H. Seidel, "Citation system for patent office," J. Pat. Off. Soc., vol. 31, no. 5 , p. 54, 1949.

[129] K. Pavitt, "Uses and Abuses of Patent Statistics," in Handbook of Quantitative Studies of Science and Technology, A. F. J. van Raan, Ed. Amsterdam: North Holland: Elsevier Publishers, 1988, pp. 509-536.

[130] T. E. Stuart and J. M. Podolny, "Local search and the evolution of technological capabilities,” Strateg. Manag. J., vol. 17, pp. 21-38, Jul. 1996. 
[131] M. Callon, J.-P. Courtial, and F. Laville, "Co-word analysis as a tool for describing the network of interactions between basic and technological research: the case of polymer chemsitry," Scientometrics, vol. 22, no. 1, pp. 155-205, Sep. 1991.

[132] M. H. Gorn, Harnessing the Genie: Science and Technology Forecasting for the Air Force 1944-1986. Washington, D.C.: U.S. Government Printing Office, 1988.

[133] S. W. Cunningham, A. L. Porter, and N. C. Newman, "Special issue on tech mining," Technol. Forecast. Soc. Change, vol. 73, no. 8, pp. 915-922, Oct. 2006.

[134] M. C. Lovell, "Data mining," Rev. Econ. Stat., vol. 65, no. 1, pp. 1-12, 1983.

[135] U. Fayyad, G. Piatetsky-shapiro, and P. Smyth, "From data mining to knowledge discovery in databases," AI Mag., vol. 17, no. 3, pp. 37-54, 1996.

[136] U. Fayyad, G. Piatetsky-Shapiro, and P. Smyth, "The KDD process for extracting useful knowledge from volumes of data," Commun. ACM, vol. 39, no. 11, pp. 27-34, Nov. 1996.

[137] H. F. Moed, W. Glanzel, and U. Schmoch, Handbook of Quantitative Science and Technology Research: The Use of Publication and Patent Statistics in Studies of S\&T Systems. New York, Boston, Dordrecht, London, Moscow: Springer Netherlandshers, 2005.

[138] R. Feldman, I. Dagan, and H. Hirsh, "Mining text using keyword distributions," J. Intell. Inf. Syst., vol. 10, no. 3, pp. 281-300, 1998.

[139] R. N. Kostoff, D. R. Toothman, H. J. Eberhart, and J. A. Humenik, "Text mining using database tomography and bibliometrics: a review," Technol. Forecast. Soc. Change, vol. 68, no. 3, pp. 223-253, 2001.

[140] R. Kostoff, H. J. Eberhart, and D. R. Toothman, "Database tomography for information retrieval,” J. Inf. Sci., vol. 23, no. 4, pp. 301-311, Aug. 1997.

[141] R. Kostoff, H. J. Eberhart, and D. R. Toothman, "Database tomography for technical intelligence: a roadmap of the near-earth space science and technology literature," Inf. Process. Manag., vol. 34, no. 1, pp. 69-85, Jan. 1998.

[142] A. L. Porter, “Tech Mining,” Competitive Intelligence Magazine, vol. 8, no. 1, pp. 30-37, 2005.

[143] A. L. Porter, “Tech Mining for Future-oriented Technology Analysis,” 2009.

[144] W. J. Frawley, G. Piatetsky-shapiro, and C. J. Matheus, Knowledge Discovery in Databases: An Overview. in Knowledge Discovery in Databases. MIT Press, 1991.

[145] R. Feldman and I. Dagan, "KDT - knowledge discovery in texts," in the First International Conference on Knowledge Discovery from Databases, 1995.

[146] T. J. O’Connor, “A methodology for analogies,” Technol. Forecast. Soc. Change, 
vol. 2, no. 3, pp. 289-309, 1971.

[147] J. P. Martino, "Forecasting the Progress of Technology," in An Introduction to Technological Forecasting, J. P. Martino, Ed. New York, Londong, Paris: Gordon and Breach, Science, 1972, pp. 13-24.

[148] T. J. Gordon and H. Hayward, "Initial experiments with the cross impact matrix method of forecasting," Futures, vol. 1, no. 2, pp. 100-116, Dec. 1968.

[149] E. H. Johnson, "Some computational aspects of cross impact matrix forecasting," Futures, vol. 2, no. 2, pp. 123-131, 1970.

[150] T. J. Gordon, "Cross-impact matrices: an illustration of their use for policy analysis," Futures, vol. 1, no. 6, pp. 527-531, Dec. 1969.

[151] E. Novaky and K. Lorant, "A method for the analysis of interrelationships between mutually connected events: a cross-impact method," Technol. Forecast. Soc. Change, vol. 12, no. 2, pp. 201-212, 1978.

[152] R. Bradfield, G. Wright, G. Burt, G. Cairns, and K. Van Der Heijden, "The origins and evolution of scenario techniques in long range business planning," Futures, vol. 37, no. 8, pp. 795-812, Oct. 2005.

[153] W. R. Huss and E. J. Honton, "Scenario planning - what style should you use?," Long Range Plann., vol. 20, no. 4, pp. 21-29, 1987.

[154] S. Enzer, "INTERAX - An interactive model for studying future business environments: Part I," Technol. Forecast. Soc. Change, vol. 17, no. 2, pp. 141159, Jun. 1980.

[155] D. W. Bunn and A. Salo, "Forecasting with scenarios," Eur. J. Oper. Res., vol. 68, no. 3, pp. 291-303, Aug. 1993.

[156] W. R. Huss, “A move toward scenario analysis," Int. J. Forecast., vol. 4, no. 3, pp. 377-388, 1988.

[157] S. Enzer, "Delphi and cross-impact techniques: an effective combination for systematic futures analysis," Futures, vol. 3, no. 1, pp. 48-61, 1971.

[158] J. W. Forrester, Industrial Dynamics. Cambridge, MA: Wright-Allen Press, 1961.

[159] J. W. Forrester, "Industrial dynamics-after the first decade," Manage. Sci., vol. 14, no. 7, pp. 398-415, 1968.

[160] J. W. Forrester, "System Dynamics and the Lessons of 35 years," in A Systemsbased Approach to Policymaking, K. B. De Greene, Ed. MIT: Springer, 1991, pp. $1-35$.

[161] J. W. Forrester, "Information sources for modeling the national economy," J. Am. Stat. Assoc., vol. 75, no. 371, pp. 555-566, 1980.

[162] J. W. Forrester, Urban Dynamics. Cambridge, MA: MIT Press, 1969.

[163] E. F. Wolstenholme, System Enquiry: A System Dynamics Approach. New York, 
NY: John Wiley and Sons, 1990.

[164] L. F. Luna-Reyes and D. L. Andersen, "Collecting and analyzing qualitative data for system dynamics: methods and models," Syst. Dyn. Rev., vol. 19, no. 4, pp. 271-296, 2003.

[165] E. F. Wolstenholme, "System dynamics in perspective," J. Oper. Res. Soc., vol. 33 , no. 6, pp. 547-556, 1982.

[166] T. J. Gordon and J. Stover, "Using perceptions and data about the future to improve the simulation of complex systems," Technol. Forecast. Soc. Change, vol. 9, no. 1-2, pp. 191-211, Jan. 1976.

[167] J. Stover, "The use of probabilistic system dynamics an analysis of national development policies: A study of the economic growth and income distribution in Uruguay," in Proceedings of the 1975 Summer Computer Simulation Conferences, 1975.

[168] J. W. Forrester, "System dynamics, systems thinking, and soft OR," Syst. Dyn. Rev., vol. 10, no. 2, pp. 245-256, 1994.

[169] G. P. Richardson, "Problems for the future of system dynamics," Syst. Dyn. Rev., vol. 12, no. 2, pp. 141-157, 1996.

[170] J. H. Holland and J. H. Miller, "Artificial adaptive agents in economic theory," Am. Econ. Rev., vol. 81, no. 2, pp. 365-370, 1991.

[171] J. M. Epstein and R. Axtell, Growing Artificial Societies: Social Science from the Bottom Up. Washington, D.C.: Brookings Institution Press, 1996.

[172] H. Dawid, "Agent-based Models of Innovation and Technological Change," in Handbook of Computational Economics, vol. 2, L. Tesfatsion and K. L. Judd, Eds. New York, London, Sydeney, Paris: North Holland, 2006, pp. 1235-1272.

[173] W. R. Ashby, An Introduction to Cybernetics. London: Chapman \& Hall Ltd, 1956.

[174] J. Von Neumann and A. W. Burks, "Theory of self-reproducing automata," IEEE Trans. Neural Networks, vol. 5, no. 1, pp. 3-14, 1966.

[175] D. E. Rumelhart, J. L. McClelland, and PDP Research Group, Parallel Distributed Processing: Explorations in the Microstructure of Cognition Volume1: Foundations. Cambridge, MA: The MIT Press, 1986.

[176] D. Harel, "Dynamic logic," in Handbook of Philosophical Logic Volume II: Extensions of Classical Logic, D. M. Gabbay and F. Guenthner, Eds. Dordrecht, Boston, Lancaster: D. Reidel, 1984, pp. 497-604.

[177] M. Wooldridge and N. R. Jennings, "Intelligent agents : theory and practice," Knowl. Eng. Rev., vol. 10, no. 2, pp. 115-152, 1995.

[178] D. J. Watts and S. H. Strogatz, "Collective dynamics of 'small-world' networks.," Nature, vol. 393, no. 6684, pp. 440-442, 1998. 
[179] J. D. Bohlmann, R. J. Calantone, and M. Zhao, "The effects of market network heterogeneity on innovation diffusion: An agent based modeling approach," $J$. Prod. Innov. Manag., vol. 27, no. 5, pp. 741-760, Jul. 2010.

[180] S. A. Delre, W. Jager, and M. A. Janssen, "Diffusion dynamics in small-world networks with heterogeneous consumers," Comput. Math. Organ. Theory, vol. 13, no. 2, pp. 185-202, 2007.

[181] T. J. Gordon, J. C. Glenn, and A. Jakil, "Frontiers of futures research: What's next?," Technol. Forecast. Soc. Change, vol. 72, no. 9, pp. 1064-1069, 2005.

[182] J. Shin and Y. Park, "Brownian agent-based technology forecasting," Technol. Forecast. Soc. Change, vol. 76, no. 8, pp. 1078-1091, 2009.

[183] A. L. Hicks and T. L. Theis, "An agent based approach to the potential for rebound resulting from evolution of residential lighting technologies," Int. J. Life Cycle Assess., vol. 19, no. 2, pp. 370-376, 2014.

[184] P. L. Kolominsky-Rabas et al., "Technology foresight for medical device development through hybrid simulation: The ProHTA Project," Technol. Forecast. Soc. Change, vol. 97, pp. 105-114, 2015.

[185] A. Negahban, L. Yilmaz, and T. Nall, "Managing production level in new product diffusion: an agent-based simulation approach," Int. J. Prod. Res., vol. 52, no. 17, pp. 4950-4966, 2014.

[186] T. C. Schelling, "Dynamic models of segregation," J. Math. Sociol., vol. 1, pp. 143-186, 1971.

[187] J. . Beasley, "Allocating fixed costs and resources via data envelopment analysis," Eur. J. Oper. Res., vol. 147, no. 1, pp. 198-216, 2003.

[188] G. Debreu, "The coefficient of resource utilization," Econometrica, vol. 19, no. 3, pp. 273-292, 1951.

[189] M. J. Farrell, "The measurement of productive efficiency," J. R. Stat. Soc. Ser. A, vol. 120 , no. 3, pp. 253-290, 1957.

[190] A. Charnes, W. W. Cooper, and E. Rhodes., "Measuring the efficiency of decision making units," Eur. J. Oper. Res., vol. 2, no. 6, pp. 429-444, 1978.

[191] R. D. Banker, A. Charnes, and W. W. Cooper, "Some models for estimating technical and scale inefficiencies in Data Envelopment Analysis," Manage. Sci., vol. 30, no. 9, pp. 1078-1092, 1984.

[192] T. R. Anderson, T. U. Daim, and J. Kim, "Technology forecasting for wireless communication," Technovation, vol. 28, no. 9, pp. 602-614, Sep. 2008.

[193] O. L. Inman, T. R. Anderson, and R. R. Harmon, "Predicting U.S. jet fighter aircraft introductions from 1944 to 1982: a dogfight between regression and TFDEA," Technol. Forecast. Soc. Change, vol. 73, no. 9, pp. 1178-1187, Nov. 2006. 
[194] O. L. Inman, "Technology Forecasting using Data Envelopment Analysis," Portland State University, 2004.

[195] T. Anderson, K. Hollingsworth, and O. L. Inman, "Assessing the rate of change in the enterprise database system market over time using DEA," PICMET ' 01. Portl. Int. Conf. Manag. Eng. Technol. Proc. Vol.1 B. Summ. (IEEE Cat. No.01CH37199), pp. 384-390, 2001.

[196] H. A. Linstone, "TFSC: 1969-1999," Technol. Forecast. Soc. Change, vol. 62, no. 1, pp. 1-8, 1999.

[197] C. W. Churchman, R. L. Ackoff, and E. L. Arnoff, Introduction to Operations Research. Oxford, England: Wiley, 1957.

[198] W. T. Martin and J. M. Sharp, "Reverse factor analysis: a modification of relevance tree techniques," Technol. Forecast. Soc. Change, vol. 4, no. 4, pp. 355-373, 1973.

[199] T. L. Saaty, The Analytic Hierarchy Process: Planning, Priority Setting, Resources Allocation. New York: McGraw-Hill, Inc., 1980.

[200] O. S. Vaidya and S. Kumar, "Analytic hierarchy process: an overview of applications," Eur. J. Oper. Res., vol. 169, no. 1, pp. 1-29, Feb. 2006.

[201] S.-B. Kim and K.-S. Whang, "Forecasting the capabilities of the Korean civil aircraft industry," Omega, vol. 21, no. 1, pp. 91-98, Jan. 1993.

[202] N. Gerdsri and D. F. Kocaoglu, "Applying the Analytic Hierarchy Process (AHP) to build a strategic framework for technology roadmapping," Math. Comput. Model., vol. 46, no. 7-8, pp. 1071-1080, Oct. 2007.

[203] I. B. Huang, J. Keisler, and I. Linkov, "Multi-criteria decision analysis in environmental sciences: ten years of applications and trends," Sci. Total Environ., vol. 409, no. 19, pp. 3578-3594, Sep. 2011.

[204] H. A. Donegan, F. J. Dodd, and T. B. M. McMaster, "A new approach to AHP decision-making,” J. R. Stat. Soc. Ser. D Stat., vol. 41, no. 3, pp. 295-302, 1992.

[205] T. L. Saaty, "A scaling method for priorities in hierarchical structures," J. Math. Psychol., vol. 15, no. 3, pp. 234-281, 1977.

[206] A. Salo, T. Gustafsson, and R. Ramanathan, "Multicriteria methods for technology foresight," J. Forecast., vol. 22, pp. 235-255, Mar. 2003.

[207] J. W. von. Goethe, Scientific Studies. New York: Suhrkamp Publishers, 1988.

[208] T. Ritchey, Wicked Problems - Social Messes: Decision Support Modelling with Morphological Analysis. London and New York: Springer Science \& Business Media, 2011.

[209] G. J. Wissema, "Morphological analysis: its application to a company TF investigation," Futures, vol. 8, no. 2, pp. 146-153, 1976. 
[210] T. Ritchey, "Fritz Zwicky, morphologie and policy analysis," in 16th Euro Conference on Operational Analysis, 1998.

[211] T. Ritchey, "Problem structuring using computer-aided morphological analysis," J. Oper. Res. Soc., vol. 57, no. 7, pp. 792-801, 2006.

[212] Swedish Morphological Society, "MA/Carma: advanced computer support for general morphological analysis," 2004. [Online]. Available: www.swemorph.com/pdf/macasper1.pdf.

[213] M. Hojer and L.-G. Mattsson, "Determinism and backcasting in future studies," Futures, vol. 32, pp. 613-634, 2000.

[214] J. B. Robinson, "Energy backcasting: a proposed method of policy analysis," Energy Policy, vol. 10, pp. 337-344, 1982.

[215] J. Quist and P. J. Vergragt, "Backcasting for industrial transformations and system innovations towards sustainability: is it useful for governance?," in the 2003 Berlin Conference on the Human Dimensions of Global Environmental Change, 2003, no. December, pp. 1-26.

[216] K. Geurs and B. Van Wee, "Backcasting as a tool for sustainable transport policy making: the environmentally sustainable transport study in the Netherlands," Eur. J. Transp. Infrastruct. Res., vol. 4, no. 1, pp. 47-69, 2004.

[217] N. Roorda, "Backcasting the future," Int. J. Sustain. High. Educ., vol. 2, no. 1, pp. 63-69, 2001.

[218] The Bartlett School of Planning and Halcrow Group Ltd, "Visioning and Backcasting for UK Transport Policy (VIBAT),” 2006.

[219] J. B. Robinson, "Futures under glass: a recipe for people who hate to predict," Futures, vol. 22, no. 8, pp. 820-842, 1990.

[220] L. Jansen, "The challenge of sustainable development," J. Clean. Prod., vol. 11, no. 3, pp. 231-245, May 2003.

[221] J. Quist and P. J. Vergragt, "Past and future of backcasting: the shift to stakeholder participation and a proposal for a methodological framework," Futures, vol. 38, no. 9, pp. 1027-1045, Nov. 2006.

[222] N. C. Dalkey, "The Delphi method: An experimental study of group opinion," Santa Monica, CA, 1969.

[223] H. A. Linstone and M. Turoff, Eds., The Delphi Method: Techniques and Applications. Reading, MA: Addison-Wesley, 1975.

[224] O. Helmer and N. Rescher, "On the epistemology of the inexact sciences," Manage. Sci., vol. 6, no. 1, pp. 25-52, 1959.

[225] M. Turoff, "The design of a policy Delphi," Technol. Forecast. Soc. Change, vol. 2, no. 2, pp. 149-171, 1970. 
[226] W. Rauch, "The decision Delphi," Technol. Forecast. Soc. Change, vol. 15, no. 3, pp. 159-169, 1979.

[227] M. Skutsch and J. L. Schofer, "Goals-Delphis for urban planning: concepts in their design,” Socioecon. Plann. Sci., vol. 7, no. 3, pp. 305-313, 1973.

[228] N. C. Dalkey, "An experimental study of group opinion: the Delphi method," Futures, vol. 1, no. 5, pp. 408-426, Sep. 1969.

[229] W. W. Chaffin and W. K. Talley, "Individual stability in Delphi studies," Technol. Forecast. Soc. Change, vol. 16, no. 1, pp. 67-73, Jan. 1980.

[230] F. Woudenberg, "An evaluation of Delphi," Technol. Forecast. Soc. Change, vol. 40, no. 2, pp. 131-150, Sep. 1991.

[231] W. T. Weaver and B. W. T. Weaver, "The Delphi forecasting," Phi Delta Kappan, vol. 52, no. 5, pp. 267-271, 1971.

[232] A. L. Delbecq, A. H. Van de Ven, and D. H. Gustafson, Group Techniques for Program Planning: A Guide to Nominal Group and Delphi Processes. Glenview, IL: Scott: Foresman and Company, 1975.

[233] A. L. Delbecq and A. H. Van De Ven, "A group process model for problem identification and program planning," J. Appl. Behav. Sci., vol. 7, no. 4, p. 466, 1971.

[234] D. S. Sink, "Using the nominal group technique effectively," Natl. Product. Rev., vol. 2, no. 2, p. 173, 1983.

[235] J. D. Claxton, J. R. B. Ritchie, and J. Zaichkowsky, "The nominal group technique: its potential for consumer research," J. Consum. Res., vol. 7, no. 3, pp. 308-313, 1980.

[236] A. H. Van De Ven and A. L. Delbecq, "The nominal group as a research instrument for exploratory health studies.," Am. J. Public Health, vol. 62, no. 3, pp. 337-42, Mar. 1972.

[237] D. Miller, R. Shewchuk, T. R. Elliot, and S. Richards, "Nominal group technique: a process for identifying diabetes self-care issues among patients and caregivers," Diabetes Educ., vol. 26, no. 2, pp. 305-314, Mar. 2000.

[238] G. Rubin, N. De Wit, V. Meineche-Schmidt, B. Seifert, N. Hall, and P. Hungin, "The diagnosis of IBS in primary care: consensus development using nominal group technique.," Fam. Pract., vol. 23, no. 6, pp. 687-92, Dec. 2006.

[239] J. Rohrbaugh, "Improving the quality of group judgment: social judgment analysis and the nominal group technique," Organ. Behav. Hum. Perform., vol. 28, no. 2, pp. 272-288, Oct. 1981.

[240] A. Bruseberg and D. Mcdonagh-Philp, "New product development by eliciting user experience and aspirations," Int. J. Hum. Comput. Stud., vol. 55, pp. 435452, Oct. 2001. 
[241] T. R. Henrich and T. J. Greene, "Using the nominal group technique to elicit roadblocks to an MRP II implementation," Comput. Ind. Eng., vol. 21, no. 1-4, pp. 335-338, 1991.

[242] P. J. H. Schoemaker, "Multiple scenario development: its conceptual and behavioral foundation,” Strateg. Manag. J., vol. 14, no. 3, pp. 193-213, 1993.

[243] H. Kahn and I. Mann, "Techniques of systems analysis," 1957.

[244] P. Wack, "Scenarios: uncharted waters ahead," Harv. Bus. Rev., vol. 63, no. 5, pp. 73-89, 1985.

[245] P. Wack, "Scenarios : shooting the rapids," Harv. Bus. Rev., vol. 63, no. 6, pp. 139-150, 1985.

[246] H. Kahn and A. J. Wiener, The Year 2000: A Framework for Speculation on the Next Thirty-Three Years. New York: Macmillan, 1967.

[247] P. J. H. Schoemaker, "Scenario planning: a tool for strategic thinking," Sloan Manage. Rev., vol. 36, no. 2, pp. 25-40, 1995.

[248] P. Schwartz, The Art of the Long View: Planning for the Future in an Uncertain World. New York: Doubleday Currency, 1991.

[249] P. W. F. van Notten, J. Rotmans, M. B. A. van Asselt, and D. S. Rothman, "An updated scenario typology," Futures, vol. 35, no. 5, pp. 423-443, Jun. 2003.

[250] D. Mietzner and G. Reger, "Advantages and disadvantages of scenario approaches for strategic foresight," Int. J. Technol. Intell. Plan., vol. 1, no. 2, p. $220,2005$.

[251] L. Borjeson, M. Hojer, K. H. Dreborg, T. Ekvall, and G. Finnveden, "Scenario types and techniques: towards a user's guide," Futures, vol. 38, no. 7, pp. 723739, 2006.

[252] K. van der Heijden, Scenarios: The Art of Strategic Conversation, 1st ed. Chichester, New York, Brisbane, Toronto, Singapore: John Wiley \& Sons, Ltd., 1996.

[253] S. M. Millett, "How scenarios trigger strategic thinking," Long Range Plann., vol. 21, no. 5, pp. 61-68, 1988.

[254] H. Leufkens, F. Haaijer-Ruskamp, A. Bakker, and G. Dukes, "Scenario analysis of the future of medicines," BMJ, vol. 309, no. 29, pp. 1137-40, Oct. 1994.

[255] R. Silberglitt, A. Hove, and P. Shulman, "Analysis of US energy scenarios: metascenarios, pathways, and policy implications," Technol. Forecast. Soc. Change, vol. 70, no. 4, pp. 297-315, May 2003.

[256] M. J. Foster, "Scenario planning for small businesses," Long Range Plann., vol. 26, no. 1, pp. 123-129, 1993.

[257] S. P. Schnaars, "How to develop and use scenarios," Long Range Plann., vol. 20, 
no. 1, pp. 105-114, 1987.

[258] T. J. Gordon, H. S. Becker, and H. Gerjuoy, Trend Impact Analysis: A New Forecasting Tool. Glastonbury, Conn.: Futures Group, 1974.

[259] T. J. Gordon, “Trend Impact Aanalysis,” Futures Research Methodology, 1994.

[260] D. Probert and M. Radnor, "Frontier experiences from industry-academia consortia: corporate roadmappers create value with product and technology roadmaps," Rsearch Technol. Manag., vol. 46, no. 2, p. 27, 2003.

[261] R. J. Harring, "Motorola's use of the product technology roadmap," in The National Communication Forum, 1984, pp. 78-80.

[262] C. H. Willyard and C. W. McClees, "Motorola's technology roadmap process," Res. Manage., no. Sept.-Oct., pp. 13-19, 1987.

[263] R. Galvin, “Science roadmaps," Science, vol. 280, no. 5365, p. 803, 1998.

[264] O. H. Bray and M. L. Garcia, "Technology roadmapping: the integration of strategic and technology planning for competitiveness," in Proceedings of the Portland International Conference on Management of Engineering and Technology (PICMET), 1997, pp. 25-28.

[265] R. Phaal, C. Farrukh, and D. Probert, "Technology roadmapping: linking technology resources to business objectives," Univ. Cambridge, pp. 1-18, 2001.

[266] R. E. Albright and T. A. Kappel, "Technology roadmapping: roadmapping the corporation," Res. Technol. Manag., vol. 46, no. 2, p. 31, 2003.

[267] P. Groenveld, "Roadmapping integrates business and technology," Res. Technol. Manag., vol. 40, no. 5, pp. 48-55, 1997.

[268] D. Barker and D. J. H. Smith, "Technology foresight using roadmaps," Long Range Plann., vol. 28, no. 2, pp. 21-28, Apr. 1995.

[269] L. Baldi, "Industry roadmaps: the challenge of complexity," Microelectron. Eng., vol. 34, no. 1, pp. 9-26, Dec. 1996.

[270] A. Jager-Waldau, "R\&D roadmap for PV," Thin Solid Films, vol. 451-452, pp. 448-454, Mar. 2004.

[271] S. Harrell, T. Seidel, and B. Fay, "The national technology roadmap for semiconductors and SEMATECH future directions," Microelectron. Eng., vol. 30, no. 1, pp. 11-15, 1996.

[272] M. L. Garcia, "Introduction to Technology Roadmapping: The Semiconductor Industry Association's Technology Roadmapping Process," New Mexico, USA, 1997.

[273] O. Saritas and M. A. Oner, "Systemic analysis of UK foresight results: joint application of integrated management model and roadmapping," Technol. Forecast. Soc. Change, vol. 71, no. 1-2, pp. 27-65, Feb. 2004. 
[274] R. Kostoff and R. R. Schaller, "Science and technology roadmaps," IEEE Trans. Eng. Manag., vol. 48, no. 2, pp. 132-143, May 2001.

[275] R. Phaal, C. Farrukh, and D. Probert, "Technology roadmapping - a planning framework for evolution and revolution," Technol. Forecast. Soc. Change, vol. 71, no. 1-2, pp. 5-26, Feb. 2004.

[276] R. Phaal, C. Farrukh, and D. Probert, "Customizing roadmapping," Res. Technol. Manag., vol. 47, no. 2, p. 26, 2004.

[277] R. Wells, R. Phaal, C. Farrukh, and D. Probert, "Technology roadmapping for a service organization," Res. Technol. Manag., vol. 47, no. 2, pp. 46-51, 2004.

[278] R. Phaal and G. Muller, "An architectural framework for roadmapping: towards visual strategy," Technol. Forecast. Soc. Change, vol. 76, no. 1, pp. 39-49, 2009.

[279] T. A. Kappel, "Perspectives on roadmaps: how organizations talk about the future," J. Prod. Innov. Manag., vol. 18, no. 1, pp. 39-50, Jan. 2001.

[280] R. Kostoff, "Disruptive technology roadmaps," Technol. Forecast. Soc. Change, vol. 71, no. 1-2, pp. 141-159, Feb. 2004.

[281] J. Linton, "Determining demand, supply, and pricing for emerging markets based on disruptive process technologies," Technol. Forecast. Soc. Change, vol. 71, no. 1-2, pp. 105-120, Feb. 2004.

[282] J. D. Strauss and M. Radnor, "Roadmapping for dynamic and uncertain environments," Res. Technol. Manag., vol. 47, no. 2, pp. 51-58, 2004.

[283] S. Enzer, "A case study using forecasting as a decision-making aid," Futures, vol. 2, no. 4, pp. 341-362, 1970.

[284] B. Yoon, R. Phaal, and D. Probert, "Morphology analysis for technology roadmapping: application of text mining," $R \& D$ Manag., vol. 38, no. 1, pp. 5168, Dec. 2007.

[285] P. A. Roussel, K. N. Saad, and T. J. Erickson, Third Generation R\&D: Managing The Link to Corporate Strategy. Boston, MA: Harvard Business Press, 1991.

[286] A. H. Rubenstein and E. Geisler, "Evaluating the outputs and impacts of R\&D/innovation," Int. J. Technol. Manag., vol. 6, no. 3, pp. 181-204, 1991.

[287] E. C. Galloway, "Evaluating R\&D performance - keep it simple," Res. Manage., vol. 14, no. 2, pp. 50-58, 1971.

[288] A. Pakes, "On patents, R \& D, and the stock market rate of return," J. Polit. Econ., vol. 93, no. 2, pp. 390-409, 1985.

[289] B. M. Werner and W. E. Souder, "Measuring R\&D performance-state of the art," Res. Technol. Manag., vol. 40, no. 2, p. 34, 1997.

[290] R. Szakonyi, "Measuring R\&D effectiveness-I," Res. Technol. Manag., vol. 37, no. 2, p. 27, 1994. 
[291] B. Gold, "Some key problems in evaluating R\&D performance," J. Eng. Technol. Manag., vol. 6, no. 1, pp. 59-70, 1989.

[292] C. H. Loch and U. A. S. Tapper, "Implementing a strategy-driven performance masurement system for an applied research group," J. Prod. Innov. Manag., vol. 19, no. 3, pp. 185-198, 2002.

[293] M. G. Brown and R. A. Svenson, "Measuring R\&D productivity," Res. Technol. Manag., vol. 41, no. 6, pp. 30-35, 1998.

[294] T. Wiesenthal, A. Mercier, B. Schade, H. Petric, and P. Dowling, "A modelbased assessment of the impact of revitalised R\&D investments on the European power sector," Renew. Sustain. Energy Rev., vol. 16, no. 1, pp. 105-112, 2012.

[295] E. A. Bøler, A. Moxnes, and K. H. Ulltveit-Moe, "R\&D, international sourcing, and the joint impact on firm performance," Am. Econ. Rev., vol. 105, no. 12, pp. 3704-3739, 2015.

[296] R. A. Pappas and D. S. Remer, "Measuring R\&D productivity," Res. Manage., vol. 31, no. 4, pp. 15-22, 1985.

[297] E. Geisler, "Key output indicators in performance evaluation of research and development organizations," Technol. Forecast. Soc. Change, vol. 47, no. 2, pp. 189-203, 1994.

[298] E. Mansfield, "Academic research and industrial innovation: a further note," Res. Policy, vol. 21, no. 3, pp. 295-296, 1992.

[299] F. M. Scherer, "The propensity to patent," Int. J. Ind. Organ., vol. 1, no. 1, p. 107, 1983.

[300] Z. Griliches, "Market value, R\&D, and patents," Econ. Lett., vol. 7, no. 2, pp. 183-187, 1981.

[301] H. Ernst, "Patenting strategies in the German mechanical engineering industry and their relationship to company performance," Technovation, vol. 15, no. 4, pp. 225-240, 1995.

[302] A. B. Jaffe, "Technological opportunity and spillovers of R\&D: evidence from firms' patents, profits and market value," Am. Econ. Rev., vol. 76, no. 5, pp. $984-$ 1001, 1986.

[303] G. K. Morbey, "R\&D: its relationship to company performance," J. Prod. Innov. Manag., vol. 5, no. 3, pp. 191-200, 1988.

[304] M. E. McGrath and M. N. Romeri, "The R\&D effectiveness index: a metric for product development performance," J. Prod. Innov. Manag., vol. 11, no. 3, pp. 213-220, 1994.

[305] H. G. Grabowski, "The determinants of industrial research and development: a study of the chemical, drug, and petroleum industries," J. Polit. Econ., vol. 76, no. 2, pp. 292-306, 1968. 
[306] W. S. Comanor and F. M. Scherer, "Patent statistics as a measure of technical change," J. Polit. Econ., vol. 77, no. 3, pp. 392-398, 1969.

[307] F. Narin, E. Noma, and R. Perry, "Patents as indicators of corporate technological strength," Res. Policy, vol. 16, no. 2-4, pp. 143-155, 1987.

[308] F. Narin and E. Noma, "Is technology becoming science?," Scientometrics, vol. 7, no. 3-6, pp. 369-381, 1985.

[309] K. Pavitt, "What makes basic research economically useful?," Res. Policy, vol. 20, no. 2, pp. 109-119, 1991.

[310] K. W. Artz, P. M. Norman, D. E. Hatfield, and L. B. Cardinal, "A longitudinal study of the impact of R\&D, patents, and product innovation on firm performance," J. Prod. Innov. Manag., vol. 27, pp. 725-740, 2010.

[311] B. Branch, "Research and development activity and profitability: a distributed lag analysis," J. Polit. Econ., vol. 82, no. 5, pp. 999-1011, 1974.

[312] E. Mansfield, "Patents and innovation: an empirical study," Manage. Sci., vol. 32, no. 2, pp. 173-181, 1986.

[313] A. Arundel and I. Kabla, "What percentage of innovations are patented? Empirical estimates for European firms," Res. Policy, vol. 27, no. 2, pp. 127141, 1998.

[314] R. Coombs, P. Narandren, and A. Richards, "A literature-based innovation output indicator," Res. Policy, vol. 25, pp. 403-413, 1996.

[315] D. Archibugi, "Patenting as an indicator of technological innovation: a review," Science and Public Policy, vol. 19, no. 6. pp. 357-368, 1992.

[316] J. M. Utterback and W. J. Abernathy, "A dynamic model of process and product innovation," Omega, vol. 3, no. 6, pp. 639-656, 1975.

[317] P. H. Francis, "Putting quality into the R\&D process," Res. Technol. Manag., vol. 35, no. 4, p. 16-, 1992.

[318] B. Wernerfelt, "A resource-based view of the firm," Strateg. Manag. J., vol. 5, no. 2, pp. 171-180, 1984.

[319] R. Whiteley, T. Parish, R. Dressler, and G. Nicholson, "Evaluating R\&D performance using the new sales ratio," Res. Technol. Manag., vol. 41, no. 5, pp. 20-22, 1998.

[320] N. R. Baker, J. Siegman, and A. H. Rubenstein, "The effects of perceived needs and means on the generation of ideas for industrial research and development projects," IEEE Trans. Eng. Manag., vol. 14, no. 4, pp. 156-164, 1967.

[321] E. J. Kleinschmidt and R. G. Cooper, "The impact of product innovativeness on performance," J. Prod. Innov. Manag., vol. 8, no. 4, pp. 240-251, 1991.

[322] F. Damanpour and S. Gopalakrishnan, "The dynamics of the adoption of product 
and process innovations in organizations," J. Manag. Stud., vol. 38, no. 1, pp. 45-65, 2001.

[323] S. Gopalakrishnan and F. Damanpour, "A review of innovation research in economics, sociology and technology management," Omega, vol. 25, no. I, pp. 15-28, 1997.

[324] R. Barras, "Towards a theory of innovation in services," Res. Policy, vol. 15, no. 4, pp. 161-173, 1986.

[325] S. J. Kline, "Innovation is not a linear process," Res. Manage., vol. 28, no. 4, pp. 36-45, 1985.

[326] T. H. Davenport, Process Innovation: Reengineering Work Through Technology. Boston, MA: Harvard Business School Press, 1993.

[327] W. C. Patterson, "Evaluating R\&D performance at Alcoa laboratories," Res. Manage., vol. 26, no. 2, pp. 23-27, 1983.

[328] G. R. Mitchell, “Alternative frameworks for technology strategy," Eur. J. Oper. Res., vol. 47, no. 2, pp. 153-161, 1990.

[329] E. Autio and T. Laamanen, "Measurement and evaluation of technology transfer: review of technology transfer mechanisms and indicators," Int. J. Technol. Mangement, vol. 10, no. 7/8, pp. 643-664, 1995.

[330] G. Azzone and P. Maccarrone, "The emerging role of lean infrastructures in technology transfer: The case of the Innovation Plaza project," Technovation, vol. 17, no. 7, pp. 391-402, 1997.

[331] M. R. Halperin and A. K. Chakrabarti, "Firm and industry characteristics influencing publications of scientists in large American companies," $R \& D$ Manag., vol. 17, no. 3, pp. 167-173, 1987.

[332] M. H. Hodge, "Rate your company's research productivity," Harv. Bus. Rev., vol. 41, no. 6, pp. 109-122, 1963.

[333] M. P. Carpenter, M. Cooper, and F. Narin, "Linkage between basic research literature and patents," Res. Manage., vol. 23, no. 2, pp. 30-35, 1980.

[334] A. Gambardella, "Competitive advantages from in-house scientific research: the US pharmaceutical industry in the 1980s," Res. Policy, vol. 21, no. 5, pp. 391407, 1992.

[335] I. H. Sher and E. Garfield, "New tools for improving and evaluating the effectiveness of research," in Research Program Effectiveness, Proceedings of the Conference sponsored by the Office of Naval Research, 1965, pp. 135-146.

[336] M. L. Flor and M. J. Oltra, "Identification of innovating firms through technological innovation indicators: an application to the Spanish ceramic tile industry," Res. Policy, vol. 33, no. 2, pp. 323-336, 2004.

[337] F. T. Rothaermel and A. M. Hess, "Building dynamic capabilities: Innovation 
driven by individual-, firm-, and network-level effects," Organ. Sci., vol. 18, no. 6, pp. 898-921, 2007.

[338] J. Bound, C. Cummins, Z. Griliches, B. H. Hall, and A. B. Jaffe, "Who does R\&D and who patents?," 1982.

[339] J. a. Hausman, B. H. Hall, and Z. Griliches, "Econometric models for count data with an application to the patents-R\&D relationship," Econometrica, vol. 52, no. 4. pp. 909-938, 1984.

[340] D. Guellec and B. Van Pottelsberghe De La Potterie, "The internationalisation of technology analysed with patent data," Res. Policy, vol. 30, no. 8, pp. 12531266, 2001.

[341] A. H. Schainblatt, "How companies measure the productivity of engineers and scientists," Res. Manage., vol. 25, no. 3, pp. 10-18, 1982.

[342] F. M. Scherer, "Corporate inventive output, profits, and growth," J. Polit. Econ., vol. 73, no. 3, pp. 290-297, 1965.

[343] F. Narin and A. Breitzman, "Inventive productivity," Res. Policy, vol. 24, no. 4, pp. 507-519, 1995.

[344] F. Narin, M. P. Carpenter, and P. Woolf, "Technological performance assessments based on patents and patent citations," IEEE Trans. Eng. Manag., vol. EM-31, no. 4, pp. 172-183, 1984.

[345] J. Faber and A. B. Hesen, "Innovation capabilities of European nations: crossnational analyses of patents and sales of product innovations," Res. Policy, vol. 33, no. 2, pp. 193-207, 2004.

[346] W. L. Robb, “How good is our research?," Res. Technol. Manag., vol. 34, no. 2, pp. 16-21, 1991.

[347] J. B. Rosenberg, "Research and market share: a reappraisal of the Schumpeter hypothesis," J. Ind. Econ., vol. 25, no. 2, pp. 101-112, 1976.

[348] M. B. Albert, D. Avery, F. Narin, and P. McAllister, "Direct validation of citation counts as indicators of industrially important patents," Res. Policy, vol. 20, no. 3, pp. 251-259, 1991.

[349] W. B. Brown and D. Gobeli, "Observations on the measurement of R\&D productivity: a case study," Eng. Manag. IEEE Trans., vol. 39, no. 4, pp. 325 331, 1992.

[350] R. R. Nelson, "Why do firms differ, and how does it matter?," Strateg. Manag. J., vol. 12, no. S2, pp. 61-74, 1991.

[351] R. M. Solow, "A contribution to the theory of economic growth," Q. J. Econ., vol. 70, no. 1, pp. 65-94, 1956.

[352] R. M. Solow, "Technical change and the aggregate production function," Rev. Econ. Stat., vol. 39, no. 3, pp. 312-320, 1957. 
[353] P. M. Romer, "Endogenous technological change," J. Polit. Econ., vol. 98, no. S5, p. S71, 1990.

[354] E. Penrose, The Theory of the Growth of the Firm: With a New Introduction by Christos N. Pitelis, Fourth. London, United Kingdom: Oxford University Press, 2009.

[355] K. R. Andrews, The Concept of Corporate Strategy. Homewood, Ill.: Dow JonesIrwin, 1971.

[356] D. J. Teece, "Economies of scope and the scope of the enterprise," J. Econ. Behav. Organ., vol. 1, no. 3, pp. 223-247, 1980.

[357] D. J. Teece, "Towards an economic theory of the multiproduct firm," J. Econ. Behav. Organ., vol. 3, no. 1, pp. 39-62, 1982.

[358] J. B. Barney, "Strategic factor markets: Expectations, luck, and business strategy," Manage. Sci., vol. 32, no. 10, pp. 1231-1241, 1986.

[359] D. J. Teece and G. Pisano, "The dynamic capabilities of firms: an introduction," Ind. Corp. Chang., vol. 3, no. 3, pp. 537-556, 1994.

[360] D. J. Teece, G. Pisano, and A. Shuen, "Dynamic capabilities and strategic management," Strateg. Manag. J., vol. 18, no. 7, pp. 509-533, 1997.

[361] C. K. Prahalad and G. Hamel, "The core competence of the corporation," Harv. Bus. Rev., vol. 68, no. 3, pp. 79-91, 1990.

[362] R. G. Cooper, "New product performance and product innovation strategies," Res. Manage., vol. 29, no. 3, pp. 17-25, 1986.

[363] D. Tennenhouse, "Intel's open collaborative model of industry-university research," Res. Technol. Manag., vol. 47, no. 4, pp. 19-26, 2004.

[364] S. L. Holak, M. E. Parry, and X. M. Song, "The relationship of R\&D/sales to firm performance: an investigation of marketing contingencies," J. Prod. Innov. Manag., vol. 8, no. 4, pp. 267-282, 1991.

[365] K. Krajewski, "Five steps to effective strategic technology initiatives," Assoc. Manage., vol. 55, no. 9, pp. 46-47, 2003.

[366] M. Leontiades and A. Tezel, "Planning perceptions and planning results," Strateg. Manag. J., vol. 1, no. 1, pp. 65-75, 1980.

[367] P. F. Drucker, "Long-range planning: challenge to management science," Manage. Sci., vol. 5, no. 3, pp. 238-249, 1959.

[368] S. S. Thune and R. J. House, "Where long-range planning pays off: findings of a survey of formal, informal planners," Bus. Horiz., vol. 13, no. 4, pp. 81-87, 1970.

[369] D. W. Karger and Z. A. Malik, "Long range planning and organizational performance," Long Range Plann., vol. 8, no. 6, pp. 60-64, 1975. 
[370] D. R. Wood Jr and R. L. LaForge, "The impact of comprehensive planning on financial performance," Acad. Manag. J., vol. 22, no. 3, pp. 516-526, 1979.

[371] R. J. Kudla, "The effects of strategic planning on common stock returns," Acad. Manag. J., vol. 23, no. 1, pp. 5-20, 1980.

[372] J. S. Armstrong, "The value of formal planning for strategic decisions: review of empirical research," Strateg. Manag. J., vol. 3, no. 3, pp. 197-211, 1982.

[373] L. C. Rhyne, "The relationship of strategic planning to financial performance," Strateg. Manag. J., vol. 7, no. 5, pp. 423-436, 1986.

[374] C. C. Miller and L. B. Cardinal, "Strategic planning and firm performance: a synthesis of more than two decades of research," Acad. Manag. J., vol. 37, no. 6, pp. 1649-1665, 1994.

[375] J. Brinckmann, D. Grichnik, and D. Kapsa, "Should entrepreneurs plan or just storm the castle? A meta-analysis on contextual factors impacting the business planning-performance relationship in small firms," J. Bus. Ventur., vol. 25, no. 1, pp. 24-40, 2010.

[376] A. R. Fusfeld, "Formulating technology strategies to meet the global challenges of the 1990s," Int. J. Technol. Manag., vol. 4, no. 6, pp. 601-612, 1989.

[377] S. A. Zahra and J. G. Covin, "Business strategy, technology policy and firm performance,” Strateg. Manag. J., vol. 14, no. 6, pp. 451-478, 1993.

[378] S. A. Zahra, "Technology strategy and financial performance: examining the moderating role of the firm's competitive environment," J. Bus. Ventur., vol. 11, no. 3, pp. 189-219, 1996.

[379] L. G. Franko, “Global corporate competition: who's winning, who's losing, and the R\&D factor as one reason why," Strateg. Manag. J., vol. 10, no. 5, pp. 449474, 1989.

[380] M. E. Mendigorri, T. G. Valderrama, and V. R. Cornejo, "Measuring the effectiveness of R\&D activities: Empirical validation of a scale in the Spanish pharmaceutical sector," Manag. Decis., vol. 54, no. 2, pp. 321-362, 2016.

[381] W. N. Leonard, "Research and development in industrial growth," J. Polit. Econ., vol. 79, no. 2, pp. 232-256, 1971.

[382] A. Griffin and A. L. Page, "An interim report on measuring product development success and failure," J. Prod. Innov. Manag., vol. 10, no. 4, pp. 291-308, 1993.

[383] A. Pakes and Z. Griliches, "Patents and R\&D at the firm level: a first report," Econ. Lett., vol. 5, no. 4, pp. 377-381, 1980.

[384] T. D. Wall et al., "On the validity of subjective measures of company performance," Pers. Psychol., vol. 57, no. 1, pp. 95-118, 2004.

[385] G. G. Dess and R. B. Robinson, "Measuring organizational performance in the absence of objective measures: the case of the privately-held firm and 
conglomerate business unit," Strateg. Manag. J., vol. 5, no. 3, pp. 265-273, 1984.

[386] R. B. Robinson and J. A. Pearce II, "Planned patterns of strategic behavior and their relationship to business-unit performance," Strateg. Manag. J., vol. 9, no. 1, pp. 43-60, 1988.

[387] W. H. Bommer, J. L. Johnson, G. A. Rich, P. M. Podsakoff, and S. B. MacKenzie, "On the interchangeability of objective and subjective measures of employee performance: a meta-analysis," Pers. Psychol., vol. 48, no. 3, pp. 587$605,1995$.

[388] L. C. Rhyne, "The relationship of strategic planning to financial performance," Strateg. Manag. J., vol. 7, no. 5, pp. 423-436, 1986.

[389] C. W. Hofer and D. Schendel, Strategy Formulation: Analytical Concepts. New York, Los Angeles, San Francisco: West Publishing Company, 1978.

[390] A. Parasuraman and L. M. Zeren, "R\&D's relationship with profits and sales," Res. Manage., vol. 26, pp. 25-28, 1983.

[391] K. F. Harling and T. F. Funk, "Competitive strategy for farm supply and grain elevator business,” Am. J. Agric. Econ., vol. 69, no. 5, pp. 1047-1055, 1987.

[392] J. S. Bracker and J. N. Pearson, "Planning and financial performance of small, mature firms," Strateg. Manag. J., vol. 7, no. 6, pp. 503-522, 1986.

[393] H. G. Grabowski and D. C. Mueller, "Industrial research and development, intangible capital stocks, and firm profit rates," Bell J. Econ., vol. 9, no. 2, pp. 328-343, 1978.

[394] G. F. Mechlin and D. Berg, "Evaluating research-ROI is not enough," Harv. Bus. Rev., vol. 58, no. 5, pp. 93-99, 1980.

[395] American Chemical Society, "The first nylon plant," Delaware, 1995.

[396] C. R. Anderson and F. T. Paine, "PIMS: a reexamination," Acad. Manag. Rev., vol. 3, no. 3, pp. 602-612, 1978.

[397] R. D. Buzzell, B. T. Gale, and R. G. Sultan, "Market share: key to profitability?," Harv. Bus. Rev., vol. 53, no. 1, pp. 97-106, 1975.

[398] S. Schoeffler, R. D. Buzzell, and D. F. Heany, "Impact of strategic planning on profit performance," Harv. Bus. Rev., vol. 7, no. 4, pp. 137-145, 1974.

[399] H. M. Wagner, "Profit wonders, investment blunders," Harv. Bus. Rev., vol. 62, no. 5, pp. 121-135, 1984.

[400] R. B. Robinson and J. A. Pearce II, "The impact of formalized strategic planning on financial performance in small organizations," Strateg. Manag. J., vol. 4, no. 3, pp. 197-207, 1983.

[401] B. T. Gale, "Market share and rate of return," Rev. Econ. Stat., vol. 54, no. 4, pp. 
412-423, 1972.

[402] L. J. Bourgeois, "Performance and consensus," Strateg. Manag. J., vol. 1, no. 3, pp. 227-248, 1980.

[403] J. B. McGuire, T. Schneeweis, and B. Branch, "Perceptions of firm quality: A cause or result of firm performance," J. Manage., vol. 16, no. 1, pp. 167-180, 1990.

[404] P. W. Roberts and R. Amit, "The dynamics of innovative activity and competitive advantage: The case of Australian retail banking, 1981 to 1995," Organ. Sci., vol. 14, no. 2, pp. 107-122, 2003.

[405] P. J. Sher and P. Y. Yang, "The effects of innovative capabilities and R\&D clustering on firm performance: The evidence of Taiwan's semiconductor industry," Technovation, vol. 25, no. 1, pp. 33-43, 2005.

[406] J. W. Fredrickson and T. R. Mitchell, "Strategic decision processes: comprehensiveness and performance in an industry with an unstable environment," Acad. Manag. J., vol. 27, no. 2, pp. 399-423, 1984.

[407] G. A. Baker, "Strategic planning and financial performance in the food processing sector," Rev. Agric. Econ., vol. 25, no. 2, pp. 470-482, 2003.

[408] H.-J. Cho and V. Pucik, "Relationship between innovativeness, quality, growth, profitability, and market value," Strateg. Manag. J., vol. 26, no. 6, pp. 555-575, 2005.

[409] P. H. Grinyer and D. Norburn, "Planning for existing markets: perceptions of executives and financial performance," J. R. Stat. Soc. Ser. A, vol. 138, no. 1, pp. 70-97, 1975.

[410] N. Capon, J. U. Farley, and S. Hoenig, "Determinants of financial performance: a meta-analysis," Manage. Sci., vol. 36, no. 10, pp. 1143-1159, 1990.

[411] C. Moorman, "Organizational market information processes: cultural antecedents and new product outcomes," J. Mark. Res., vol. 32, no. 3, pp. 318-335, 1995.

[412] R. Deshpandé, J. U. Farley, and F. E. Webster, "Corporate culture, customer orientation, and innovativeness in Japanese firms: a quadrad analysis," J. Mark., vol. 57, no. 1, pp. 23-37, 1993.

[413] L. W. Steele, "Evaluating the technical operation," Res. Technol. Manag., vol. 31, no. 5, pp. 11-18, 1988.

[414] D. C. Hambrick and I. C. Macmillan, "Efficiency of product R\&D in business units: the role of strategic context," Acad. Manag. J., vol. 28, no. 3, pp. 527-547, 1985.

[415] G. K. Morbey and R. M. Reithner, "How R\&D affects sales growth, productivity and profitability," Res. Technol. Manag., vol. 33, no. 3, pp. 11-14, 1990.

[416] M. S. Brenner and B. M. Rushton, "Sales growth and R\&D in the chemical 
industry," Res. Technol. Manag., vol. 32, no. 2, pp. 8-15, 1989.

[417] L. W. Ellis, "Optimum research spending reexamined," Res. Manage., vol. 23, no. 3, pp. 22-24, 1980.

[418] D. M. Herold, "Long-range planning and organizational performance: a crossvaluation study," Acad. Manag. J., vol. 15, no. 1, pp. 91-102, 1972.

[419] E. L. Reynard, "A method for relating research spending to net profits," Res. Manage., vol. 22, pp. 12-14, 1979.

[420] G. K. Morbey, "R\&D expenditures and profit growth," Res. Technol. Manag., vol. 32, no. 3, pp. 20-23, 1989.

[421] W. Boulding and R. Staelin, "Identifying generalizable effects of strategic actions on firm performance: the case of demand-side returns to R\&D spending," Mark. Sci., vol. 14, no. 3 Supplement, pp. G222-G236, 1995.

[422] R. E. Hoskisson, M. A. Hitt, R. A. Johnson, and D. D. Moesel, "Construct validity of an objective (entropy) categorical measure of diversification strategy," Strateg. Manag. J., vol. 14, no. 3, pp. 215-235, 1993.

[423] J. C. Chambers, S. K. Mullick, and D. D. Smith, "How to choose the right forecasting technique," Harv. Bus. Rev., vol. 49, no. 4, pp. 45-70, 1971.

[424] A.-C. Cheng, C.-J. Chen, and C.-Y. Chen, "A fuzzy multiple criteria comparison of technology forecasting methods for predicting the new materials development," Technol. Forecast. Soc. Change, vol. 75, no. 1, pp. 131-141, 2008.

[425] T. J. Erickson, J. F. Magee, P. A. Roussel, and K. N. Saad, "Managing technology as a business strategy," Sloan Manage. Rev., vol. 31, no. 3, pp. 73$78,1990$.

[426] J. M. Utterback, Mastering the Dynamics of Innovation. Cambridge, MA: Harvard Business School Press, 1994.

[427] Y. Cho and T. U. Daim, "Technology Forecasting Methods," in Research and Technology Management in the Electricity Industry: Methods, Tools and Case Studies, London, United Kingdom: Springer, 2013, pp. 67-112.

[428] V. Walsh, "Invention and innovation in the chemical industry: demand-pull or discovery-push?," Res. Policy, vol. 13, no. 4, pp. 211-234, 1984.

[429] I. C. Kerssens-van Drongelen and A. Cook, "Design principles for the development of measurement systems for research and development processes," $R \& D$ Manag., vol. 27, no. 4, pp. 345-357, 1997.

[430] M. L. Tushman, "Winning through innovation," Strateg. Leadersh., vol. 25, no. 4, pp. 14-19, 1997.

[431] W. J. Abernathy and P. L. Townsend, "Technology, productivity and process change,” Technol. Forecast. Soc. Change, vol. 7, no. 4, pp. 379-396, 1975. 
[432] W. J. Abernathy and J. M. Utterback, "Patterns of industrial innovation," Technol. Rev., vol. 80, no. 7, pp. 41-47, 1978.

[433] A. N. Afuah and J. M. Utterback, "Responding to structural industry changes: a technological evolution perspective," Ind. Corp. Chang., vol. 6, no. 1, pp. 183202, 1997.

[434] H. A. Linstone, "Twenty years of TF\&SC," Technol. Forecast. Soc. Change, vol. 36, no. 1, pp. 1-13, 1989.

[435] N. W. McGaughey, “Corporate technology planning,” Ind. Manag., vol. 32, no. 2, pp. 1-2, 1990.

[436] J. B. Quinn, "Long-range planning of industrial research," Harv. Bus. Rev., vol. 39, no. 4, pp. 88-102, 1961.

[437] F. Betz, Managing Technological Innovation: Competitive Advantage from Change, 2nd ed. New Jersey: John Wiley \& Sons, Inc., 2003.

[438] P. D. Metz, "Integrating technology planning with business planning," Res. Technol. Manag., vol. 39, no. 3, pp. 19-22, 1996.

[439] R. M. Hogarth and S. Makridakis, "Forecasting and planning: an evaluation," Manage. Sci., vol. 27, no. 2, pp. 115-138, 1981.

[440] E. Mansfield, "Industrial research and development expenditures: determinants, prospects, and relation to size of firm and inventive output," J. Polit. Econ., vol. 72, no. 4, pp. 319-340, 1964.

[441] J. S. Bracher, B. W. Keats, and J. N. Pearson, "Planning and financial performance among small firms in a growth industry," Strateg. Manag. J., vol. 9, no. 6, pp. 591-603, 1988.

[442] E. Brouwer and A. Kleinknecht, "Innovative output, and a firm's propensity to patent: an exploration of CIS micro data," Res. Policy, vol. 28, no. 6, pp. 615624, 1999.

[443] E. Mansfield, M. Schwartz, and S. Wagne, "Imitation costs and patents: an empirical study," Econ. J., vol. 91, no. 364, pp. 907-918, 1981.

[444] W. M. Cohen, R. C. Levin, and D. C. Mowery, "Firm size and R\&D intensity: a re-examination," 1987.

[445] D. J. Teece, "Technology transfer by multinational firms: the resource cost of transferring technological know-how," Econ. J., vol. 87, no. 346, pp. 242-261, 1977.

[446] N. R. Baker, S. G. Green, and A. S. Bean, "Why R\&D projects succeed or fail," Res. Manage., vol. 29, no. 6, 1986.

[447] S. M. Millett, "The strategic management of technological R\&D: an ideal process for the 1990s," Int. J. Technol. Manag., vol. 5, no. 1, 1990. 
[448] O. H. Poensgen and H. Hort, "R\&D management and financial performance," IEEE Trans. Eng. Manag., vol. 30, no. 4, pp. 212-222, 1983.

[449] J. B. Quinn and J. A. Mueller, "Transferring research results to operations," Harv. Bus. Rev., vol. 41, no. 1, pp. 49-66, 1963.

[450] R. Rothwell, "Innovation and re-innovation: a role for the user," J. Mark. Manag., vol. 2, no. 2, pp. 109-123, Jan. 1986.

[451] R. Szakonyi, "Critical issues in long-range planning," Res. Manag., vol. 32, no. 3, pp. 28-32, 1989.

[452] H. Ernst, "Patent applications and subsequent changes of performance: evidence from time-series cross-section analyses on the firm level," Res. Policy, vol. 30, no. 1, pp. 143-157, 2001.

[453] E. J. Pedhazur, "Structural Equation Models with Observed Variables: Path Analysis," in Multiple Regression in Behavioral Research: Explanation and Prediction, 3rd ed., Fort Worth, TX: Harcourt Brace, 1997, pp. 765-807.

[454] G. M. Maruyama, Basics of Structural Equation Modeling. London: SAGE Publications, 1998.

[455] S. Wright, "On the nature of size factors," Genetics, vol. 3, no. 4, p. 367, 1918.

[456] K. A. Bollen, "Latent variables in psychology and the social sciences," Annu. Rev. Psychol., vol. 53, no. 1, pp. 605-634, 2002.

[457] S. Wright, "The method of path coefficients," Ann. Math. Stat., vol. 5, no. 3, pp. $161-215,1934$.

[458] M. E. Sobel, "Asymptotic confidence intervals for indirect effects in structural equation models," Sociol. Methodol., vol. 13, pp. 290-312, 1982.

[459] J. Cheong and D. P. MacKinnon, "Mediation/Indirect Effects in Structural Equation Modeling," in Handbook of Structural Equation Modeling, R. H. Hoyle, Ed. New York, London: The Guilford Press, 2012, pp. 417-435.

[460] D. P. MacKinnon, C. M. Lockwood, J. M. Hoffman, S. G. West, and V. Sheets, "A comparison of methods to test mediation and other intervening variable effects.," Psychol. Methods, vol. 7, no. 1, pp. 83-104, 2002.

[461] R. M. Baron and D. A. Kenny, "The moderator-mediator variable distinction in social psychological research: conceptual, strategic, and statistical considerations.," Journal of Personality and Social Psychology, vol. 51, no. 6. pp. 1173-1182, 1986.

[462] R. L. Matsueda, "Key Advances in the History of Structural Equation Modeling," in Handbook of Sructural Equation Modeling, R. Hoyle, Ed. New York, NY: Guilford Press, 2012, pp. 17-42.

[463] J. K. Ford, R. C. MacCallum, and M. Tait, "The application of exploratory factor analysis in applied psychology: a critical review and analysis," Pers. Psychol., 
vol. 39, no. 2, pp. 291-314, 1986.

[464] E. J. Fabrigar, L.R.; MacCallum, R.C.; Wegener, D.T.; Strahan, "Evaluating the use of exploratory factor analysis in psychological research," Psychol. Methods, vol. 4, no. 3, pp. 272-299, 1999.

[465] J. M. Conway and A. I. Huffcutt, "A review and evaluation of exploratory factor analysis practices in organizational research," Organ. Res. Methods, vol. 6, no. 2, pp. 147-168, 2003.

[466] J. T. Newsom, Longitudinal Structural Equation Modeling: A Comprehensive Introduction. Routledge, 2015.

[467] K. J. Preacher and R. C. MacCallum, "Repairing Tom Swift's electric factor analysis machine," Underst. Stat. Stat. Issues Psychol. Educ. Soc. Sci., vol. 2, no. 1, pp. 13-43, 2003.

[468] S. C. Snook and R. L. Gorsuch, "Component analysis versus common factor analysis: a Monte Carlo study," Psychol. Bull., vol. 106, no. 1, p. 148, 1989.

[469] R. H. Hoyle, "Confirmatory Factor Analysis," in Handbook of Applied Multivariate Statistics and Mathematical Modeling, H. E. A. Tinsley and S. D. Brown, Eds. San Diego, San Francisco, New York, Boston, London, Sydney, Tokyo: Academic Press, 2000, pp. 465-497.

[470] F. J. Fowler, Survey Research Methods, Fifth. Los Angeles, London, New Delhi, Singapore, Washington D.C.: SAGE publications, 2014.

[471] C. Cobanoglu, B. Warde, and P. J. Moreo, "A comparison of mail, fax and webbased survey methods," Int. J. Mark. Res., vol. 43, no. 4, pp. 405-410, 2001.

[472] D. A. Dillman, J. D. Smyth, and L. M. Christian, Internet, Phone, Mail, and Mixed-Mode Surveys: The Tailored Design Method, Fourth. New Jersey: John Wiley \& Sons, Inc., 2014.

[473] V. M. Sue and L. A. Ritter, Conducting Online Surveys, 2nd ed. Los Angeles, London, New Delhi, Singapore, Washington D.C.: Sage, 2012.

[474] M. Schonlau, R. D. Fricker, and M. N. Elliott, Conducting Research Surveys via E-mail and The Web. Santa Monica, CA: RAND, 2002.

[475] J. R. Evans and A. Mathur, "The value of online surveys," Internet Res., vol. 15, no. 2, pp. 195-219, 2005.

[476] D. A. Dillman, Mail and Internet Surveys: The Tailored Design Method, 2nd ed. New York: Wiley, 2000.

[477] S. E. Griffis, T. J. Goldsby, and M. Cooper, "Web-based and mail surveys a comparison of response, data, and cost," Journal of Business Logistics, vol. 24, no. 2. pp. 237-258, 2003.

[478] P. C. Hardigan, C. T. Succar, and J. M. Fleisher, "An analysis of response rate and economic costs between mail and web-based surveys among practicing 
dentists: A randomized trial," J. Community Health, vol. 37, no. 2, pp. 383-394, 2012.

[479] C. Greenlaw and S. Brown-Welty, "A comparison of web-based and paper-based survey methods: testing assumptions of survey mode and response cost," Eval. Rev., vol. 33, no. 5, pp. 464-480, 2009.

[480] D. R. Cooper and P. S. Schindler, Business Research Methods, 12th ed. New York: McGraw-Hill/Irwin, 2014.

[481] M. D. Kaplowitz, T. D. Hadlock, and R. Levine, "A comparison of web and mail survey response rates,” Public Opin. Q., vol. 68, no. 1, pp. 94-101, 2004.

[482] D. a. Dillman et al., "Response rate and measurement differences in mixed-mode surveys using mail, telephone, interactive voice response (IVR) and the Internet," Soc. Sci. Res., vol. 38, no. 1, pp. 1-18, 2009.

[483] E. Sanchez, "Effects of questionnaire design on the quality of survey data," Public Opin. Q., vol. 56, no. 2, pp. 206-217, 1992.

[484] M. P. Couper, M. W. Traugott, and M. J. Lamias, "Web survey design and administration," Public Opin. Q., vol. 65, no. 2, pp. 230-253, 2001.

[485] R. Tourangeau, "Cognitive Sciences and Survey Methods," in Cognitive Aspects of Survey Methodology: Building a Bridge Between Disciplines, 1984, pp. 73100.

[486] K. A. Ericksson and H. A. Simon, Protocol Analysis: Verbal Reports As Data, Revised ed. Massachusetts: The MIT Press, 1984.

[487] C. F. Cannell, J. Floyd J. Fowler, and K. H. Marquis, The Influence of Interviewer and Respondent Psychological and Behavioral Variables on the Reporting in Household Interviews, Vital Heal. Washington, D.C., Government Printing Office, 1968.

[488] C. Turner and E. Martin, Surveying Subjective Phenomena, Vol. 2. Russell Sage Foundation, 1984.

[489] R. M. Groves, F. J. Fowler, M. P. Couper, J. M. Lepkowski, E. Singer, and R. Tourangeau, Survey Methodology, 2nd ed., vol. 2nd. John Wiley \& Sons, Inc., 2004.

[490] D. A. Dillman, Mail and Internet Surveys: The Tailored Design Method, 2nd ed. New Jersey: Hoboken, Wiley, 2007.

[491] G. A. Churchill, "A paradigm for developing better measures of marketing constructs," J. Mark. Res., vol. 16, no. 1, pp. 64-73, 1979.

[492] K. Ramamurthy, "The influence of planning an implementation success of advanced manufacturing technologies," IEEE Trans. Eng. Manag., vol. 42, no. 1, pp. 62-73, 1995.

[493] W. S. Edwards and D. Cantor, "Toward a Response Model in Establishment 
Surveys," in Measurement Errors in Surveys, P. P. Biemer, R. M. Groves, L. E. Lyberg, N. A. Mathiowetz, and S. Sudman, Eds. John Wiley \& Sons, Inc., 1991, pp. 211-233.

[494] D. K. Willimack and E. Nicholes, "Building an alternative response process model for business surveys," in The Annual Meeting of the American Statistical Association, 2001, pp. 5-9.

[495] J.-C. Larreche and R. Moinpour, "Managerial judgment in marketing: The concept of expertise," J. Mark. Res., vol. 20, no. 2, pp. 110-121, 1983.

[496] G. Rowe, G. Wright, and F. Bolger, "Delphi: A reevaluation of research and theory," Technol. Forecast. Soc. Change, vol. 39, no. 3, pp. 235-251, 1991.

[497] M. J. Centron and C. A. Ralph., Industrial Applications of Technological Forecasting. Canada: John Wiley \& Sons, Inc., 1971.

[498] J. C. Anderson and D. W. Gerbing, "The effect of sampling error on convergence, improper solutions, and goodness-of-fit indices for maximum likelihood confirmatory factor analysis," Psychometrika, vol. 49, no. 2, pp. 155 173, 1984.

[499] J. S. Tanaka, “'How big is big enough?': sample size and goodness of fit in structural equation models with latent variables," Child Dev., vol. 58, no. 1, pp. 134-146, 1987.

[500] P. M. Bentler and C.-P. Chou, "Practical issues in structural modeling," Sociol. Methods Res., vol. 16, no. 1, pp. 78-117, 1987.

[501] J. Nevitt and G. Hancock, "Evaluating small sample approaches for model test statistics in structural equation modeling," Multivariate Behav. Res., vol. 3171, no. October 2013, pp. 37-41, 2004.

[502] D. L. Jackson, "Sample size and number of parameter estimates in maximum likelihood confirmatory factor analysis: a Monte Carlo investigation," Struct. Equ. Model., vol. 8, no. 2, pp. 205-223, 2001.

[503] C.-Y. Yu, "Evaluating Cutoff Criteria of Model Fit Indices for Latent Variable Models with Binary and Continous Outcomes," Doctor of Philosophy, University of California Los Angeles, 2002.

[504] J. Nevitt and G. R. Hancock, "Performance of bootstrapping approaches to model test statistics and parameter standard error estimation in structural equation modeling," Struct. Equ. Model., vol. 8, no. 3, pp. 353-377, 2001.

[505] L. Hu and P. M. Bentler, "Cutoff criteria for fit indexes in covariance structure analysis: conventional criteria versus new alternatives," Struct. Equ. Model. A Multidiscip. J., vol. 6, no. 1, pp. 1-55, 1999.

[506] V. Savalei and P. M. Bentler, "A statistically justified pairwise ML method for incomplete nonnormal data: a comparison with direct ML and pairwise ADF," Struct. Equ. Model. A Multidiscip. J., vol. 12, no. 2, pp. 183-214, 2005. 
[507] C. G. Forero, A. Maydeu-Olivares, and D. Gallardo-Pujol, "Factor analysis with ordinal indicators: a Monte Carlo study comparing DWLS and ULS estimation," Struct. Equ. Model., vol. 16, no. 4, pp. 625-641, 2009.

[508] X. Fan, B. Thompson, and L. Wang, "Effects of sample size, estimation methods, and model specification on structural equation modeling fit indexes," Struct. Equ. Model., vol. 6, no. 1, pp. 56-83, 1999.

[509] J. S. Tanaka, "Multifaceted Conceptions of Fit in Structural Equation Models," in Testing Structural Equation Models, K. A. Bollen and J. S. Long, Eds. Newbury Park, London, New Delhi: SAGE publications, 1993, pp. 10-39.

[510] P. M. Bentler, "Comparative fit indexes in structural models," Psychol. Bull., vol. 107, no. 2, pp. 238-246, 1990.

[511] K. A. Bollen, "A new incremental fit index for general structural equation models," Sociol. Methods Res., vol. 17, no. 3, pp. 303-316, 1989.

[512] H. W. Marsh, J. R. Balla, and R. P. McDonald, "Goodness-of-fit indexes in confirmatory factor analysis: the effect of sample size," Psychol. Bull., vol. 103, no. 3, pp. 391-410, 1988.

[513] D. W. Gerbing and J. C. Anderson, "Monte Carlo evaluations of goodness of fit indices for structural equation models," Sociol. Methods Res., vol. 21, no. 2, pp. 132-160, 1992.

[514] J. H. Steiger, "Structural model evaluation and modification: an interval estimation approach," Multivariate Behav. Res., vol. 25, no. 2, pp. 173-180, 1990.

[515] B. M. Byrne, Structural Equation Modeling with LISREL, PRELIS, and SIMPLIS: Basic Concepts, Applications, and Programming. New Jersey: Lawrence Erlbaum Associates, Inc., 1998.

[516] J. B. Schreiber, A. Nora, F. K. Stage, E. A. Barlow, and J. King, "Reporting structural equation modeling and confirmatory factor analysis results: a review," J. Educ. Res., vol. 99, no. 6, pp. 323-338, 2006.

[517] W. M. Trochim, Research Methods Knowledge Base, 2nd ed. Cornell University, 1999.

[518] C.-E. Särndal, B. Swensson, and J. Wretman, Model Assisted Survey Sampling. New York: Springer Science \& Business Media, 2003.

[519] A. S. Göritz, "Incentives in web studies: Methodological issues and a review," Int. J. Internet Sci., vol. 1, no. 1, pp. 58-70, 2006.

[520] J. D. Wright and P. V. Marsden, "Survey Research and Social Science: History, Current Practice, and Future Prospects," in Handbook of Survey Research, Second., P. V. Marsden and J. D. Wright, Eds. UK: Emerald Group Publishing Limited, 2010, pp. 3-24. 
[521] P. D. Larson, "A note on mail surveys and response rates in logistics research," $J$. Bus. Logist., vol. 26, no. 2, pp. 211-222, 2005.

[522] L. J. Sax, S. K. Gilmartin, and Alyssa N. Bryant., "Assessing response rates and nonresponse bias in web and paper surveys," Res. High. Educ., vol. 44, no. 4, pp. 409-432, 2003.

[523] R. M. Groves, "Nonresponse rates and nonresponse bias in household surveys," Public Opin. Q., vol. 70, no. 5, pp. 646-675, 2006.

[524] R. P. Bagozzi, "Evaluating structural equation models with unobservable variables and measurement error: a comment," J. Mark. Res., vol. 18, no. 3, pp. 375-381, 1981.

[525] J. Hulland, Y. H. Chow, and S. Lam, "Use of causal models in marketing research: A review," Int. J. Res. Mark., vol. 13, no. 2, pp. 181-197, 1996.

[526] Tugrul U. Daim, "Technology Evaluation and Acquisition Strategies and their Implications in the United States Electronics Manufacturing Industry," Doctor of Philosophy, Portland State University, 1998.

[527] I. Sudrajat, "Supply Chain Integration Practices in the U.S. Electronics Industry," Doctor of Philosophy, Portland State University, 2007.

[528] T. R. Tucker, "Supply Chain Orientation: Refining a Nascent Construct," Doctor of Philosophy, University of Waterloo, 2011.

[529] N. A. Behkami, "Examining Health Information Technology Implementations: Case of the Patient-Centered Medical Home," Doctor of Philosophy, Portland State University, 2012.

[530] R. H. Salman, "Exploring Capability Maturity Models and Relevant Practices as Solutions Addressing IT Service Offshoring Project Issues," Doctor of Philosophy, Portland State University, 2014.

[531] F. A. Aldhaban, "Exploratory Study of the Adoption and Use of the Smartphone Technology in Emerging Regions: Case of Saudi Arabia," Doctor of Philosophy, Portland State University, 2016.

[532] Small Business Administration, "Table of USA Small Business Size Standards," 2016.

[533] J. S. Armstrong and T. S. Overton, "Estimating nonresponse bias in mail surveys," J. Mark. Res., vol. 14, no. 3, pp. 396-402, 1977.

[534] D. A. Dillman, J. L. Eltinge, R. M. Groves, and R. J. Little, "Survey Nonresponse in Design, Data Collection, and Analysis," in Survey Nonresponse, New York: John Wiley \& Sons, 2002, pp. 3-26.

[535] R. J. A. Little, "Survey nonresponse adjustments for estimates of means," Int. Stat. Rev., vol. 54, no. 2, pp. 139-157, 1986.

[536] P. R. Rosenbaum and D. B. Rubin, "The central role of the propensity score in 
observational studies for causal effects," Biometrika, vol. 70, no. 1, pp. 41-55, 1983.

[537] F. Kreuter, M. Lemay, and C. Casas-cordero, "Using proxy measures of survey outcomes in post-survey adjustments: Examples from the European Social Survey (ESS)," in Survey Research Methods, 2007, no. 1983, pp. 3142-3149.

[538] J. L. Schafer and J. W. Graham, "Missing data: our view of the state of the art," Psychol. Methods, vol. 7, no. 2, pp. 147-177, 2002.

[539] C. K. Enders, "A primer on maximum likelihood algorithms available for use with missing data," Struct. Equ. Model., vol. 8, no. 1, pp. 128-141, 2001.

[540] J. R. Hauser, "Research, development, and engineering metrics," Manage. Sci., vol. 44, no. 12-NaN-1, pp. 1670-1689, 1998.

[541] R. Leifer and T. Triscari, "Research versus development: differences and similarities," IEEE Trans. Eng. Manag., vol. 34, no. 2, pp. 71-78, 1987.

[542] B. M. Werner and W. E. Souder, "Measuring R\&D performance-state of the art," Res. Manag., vol. 40, no. 2, pp. 34-42, 1997.

[543] OECD, "Introduction to R\&D statistics and the Frascati Manual," in Frascati Manual 2015: Guidelines for Collecting and Reporting Data on Research and Experimental Development, Paris, France: Organisation for Economic Cooperation and Development, 2015, pp. 19-40.

[544] D. Hooper, J. Coughlan, and M. Mullen, "Structural equation modeling: Guidelines for determining model fit," Electron. J. Bus. Res. Methods, vol. 6, no. 1, pp. 53-60, 2008.

[545] J. C. Nunnally, Psychometric Theory. New York: McGraw-hill, 1967.

[546] K. Han and J. Shin, "A systematic way of identifying and forecasting technological reverse salients using QFD, bibliometrics, and trend impact analysis: A carbon nanotube biosensor case," Technovation, vol. 34, no. 9, pp. 559-570, 2014.

[547] K. Pavitt and R. Rothwell, "A comment on 'A dynamic model of process and product innovation,"' Omega, vol. 4, no. 4, pp. 375-377, 1976.

[548] D. R. King, J. G. Covin, and W. H. Hegarty, "Complementary resources and the exploitation of technological innovations," J. Manage., vol. 29, no. 4, pp. 589606, 2003.

[549] H. W. Chesbrough, "The era of open innovation," MIT Sloan Manag. Rev., vol. 44, no. 3, pp. 35-41, 2003.

[550] A. Pyka, "Informal networking and industrial life cycles," Technovation, vol. 20, no. 1, pp. 25-35, 2000.

[551] M. Berry, "Strategic planning in small high tech companies," Long Range Plann., vol. 31, no. 3, pp. 455-466, 1998. 
[552] D. Dvir, E. Segev, and A. Shenhar, "Technology's varying impact on the success of strategic business units within the Miles and Snow typology," Strateg. Manag. $J$. , vol. 14, no. 2, pp. 155-161, 1993.

[553] D. J. Teece, "Explicating dynamic capabilities: the nature and microfoundations of (sustainable) enterprise performance," Strateg. Manag. J., vol. 28, no. 13, pp. 1319-1350, 2007.

[554] D. Shefer and A. Frenkel, "R\&D, firm size and innovation: an empirical analysis," Technovation, vol. 25, no. 1, pp. 25-32, 2005.

[555] T. Bayoumi, D. T. Coe, and E. Helpman, "R and D spillovers and global growth," J. Int. Econ., vol. 47, no. 2, pp. 399-428, 1999.

[556] Z. J. Acs and D. B. Audretsch, "Innovation in large and small firms: an empirical analysis," Am. Econ. Rev., vol. 78, no. 4, pp. 678-690, 1988.

[557] G. Dosi, "Sources, procedures, and microeconomic effects of innovation," $J$. Econ. Lit., vol. 26, no. 3, pp. 1120-1171, 1988.

[558] J. Irvine and Ben R. Martin, Foresight in Science: Picking the Winners. London and Dover, N.H.: Frances Pinter, 1984.

[559] Ben R. Martin and J. Irvine, Research Foresight And The Exploitation of The Science Base. London, United Kingdom: Sussex Univ. Brighton : Science Policy Research Unit, 1993. 


\title{
Appendices
}

\section{Appendix A. Human Subjects Approval}

\section{S Portland State}

\author{
Post Office Box $751 \quad$ 503-725-2227 tel \\ Portland, Oregon 97207-0751 503-725-8170 fax \\ Research Integrity (Research \& Strategic Partnerships) \\ IRB (Human Subjects Research Review Committee) \\ hsrrc@pdx.edu
}

Date: January 31,2017

To: Tugrul Daim and Joseph Cho, Engineering \& Technology Management

From: Lindsey Wilkinson, IRB Chair

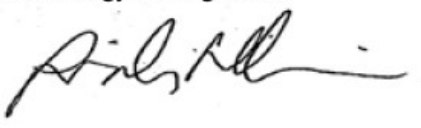

Re: IRB review determination for your protocol \#163982, entitled: "Exploring technology forecasting and its implications for strategic technology planning"

\section{Notice of IRB Review and Determination - Initial Review \\ Exempt Review Category \#2; as per Title 45 CFR Part 46}

In accordance with your request, the PSU Research Integrity office, on behalf of the IRB (Human Subjects Research Review Committee), has reviewed and approved your protocol for compliance with PSU policies and DHHS regulations covering the protection of human subjects. Research Integrity has determined your protocol qualifies for exempt review and is satisfied that your provisions for protecting the rights and welfare of all subjects participating in the research are adequate. Please note the following requirements:

Approval: You are approved to conduct this research study after receipt of this approval letter, and the research must be conducted according to the plans and protocol submitted (approved copy enclosed).

Consent: You must use IRB-approved consent materials with study participants.

Changes to Protocol: Any changes in the proposed study, whether to procedures, survey instruments, consent forms or cover letters, must be outlined and submitted to Research Integrity immediately. The proposed changes cannot be implemented before they have been reviewed and approved by Research Integrity.

Adverse Reactions and/or Unanticipated Problems: If any adverse reactions or unanticipated problems occur as a result of this study, you are required to notify Research Integrity office within 5 days of the event. If the issue is serious, approval may be withdrawn pending an investigation by the IRB.

Completion of Study: Please notify Research Integrity as soon as your research has been completed. Study records, including protocols and signed consent forms for each participant, must be kept by the investigator in a secure location for three years following completion of the study (or per any requirements specified by the project's funding agency).

If you have questions or concerns, please contact the Research Integrity office in Research \& Strategic Partnerships at hsrrc@pdx.edu or call 503-725-2227. 
You are invited to participate in a research study, conducted by Ph.D. candidate Joseph Cho and faculty member Tugrul Daim with the Engineering \& Technology Management department at Portland State University, about how companies conduct technology forecasting or technology planning activities and we are contacting you because you are the CEO, CTO, or General Manager in charge of R\&D.

The purpose of this research is to provide a more intensive investigation of the organizational, technological, methodological, and industrial context in which technology forecasting or technology planning activities are, or are not, found. In addition, it will provide comprehensive evidence on the extent and nature of technology forecasting in industry. We are living in a drastically changing world. You might use different terms or activities for technology forecasting or technology planning to do the same or similar things in your organization. If you are unfamiliar with technology forecasting, here is a brief explanation: In 1962 Lenz, one of the pioneers of technology forecasting, defined technology forecasting as "the prediction of the invention, characteristics, dimensions, or performance of a machine serving some useful purpose .... The qualities sought for the methods of prediction are explicitness, quantitative expression, reproducibility of results, and derivation on a logical basis."

There are no known risks if you decide to participate in this research study. There are no costs to you for participating in the study. The information you provide will be used to complete the requirements of a doctoral degree, and may be published in aggregate form. The questionnaire will take about 10 minutes to complete. While the information collected may not benefit you directly, the information learned in this study should provide more general benefits.

This survey is anonymous. We are sending anonymous link not collecting IP addresses. No one will be able to identify you or your answers, and no one will know whether or not you participated in the study. Individuals from the Institutional Review Board may inspect these records.

Your participation in this study is voluntary. By completing the survey, you are voluntarily agreeing to participate. You are free to decline to answer any particular question you do not wish to answer for any reason.

If you have any questions about the study, please contact Joseph Cho at yonghee@pdx.edu or by phone at 503-616-0218, or contact Tugrul Daim (faculty advisor) at tugrul.u.daim@pdx.edu.

The Portland State University Institutional Review Board has reviewed this project. If you have any concerns about your rights in this study, please contact the PSU Office of Research Integrity at (503) 725-2227 or email hsrrc@pdx.edu.

If you feel that someone else is better qualified to fill out the survey, please forward this survey to him or her. If you are interested in the results of this research, we are more than happy to send the summary of this survey results and document as well. As a sign $Q$ A PRBREG

$$
1 / 31 / 2017
$$

Portland State University Office of Research Integrity

\footnotetext{
RECEIVED

Portland State University

your feedback, we will provide ten $\$ 70$ Amazon gift cards to randomly selectechfpardfripsatsh Integrity after completion of this survey.

Thank you very much for your time and help.
} 


\title{
Appendix B. Survey Questionnaire
}

\section{To start and proceed the survey, please click next arrow at the bottom of the page}

\author{
Informed Consent Form
}

You are invited to participate in a research study, conducted by $\mathrm{PhD}$ candidate Joseph Cho and faculty member Tugrul Daim with the Engineering \& Technology Management department at Portland State University (PSU), about how firms conduct technology forecasting or technology planning activities and we are contacting you because you are the CEO, CTO, Vice President, or General Manager in charge of Research and Development (R\&D).

The purpose of this research is to provide a more intensive investigation of the organizational, technological, methodological, and industrial context in which technology forecasting or technology planning activities are, or are not, found. In addition, it will provide comprehensive evidence on the extent and nature of technology forecasting in industry. You might use different terms or activities for technology forecasting or technology planning to do the same or similar things in your organization. If you are unfamiliar with technology forecasting, here is a brief explanation: In 1962 Lenz, one of the pioneers of technology forecasting, defined technology forecasting as "the prediction of the invention, characteristics, dimensions, or performance of a machine serving some useful purpose .... The qualities sought for the methods of prediction are explicitness, quantitative expression, reproducibility of results, and derivation on a logical basis."

There are no known risks if you decide to participate in this research study. There are no costs to you for participating in the study. The information you provide will be used to complete the requirements of a doctoral degree, and may be published in aggregate form.

The questionnaire will take about 10 minutes to complete.

While the information collected may not benefit you directly, the information learned in this study should provide more general benefits. This survey is anonymous. We are sending anonymous link not collecting IP addresses. No one will be able to identify you or your answers, and no one will know whether or not you participated in the study. Individuals from the Institutional Review Board may inspect these records. Your participation in this study is voluntary. By completing the survey, you are voluntarily agreeing to participate. You are free to decline to answer any particular question you do not wish to answer for any reason.

If you have any questions about the study, please contact Joseph Cho at yonghee@pdx.edu or by phone at 503-616-0218, or contact Tugrul Daim (faculty advisor) at tugrul.u.daim@pdx.edu.

The Portland State University Institutional Review Board has reviewed this project. If you have any concerns about your rights in this study, please contact the PSU Office of Research Integrity at (503) 725-2227 or email hsrrc@pdx.edu.

If you feel that someone else is better qualified to fill out the survey, please forward this survey to him or her.

If you are interested in the results of this research, we are more than happy to send the executive summary of this survey results and document as well. As a sign of appreciation for your feedback, we will provide seven $\$ 70$ Amazon gift cards to randomly selected participants after completion of this survey.

Thank you so much for your time and help. 
Basic Info..

Please provide your basic information to verify your response.

Company:
Total No. of employees of your firm
Position:
Industry experience(years):
City
State
Zip Code

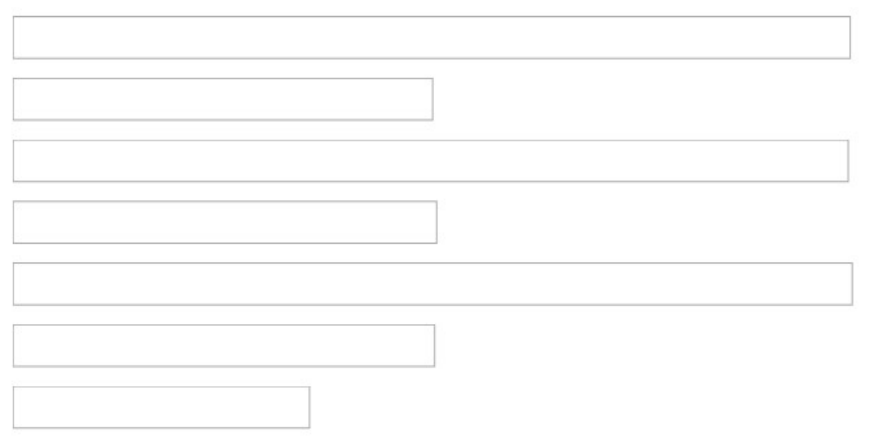

Q1. Which of the following activities are conducted in your organization? (Multiple Choices)

(Note: If you place your mouse on each answer, you will notice the definition of each terminology)

\begin{tabular}{|c|c|c|c|c|c|}
\hline & No use & $\begin{array}{l}\text { Not often } \\
\text { conducted }\end{array}$ & $\begin{array}{l}\text { Somewhat often } \\
\text { conducted }\end{array}$ & Often conducted & $\begin{array}{l}\text { Very often } \\
\text { conducted }\end{array}$ \\
\hline Market Forecasting & 0 & 0 & O & O & 0 \\
\hline $\begin{array}{l}\text { Technology Forecasting (three } \\
\text { to five years) }\end{array}$ & O & O & O & O & O \\
\hline $\begin{array}{l}\text { Technology Forecasting (over } \\
\text { five years) }\end{array}$ & O & O & O & O & O \\
\hline Technology Planning & O & 0 & O & O & 0 \\
\hline $\begin{array}{l}\text { Short-term Forecasting (less } \\
\text { than one year) }\end{array}$ & O & O & O & O & O \\
\hline Annual Planning & O & O & O & O & O \\
\hline $\begin{array}{l}\text { Action Planning or Operational } \\
\text { Planning (one to three years) }\end{array}$ & O & O & 0 & O & O \\
\hline $\begin{array}{l}\text { Strategic Planning (three to } \\
\text { five years) }\end{array}$ & O & O & O & O & O \\
\hline $\begin{array}{l}\text { Long-range Planning (over five } \\
\text { years) }\end{array}$ & O & $\mathrm{O}$ & O & O & O \\
\hline Others (Please, specifv it) & 0 & 0 & O & O & 0 \\
\hline
\end{tabular}


Q2. If your firm conducts technology forecasting for each of the following purposes, how do you rate the importance of technology forecasting performed by your planning staff(s) in your organization. (Multiple Choices)

\begin{tabular}{|c|c|c|c|c|c|}
\hline & Of no use & Not important & Moderate & Important & $\begin{array}{l}\text { Extremely } \\
\text { important }\end{array}$ \\
\hline $\begin{array}{l}\text { As an aid in business planning } \\
\text { and strategy }\end{array}$ & $\bigcirc$ & $\bigcirc$ & $\bigcirc$ & $\bigcirc$ & $\bigcirc$ \\
\hline $\begin{array}{l}\text { As an aid in R\&D or } \\
\text { technology planning }\end{array}$ & $\bigcirc$ & $\bigcirc$ & $\bigcirc$ & $\bigcirc$ & $\bigcirc$ \\
\hline $\begin{array}{l}\text { As an aid in allocating } \\
\text { resources }\end{array}$ & $\bigcirc$ & $\bigcirc$ & $\bigcirc$ & $\bigcirc$ & $\bigcirc$ \\
\hline $\begin{array}{l}\text { As an aid in evaluating } \\
\text { projects }\end{array}$ & $\bigcirc$ & $\bigcirc$ & 0 & $\mathrm{O}$ & 0 \\
\hline $\begin{array}{l}\text { To help justify a previously } \\
\text { made decision }\end{array}$ & $\bigcirc$ & $\bigcirc$ & $\bigcirc$ & $\bigcirc$ & $\bigcirc$ \\
\hline $\begin{array}{l}\text { To help in acquiring a } \\
\text { government contract or } \\
\text { subcontract }\end{array}$ & O & $\bigcirc$ & $\bigcirc$ & $\bigcirc$ & $\bigcirc$ \\
\hline $\begin{array}{l}\text { To redesign business or } \\
\text { manufacturing process }\end{array}$ & $\bigcirc$ & $\bigcirc$ & $\bigcirc$ & $\bigcirc$ & $\bigcirc$ \\
\hline $\begin{array}{l}\text { To develop a new product or } \\
\text { service }\end{array}$ & $\bigcirc$ & $\bigcirc$ & $\bigcirc$ & $\bigcirc$ & $\bigcirc$ \\
\hline $\begin{array}{l}\text { To identify new opportunities or } \\
\text { threats }\end{array}$ & $\bigcirc$ & $\bigcirc$ & $\bigcirc$ & $\bigcirc$ & $\bigcirc$ \\
\hline Others (Please. specifv it) & 0 & 0 & 0 & 0 & 0 \\
\hline
\end{tabular}

Q3. Who are involved in technology forecasting activities within your organization? (Multiple Choices) Please, rate how effectively they are engaged in technology forecasting activities.

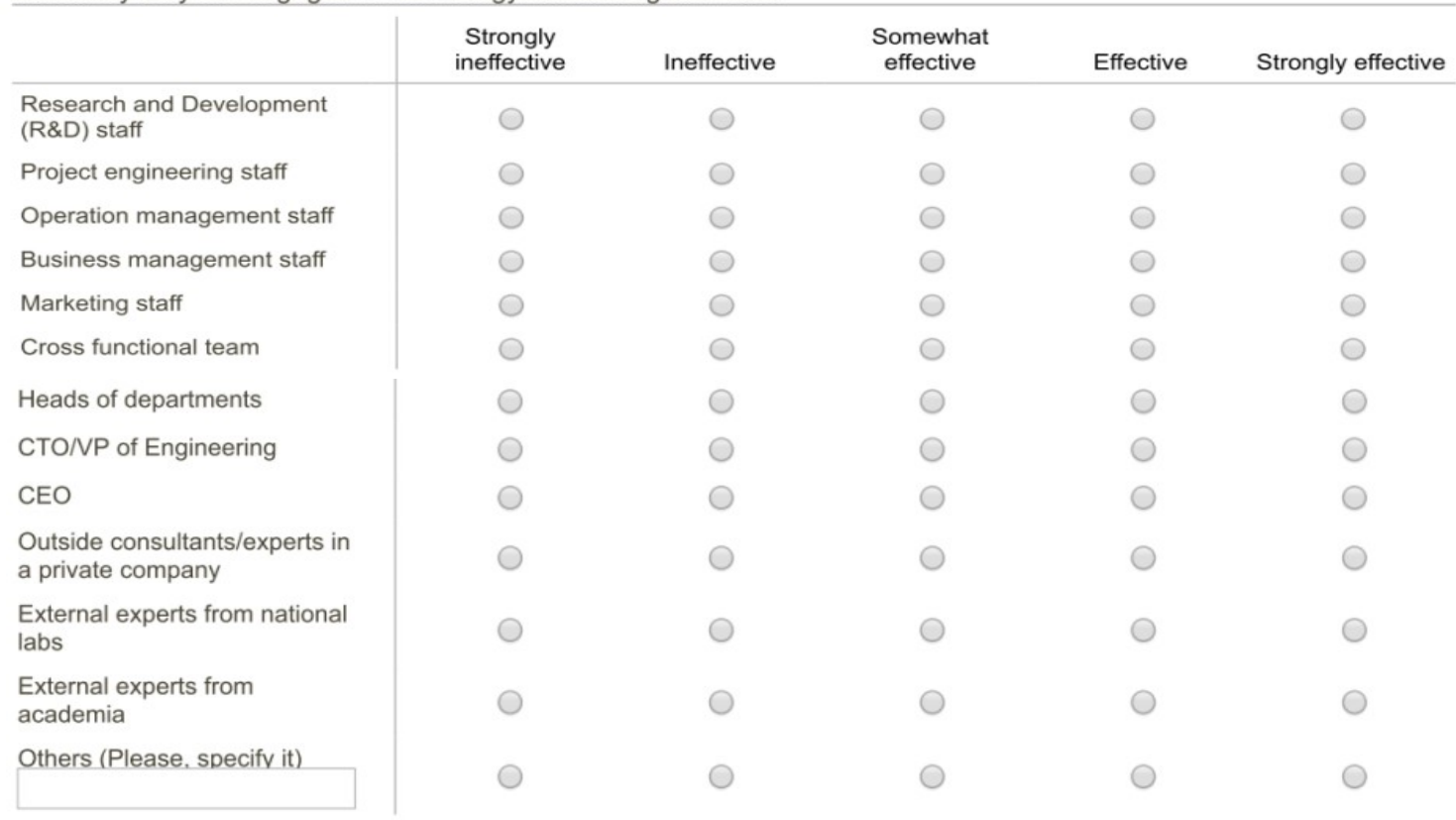


Q4. Based on your knowledge and experience about applicable organizational structure of technology forecasting, please rate each organization's effectiveness for efficient technology forecasting activities? (Multiple Choices)

\begin{tabular}{|c|c|c|c|c|c|}
\hline & $\begin{array}{l}\text { Strongly } \\
\text { ineffective }\end{array}$ & Ineffective & $\begin{array}{l}\text { Somewhat } \\
\text { effective }\end{array}$ & Effective & $\begin{array}{l}\text { Strongly } \\
\text { effective }\end{array}$ \\
\hline Within R\&D Division & ○ & ○ & $\bigcirc$ & O & ○ \\
\hline Within Engineering & $\bigcirc$ & ○ & $\bigcirc$ & $\bigcirc$ & ○ \\
\hline Within Business Management & O & ○ & $\bigcirc$ & ○ & O \\
\hline Within Operation Management & $\bigcirc$ & ○ & O & ○ & 0 \\
\hline Within Marketing & ○ & O & $\bigcirc$ & $\bigcirc$ & $\bigcirc$ \\
\hline Cross Functional Team & $\bigcirc$ & O & ○ & ○ & ○ \\
\hline Outsourcing to a consulting firm & 0 & 0 & 0 & 0 & O \\
\hline Outsourcing to academia & $\bigcirc$ & ○ & ○ & $\bigcirc$ & ○ \\
\hline Outsourcing to national labs & $\bigcirc$ & ○ & $\bigcirc$ & $\bigcirc$ & ○ \\
\hline $\begin{array}{l}\text { Separate Technology Forecasting } \\
\text { Unit }\end{array}$ & $\bigcirc$ & O & $\bigcirc$ & $\bigcirc$ & O \\
\hline Others (please specifv it) & $\bigcirc$ & ○ & ○ & ○ & ○ \\
\hline
\end{tabular}

Q5. What sources of data does your organization often use to forecast technological changes while conducting technology planning or other planning activities within your firm? (Multiple Choices)

\begin{tabular}{|c|c|c|c|c|c|}
\hline & No use & Not often & Somewhat often & Often & Very often \\
\hline Newsletters & $\bigcirc$ & $\bigcirc$ & ○ & 0 & O \\
\hline Magazines & ○ & $\bigcirc$ & $\bigcirc$ & $\bigcirc$ & $\bigcirc$ \\
\hline Conference proceedings & O & 0 & ○ & 0 & 0 \\
\hline Technical reports & $\bigcirc$ & $\bigcirc$ & ○ & $\bigcirc$ & ○ \\
\hline Research journals & $\bigcirc$ & $\bigcirc$ & $\bigcirc$ & $\bigcirc$ & $\bigcirc$ \\
\hline Patents & ○ & $\bigcirc$ & $\bigcirc$ & O & ○ \\
\hline Internal technical data & $\bigcirc$ & $\bigcirc$ & $\bigcirc$ & O & O \\
\hline External experts opinions & $\bigcirc$ & $\bigcirc$ & $\bigcirc$ & $\bigcirc$ & $\bigcirc$ \\
\hline Internal experts opinions & $\bigcirc$ & ○ & $\bigcirc$ & $\bigcirc$ & O \\
\hline $\begin{array}{l}\text { Intuitive decision of top } \\
\text { managers }\end{array}$ & ○ & O & $\bigcirc$ & O & $\bigcirc$ \\
\hline Internal market data & $\bigcirc$ & $\bigcirc$ & $\bigcirc$ & O & ○ \\
\hline External market data & ○ & O & ○ & O & O \\
\hline Vendors input & O & 0 & 0 & 0 & 0 \\
\hline Customers input & ○ & O & $\bigcirc$ & O & O \\
\hline Others (please specify it) & O & O & ○ & 0 & 0 \\
\hline
\end{tabular}


Q6. In your opinion, what sources of data would help your organization in technology forecasting for planning activities ? (Multiple Choices)

\begin{tabular}{|c|c|c|c|c|c|}
\hline & Of no use & Not important & Moderate & Important & $\begin{array}{l}\text { Extremely } \\
\text { important }\end{array}$ \\
\hline Newsletters & $\bigcirc$ & $\bigcirc$ & $\bigcirc$ & $\bigcirc$ & $\bigcirc$ \\
\hline Magazines & $\bigcirc$ & $\bigcirc$ & ○ & $\bigcirc$ & ○ \\
\hline Conference proceedings & $\bigcirc$ & $\bigcirc$ & $\bigcirc$ & $\bigcirc$ & $\bigcirc$ \\
\hline Technical reports & $\bigcirc$ & $\bigcirc$ & $\bigcirc$ & $\bigcirc$ & $\bigcirc$ \\
\hline Research journals & $\bigcirc$ & $\bigcirc$ & ○ & $\bigcirc$ & $\bigcirc$ \\
\hline Patents & $\bigcirc$ & $\bigcirc$ & $\bigcirc$ & $\bigcirc$ & $\bigcirc$ \\
\hline Internal technical data & $\bigcirc$ & $\bigcirc$ & ○ & $\bigcirc$ & $\bigcirc$ \\
\hline External experts opinions & $\bigcirc$ & $\bigcirc$ & ○ & $\bigcirc$ & $\bigcirc$ \\
\hline Internal experts opinions & $\bigcirc$ & $\bigcirc$ & $\bigcirc$ & $\bigcirc$ & $\bigcirc$ \\
\hline $\begin{array}{l}\text { Intuitive decision of top } \\
\text { managers }\end{array}$ & $\bigcirc$ & $\bigcirc$ & O & $\bigcirc$ & ○ \\
\hline Internal market data & $\bigcirc$ & $\bigcirc$ & ○ & $\bigcirc$ & $\bigcirc$ \\
\hline External market data & $\bigcirc$ & $\bigcirc$ & ○ & $\bigcirc$ & $\bigcirc$ \\
\hline Vendors input & $\bigcirc$ & $\bigcirc$ & $\bigcirc$ & $\bigcirc$ & $\bigcirc$ \\
\hline Customers input & ○ & $\bigcirc$ & ○ & $\bigcirc$ & $\bigcirc$ \\
\hline Others (please specify it) & $\bigcirc$ & $\bigcirc$ & $\bigcirc$ & $\bigcirc$ & $\bigcirc$ \\
\hline
\end{tabular}

Q7. How familiar are you with each of the following 'exploratory' technology forecasting methods? (exploratory; forecasting starts from the present using historical data)

(Note: If you place your mouse on each answer, you will notice the definition of each terminology)

\begin{tabular}{|c|c|c|c|c|c|c|c|}
\hline & $\begin{array}{c}\text { Never } \\
\text { heard of it }\end{array}$ & Heard of it & $\begin{array}{c}\text { Read about } \\
\text { it }\end{array}$ & $\begin{array}{c}\text { Considered } \\
\text { it }\end{array}$ & $\begin{array}{l}\text { Plan to use } \\
\text { it }\end{array}$ & Used it & $\begin{array}{l}\text { Currently in } \\
\text { use }\end{array}$ \\
\hline Trend Extrapolation & ○ & $\bigcirc$ & $\bigcirc$ & $\bigcirc$ & $\bigcirc$ & $\bigcirc$ & ○ \\
\hline $\begin{array}{l}\text { Growth Curves: S-Curves, } \\
\text { BASS Model }\end{array}$ & 0 & O & $\bigcirc$ & ○ & ○ & $\bigcirc$ & ○ \\
\hline Bibliometrics; Scientometrics & $\bigcirc$ & $\bigcirc$ & $\bigcirc$ & $\bigcirc$ & $\bigcirc$ & $\bigcirc$ & $\bigcirc$ \\
\hline $\begin{array}{l}\text { Data Mining: Text (Data) } \\
\text { Mining }\end{array}$ & ○ & $\bigcirc$ & $\bigcirc$ & $\bigcirc$ & $\bigcirc$ & $\bigcirc$ & $\bigcirc$ \\
\hline $\begin{array}{l}\text { Growth Analogies: } \\
\text { Comparison-Based Prediction }\end{array}$ & ○ & $\bigcirc$ & ○ & ○ & $\bigcirc$ & ○ & $\bigcirc$ \\
\hline$\underline{\text { Cross Impact Analysis }}$ & ○ & $\bigcirc$ & O & $\bigcirc$ & O & $\bigcirc$ & ○ \\
\hline System Dynamics & $\bigcirc$ & $\bigcirc$ & ○ & $\bigcirc$ & $\bigcirc$ & $\bigcirc$ & ○ \\
\hline $\begin{array}{l}\text { Technology Forecasting Using } \\
\text { Data Envelopment Analysis } \\
\text { (TFDEA) }\end{array}$ & ○ & $\bigcirc$ & ○ & $\bigcirc$ & $\bigcirc$ & ○ & ○ \\
\hline Multivariate Analysis & $\bigcirc$ & $\bigcirc$ & $\bigcirc$ & $\bigcirc$ & $\bigcirc$ & $\bigcirc$ & $\bigcirc$ \\
\hline Environmental Scanning & $\bigcirc$ & $\bigcirc$ & ○ & $\bigcirc$ & ○ & ○ & ○ \\
\hline Probabilistic Forecasts & ○ & $\bigcirc$ & ○ & $\bigcirc$ & $\bigcirc$ & $\bigcirc$ & $\bigcirc$ \\
\hline Life Cycle Analysis & $\bigcirc$ & $\bigcirc$ & $\bigcirc$ & $\bigcirc$ & $\bigcirc$ & 0 & O \\
\hline Agent-Based Model & $\bigcirc$ & O & ○ & O & $\bigcirc$ & $\bigcirc$ & ○ \\
\hline $\begin{array}{l}\text { TRIZ (The theory of inventive } \\
\text { problem solving) }\end{array}$ & $\bigcirc$ & $\bigcirc$ & $\bigcirc$ & $\bigcirc$ & $\bigcirc$ & $\bigcirc$ & ○ \\
\hline Others (please specify it) & $\bigcirc$ & ○ & $\bigcirc$ & $\bigcirc$ & $\bigcirc$ & $\bigcirc$ & $\bigcirc$ \\
\hline
\end{tabular}


Q8. What is your level of familiarity with each of the following 'normative' technology forecasting methods? (normative; forecasting begins with the future environment or scenario)

(Note: If you place your mouse on each answer, you will notice the definition of each terminology)

\begin{tabular}{|c|c|c|c|c|c|c|c|}
\hline & $\begin{array}{c}\text { Never } \\
\text { heard of it }\end{array}$ & Heard of it & $\begin{array}{l}\text { Read about } \\
\text { it }\end{array}$ & $\begin{array}{c}\text { Considered } \\
\text { it }\end{array}$ & $\begin{array}{c}\text { Plan to use } \\
\text { it }\end{array}$ & Used it & $\begin{array}{l}\text { Currently in } \\
\text { use }\end{array}$ \\
\hline$\underline{\text { Relevance Trees }}$ & O & O & O & $\bigcirc$ & O & $\bigcirc$ & $\bigcirc$ \\
\hline $\begin{array}{l}\text { Analytic Hierarchy Process } \\
\text { (AHP), Analytic Network } \\
\text { Process (ANP), Multi-Criteria } \\
\text { Decision Model }\end{array}$ & O & ○ & O & ○ & O & ○ & O \\
\hline Morphological Analysis & O & 0 & ○ & ○ & O & O & O \\
\hline Backcasting & $\bigcirc$ & $\bigcirc$ & $\bigcirc$ & O & $\bigcirc$ & $\bigcirc$ & $\bigcirc$ \\
\hline Delphi & $\mathrm{O}$ & $\bigcirc$ & $\bigcirc$ & $\bigcirc$ & $\bigcirc$ & 0 & O \\
\hline $\begin{array}{l}\text { Nominal Group Technique } \\
\text { (NGT); Brain Storming }\end{array}$ & $\mathrm{O}$ & O & O & O & O & 0 & O \\
\hline$\underline{\text { Scenario Planning / Writing }}$ & 0 & ○ & $\bigcirc$ & $\bigcirc$ & $\bigcirc$ & $\bigcirc$ & $\bigcirc$ \\
\hline$\underline{\text { Trend Impact Analysis }}$ & $\bigcirc$ & ○ & $\bigcirc$ & $\bigcirc$ & $\bigcirc$ & $\bigcirc$ & $\bigcirc$ \\
\hline Technology Roadmapping & O & O & $\bigcirc$ & $\bigcirc$ & O & $\bigcirc$ & O \\
\hline$\underline{\text { Survey }}$ & $\bigcirc$ & ○ & 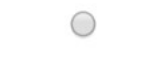 & $\bigcirc$ & O & ○ & $\bigcirc$ \\
\hline Focus Group Interview & O & ○ & O & 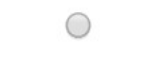 & $\bigcirc$ & 0 & $\bigcirc$ \\
\hline $\begin{array}{l}\text { Planning Assistance Through } \\
\text { Technical Evaluation of } \\
\text { Relevance Numbers } \\
\text { (PATTERN) }\end{array}$ & O & O & O & O & O & O & O \\
\hline$\underline{\text { Simulation and Games }}$ & O & O & O & O & O & O & O \\
\hline$\underline{\text { Risk Analysis }}$ & $\bigcirc$ & $\bigcirc$ & $\bigcirc$ & $\bigcirc$ & $\bigcirc$ & $\bigcirc$ & $\bigcirc$ \\
\hline Others (please specify it & O & O & O & O & O & O & O \\
\hline
\end{tabular}

Q9. Has your company ever used two or more technology forecasting tools simultaneously to improve the effectiveness of technology forecasting?

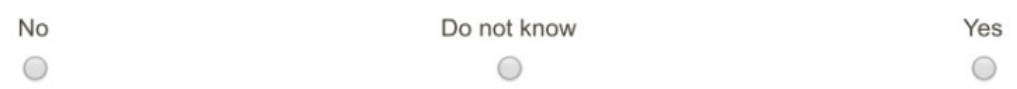

Q10. Based on your experience and knowledge, to what degree are you satisfied with the results of technology forecasting activities in your firm?

$\begin{array}{ccccccc}\text { Very Unsatisfied } 1 & 2 & 3 & 4 & 5 & 6 & \text { Very Satisfied } 7 \\ 0 & 0 & 0 & 0 & 0 & 0 & 0\end{array}$

Q11. Based on your experience and knowledge, how do you think technology forecasting activities affect the effectiveness of technology planning and strategy within your firm?

$\begin{array}{ccccccc}\text { Very Negative } 1 & 2 & 3 & 4 & 5 & 6 & \text { Very Positive 7 } \\ 0 & 0 & 0 & 0 & 0 & 0 & 0\end{array}$

Q12. What proportion of revenues does your company invest in Research \& Development?
Do not know
less than $1 \%$
$1-3 \%$
$3-5 \%$
5-7\%
7-10\%
over $11 \%$
○
$\mathrm{C}$
O
○
○
$\bigcirc$ 
Q13. What proportion of your R\&D effort (in terms of human and financial resource) is spent on the product or service developments?

(Please make sure that it approximately adds up to $100 \%$ )

\begin{tabular}{|c|c|c|c|c|c|c|c|c|c|c|}
\hline & $\begin{array}{l}\text { Less } \\
\text { than } \\
10 \%\end{array}$ & $10-20 \%$ & $20-30 \%$ & $30-40 \%$ & $40-50 \%$ & $50-60 \%$ & $60-70 \%$ & $70-80 \%$ & $80-90 \%$ & $\begin{array}{c}90- \\
100 \%\end{array}$ \\
\hline $\begin{array}{l}\text { Fundamental or basic } \\
\text { research (for the sake of } \\
\text { knowledge related to } \\
\text { disruptive product/process or } \\
\text { service) }\end{array}$ & 0 & 0 & 0 & 0 & 0 & 0 & 0 & 0 & 0 & 0 \\
\hline $\begin{array}{l}\text { Applied research (directly } \\
\text { related to next generation } \\
\text { product/process or service) }\end{array}$ & 0 & 0 & 0 & 0 & 0 & 0 & $\bigcirc$ & 0 & 0 & 0 \\
\hline $\begin{array}{l}\text { Development (new } \\
\text { applications/discoveries to the } \\
\text { current product/process or } \\
\text { service) }\end{array}$ & 0 & 0 & 0 & 0 & 0 & 0 & 0 & 0 & 0 & 0 \\
\hline
\end{tabular}

Q14. Please indicate the magnitude of changes of your business over the last five years.

(Note: If you place your mouse on each answer, you will notice the definition of each terminology)

\begin{tabular}{|c|c|c|c|c|c|c|c|}
\hline & $\begin{array}{l}\text { Less than } \\
-30 \%\end{array}$ & -10 to $-20 \%$ & $>=-10 \%$ & 0 & $<=10 \%$ & 10 to $20 \%$ & Over $30 \%$ \\
\hline$\underline{\text { Sales growth }}$ & ○ & O & $\bigcirc$ & 0 & ○ & ○ & ○ \\
\hline Return on assets (ROA) & 0 & O & O & ○ & 0 & $\bigcirc$ & $\mathrm{O}$ \\
\hline Earnings growth & O & O & ○ & ○ & 0 & 0 & O \\
\hline $\begin{array}{l}\text { Market share on your most } \\
\text { relevant market }\end{array}$ & ○ & O & $\bigcirc$ & O & $\bigcirc$ & $\bigcirc$ & ○ \\
\hline $\begin{array}{l}\text { Your competitive position in } \\
\text { general }\end{array}$ & 0 & 0 & 0 & 0 & 0 & 0 & 0 \\
\hline
\end{tabular}

. Are you interested in receiving the summary results of this research?

Yes No

Contact Info.

Please make sure to provide your email address and contact information to receive the results of this research, but also to be eligible to win a gift card:

First name:

Last name:

Email:

Fax: 
Appendix C. Variables (Descriptive Statistics)

\begin{tabular}{|c|c|c|c|c|}
\hline Variables & Min. & Max. & Mean & Std. Deviation \\
\hline $\begin{array}{l}\text { Technology forecasting } \\
\text { ( } 3 \text { to } 5 \text { years) }\end{array}$ & 1.0 & 5.0 & 3.498 & 1.0872 \\
\hline $\begin{array}{l}\text { Technology forecasting } \\
\text { (over } 5 \text { years) }\end{array}$ & 1.0 & 5.0 & 2.876 & 1.1660 \\
\hline Technology planning & 1.0 & 5.0 & 3.723 & .9936 \\
\hline $\begin{array}{l}\text { Short-term forecasting } \\
\text { (less than } 1 \text { year) }\end{array}$ & 1.0 & 5.0 & 4.183 & 1.0703 \\
\hline Annual planning & 1.0 & 5.0 & 4.398 & .9121 \\
\hline $\begin{array}{l}\text { Action planning or operational } \\
\text { Planning ( } 1 \text { to } 3 \text { years) }\end{array}$ & 1.0 & 5.0 & 4.082 & .9678 \\
\hline $\begin{array}{l}\text { Strategic planning } \\
\text { ( } 3 \text { to } 5 \text { years) }\end{array}$ & 1.0 & 5.0 & 3.864 & 1.0636 \\
\hline $\begin{array}{l}\text { Long-range planning } \\
\text { (over } 5 \text { years) }\end{array}$ & 1.0 & 5.0 & 3.183 & 1.2466 \\
\hline $\begin{array}{l}\text { As an aid in business planning and } \\
\text { strategy }\end{array}$ & 1.0 & 5.0 & 3.890 & .9391 \\
\hline $\begin{array}{l}\text { As an aid in R\&D or technology } \\
\text { planning }\end{array}$ & 1.0 & 5.0 & 4.060 & .9406 \\
\hline As an aid in allocating resources & 1.0 & 5.0 & 3.648 & .8724 \\
\hline As an aid in evaluating projects & 1.0 & 5.0 & 3.664 & .8290 \\
\hline $\begin{array}{l}\text { To help justify a previously made } \\
\text { decision }\end{array}$ & 1.0 & 5.0 & 2.868 & .9935 \\
\hline $\begin{array}{l}\text { To help in acquiring a government } \\
\text { contract or subcontract }\end{array}$ & 1.0 & 5.0 & 2.284 & 1.1635 \\
\hline To assess technology portfolios & 1.0 & 5.0 & 3.143 & 1.1558 \\
\hline $\begin{array}{l}\text { To redesign business or } \\
\text { manufacturing process }\end{array}$ & 1.0 & 5.0 & 3.306 & 1.0148 \\
\hline $\begin{array}{l}\text { To develop a new product or } \\
\text { service }\end{array}$ & 1.0 & 5.0 & 4.087 & .8866 \\
\hline $\begin{array}{l}\text { To identify new opportunities or } \\
\text { threats }\end{array}$ & 1.0 & 5.0 & 4.037 & .9426 \\
\hline $\begin{array}{l}\text { Research and Development (R\&D) } \\
\text { staff }\end{array}$ & 1.0 & 5.0 & 3.895 & .9726 \\
\hline Project engineering staff & 1.0 & 5.0 & 3.471 & .9405 \\
\hline Operation management staff & 1.0 & 5.0 & 3.148 & 1.0223 \\
\hline Business management staff & 1.0 & 5.0 & 3.455 & 1.0381 \\
\hline Marketing staff & 1.0 & 5.0 & 3.300 & 1.0629 \\
\hline Cross functional team & 1.0 & 5.0 & 3.505 & .9700 \\
\hline Heads of departments & 1.0 & 5.0 & 3.474 & .9610 \\
\hline CTO/VP of Engineering & 1.0 & 5.0 & 3.882 & .9930 \\
\hline $\mathrm{CEO}$ & 1.0 & 5.0 & 3.380 & 1.1426 \\
\hline $\begin{array}{l}\text { Outside consultants/experts in a } \\
\text { private company }\end{array}$ & 1.0 & 5.0 & 2.759 & 1.0246 \\
\hline
\end{tabular}




\begin{tabular}{|c|c|c|c|c|}
\hline External experts from national labs & 1.0 & 5.0 & 2.600 & .9893 \\
\hline External experts from academia & 1.0 & 5.0 & 2.658 & 1.0012 \\
\hline Within R\&D division & 1.0 & 5.0 & 3.772 & .9442 \\
\hline Within engineering & 2.0 & 5.0 & 3.629 & .8310 \\
\hline Within business management & 1.0 & 5.0 & 3.275 & .8324 \\
\hline Within operation management & 1.0 & 5.0 & 2.949 & .9408 \\
\hline Within marketing & 1.0 & 5.0 & 3.136 & .9193 \\
\hline Cross functional team & 1.0 & 5.0 & 3.330 & .9353 \\
\hline Outsourcing to a consulting firm & 1.0 & 5.0 & 2.546 & 1.0307 \\
\hline Outsourcing to academia & 1.0 & 4.0 & 2.371 & .9793 \\
\hline Outsourcing to national labs & 1.0 & 4.0 & 2.296 & .9297 \\
\hline $\begin{array}{l}\text { Separate technology forecasting } \\
\text { unit }\end{array}$ & 1.0 & 5.0 & 2.633 & 1.1694 \\
\hline Newsletters & 1.0 & 5.0 & 2.859 & 1.0741 \\
\hline Magazines & 1.0 & 5.0 & 2.942 & 1.0062 \\
\hline Conference proceedings & 1.0 & 5.0 & 3.422 & 1.0048 \\
\hline Technical reports & 1.0 & 5.0 & 3.577 & 1.0112 \\
\hline Research journals & 1.0 & 5.0 & 3.396 & 1.1067 \\
\hline Patents & 1.0 & 5.0 & 3.196 & 1.2155 \\
\hline Internal technical data & 1.0 & 5.0 & 3.816 & 1.0094 \\
\hline External experts opinions & 1.0 & 5.0 & 3.318 & .9964 \\
\hline Internal experts opinions & 2.0 & 5.0 & 3.969 & .8533 \\
\hline Intuitive decision of top managers & 1.0 & 5.0 & 3.415 & 1.0017 \\
\hline Internal market data & 1.0 & 5.0 & 3.484 & 1.0025 \\
\hline External market data & 1.0 & 5.0 & 3.472 & 1.0269 \\
\hline Vendors input & 1.0 & 5.0 & 3.042 & 1.0175 \\
\hline Customers input & 1.0 & 5.0 & 3.863 & .9723 \\
\hline Trend extrapolation & 1.0 & 7.0 & 4.040 & 2.2300 \\
\hline $\begin{array}{l}\text { Growth curves; S-curves, BASS } \\
\text { model }\end{array}$ & 1.0 & 7.0 & 3.430 & 2.1449 \\
\hline Bibliometrics; Scientometrics & 1.0 & 7.0 & 1.980 & 1.5721 \\
\hline Data mining; Text (Data) mining & 1.0 & 7.0 & 4.627 & 1.9455 \\
\hline $\begin{array}{l}\text { Growth analogies; Comparison- } \\
\text { based prediction }\end{array}$ & 1.0 & 7.0 & 3.238 & 2.0679 \\
\hline Cross impact analysis & 1.0 & 7.0 & 2.712 & 1.9644 \\
\hline System dynamics & 1.0 & 7.0 & 2.675 & 1.9716 \\
\hline TFDEA & 1.0 & 7.0 & 1.984 & 1.6000 \\
\hline Agent-based model & 1.0 & 7.0 & 2.222 & 1.6706 \\
\hline Relevance trees & 1.0 & 7.0 & 2.582 & 1.9758 \\
\hline $\begin{array}{l}\text { Analytic Hierarchy Process (AHP), } \\
\text { Analytic Network Process (ANP), } \\
\text { Multi-Criteria methods }\end{array}$ & 1.0 & 7.0 & 2.113 & 1.7447 \\
\hline Morphological analysis & 1.0 & 7.0 & 1.971 & 1.6776 \\
\hline Backcasting & 1.0 & 7.0 & 2.253 & 1.7813 \\
\hline Delphi & 1.0 & 7.0 & 2.313 & 1.8152 \\
\hline Nominal Group Technique (NGT); & 1.0 & 7.0 & 3.899 & 2.4267 \\
\hline
\end{tabular}




\begin{tabular}{|l|r|r|r|r|}
\hline Brain storming & & & & \\
\hline Scenario planning / writing & 1.0 & 7.0 & 4.350 & 2.3242 \\
\hline Trend impact analysis & 1.0 & 7.0 & 4.033 & 2.2825 \\
\hline Technology roadmapping & 1.0 & 7.0 & 5.415 & 2.0814 \\
\hline Focus group interview & 1.0 & 7.0 & 4.983 & 1.9592 \\
\hline Satisfaction with the results of TF & .0 & 7.0 & 4.051 & 1.5188 \\
\hline $\begin{array}{l}\text { The usefulness of TF on } \\
\text { technology planning }\end{array}$ & 1.0 & 7.0 & 4.710 & 1.4321 \\
\hline R\&D Investment & .0 & 7.0 & 4.469 & 2.0030 \\
\hline Fundamental or basic research & 1.0 & 10.0 & 2.303 & 1.9093 \\
\hline Applied research & 1.0 & 10.0 & 4.070 & 2.2838 \\
\hline Development & 1.0 & 11.0 & 5.111 & 2.6903 \\
\hline Sales growth & 1.0 & 7.0 & 5.296 & 1.3411 \\
\hline Return on assets (ROA) & 1.0 & 7.0 & 4.966 & 1.2231 \\
\hline Earnings growth & 1.0 & 7.0 & 5.142 & 1.2630 \\
\hline Market share & 1.0 & 7.0 & 5.3675 \\
\hline Your competitiveness & & & & 1.2199 \\
\hline
\end{tabular}


Appendix D. Glossary of Conceptual Terms

\begin{tabular}{|c|c|}
\hline Term & Definition \\
\hline Basic research & $\begin{array}{l}\text { Experimental or theoretical work undertaken primarily } \\
\text { to acquire knowledge related to disruptive } \\
\text { product/process or service }\end{array}$ \\
\hline Applied research & $\begin{array}{l}\text { Original investigation undertaken to acquire knowledge } \\
\text { directly related to next generation product/process or } \\
\text { service }\end{array}$ \\
\hline Development & $\begin{array}{l}\text { Systematic work or practical research for new } \\
\text { applications/discoveries related to the current } \\
\text { product/process or service }\end{array}$ \\
\hline Market Forecasting & $\begin{array}{l}\text { It projects the future numbers, characteristics, and } \\
\text { trends in your target market }\end{array}$ \\
\hline $\begin{array}{l}\text { Technology Forecasting } \\
\text { (three to five years) }\end{array}$ & $\begin{array}{l}\text { It projects the invention, characteristics, dimensions, or } \\
\text { performance of a machine serving some useful purpose } \\
\text { within three to five years }\end{array}$ \\
\hline $\begin{array}{l}\text { Technology Forecasting } \\
\text { (over five years) }\end{array}$ & $\begin{array}{l}\text { It projects the invention, characteristics, dimensions, or } \\
\text { performance of a machine serving some useful purpose } \\
\text { over five years }\end{array}$ \\
\hline Technology Planning & $\begin{array}{l}\text { It lets an organization know where they are now and } \\
\text { where they want to be some time in the future with } \\
\text { regard to the technology and infrastructure in their } \\
\text { organization }\end{array}$ \\
\hline $\begin{array}{l}\text { Short-term Forecasting } \\
\text { (less than one year) }\end{array}$ & $\begin{array}{l}\text { It covers short term objectives less than one year for } \\
\text { example material requirement planning, scheduling, } \\
\text { budgeting etc. }\end{array}$ \\
\hline Annual Planning & $\begin{array}{l}\text { It covers an organization's financial plan for the fiscal } \\
\text { year }\end{array}$ \\
\hline $\begin{array}{l}\text { Action Planning or } \\
\text { Operational Planning } \\
\text { (one to three years) }\end{array}$ & $\begin{array}{l}\text { It presents highly detailed information specifically to } \\
\text { direct people to perform the day-to-day tasks required } \\
\text { in the running the organization within three years. It } \\
\text { plans the implementation of strategies contained within } \\
\text { the strategic plan }\end{array}$ \\
\hline $\begin{array}{l}\text { Strategic Planning } \\
\text { (three to five years) }\end{array}$ & $\begin{array}{l}\text { It sets a direction for the organization, devises goals and } \\
\text { objectives and identifies a range of strategies to pursue } \\
\text { so that the organization might achieve its goals in } \\
\text { targeted market within three to five years }\end{array}$ \\
\hline $\begin{array}{l}\text { Long-range Planning } \\
\text { (over five years) }\end{array}$ & $\begin{array}{l}\text { It aims at formulating a long-term plan, to meet future } \\
\text { needs estimated usually by extrapolation of present or } \\
\text { known needs over five years. It generally includes } \\
\text { short-term (operational or tactical plans) for achieving } \\
\text { interim goals }\end{array}$ \\
\hline
\end{tabular}

